\title{
Aplicaciones fotoroltaicas \\ de la energía solar en los sectores residencial, servicio e industrial
}

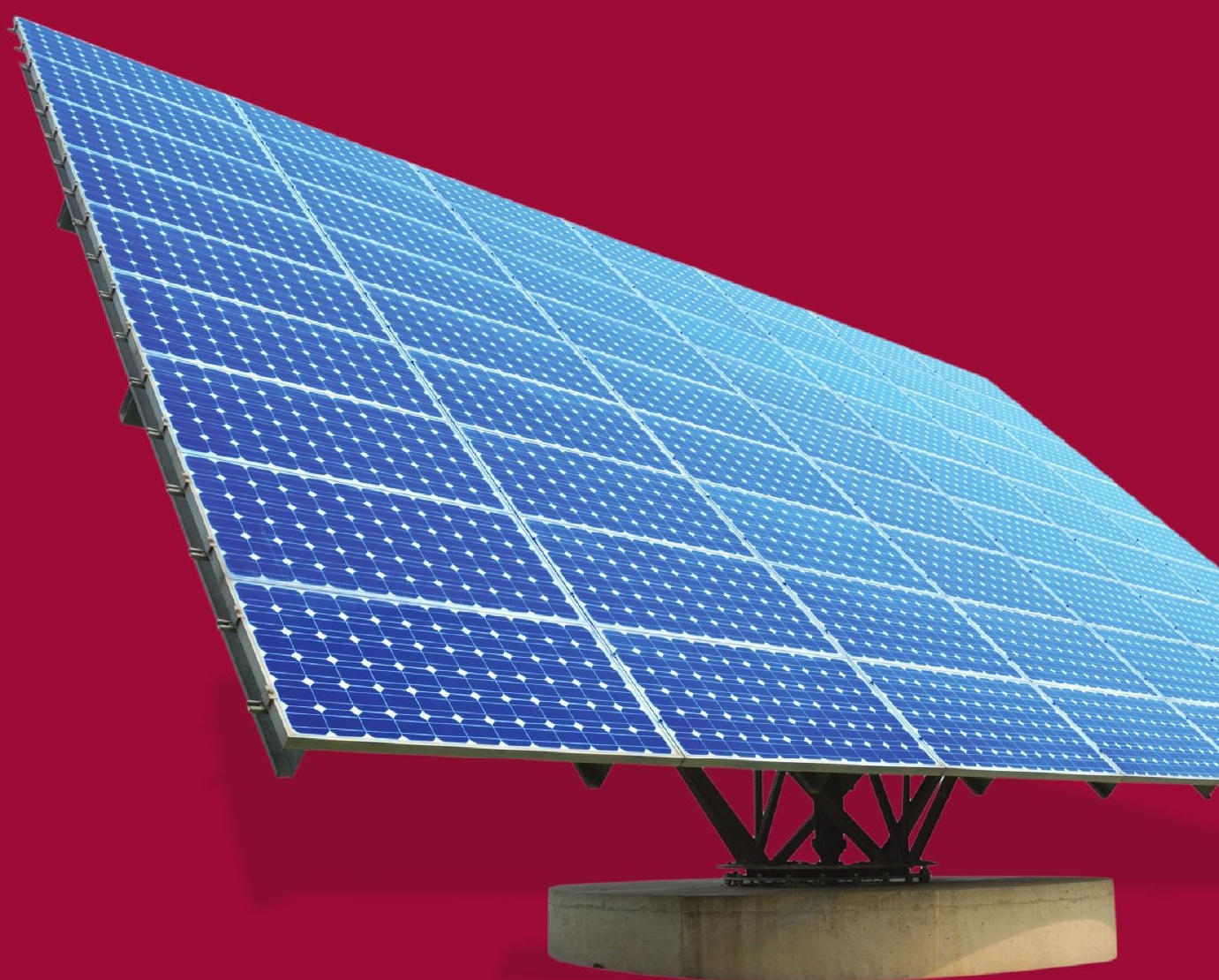

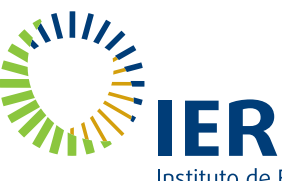

Instituto de Energías Renovables
Aarón Sánchez Juárez, Dalia Martínez Escobar, Rocío de la Luz Santos Magdaleno, José Ortega Cruz y Pedro Andrés Sánchez Pérez 




\section{Aplicaciones fotovoltaicas \\ de la energía solar en los sectores residencial, servicio e industrial}




\section{Instituto de Energías Renovables, UNAM}

Director: Dr. Jesús Antonio del Río Portilla

Secretaria Académica: Dra. Marina Rincón

Secretaria de Innovación y Transferencia Tecnológica: Dra. Karla Cedano

Edición: Juan Tonda Mazón

Diseño y formación: Georgina Reyes Coria

Corrección: Edgar Gómez Marín

Portada y figuras: Georgina Reyes Coria

Fotografía de portada: Shutterstock (C)

Primera edición: 9 de abril de 2017

D.R. ( 2017 Universidad Nacional Autónoma de México

Av. Universidad 3000 Ciudad Universitaria

Col. Universidad Nacional Autónoma de México

Coyoacán, 04510, Ciudad de México

Instituto de Energías Renovables

(C) Aarón Sánchez Juárez, Dalia Martínez Escobar, Rocío de la Luz Santos Magdaleno, José Ortega Cruz y Pedro Andrés Sánchez Pérez.

ISBN: 978-523-04-1732-3

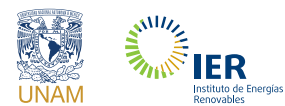

\footnotetext{
Agrademos el apoyo a Conacyt por financiar esta publicación a través de PROYECTO FORDECYT 190603, Estudio sobre el uso de la energía solar en aplicaciones residenciales, industriales y comerciales en diferentes estados del país.
}

Todos lo derechos reservados.

Ninguna parte de esta publicación puede ser reproducida, trasmitida o almacenada de manera alguna sin el permiso previo del editor.

Impreso y hecho en México 


\section{Aplicaciones fotovoltaicas de la energía solar en los sectores residencial, servicio e industrial}

Guía para el dimensionamiento y diseño de sistemas fotovoltaicos

Aarón Sánchez Juárez, Dalia Martínez Escobar, Rocío de la Luz Santos Magdaleno, José Ortega Cruz y Pedro Andrés Sánchez Pérez
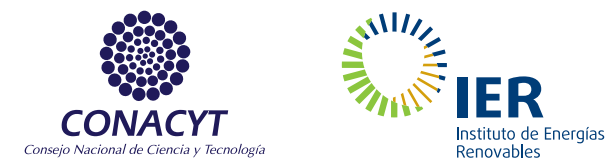



\section{ÍNDICE}

PRÓLOGO

1 PANORAMA DE LAS APLICACIONES FOTOVOLTAICAS

1.1. Introducción

1.2. Antecedentes

1.3. La experiencia fotovoltaica en México 39

1.4. Situación actual FV al 2016 en México 49

1.5. Prospectiva económica 55

1.6. El binomio de generación limpia: sol-TFV 58

2 Conceptos básicos de energía solar

2.1. Introducción 65

2.2. La luz solar 65

2.3. Irradiancia e irradiación 67

2.5. Radiación directa, difusa y global 71 
2.6. El concepto de hora pico 76

2.7. Aparatos para medir la radiación solar $\quad 78$

2.8. Datos de dadiación solar en México 81

2.9. Bases de datos de radiación solar 84

2.11. Generalidades 98

\section{LA TECNOLOGÍA FV Y SU PROSPECTIVA FUTURA DE DESARROLLO}

3.1. Introducción 103

3.2. Efecto fotovoltaico y parámetros eléctricos 104

3.3. Tecnologías de celdas solares: historia y su estado de desarrollo $\quad 108$

3.4. Principios de la conversión fotovoltaica 116

3.5. La celda solar de silicio cristalino 119

3.6. Parámetros eléctricos de una celda solar 120

3.7. Efecto de la irradiancia, superficie de captación, temperatura y sombreado $\quad 126$

3.8. Notas finales 138

\section{LOS CONVERTIDORES FOTOVOLTAICOS}

4.1. El módulo fotovoltaico

4.2. Parámetros eléctricos de un módulo 154

4.3. Certificación de módulos 158

4.4. Efecto de la intensidad luminosa $\quad 160$

4.5. Efecto de la temperatura 162

4.6. El voltaje de diseño bajo condiciones de operación

4.7. Arreglos fotovoltaicos

4.8. Energía generada por un módulo 178

4.9. Orientación óptima del arreglo fotovoltaico

4.10. Los sistemas fotovoltaicos 
4.11. Proyectos de aplicación y regulaciones existentes

\section{DIMENSIONANDO SISTEMAS}

5.1. El dimensionamiento fotovoltaico

5.2. Capacidad de almacenamiento en baterías 210

5.3. Ejemplos de dimensionamiento

\section{REQUERIMIENTOS PARA EL DISEÑO}

6.1. El marco regulatorio 241

6.2. Aspectos relacionados con el diseño de SFV 242

6.3. Definiciones 243

6.4. Componentes 244

\section{EJEMPLO DE DISEÑO: PLANTA} FOTOVOLTAICA DE 27.0 KW

7.1. Cálculo de Ampacidades

7.2. La estructura: unidad básica mecánica

7.3. Conexión eléctrica entre módulos y cadenas 286

7.4. Caja de combinación, $\mathrm{c}_{\mathrm{c}}$.

7.5. Inversores $\mathrm{cd} / \mathrm{ca}$ o acondicionadores de potencia

7.6. Análisis energético 293

7.7. Conclusiones 296

EPÍLOGO 



\section{PRÓLOGO}

La generación de energía es uno de los problemas críticos que enfrentan las sociedades contemporáneas. Como consecuencia de la disminución en la producción y la tendencia a la alza en los precios de los combustibles fósiles, aunado con los efectos climatológicos derivados de la contaminación ambiental producida por los gases de efecto de invernadero, la gran mayoría de los países se encuentran en una búsqueda constante de alternativas energéticas que permitan, tanto disminuir el consumo de combustibles contaminantes como reducir su dependencia en los procesos productivos, con la meta de buscar los caminos que conlleven a una sustentabilidad energética mediante la implementación, uso y adopción de tecnologías viejas, nuevas y emergentes basadas en las Fuentes de Energía Renovables (FER) y del uso eficiente de la energía.

La necesidad de diversificar la generación de energía, sobre todo, la eléctrica, han impulsado a la gran mayoría de los países a establecer proyectos y programas de investigación, desarrollo tecnológico, innovación, fomento, aplicación y adopción de tecnologías basadas en las FER, sobre todo aquellas que usan la Energía Solar derivado de su alto potencial para la producción de electricidad. Una de ellas, la Tecnología Fotovoltaica $(T F V)$, que a través de su unidad básica llama- 
da la celda solar que transforma directamente la luz solar en electricidad del tipo de corriente continua o directa (c.c.), está representando una alternativa real para la generación de potencia eléctrica tanto en el ámbito rural como en el urbano. Su versatilidad, modularidad, larga duración y confiabilidad ha sido demostrada por el gran número de sistemas que a nivel mundial, se han instalado tanto en proyectos centralizados como distribuidos.

El Gobierno Mexicano no se ha quedado atrás en la búsqueda de nuevos esquemas de generación eléctrica y está impulsando, con el marco legal y normativo actual, el uso de fuentes de energía renovable como lo son la eólica, solar, hidráulica, geotermia y biomasa que, a través de las tecnologías comerciales asociadas a ellas, se produce electricidad tanto para su aplicación en el ámbito rural (localidades fuera de la red de transmisión eléctrica, sitios remotos o aislados o de difícil acceso) como en las zonas conurbanas y urbanas. Como consecuencia de dicho fomento, la $T F V$ se ha venido usando en nuestro país para proyectos de beneficio social como lo son iluminación básica, purificación de agua, refrigeración de vacunas, educación a distancia, así como para proyectos que han impulsado el desarrollo y explotación de actividades productivas que tienden a disminuir la pobreza en el ámbito rural y urbano.

Así, con el objeto de fomentar la investigación, innovación y desarrollo tecnológico, implementación y adopción de tecnologías basadas en las FER para incrementar el rendimiento energético en el ámbito doméstico, residencial, industrial y de los proyectos productivos agropecuarios en las zonas conurbanas, el Gobierno Mexicano, a través de los diferentes programas de apoyo económico de los Fondos Sectoriales y el CONACYT, están promoviendo la creación, implementación y puesta en operación de proyectos energéticos que conlleven hacia la sustentabilidad energética nacional. Así, se han fomentado e impulsado proyectos para la generación de 
biogás mediante biodigestores, generación de calor de proceso mediante colectores solares de baja y media temperatura, y generación de electricidad mediante la $T F V$, la geotermia, la micro hidráulica y la eólica.

Dentro de los anteriores proyectos, los fotovoltaicos $(F V)$ son los que han tenido la mejor aceptación y adopción por los diferentes sectores sociales y productivos gracias a que generan, en sitio, la electricidad que consume su proyecto, y se interconectan a la Red Eléctrica Convencional (REC) a través de Acondicionadores de Potencia diseñados para tal propósito. Las aplicaciones $F V$ 's interactivas con la REC en el medio urbano, con proyectos de generación eléctrica que van desde unos cuantos Watt hasta $M W$, que se están fomentando fuertemente, han abierto un nicho de mercado en nuestro país que ha sido estimado del orden de 1,000 MW durante los próximos 5 años. De aquí que se espera una fuerte demanda de Sistemas FV interconectados a la red $(S F V-I)$ en un futuro muy próximo. En consecuencia, para garantizar la adopción, permanencia y largo tiempo de operación de los proyectos $S F V$ - $I$ se requiere de proyectos demostrativos sujetos a estudios sistemáticos sobre su desempeño energético, seguridad y durabilidad a largo plazo; así mismo, se necesita personal técnico capacitado para el desarrollo, implementación, instalación y mantenimiento de proyectos de generación de electricidad basados en dicha tecnología y también, material didáctico que proporcione la información necesaria para el buen dimensionamiento y diseño de tales sistemas basados en las normas nacionales e internacionales que están rigiendo la instalación eléctrica de ellos.

Como un ejemplo de dichas acciones, el Consejo Nacional de Ciencia y Tecnología, CONACYT, a través del Fondo Institucional de Fomento Regional para el Desarrollo Científico, Tecnológico y de Innovación (FORDECyT), junto con la participación de los Estados de Zacatecas, Tabasco y Morelos, en su convocatoria M0037-2012-01, ha financiado el proyecto No. 190603 "Estudio sobre el uso de la energía solar en apli- 
caciones residenciales, industriales y comerciales en diferentes estados del país", el cual tiene como propósito validar, mediante estudios sistemáticos en proyectos demostrativos piloto en condiciones reales de operación, relacionados con la tecnología termosolar y fotovoltaica disponibles en el mercado y/o en desarrollo pre-comercial, que el uso de las tecnologías para el aprovechamiento de la energía solar, son viables y que tienen un impacto positivo en la economía, en el medio ambiente y en la sociedad en su conjunto.

Este libro es uno de los productos del área fotovoltaica del proyecto FORDECYT 190603 y ha sido concebido como un documento básico que contiene la información necesaria que permitirá la adquisición de conocimientos para formar recursos humanos tanto como tecnólogos para el dimensionamiento, diseño, implementación, instalación, operación y mantenimiento de sistemas fotovoltaicos. Aquí, se proporcionan los criterios de dimensionamiento y diseño eléctrico de $S F V-I$ en Baja Escala aplicados en Proyectos Energéticos para usuarios domésticos, residenciales, comerciales y Proyectos Productivos Agropecuarios. Para esto, se incluye una visión general de la Tecnología Fotovoltaica abarcando aspectos básicos de la generación, las diferentes tecnologías disponibles en el mercado, una metodología de dimensionamiento para proyectos específicos, un esbozo de las regulaciones y normatividad correspondiente que se debe aplicar al diseño eléctrico de la instalación y aspectos relevantes a la operación y mantenimiento de dichos sistemas.

El presente libro está dirigido a todas aquellas personas que estén involucradas en la implementación, desarrollo, y operación de proyectos productivos agropecuarios basados en la disponibilidad del recurso solar del sitio de instalación, así como a vendedores e instaladores de dicha tecnología, y productores agropecuarios. 
Aunque el lenguaje técnico en muchas ocasiones es complicado, se ha tratado de usar palabras comunes con el objeto de que los conceptos sean entendidos. 


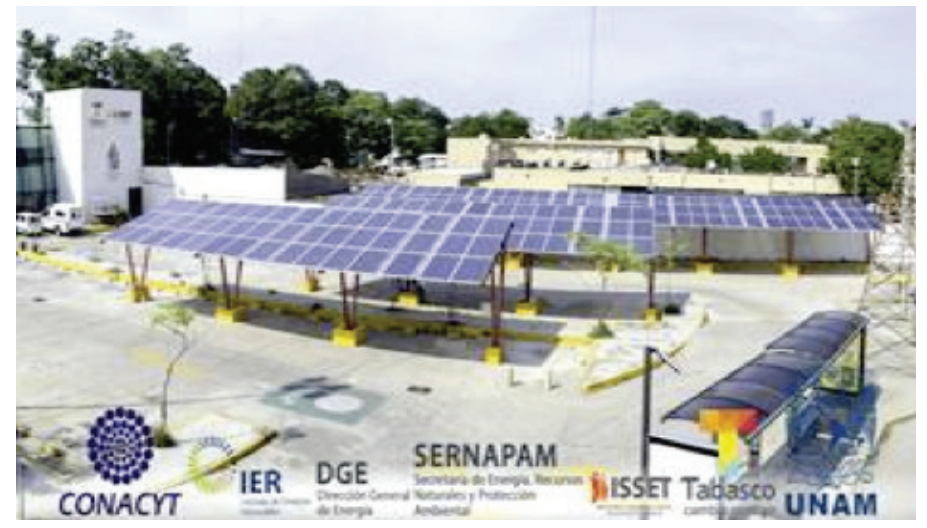

Vista desde el sur de los arreglos FV

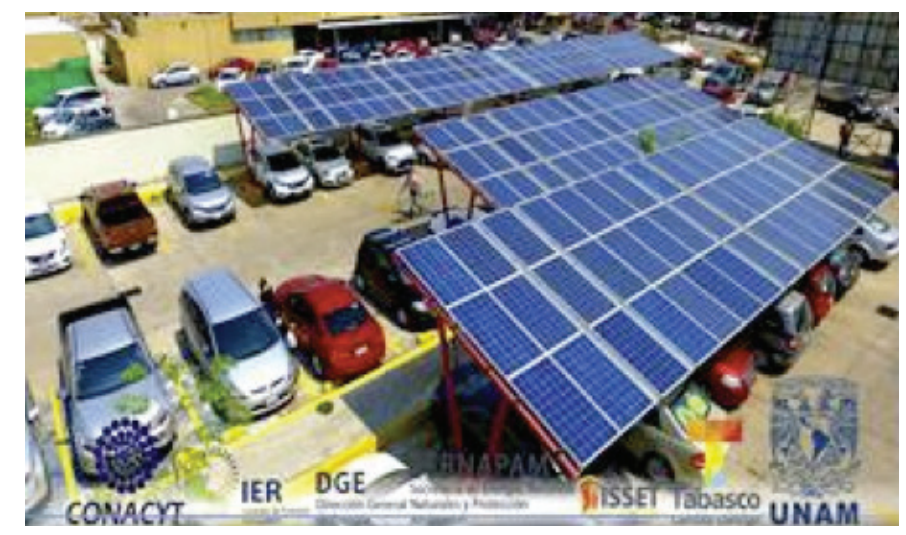

Vista aérea de los 4 Arreglos FV, cada uno de 11.25 kW

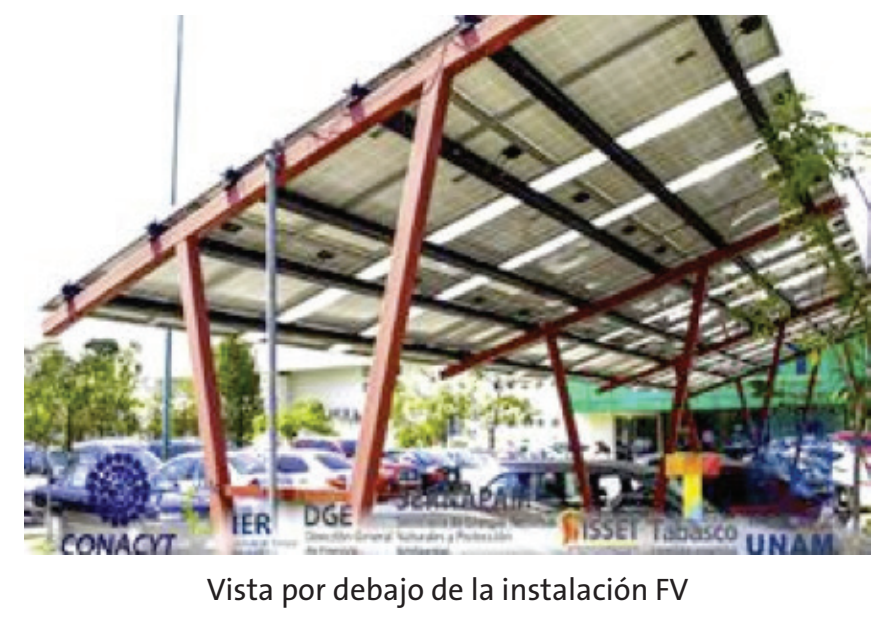




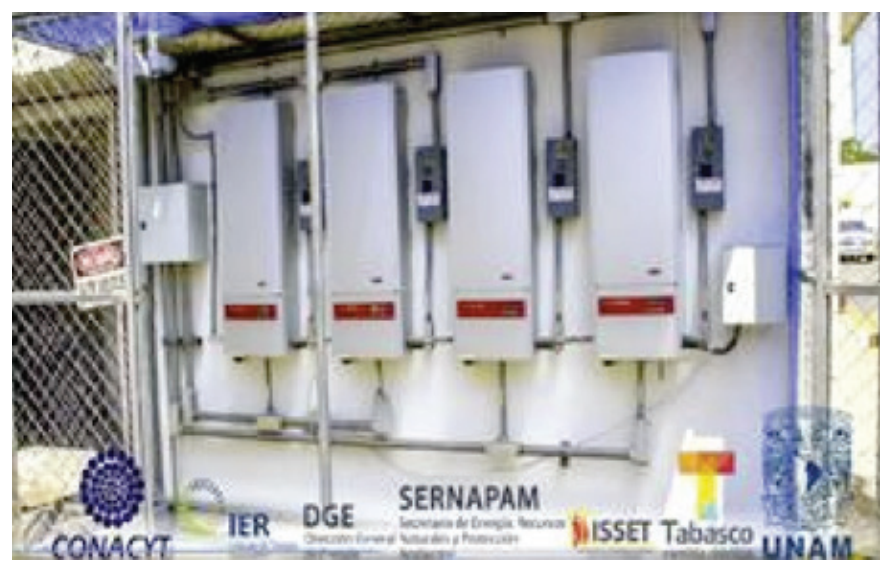

Vista de los 4 inversores de $11.4 \mathrm{~kW}$

Sistema Fotovoltaico Demostrativo dentro del Proyecto FORDECyT No. 190603 "Estudio sobre el uso de la energía solar en aplicaciones residenciales, industriales y comerciales en diferentes estados del país", con la participación de: el Instituto de Seguridad Social del Estado de Tabasco (ISSET), la Secretaría de Energía, Recursos Naturales y Protección Ambiental, la Dirección General de Energía, dependencias del Estado de Tabasco.

Instalación ubicada en la Unidad de Medicina Familiar Centro del ISSET, Municipio, Centro, Villahermosa Tabasco: SFV-I compuesto por cuatro Arreglo Fotovoltaicos de $11.25 \mathrm{~kW}$ pico, dando un total de $45.0 \mathrm{~kW}$ y cuatro inversores, cada uno con una potencia nominal de 11.4 kW (Fotos LANEFVIER-UNAM). 



\section{AGRADECIMIENTOS}

Antes que nada, se agradece al Consejo Nacional de Ciencia y Tecnología, CONACYT, que a través del Fondo Institucional de Fomento Regional para el Desarrollo Científico, Tecnológico y de Innovación (FORDECyT), junto con la participación de los Estados de Zacatecas, Tabasco y Morelos, en su convocatoria M0037-2012-01, ha financiado el proyecto No. 190603 "Estudio sobre el uso de la energía solar en aplicaciones residenciales, industriales y comerciales en diferentes estados del país", cuyo propósito ha sido validar, mediante estudios sistemáticos en proyectos demostrativos piloto en condiciones reales de operación, la funcionalidad, ventajas y oportunidades de desarrollo tecnológico de las tecnologías termosolar y fotovoltaica que estan disponibles en el mercado y/o en desarrollo pre-comercial, y que su uso, son viables y que tienen un impacto positivo en la economía, en el medio ambiente y en la sociedad en su conjunto.

El material consultado para la realización de éste libro proviene de muchas fuentes, públicas y privadas, todas ellas disponibles en la literatura o en sitios electrónicos. Abarca desde el esfuerzo realizado inicialmente por el Banco Mundial en el área de Bombeo desde 1978, que culminó con la edición de un manual llamado "Handbook on Solar Water Pumping", 
publicado en 1984, hasta los esfuerzos realizados hoy en día. Se incluye también el esfuerzo de otras instituciones que a través de Programas para el fomento del uso de la tecnología fotovoltaica han generado experiencias y lecciones aprendidas, entre los que destacan: el Programa de Energías Renovables para México (1994-2000) de Sandia National Laboratories, USA, los Programas Energías Renovables para la Agricultura (2000-2006) y Proyecto de Desarrollo Rural Sustentable (2008-2012) implementados y operados por el Fideicomiso de Riesgo Compartido, dependencia técnica de la Secretaría de Agricultura, Desarrollo Rural, Alimentación y Pesca (FIRCO-SAGARPA) que ha contribuido en gran medida con sus experiencias directas adquiridas por la implementación de dichos proyectos.

También es importante reconocer el esfuerzo que ha realizado la Secretaría de Energía (SENER), la Comisión Reguladora de Energía (CRE) y la Comisión Federal de Electricidad (CFE) por la edición e implementación del Marco Legal y Normativo para el Aprovechamiento de las Energías Renovables, que a través de alianzas estratégicas con otras instituciones, han generado documentos que han fortalecido el conocimiento sobre el uso y aplicación de la tecnología fotovoltaica. Cabe destacar la gran colaboración entre la SENER y el Gobierno de la República de Alemania, que a través de la agencia Deutsche Gesellschauffür Internacionale Zusammenarbeit (GIZ) GmbH, se ha elaborado un estudio de mercado sobre sistemas fotovoltaicos interconectados a la red [1] y se ha propuesto un Programa para el fomento de la tecnología fotovoltaica [2].

A todas ellas y a su personal que han contribuido con la aportación de material didáctico y escrito, producto de sus experiencias de muchos años en ésta área, se les extiende un sincero agradecimiento.

Se agradece la colaboración especial en la búsqueda de material fuente a las siguientes personas: Ing. Vicente Estra- 
da Cajigal Ramírez, M en I Juan Carlos Percino Picazo, Ing. Amilcar Reyes Roldán, Ing. José Ramón Sánchez Cerezuela

Los autores de ésta Guía son:

Dr. Aarón Sánchez-Juárez; Dra. Dalia Martínez Escobar, M en I Rocío de la Luz Santos Magdaleno, M en ES José Ortega Cruz, Ing. Pedro Andrés Sánchez Pérez

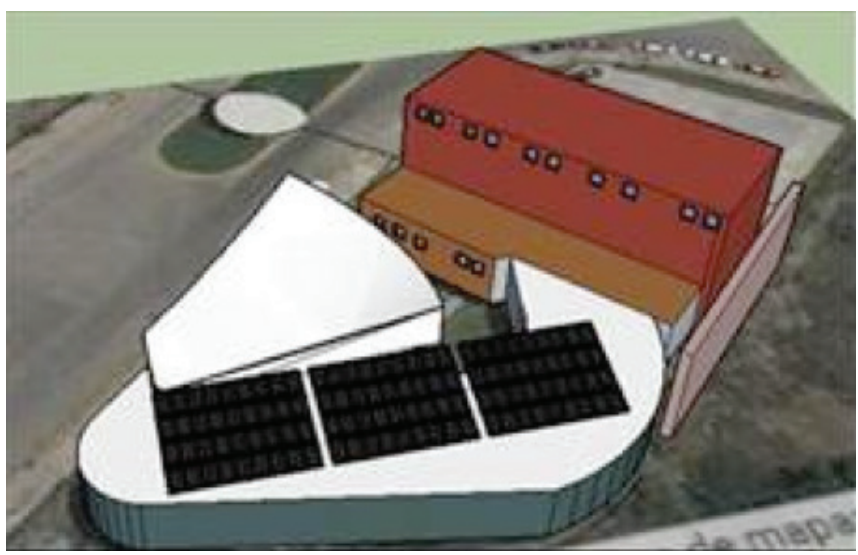

Render de la instalación

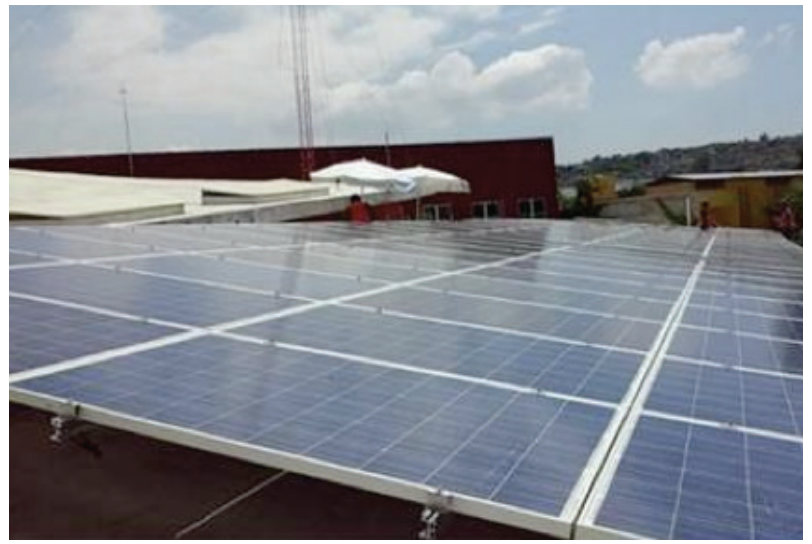

Vista de los módulos fotovoltaicos 


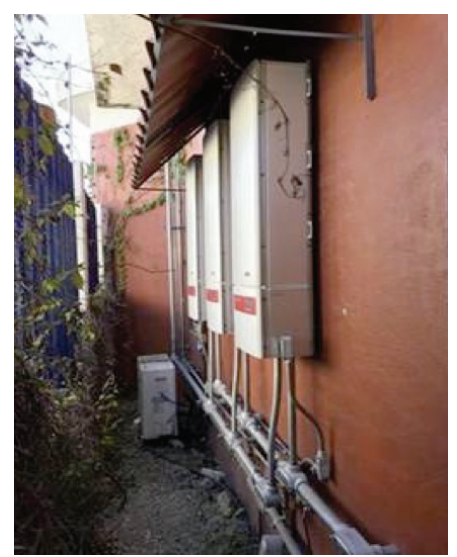

Vista de los tres inversores

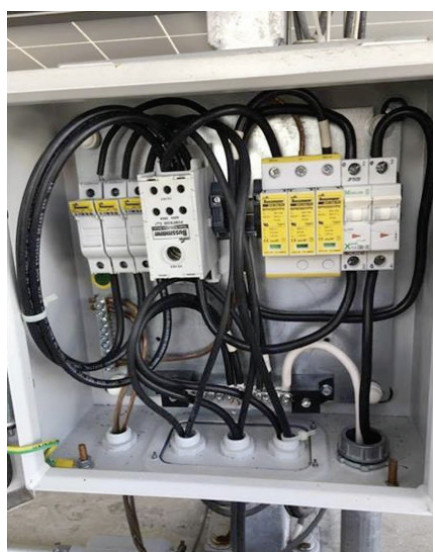

Caja de Combinación: Dispositivos de seguridad

Sistema Fotovoltaico Demostrativo dentro del Proyecto FORDECyT No. 190603 "Estudio sobre el uso de la energía solar en aplicaciones residenciales, industriales y comerciales en diferentes estados del país", con la participación de la Secretaría de Innovación y Desarrollo Tecnológico del Estado de Morelos.

Instalación ubicada en el Centro Morelense de Innovación Agropecuaria, CEMIAGRO, Emiliano Zapata Morelos: SFV-I compuesto por un Arreglo Fotovoltaico de $27.0 \mathrm{~kW}$ pico y tres inversores, cada uno con una potencia nominal de $10.0 \mathrm{~kW}$ (Fotos LANEFV-IER-UNAM). 


\section{RENUNCIA}

Esta Guía fue escrita para que sirva de material de apoyo para el desarrollo de proyectos de Sistemas Fotovoltaicos Interconectados a la Red Eléctrica Convencional y su elaboración se realizó dentro del marco de los entregables del proyecto No. 190603 “Estudio sobre el uso de la energía solar en aplicaciones residenciales, industriales y comerciales en diferentes estados del país", financiado por el FORDECyT, Fondo M0037.

$\mathrm{Ni}$ el CONACYT, ni el FORDECyT, ni la Universidad Nacional Autónoma de México a través del Instituto de Energías Renovables, ni alguno de sus investigadores o empleados, garantiza o asume responsabilidad legal alguna, tanto explícitamente como implícitamente, por la exactitud, integridad o utilidad de cualquier información, aparato, producto o proceso mencionado, ni manifiesta que su uso no infringe derechos de propiedad privada.

Las prácticas y procedimientos que se presentan en este manual son recomendaciones solamente y no reemplazan ninguna normativa local, estatal o nacional aplicable a los edificios, electricidad, plomería u otros requisitos normativos. El lector es responsable de determinar los requerimientos normativos aplicables y permanecer en el cumplimiento con ellos. 
Ni los autores y ni los colaboradores así como las instituciones que se mencionan ofrecen garantía alguna sobre el uso y aplicaciones de esta publicación. Este documento fue escrito de buena fe. La información y datos, los que provienen de fuentes públicas, se consideran correctos en la fecha de su publicación. La mención explícita o implícita de marcas comerciales, fabricantes, productos y servicios no implica que ellas hayan aportado apoyos, patrocinios, endosos o recomendación al autor o instituciones mencionadas; sólo se incluyen para facilitar el entendimiento de los temas cubiertos.

Cualquier comentario, sugerencia o aclaración deber dirigirse por escrito a:

Dr. Aarón Sánchez-Juárez

INSTITUTO DE ENERGÍAS RENOVABLES- UNAM

Pr4. de Xochicalco s/n, Col. Centro, CP 62580

Temixco, Mor., MÉXICO

e-mail: asj@ier.unam.mx

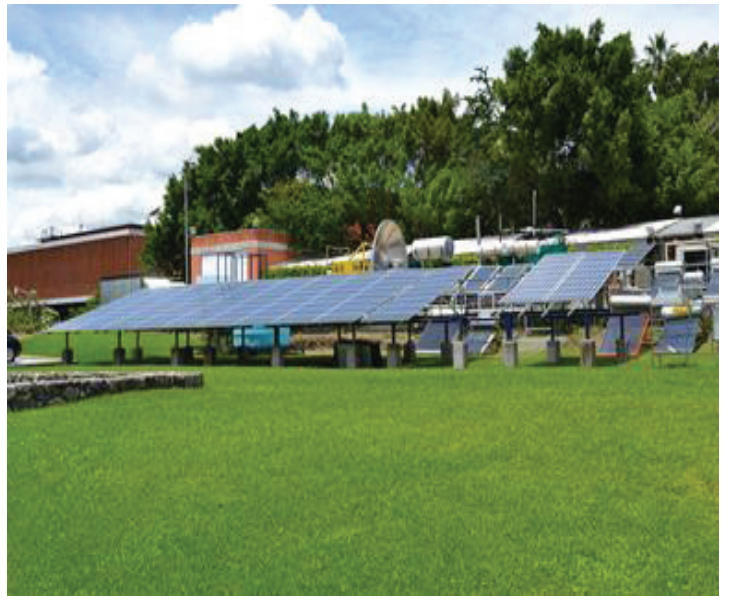

Plataforma FV del IER-UNAM 


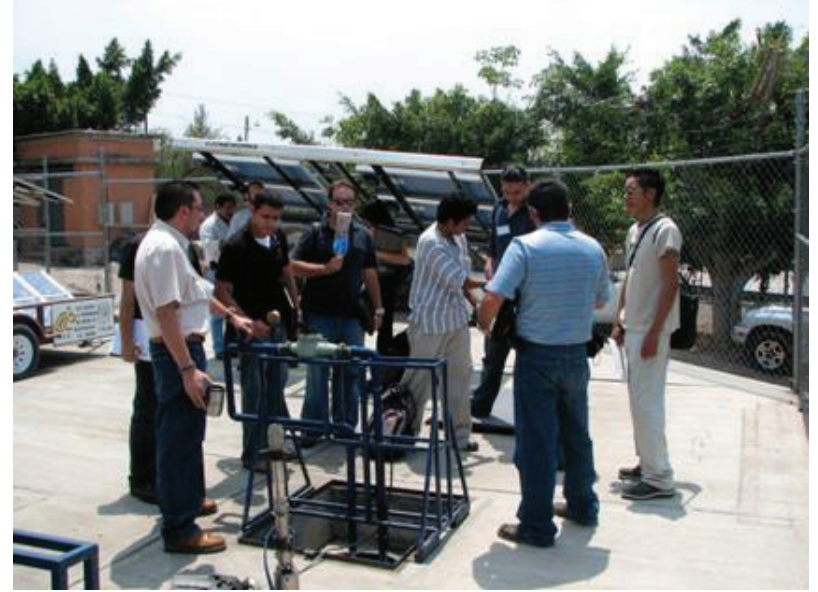

Participantes en un curso de capacitación FV en el IER-UNAM 



\section{1}

\section{PANORAMA DE LAS APLICACIONES FOTOVOLTAICAS}

\subsection{Introducción}

La disponibilidad de la Energía Solar en todo el mundo y su carácter de Fuente de Energía Renovable hacen de ésta una energía universal, la que es responsable también de la aparición de otras fuentes de energía como lo son: la energía del viento, la hidroeléctrica y la maremotríz, sin considerar aquellas posibles fuentes derivadas de la descomposición de desechos biológicos (biomasa).

Además de los procesos fotosintéticos, hay dos formas tecnológicas conocidas en que el ser humano puede aprovechar la energía solar: una es por medio de procesos fototérmicos para calentamiento de fluidos y generar calor de proceso; y la otra es por medio del Efecto Fotovoltaico a través del cual, la luz solar se convierte en electricidad sin usar algún proceso intermedio. Los dispositivos donde se lleva a cabo la transformación de luz solar en electricidad se llaman Generadores Fotovoltaicos y a la unidad mínima en la que se realiza dicho efecto se le conoce como Celda Solar.

La Tecnología Fotovoltaica $(T F V)$ integrada en el concepto de Sistema Fotovoltaico $(S F V)$, es una de las llaves que puede sustentar la diversificación energética que en un futuro 
muy próximo nuestro país requerirá derivado del agotamiento de los recursos fósiles. Nuestro país cuenta con un amplio recurso solar estimado con una densidad energética promedio diario anual de $5.0 \mathrm{kWh} / \mathrm{m}^{2}$; y aprovechado la $T F V$, se podrían resolver los problemas energéticos que se tendrán en un futuro cercano derivado de la carencia de combustibles fósiles. Como un indicador, en una superficie de $100 \mathrm{~m}^{2}$ y usando cualquiera de las $T F V$ s comerciales, se puede generar la energía eléctrica suficiente para abastecer 10 hogares o viviendas típicas mexicanas con un área habitacional menor a $80 \mathrm{~m}^{2}$. Lo anterior sugiere su uso en pequeños condominios verticales que podrían construirse en sitios alejados de la red, ó inclusive, en las zonas urbanas en la modalidad de interacción con la red eléctrica convencional.

Un Sistema Fotovoltaico ( $S F V$ ) es un conjunto de elementos formados por el generador $F V$ y un conjunto de dispositivos eléctricos-electrónicos que permiten controlar, transformar, almacenar y distribuir la energía eléctrica producida por la $T F V$ a un voltaje específico para su consumo por el usuario en las "cargas eléctricas" consideradas (aparatos eléctricos tales como lámparas, radios, bombas, motores, etc.). A dicho conjunto de dispositivos que acondicionan la potencia eléctrica para su uso respectivo que conforman lo que se le llama "balance del sistema", (BOS por sus siglas en inglés: balance of system). La Figura 1.1 muestra un diagrama esquemático de un Sistema Fotovoltaico.

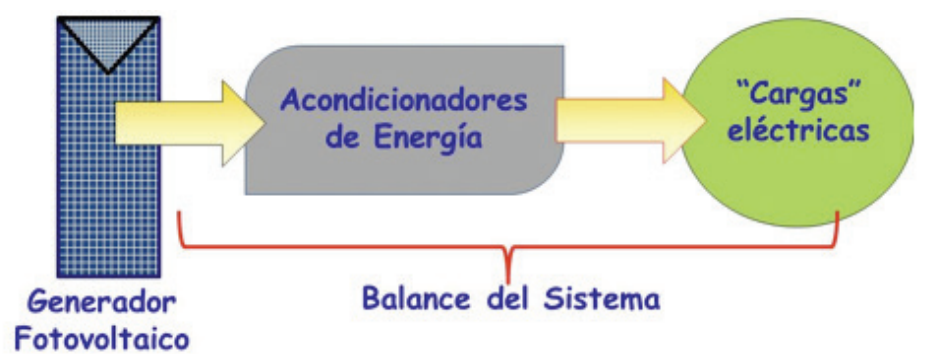

Figura 1.1: Diagrama esquemático de un Sistema Fotovoltaico. 
Los $S F V$ 's basan su operación en unidades mínimas de transformación llamadas comúnmente celdas solares que se integran y encapsulan en unidades mínimas de potencia llamadas módulos fotovoltaicos (MFV) o generadores fotovoltai$\cos (G F V)$; ellos son los encargados de absorber la luz del Sol y convertir su energía en electricidad del tipo corriente continua (dc por sus siglas en inglés: direct current). La transformación se realiza de manera directa sin ningún proceso intermedio: si el $G F V$ recibe luz solar, se genera electricidad, si no la recibe, no se realiza la generación; en otras palabras, la generación de potencia eléctrica solo se realiza durante las horas sol, por lo que para tener disposición de la energía generada durante el día, hay que almacenarla. Esto representa uno de los pocos inconvenientes de la tecnología fotovoltaica. Sin embargo, tiene muchas ventajas respecto de otras tecnologías, las que la hacen un candidato excelente para la generación de electricidad en lugares remotos.

Los nichos de aplicación de los $S F V$ ’s cubren prácticamente todos los ámbitos en donde se requiera electricidad para desarrollar actividades humanas. Se encuentran aplicaciones de ella en el ámbito rural, zonas urbanas, zonas remotas o aisladas, y aplicaciones espaciales. Para el caso de nuestro país, las aplicaciones rurales son las que más se habían fomentado por los diferentes organismos e instituciones debido a la falta de cobertura de la red eléctrica convencional. Este tipo de sistemas en donde el único generador es el Arreglo FV han recibido el nombre de autosustentados $(S F V-A)$. Ejemplos típicos de estos sistemas han sido implementados por PEMEX, Secretaría de Marina, Secretaría de Comunicaciones, SEP, Secretaría de Desarrollo Social, FIRCO-SAGARPA, TELMEX, compañías televisivas, entre otras, que han tenido necesidad de elaborar proyectos de desarrollo social o técnico, en sitios apartados de la red eléctrica convencional, para los cuales la $T F V$ ha sido la más apropiada, tanto técnicamente como económicamente. 
Los $S F V$ presentan las siguientes ventajas y bondades:

- No consumen combustible ya que operan con la luz solar.

- No se producen desechos contaminantes durante la conversión.

- No se genera ruido.

- El sistema del que forman parte es en consecuencia de mínimo impacto ambiental.

- En el proceso de generación no hay partes móviles, lo que indica un mantenimiento mecánico nulo.

- No requieren de un operador para funcionar. Se diseñan para que operen automáticamente.

- Requieren de un mantenimiento mínimo para su funcionamiento y su costo de operación es bajo.

- Son modulares, es decir, solo se instala la cantidad de energía que requiere la aplicación, lo que los hace en sistemas con un rendimiento energético cercano a la unidad (la energía que se genera es cercana a la que se consume).

Una de las desventajas que ha limitado el uso masivo de ésta tecnología es su alto costo de inversión inicial; sin embargo, con la implementación de programas gubernamentales de desarrollo social, educativo y económico, esquemas de financiamiento, iniciativas en el sector público y privado en función de sus necesidades energéticas, han permitido que ésta tecnología tenga sus nichos de aplicación. El ejemplo de esto ha sido la implementación de un sinnúmero de programas gubernamentales tanto nacionales como internacionales que han permitido establecer y confirmar que ésta tecnología es la mejor alternativa, tecnológica y económicamente más viable, para generar electricidad con fines sociales y productivos en sitios alejados de las líneas de distribución eléctrica; y actualmente, en las zonas urbanas en la modalidad de Sistemas Fotovoltaicos Interconectados $(S F V-I)$ a la Red Eléctrica Convencional (REC). 
Sin considerar el costo inicial de inversión, la popularidad de los $S F V$ 's se basa en su fácil uso, confiabilidad, relativo bajo mantenimiento y la disponibilidad del recurso solar. Debido a que son modulares, los $S F V$ 's pueden ser dimensionados para satisfacer las necesidades exactas de energía del usuario, disminuyendo el costo global sistema e incrementando la eficiencia del mismo. Conforme aumentan las necesidades energéticas del usuario, el tamaño energético del sistema se puede expandir.

Aunado a esto y derivado de las acciones de fomento y desarrollo de la TFV que se han impulsado en otros países, el precio de ella ha decrecido notablemente, se ha hecho muy popular y se está incrementando gradualmente su demanda. En el caso de nuestro país, eso ha impulsado los proyectos para la interconexión a la red para uso doméstico, comercial y proyectos productivos agropecuarios; e inclusive ya se tienen en operación sistemas instalados de más de 100 kW, como es el caso de los proyectos de CFE en Santa Rosalía Baja California Sur (1.0 MW), Cerro Prieto BCS (5.0 MW); tiendas comerciales como Bodega Aurrera en Aguascalientes Ags (174.24 kW), Sam’s Club Cola de Ballena, La Paz BCS (200.5 kW), Centro de Energía en Durango, Dgo $(500.0 \mathrm{~kW})$; proyectos asociados a procesos productivos agropecuarios (ver Figura 1.2), aunado a otros proyectosl.

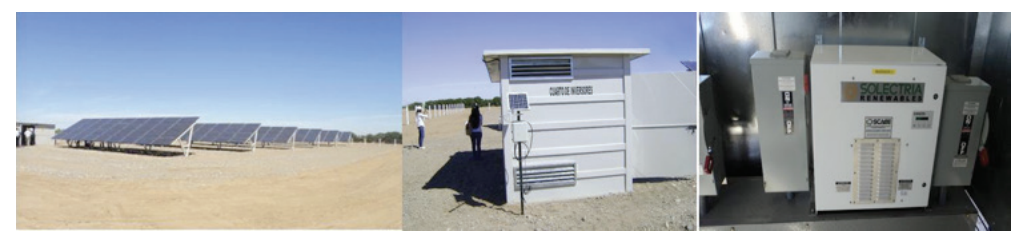

Figura 1.2: SFV-I de $45.0 \mathrm{~kW}$ para una procesadora de cárnicos

1 Datos propios obtenidos de información periodística y visita a los sitios; Aarón Sánchez Juárez 
En consecuencia, para garantizar la adopción, permanencia y largo tiempo de operación de los $S F V-I$ se requiere y necesita personal técnico capacitado para el desarrollo, implementación, instalación y mantenimiento de proyectos de generación de electricidad basados en dicha tecnología, y claro está, material didáctico confiable que permita a los integradores, promotores, vendedores y usuarios disponer de las herramientas teóricas para el dimensionamiento y la información relativa a la normatividad involucrada para el buen diseño de la instalación eléctrica que garantice confiabilidad, durabilidad y seguridad.

\subsection{Antecedentes}

Desde que fue reportada la primera celda solar de silicio cristalino en 1954 [1], el desarrollo de la $T F V$ ha tenido un fuerte impulso en la investigación y aplicación que la ha hecho hoy en día, una tecnología madura, confiable y de larga duración. Inicialmente y debido a sus altos costos, sus primeras aplicaciones estuvieron acotadas en proyectos en donde el precio de la misma no fue una limitante, como es el caso de las aplicaciones espaciales o en los sitios remotos lejos de las redes eléctricas de distribución. Afortunadamente, con los resultados de la investigación y desarrollo de la $T F V$, que han traído como consecuencia procesos de producción masiva, así como los proyectos de fomento y de aplicación que se han instaurado alrededor del mundo, especialmente en Alemania, Estados Unidos de América, Italia, España, Japón, por decir algunos, los costos de producción de ésta se han ido reduciendo a tal grado que el precio por Watt para su venta al menudeo fluctúa alrededor de usd $\$ 0.60$ por Watt [3].

De la misma manera en que se fue desarrollando la $T F V$, los fabricantes de dispositivos eléctricos y electrónicos se abocaron a la tarea de diseñar y construir dispositivos que fueran susceptibles de funcionar con ésta tecnología que produce 
electricidad del tipo continuo, así como acondicionadores de potencia eléctrica que propicien altos rendimientos energéticos en el acoplamiento. En consecuencia, los proyectos de aplicación terrestre, usando dichos equipamientos, muestran un panorama de competitividad económica con tecnologías convencionales para generar electricidad, y su uso, se ha venido haciendo cada vez más popular para generar electricidad en sitios remotos apartados de la red eléctrica convencional o para proyectos en donde se requiere de un generador confiable, limpio y que no impacte al ambiente.

Una de las aplicaciones principales que se detectó en los inicios del desarrollo de la $T F V$ fue el extraer agua del subsuelo, dadas las necesidades del vital líquido para el desarrollo de la vida vegetal o animal. Por esa razón, en los años 70's se tiene el reporte de la primera aplicación de un motor de corriente directa, de imán permanente, acoplado mediante una flecha, a una bomba sumergible energizado con un sistema FV. Este sistema fue desarrollado por la compañía francesa Pompes Guinard [2]. Varias unidades de este tipo fueron instaladas en dichos años.

Posteriormente, a fines de los años 70's, el Banco Mundial emite una convocatoria para desarrollar sistemas de bombeo de agua mediante el uso de la Energía Solar, especialmente usando la $T F V$ con el objeto de abastecer de éste vital líquido a pequeñas granjas para propósito de irrigación a baja escala. Un total de 11 proyectos fueron instalados y los resultados del estudio, dados a conocer en 1981, demostraron en todos los casos que dicha tecnología se puede acoplar a sistemas convencionales de bombeo de agua, y como producto, la extracción de agua de una manera segura y confiable.

Como continuación del programa se instalaron 64 sistemas adicionales los que fueron sometidos a estudios técnicos y económicos. El reporte final fue realizado en 1983, el cual arrojó resultados muy interesantes. En primera instancia se concluyó que los sistemas de bombeo $F V$ son económica- 
mente competitivos con sistemas de generación de electricidad convencionales y su aplicación se justifica claramente en sitios con insolaciones altas en donde el costo del combustible (diesel, gasolina, gas) es alto, la velocidad del viento es baja, y el ciclo hidráulico es menor de $500 \mathrm{~m}^{4}$ (extraer $1.0 \mathrm{~m}^{3}$ de agua de $500 \mathrm{~m}$ de carga hidráulica ó extraer500 $\mathrm{m}^{3}$ de agua con una carga hidráulica de $1.0 \mathrm{~m}$ ). Se demostró que para aplicaciones de consumo humano el sistema de bombeo $F V$ es más barato que un sistema convencional.

Como consecuencia de dicho esfuerzo se publicó en 1984 el manual Handbook on Solar Water Pumping, el cual fue actualizado en 1986, y posteriormente en 1993 se presenta la última versión [2]: Solar Pumping: An Introduction and Update on the Technology, Performance, Cost, and Economics. A esa fecha se habían instalaron del orden de 10,000 sistemas de bombeo fotovoltaico alrededor del mundo que demostraron la confiabilidad y simpleza de dicha tecnología; y gracias al avance tecnológico en el incremento de la eficiencia de las celdas solares, incremento de la producción masiva, y el desarrollo de nuevas tecnologías de control en los sistemas de bombeo, trajeron como consecuencia una reducción en los precios de los sistemas de bombeo $F V$. En consecuencia, la competitividad económica de los mismos se amplió hasta ciclos hidráulicos inferiores a $\operatorname{los} 1,500 \mathrm{~m}^{4}$ para sistemas alejados a $2.0 \mathrm{~km}$ de las redes de distribución de electricidad, con respecto a las tecnologías convencionales (motobombas, motogeneradores y electrobombas, y aerobombas).

Por otra parte, el desarrollo tecnológico realizado a nivel internacional desde la década de los 80 's en los acondicionadores de potencia, especialmente en los inversores de c.c./ c.a., abrieron la oportunidad de interconectar los GFV's a la REC, dando así inicio a los grandes proyectos internacionales de interconexión, como es el caso de los programas de fomento e implementación de Estados Unidos de América, Japón, España, Alemania, y otros. Dichos programas detonaron el 
mercado internacional e impulsaron la aparición de numerosas compañías de fabricación de celdas y módulos fotovoltaicos, tal que desde 1999 al 2011, se ha cuantificado aproximadamente una producción acumulada de 97 GW. La Figura 1.3 muestra la producción mundial de celdas solares desde 1999 hasta 2011 con un valor estimado para la producción de 2012 de 52.11 GW según la revista Photon [4].

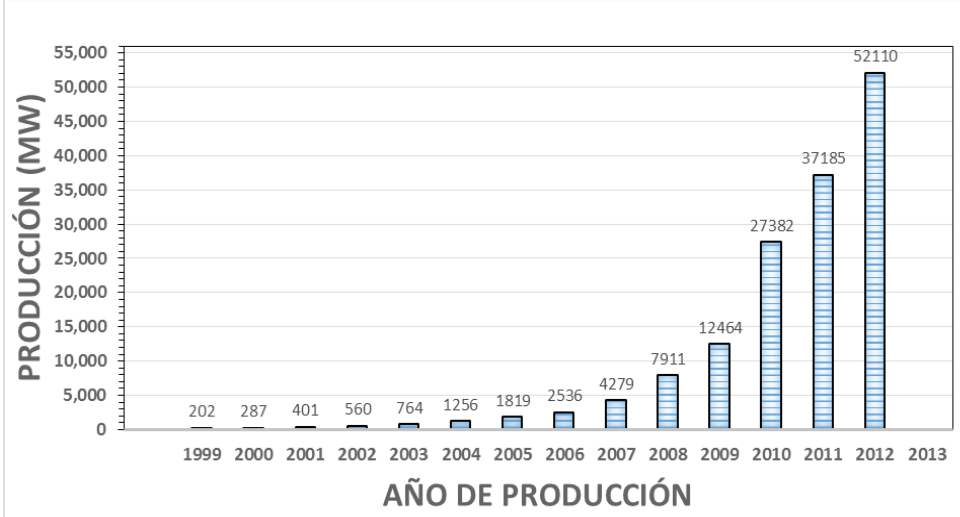

Figura 1.3: Producción de celdas solares desde el año 1999 a 2012 (Adaptado de la revista "Photon, la Revista Fotovoltaica, 4/2012".

El reporte realizado por la agencia REN21 Renewable Energy Policy Network for the 21st Centuy muestra, en su reporte Renewables 2016 Global Status Report, que la Capacidad instalada de Sistemas Fotovoltaicos a nivel mundial a fines del año 2015 es de 227 GW, siendo China el país que, en el año 2015, adicionó más potencia instalada (15.2 GW) que los demas paises como Alemania (1.5 GW), Japon (11.0 GW), USA (7.3 GW), Inglaterra $(3.7 \mathrm{GW})$, entre otros. La Figura 1.4 muestra una gráfica de la potencia instalada desde 2005 al 2015 .

Como una consecuencia de la gran producción asociada a la demanda de la tecnología mediante los programas de fomento internacional, los precios de la tecnología se han reducido 
notablemente en comparación con aquellos que se tenían en los años 90's e inclusive con la tendencia observada en dicho periodo (ver la Figura 1.5). Con base en dicho comportamiento, David E. Carlson de BP Solar realizó una estimación del comportamiento del precio de venta en términos de la producción hacia el año 2030 [5]. Según este autor, se esperaba que para el 2010 se tuviera una producción cercana a los $10 \mathrm{GWp}$ con precios de venta aproximados de usd $\$ 2.70$ por Wp; sin embargo la historia es otra. La Figura 1.3 muestra que en el año 2010 se produjeron $27.38 \mathrm{GWp}$, es decir se produjeron 2.7veces más que la producción estimada con precios de venta cercanos a los usd $\$ 2.00$ por $\mathrm{Wp}$, menor al proyectado debido a la alta producción en masa.

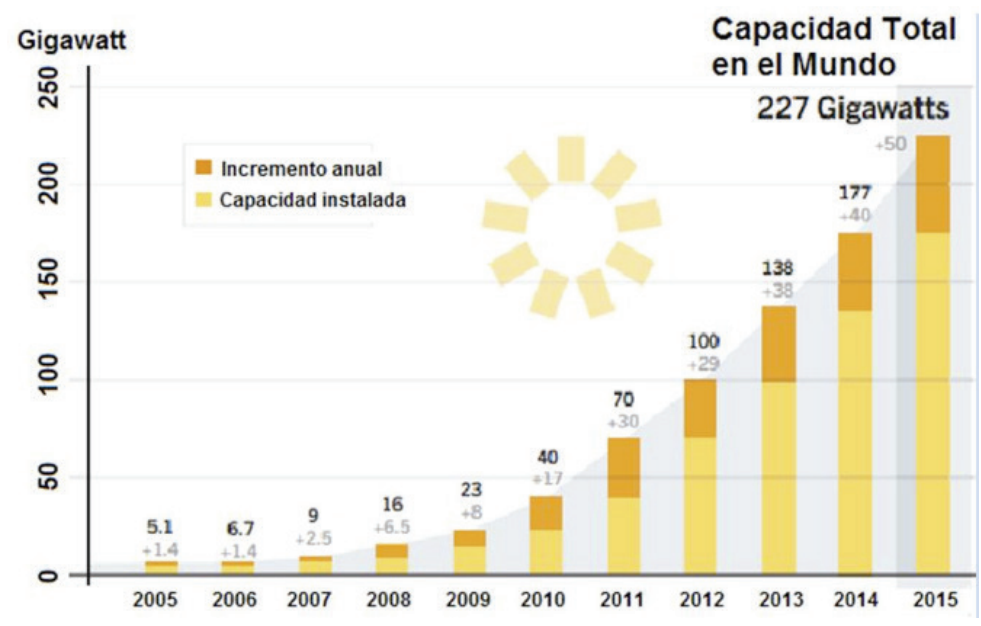

Figura 1.4: Potencia Pico FV instalada en el mundo. Fuente: Renewables 2016 Global Status Report, pag. 63; REN21 Renewable Energy Policy Network for the 21st Centuy. 


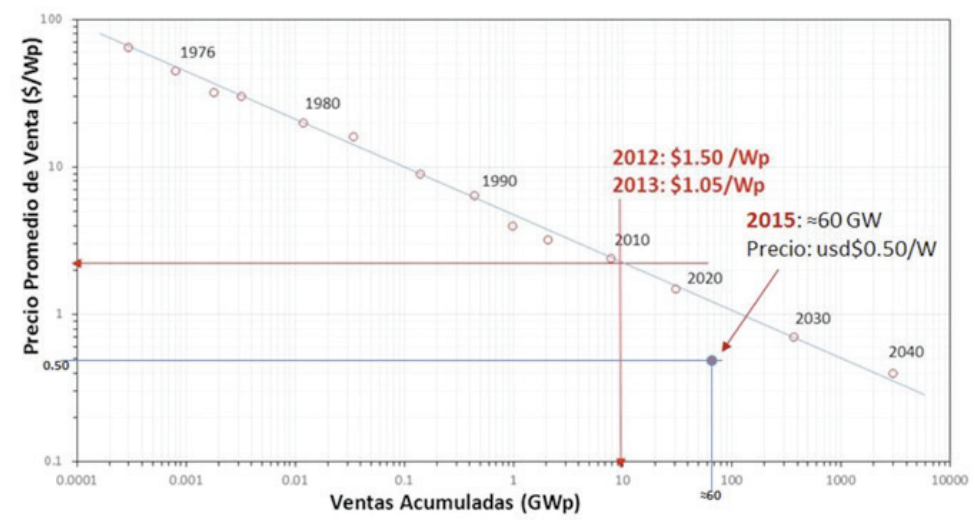

Figura 1.5: Comportamiento del precio de venta de la tecnología FV. Adaptado de David E. Carlson, BP Solar, October 2007. El precio de venta público al menudeo en nuestro país se sitúa, dependiendo de las cadenas de proveeduría, entre usd\$0.55 a usd\$0.75 para las diferentes tecnologías comerciales de aplicación terrestre.

La Figura 1.6 muestra fotografías representativas de las diferentes tecnologías fotovoltaicas que actualmente están disponibles comercialmente. La oferta comercial cubre tanto módulos diseñados para cargar acumuladores a 12 Vcd nominales como aquellos para la interconexión a la red eléctrica convencional, con eficiencias que van desde un $6 \%$ hasta un $22 \%$.

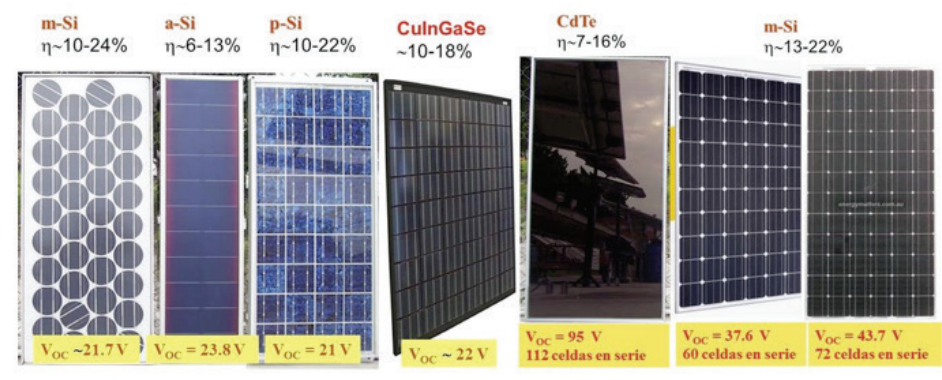

Figura 1.6: Fotografías de tecnologías fotovoltaicas disponibles en el mercado así como el rango de la eficiencia de transformación. 
En forma general, la mayoría de las instituciones de investigación en conjunto con las empresas siguen con la meta de fabricar celdas solares con eficiencias altas, mayores del 15\%, con altos volúmenes de producción y bajo costo, tendiendo a tener dispositivos con costos de fabricación menores a usd $\$ 50.00$ por metro cuadrado. De acuerdo al trabajo realizado por Shyam Mehta en su artículo PV Technology and Cost Outlook, 2013-2017 [6], el costo de producción de los mejores módulos fotovoltaicos de silicio cristalino fabricados en China en el 4 trimestre del 2010 fue de usd $\$ 1.10$ por Watt, y para el cuarto trimestre del 2012 se tuvo una reducción de costos hasta $\$ 0.50$ derivado de una alta producción e innovaciones en las líneas de producción que favorecieron un incremento en la eficiencia de producción del producto.

Con el empuje tecnológico impulsado por las empresas Chinas tales como Jinko Solar, Renesola, Trina Solar and Yingli Green Energy, el autor del artículo predijo que en el 2017 se se tendrán costos de producción de usd $\$ 0.36$ por Watt derivado de innovaciones tecnológicas tales como sierras de diamante ultradelgadas para cortar las obleas de silicio, procesos avanzados para la metalización, y un aumento en la automatización para disminuir la mano de obra. En el caso de nuestro país, en el 2016, las 8 empresas nacionales que fabrican MFV's de silicio cristalino, con celdas con eficiencias superiores al $15 \%$, ofertaron sus productos a un precio entre usd $\$ 0.55$ y usd $\$ 0.65$ por Watt, lo que estaría indicando costos de producción cercanos a usd $\$ 50.00$ por metro cuadrado, los cuales estarían generando electricidad durante su ciclo de vida útil, en localidades con recurso solar mayor de 4.0 $\mathrm{kWh} / \mathrm{m}^{2}$, con costos comparables a aquellos que se obtienen por la quema de combustibles fósiles [7]. 


\section{3.- La experiencia fotovoltaica en México}

En México como en muchos países, los Sistemas Fotovoltaicos Autónomos (SFV-A) han sido la mejor alternativa de electrificación para sitios alejados de la REC. Debido a la falta de cobertura de la REC, las aplicaciones rurales han sido fomentadas e implementadas por diferentes organismos gubernamentales, gobiernos municipales y compañías particulares. El primer programa social masivo impulsado por el gobierno Federal para la electrificación rural usando la Tecnología Fotovoltaica (TFV) fue el de PRONASOL 1988-1994, instalándose del orden de 1.4 MW-pico de paneles solares (ver fotografías en la fig. No.8); así mismo, TELMEX, con su programa de telefonía rural instaló del orden de 1.3 MW-pico. La potencia pico instalada acumulada desde 1980 a 1992 fue aproximadamente de 3.7 MW [8]; y en el año 2007 se realizó una estimación de la TFV instalada obteniéndose un valor aproximado de $21 \mathrm{MW}$ [9].

En 1994, la entidad gubernamental mexicana Fideicomiso de Riesgo Compartido, dependencia técnica de la Secretaría de Agricultura, Ganadería, Desarrollo Rural, Alimentación y Pesca (FIRCO-SAGARPA), adoptó el uso y promoción de Tecnologías basadas en las Energías Renovables, especialmente la $F V$, para aplicaciones agropecuarias. Con estos fines se unió a los esfuerzos de Sandia National Laboratories (SNL), organismo perteneciente al Departamento de Energía de los Estados Unidos (USDOE), en la implementación de tecnologías de energía renovable en aplicaciones productivas, y acordaron promover, el uso de sistemas de bombeo FV ya que representaba una alternativa conveniente para el abrevadero de animales en regiones apartadas de la red eléctrica convencional. Y para garantizar el éxito del programa, el FIRCO capacitó a personal técnico sobre la dinámica de identificación de proyectos factibles, operación de estos sistemas, dimensionamiento y evaluación técnica y económica de propuestas. Paralelamente, el personal técnico de Sandia puso 
en marcha un programa de capacitación y asesoramiento de proveedores, diseñadores y casas distribuidoras de material de bombeo y solar con el fin asegurar una máxima calidad en las instalaciones y productos instalados.

Los buenos resultados obtenidos en esta fase proporcionaron un incentivo para continuar el programa y extenderlo a otras aplicaciones como lo son la iluminación básica, refrigeración y comunicaciones. Durante los siguientes cinco años, se instalaron con éxito 195 sistemas de bombeo de distintas capacidades. Las experiencias y lecciones aprendidas en el desarrollo de éstos proyectos dieron como resultado un manual llamado "Guía para el Desarrollo de Proyectos de Bombeo de Agua con Energía Fotovoltaica", que fue editado por el Southwest Technology Development Institute of New México State University (SWTSI-NMSU) en el año de 1999.

A raíz de los resultados obtenidos en dicho programa, el FIRCO solicitó un donativo al Banco Mundial, del Fondo Mundial del medio Ambiente (Global Environment Facility; GEF), para que dicha institución continuara impulsando las experiencias anteriores, mediante el establecimiento del "Proyecto de Energía Renovable para la Agricultura" (PERA), que consideró el fortalecer los cuadros técnicos, el establecer módulos demostrativos, y la promoción y difusión de la tecnología FV. Para esto, el programa contempló la realización de cursos, eventos y la capacitación de técnicos y funcionarios tanto de los gobiernos estatales, de la SAGARPA, como del propio FIRCO, empresas prestadoras de servicios y productores, que minimizarán la barrera del desconocimiento sobre el uso de estas tecnologías; requiriéndose para esto la obtención de material didáctico que servirá de apoyo a la instrucción planteada. De ésta manera y como resultados importantes del desarrollo del PERA se destacan los siguientes:

a) Más de 40 técnicos del FIRCO capacitados como instructores para la promoción, fomento, desarrollo, 
implementación, y evaluación técnica y económica de proyectos fotovoltaicos aplicados a los agronegocios.

b) Más de 1500 técnicos de las diferentes instituciones gubernamentales, proveedores, estudiantes y usuarios de la $T F V$.

c) Un documento en donde se plasman las Especificaciones Técnicas para Sistemas Fotovoltaicos aplicados al Bombeo de Agua.

d) Más de 1,900 sistemas de bombeo fotovoltaico instalados en la República Mexicana que han servido de sistemas demostrativos para instalar más sistemas fotovoltaicos (la Figura 1.7 muestra fotografías de varios sistemas de bombeo instalados).

e) Un libro titulado "Tecnología Fotovoltaica Aplicada al Bombeo de Agua'; editado por el Fideicomiso de Riesgo compartido FIRCO-SAGARPA 2006 cuyo autor es Dr. Aarón Sánchez-Juárez.

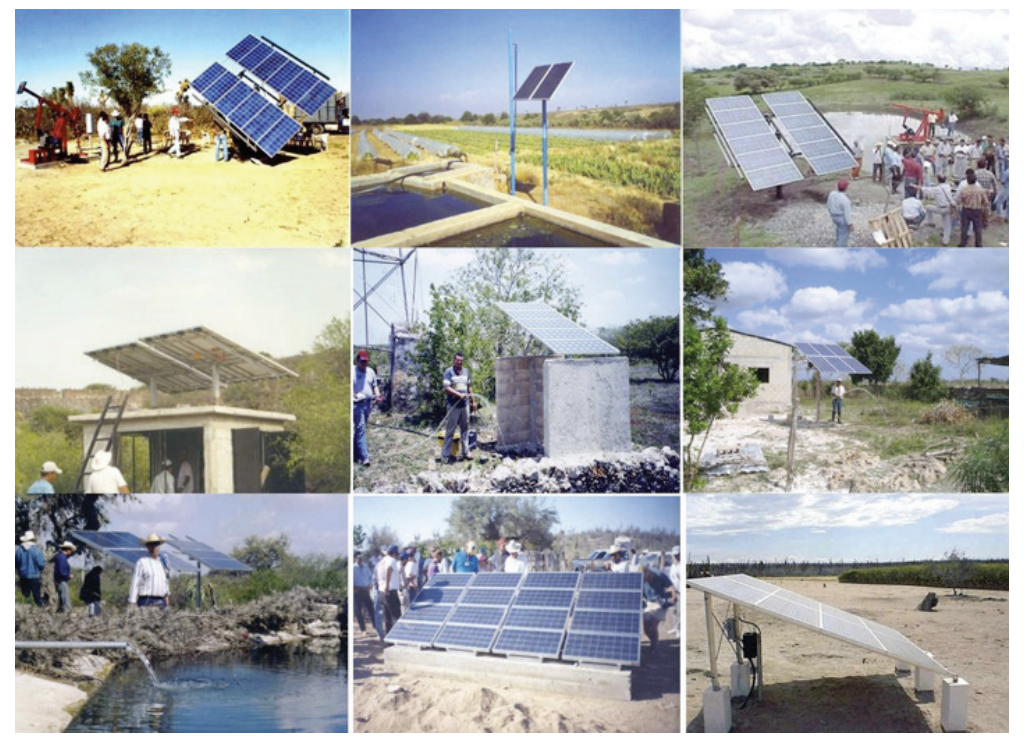

Figura 1.7: Ejemplos de sistemas de bombeo FV financiados por el programa PERA del FIRCO-SAGARPA (Fotos propias). 
El PERA también contempló dentro de sus metas la cuantificación del mercado potencial de tecnologías asociadas a las energías renovables. El estudio fue realizado por el bufet de consultores ConEstadística/ANES para el FIRCO-SAGARPA llamado "Estudio del Mercado de las Fuentes de Energía Renovable en el Sector Agropecuario" que comprendió, entre otros tópicos el estudio Electrificación de Agronegocios con Tecnología Fotovoltaica, realizado por A. Sánchez-Juárez [10], cuya meta fue la estimación de la demanda de los sistemas fotovoltaicos aplicados en agronegocios abarcando las aplicaciones de: Bombeo de agua para abrevaderos, ganadería (pastoreo, leche y carne), invernaderos, acuacultura, granjas, establos, refrigeración, irrigación en pequeña escala, empacadoras, etc; estén o no electrificados, se identificó que en el año 2005, el universo de usuarios potenciales era de 98,872, los que representaban un requerimiento con proyectos $F V^{\prime}$ 's de 29.24 MW.

Además de los proyectos $F V^{\prime}$ s autónomos, los proyectos internacionales de la interconexión de los $S F V$ 's a la REC despertó mucho interés en nuestro país, tanto en sectores gubernamentales, privados y centros investigación porque representan una alternativa para la diversificación energética. A fines de los años 90’s, el Instituto de Investigaciones Eléctricas (IIE) establece alianzas estratégicas con CFE y la extinta compañía Luz y Fuerza del Centro para analizar el comportamiento de sistemas $F V^{\prime}$ 's interconectados a la red para aplicaciones residenciales de baja potencia. En el 2005 se instala el primer $S F V$ interconectado a la red de distribución de Luz y Fuerza en el Distrito Federal con una potencia de $30.0 \mathrm{~kW}$ en un restaurant vegetariano llamado The Green Corner, cuyo propietario es el Sr. Bensi Levy, el cual ha sido monitoreado desde entonces por el IIE. Los resultados sobre el desempeño de dicha instalación despertaron mucho interés gubernamental, y por ese motivo y para establecer lineamientos de la interconexión, en Junio de 2007 la Comisión Reguladora de 
Energía (CRE) emite el modelo de Contrato de Interconexión a la REC, bajo el esquema de medición neta [11], para $S F V$ 's a lo más de $30.0 \mathrm{~kW}$.

En el 2007, el IIE recibe financiamiento del Programa para el Desarrollo de las Naciones Unidas (UNDP por sus siglas en inglés: United Nations Development Programme in Mexico) y del Global Environment Facility (GEF) bajo el programa de Estrategias para la Mitigación del Cambio Climático para desarrollar el proyecto "Small grid connected photovoltaic systems", cuyos objetivos principales fueron: establecer las condiciones básicas para facilitar la introducción en gran escala de los sistemas fotovoltaicos conectados a la red en México, con un doble objetivo: a) reducir los picos de demanda en las regiones con diferencias significativas entre la demanda durante las horas pico y no pico hora, como resultado de la utilización de refrigeradores o acondicionadores de aire y b) apoyar la demanda a la red eléctrica en sitios en donde la demanda pico está limitada por la capacidad instalada. El proyecto se realizó en el periodo 2007-2012 y la evaluación de los resultados, realizada por Agostinho Miguel Garcia, jefe de Desarrollo e ingeniería de Sun Businnes Development en Portugal, se pueden consultar en: http://erc.undp.org/evaluationadmin/manageevaluation/viewevaluationdetail.html? evalid $=6275$.

Por otra parte, derivado de las inquietudes externadas por diferentes sectores energéticos respecto de dicha limitación en potencia, posteriormente a la emisión de la primera regulación, en abril de 2008, se emite el Contrato de Interconexión a la REC para Fuentes de Energía Renovable o Sistema de Cogeneración en Mediana Escala [12] que contempla la interconexión a la REC de $S F V$ 's hasta de $500.0 \mathrm{~kW}$. Un diagrama esquemático de un Sistema Fotovoltaico Interconectado a la Red Eléctrica Local $(S F V-I)$ se muestra en la Figura 1.8, en donde se identifica al Generador Fotovoltaico (GFV) que generalmente está formado por un arreglo de módulos fotovol- 
taicos conectados en serie y/o en paralelo montados sobre una estructura metálica (E); un Sistema de Protección (SP) antes y después del Acondicionador de Potencia (AP), que en este caso corresponde a un inversor de corriente directa (c.d.) a corriente alterna (c.a.); el Tablero de conexión en paralelo con la red de distribución local o SEN; un Medidor Bidireccional (MB) y las Cargas Eléctricas Locales (CEL). El cableado, la estructura, los sistemas de protección y el inversor componen al Balance del Sistema (BOS: Balance of System), sin el cual, no sería posible usar la electricidad generada por el $G F V$.

Para impulsar el fomento sobre el uso de las energías renovables, en noviembre de 2008 se publica en el Diario Oficial de la Federación la Ley para el Aprovechamiento de Energías Renovables y el Financiamiento de la Transición Energética (LAERFTE), así como la Ley para el Aprovechamiento Sustentable de la Energía (LASE), y posteriormente, en el año 2009 se publican sus reglamentos respectivos.

Aunado a lo anterior, desde 2004 ya se había emitido un apartado en la Ley del Impuesto Sobre la Renta para fomentar el uso de maquinaria y equipo para generar energía con fuentes renovables de energía. Con este apartado, desde 2004 las personas morales pueden deducir fiscalmente [13] el 100\% del costo de un SFV.

La apertura del gobierno federal al emitir las leyes anteriores y las lecciones aprendidas por los proyectos que se han implementado, por ejemplo el de FIRCO-SAGARPA [14], han despertado e incentivado acciones gubernamentales que van desde la elaboración de estudios para estimar el mercado potencial hasta la implementación de muchos proyectos demostrativos interconectados a la red tanto de particulares como gubernamentales. 


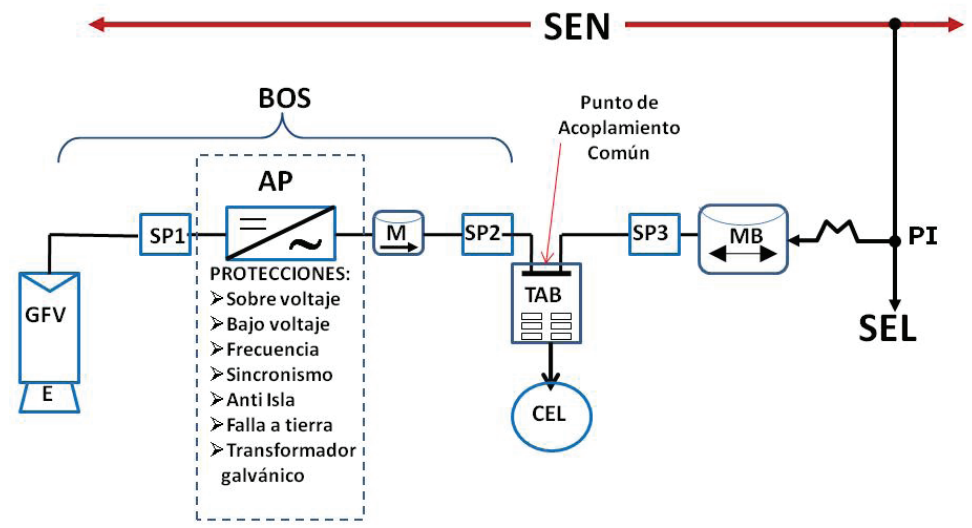

Figura 1.8: Diagrama esquemático de un Sistema FV interconectado a la red eléctrica convencional (Fuente: Elaboración propia).

Así, con el objeto de analizar la posibilidad de establecer un Programa Nacional gubernamental para el fomento e implementación de SFV's interconectados a la red en el sector residencial, la Secretaria de Energía (SENER), a través de la Comisión Nacional para el Uso Eficiente de la Energía (CONUEE), dentro del marco de colaboración internacional con el Gobierno de la República de Alemania, encargó a la agencia Deutsche Gesellschauffür Internacionale Zusammenarbeit (GIZ) GmbH, elaborar un Estudio de Mercado para analizar el tamaño y las implicaciones de su implementación. En dicho estudio se estimó un mercado potencial para aplicaciones residenciales de $200 \mathrm{MW}$ [15], los que podría generar 800 MWh por día y por lo tanto, un ahorro sustancial en combustibles fósiles y toneladas de $\mathrm{CO}_{2}$ evitado.

Como una consecuencia de las acciones de fomento y desarrollo de la $T F V$ que se han impulsado en nuestro país y debido al decrecimiento en su precio, se han estado incrementando gradualmente las instalaciones de sistemas interconectados a la red para uso doméstico, comercial y proyectos productivos agropecuarios. Se tienen en operación sistemas instalados de más de 100 kW, como es el caso de los proyec- 
tos de CFE en Santa Rosalía BCS (1.0 MW), Cerro Prieto BCS (5.0 MW), Bodega Aurrera en Aguascalientes Ags (174.24 kW); Sam’s Club Cola de Ballena, La Paz BCS (200.5 kW), Centro de Energía en Durango, Dgo $(500.0 \mathrm{~kW})$, aunado a otros proyectos [16]. La Figura 1.9 muestra fotografías de un conjunto de proyectos FV's interconectados a la red en varios sitios de la República Mexicana.

Por otra parte y paralelamente a los esfuerzos anteriores, derivado del éxito que tuvo el FIRCO-SAGARPA en la implementación, puesta en operación, ejecución y seguimiento del PERA, en el año 2008 se abrió la oportunidad de implementar un nuevo programa llamado Proyecto de Desarrollo Rural Sustentable (PDRS-FIRCO) que ha proporcionado apoyos económicos a los productores para el establecimiento de tecnologías que fomenten la conservación y protección del medio ambiente, en específico sistemas de energía renovable y prácticas de eficiencia energética que estén orientados hacia la adquisición de tecnologías que propicien un mayor rendimiento energético en los procesos y una disminución en las facturaciones correspondientes por consumo de energía.

Ya que la $T F V$ ha sido utilizada en proyectos apoyados por el FIRCO dentro del sector agropecuario desde hace algunos años para bombeo de agua, conservación de productos perecederos con refrigeradores autónomos y para satisfacer necesidades domesticas en sitios alejados de la REC, como una acción evolutiva en el fomento de esta tecnología, se ha abierto la oportunidad de apoyar con el programa PDRS-FIRCO proyectos productivos que usen la $T F V$ pero en la modalidad de interconexión a la red. Dentro de estos y a manera de ejemplo la Tabla 1.1 muestra una relación de las actividades productivas que se han apoyado. 


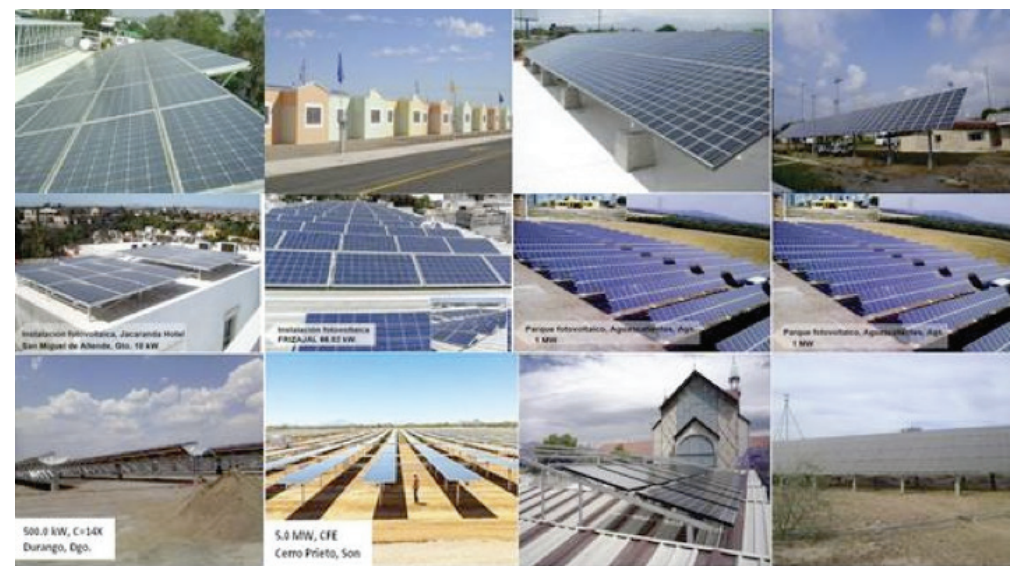

Figura 1.9: Conjunto de fotografías de sistemas FV's instalados y en operación a lo largo de la República Mexicana (Fotos cortesía de varios colaboradores).

Tabla 1.1: Actividades productivas agropecuarias apoyadas por el FIRCO bajo el programa PDRS para la instalación de SFV interconectados a la red.

\begin{tabular}{|c|c|c|}
\hline $\begin{array}{l}\text { Cadena } \\
\text { productiva }\end{array}$ & Actividad productiva & $\begin{array}{l}\text { Capacidad } \\
\text { instalada }\end{array}$ \\
\hline \multirow{6}{*}{ Agroindustria } & Invernaderos & \multirow{10}{*}{$\begin{array}{c}\text { Sistemas de } \\
\text { pequeña escala } \\
\text { (hasta } 30 \mathrm{~kW} \text { ) y } \\
\text { mediana escala } \\
\text { (mayores de } 30 \\
\text { kW) }\end{array}$} \\
\hline & $\begin{array}{c}\text { Producción y comercialización } \\
\text { de productos agrícolas }\end{array}$ & \\
\hline & $\begin{array}{l}\text { Elaboración de productos } \\
\text { lácteos }\end{array}$ & \\
\hline & $\begin{array}{l}\text { Procesadora de frutos y } \\
\text { alimentos }\end{array}$ & \\
\hline & Procesadora de Bio-fertilizantes & \\
\hline & $\begin{array}{c}\text { Elaboración de productos } \\
\text { alimenticios }\end{array}$ & \\
\hline Cárnicos & Rastros, Empacadora de Carne & \\
\hline \multirow{2}{*}{$\begin{array}{l}\text { Subsector } \\
\text { Pecuario }\end{array}$} & $\begin{array}{c}\text { Granjas Avícolas, Granjas } \\
\text { Porcinas }\end{array}$ & \\
\hline & $\begin{array}{c}\text { Granjas Acuícolas, Establos } \\
\text { Lecheros }\end{array}$ & \\
\hline $\begin{array}{l}\text { Desarrollo } \\
\text { Turístico }\end{array}$ & Turismo rural & \\
\hline
\end{tabular}


La mayor demanda de proyectos solicitados por los productores son las aplicaciones en invernaderos en donde se producen verduras, hortalizas y flores de ornato; elaboración de productos alimenticios; empaquetadoras de productos alimenticios, procesadoras de frutos y jugos; elaboración de productos lácteos como queso y crema; ordeñadoras de leche en establos; recirculación de agua en granjas piscícolas; y otras más aplicaciones. Los sistemas instalados cubren un amplio rango de potencias $F V^{\prime}$ 's, estando la mayoría de los proyectos clasificados como sistemas de mediana escala [17], es decir $A F V^{\prime}$ s con potencias pico instaladas mayores de 30.0 kW. En la Figura 1.10 se muestra un conjunto de fotografías de proyectos $F V^{\prime}$ 's instalados asociados a proyectos productivos agropecuarios que han sido beneficiados mediante el programa PDRS-FIRCO.

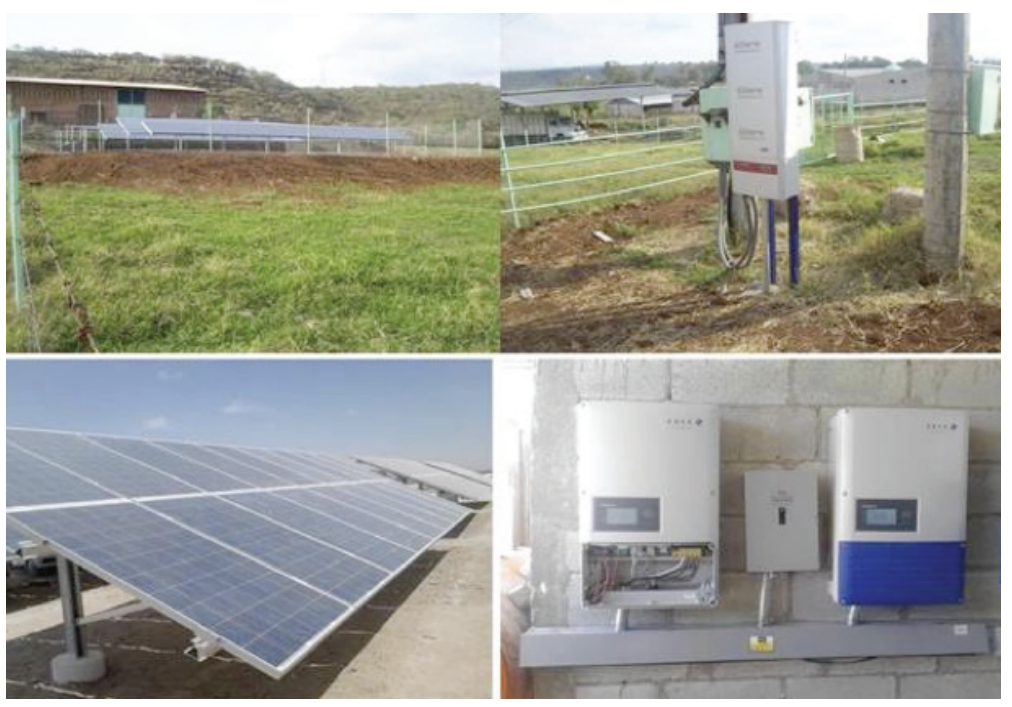

Figura 1.10: Proyectos FV's interconectados a la REC financiados por el programa PDRS-FIRCO (Cortesia del FIRCO).

Los esfuerzos anteriores motivaron a la SENER a diseñar un Programa de Fomento de esta tecnología con el apoyo técnico y la experiencia de GIZ cuyo nombre es "Programa 
de Fomento de Sistemas Fotovoltaicos en México", ProSolar [18], que se ha publicado y cuyo objetivo principal es impulsar el uso de la $T F V$ por medio de 4 ejes fundamentales: Marco regulatorio y normativo, Financiamiento, Capacitación e Información y difusión; a través de los cuales se garantice el desarrollo del mercado local y la industria nacional y se garantice el crecimiento del mercado con fortaleza y calidad.

Considerando el incremento de solicitudes de interconexión a la red de grandes sistemas de generación $F V$ o cogeneración con fuentes de energía renovable, y con el objeto de regular a todos los sistemas que se interconectaran al Sistema Eléctrico Nacional (SEN), la CRE emite el 29 de marzo de 2012 la Resolución RES/119/2012 [19] que establece las Reglas Generales de Interconexión al SEN para Generadores o Permisionarios con Fuentes de Energías Renovables o Cogeneración Eficiente. Sin embargo, a partir del 2014 y raíz de la Reforma Energética impulsada por el Gobierno Federal el panorama normativo se ha modificado.

\subsection{Situación actual FV al 2016 en México}

Existen una gran cantidad de $S F V$ instalados a lo largo del territorio nacional, con capacidades que van desde unos cuantos kilowatts hasta plantas del orden de megawatts. En un esfuerzo por realizar una estimación de la potencia instalada, se puede encontrar información en diferentes dependencias gubernamentales tales como: la Secretaria de Energía (SENER), la Comisión Reguladora de Energía (CRE), la Comisión Federal de Electricidad (CFE), el Centro Nacional de Control de Energía (CENACE) y el Instituto Nacional de Estadística y Geografía (INEGI). Los reportes encontrados fueron: el Reporte de Avances de Energías Limpias 2015 y el Inventario Nacional de Energía Renovables (INERE). 


\section{4.a. Reporte de avances de energías limpias 2015}

De acuerdo al reporte de avance de energías Limpias 2015 realizado por la SENER, con información de la CRE y CFE, se tiene reportada una potencia instalada de energía renovable de 17,140.48 MW, de la cual se estima que la tecnología fotovoltaica contribuye con $170.24 \mathrm{MW}^{2}$. En relación a la energía producida, se estima que la energía generada por las PFV en el año 2015 fue de $190.26 \mathrm{GWh}$, lo que corresponde al $0.06 \%$ de la generación total (ver Tabla 1.2).

Tabla 1.2: Participación por tecnología en la generación de energía eléctrica 2015.

\begin{tabular}{|c|c|c|c|}
\hline & Tecnología & $\begin{array}{c}\text { Potencia } \\
(\mathrm{mw})\end{array}$ & Energía (gwh/año) \\
\hline \multirow{2}{*}{ Fósiles } & - & $48,778.39$ & $246,600.66$ \\
\hline & Hidroeléctrica & $12,488.50$ & $30,891.54$ \\
\hline \multirow{2}{*}{ Renovables } & Eólica & $2,805.12$ & $8,745.15$ \\
\hline & Biogás & 80.80 & 203.57 \\
\hline & Geotermia & 925.60 & $6,303.98$ \\
\hline & Bagazo & 670.18 & $1,187.26$ \\
\hline \multirow{2}{*}{ Otras limpias } & Solar & 170.24 & 190.26 \\
\hline Total & - & $2,125.16$ & $15,403.32$ \\
\hline
\end{tabular}

Por su parte, la tendencia de crecimiento en los últimos años de la energía solar fotovoltaica en México, ha tenido un crecimiento exponencial. De acuerdo al reporte de avances de energías limpias 2015, se tiene la tendencia mostrada en la Figura 1.11.

2 http://www.gob.mx/cms/uploads/attachment/file/118995/Informe_Renovables_2015_2.pdf 


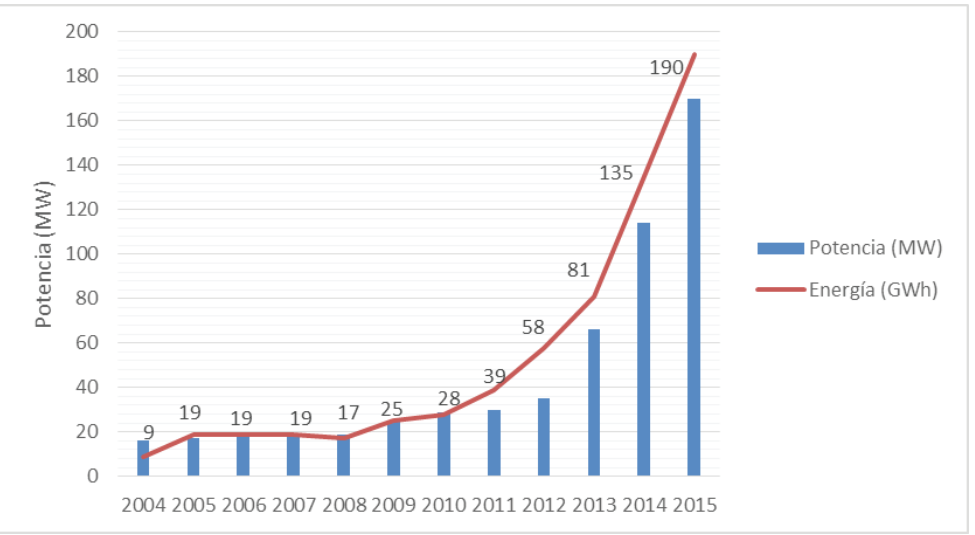

Figura 1.11. Crecimiento de la potencia instalada en el periodo 2004-2015.

\section{4.b. Inventario Nacional de Energía Renovable (INERE)}

De acuerdo a la información obtenida del INERE ${ }^{3}$, la capacidad instalada de Plantas Fotovoltaicas (PFV) en México, hasta junio de 2015, fue de $66 \mathrm{MW}$, con una generación de energía de $62 \mathrm{GWh}$ en el año inmediato anterior (junio de 2014-junio 2015 (ver Tabla 1.3).

Tabla 1.3: Generación de energía renovable anual al año 2015

\begin{tabular}{|c|c|}
\hline Tipo de central & Generación (gwh/año) \\
\hline Hidráulica & $36,991.00$ \\
\hline Geotérmica & $6,027.00$ \\
\hline Eólica & $7,676.00$ \\
\hline Biomasa & $1,414.00$ \\
\hline Solar & 62.00 \\
\hline Oceánica & No produce \\
\hline
\end{tabular}

Sin embargo, los resultados de la primera y segunda subasta eléctrica no se incluyen en dichos reportes, por lo que se decidió verificar los permisos de generación otorgados por parte de la CRE para plantas mayores a $0.5 \mathrm{MW}$ y se verificaron los permisos de interconexión otorgados por la CFE y

3 http://inere.energia.gob.mx/version4.5/ 
reportados por la CRE, para sistemas menores o iguales a 0.5 MW. Los indicadores son los siguientes:

\section{4.c. Permisos Otorgados por la CRE}

La Comisión Reguladora de Energía (CRE) ha otorgado, en el periodo 2011-2016, un total de 319 contratos de interconexión para Plantas Fotovoltaicas $(P F V)^{4}$, dando un total de 9,408.86 MW, de los cuales; 115.60 MW se encuentran en operación, 9,277.63 MW están en proceso de instalación o están por iniciar obras y adicionalmente una planta en el estado de Durango de 15.62 MW posee un estatus de inactivo. Se puede observar en la Figura 1.12 un resumen de los proyectos en operación, en construcción e inactivos por entidad federativa. Los estados con mayor potencia $F V$ en proceso de construcción son Chihuahua y Sonora, con más de 2,000 MW cada uno, seguidos por Coahuila, Guanajuato y Jalisco, con proyectos que suman alrededor de $500 \mathrm{MW}$ para cada entidad. Por su parte, los estados que actualmente cuentan con PFV's en operación son: Durango, Baja California Sur, Estado de México, Baja California, Sinaloa, Guanajuato y Aguascalientes.

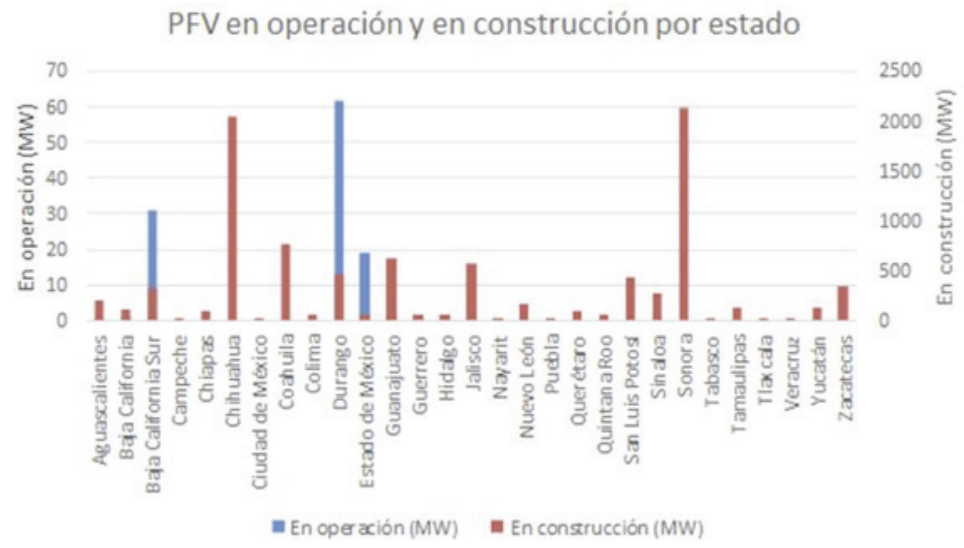

Figura 1.12: Potencia Pico instalada por Estado.

4 http://datos.gob.mx/busca/dataset/permisos-vigentes-de-generacion-electrica-por-tipo-de-tecnologia 
Los $S F V$ con capacidades menores a $500 \mathrm{~kW}$ no requieren de un permiso de generación ante la CRE, solo basta con solicitar el contrato de interconexión ante Comisión Federal de Electricidad (CFE). Los $S F V$ para uso residencial (menores o iguales a $10 \mathrm{~kW}$ ), los de uso general en baja tensión (menor o igual a $30 \mathrm{~kW}$ ), así como los usuarios con $S F V$ de hasta 500 $\mathrm{kW}$ que no requieran portear la energía a sus cargas entran en esta categoría. En la Figura 1.13 se muestra un diagrama en donde se encuentra la clasificación de los Sistemas Fotovoltaicos Interconectados a la REC de acuerdo a su potencia pico y a la tensión de suministro.

\section{Contrato de interconexión}

\section{Pequeña escala}

Mediana escala

Uso residencial hasta $10 \mathrm{~kW}$

Tensión $<1$ kV
Uso general hasta $30 \mathrm{~kW}$

Tensión $<1$ kV
Uso general hasta $500 \mathrm{~kW}$ Tensión $<69$ kV

Figura 1.13: Clasificación de los SFV-I de acuerdo a los requerimientos de la CRE.

De a acuerdo al reporte publicado por la $\mathrm{CRE}^{5}$, el número de contratos de interconexión otorgados hasta finales de 2015 para plantas de generación de energía eléctrica con energías renovables fue de 16,977. En términos de potencia se estima que 92.4 MW corresponden a sistemas fotovoltaicos en pequeña y mediana escala, mientras que el resto corresponden a proyectos de generación con biomasa, biogás y energía eólica (Ver tabla 4).

5 http://cre.gob.mx/documento/2109.pdf 
Tabla 1.4: Resumen de proyectos de generación con energía renovable a

\begin{tabular}{|c|c|c|c|c|}
\hline \multirow{2}{*}{$\begin{array}{l}\text { Tipo de } \\
\text { proyecto }\end{array}$} & \multirow{2}{*}{$\begin{array}{c}\text { Capacidad } \\
\text { instalada } \\
2007-2015 \\
(K w)\end{array}$} & \multicolumn{2}{|c|}{$\begin{array}{l}\text { Energía producida en } 2015 \\
\text { (kwh) }\end{array}$} & \multirow{2}{*}{$\begin{array}{c}\text { Factor de } \\
\text { planta }\end{array}$} \\
\hline & & $\begin{array}{l}\text { Intercambiada } \\
\text { con el sen }\end{array}$ & $\begin{array}{c}\text { Generación } \\
\text { estimada }\end{array}$ & \\
\hline $\begin{array}{l}\text { Biogas en } \\
\text { mediana } \\
\text { escala }\end{array}$ & 3,255 & $1,240,207$ & $14,258,739$ & 0.5 \\
\hline $\begin{array}{l}\text { Biogas en } \\
\text { pequeña } \\
\text { escala }\end{array}$ & 74 & 33,599 & 325,609 & 0.5 \\
\hline $\begin{array}{c}\text { Biomasa } \\
\text { en } \\
\text { mediana } \\
\text { escala }\end{array}$ & 240 & 47,310 & $1,051,200$ & 0.5 \\
\hline $\begin{array}{l}\text { Eólica en } \\
\text { pequeña } \\
\text { escala }\end{array}$ & 22 & 3,518 & 53,669 & 0.3 \\
\hline $\begin{array}{l}\text { Solar- } \\
\text { eólico } \\
\text { pequeña } \\
\text { escala }\end{array}$ & 41 & 0 & 90,338 & 0.25 \\
\hline $\begin{array}{l}\text { Solar- } \\
\text { eólico } \\
\text { mediana } \\
\text { escala }\end{array}$ & 22 & 3,965 & 24,453 & 0.15 \\
\hline $\begin{array}{l}\text { Solar en } \\
\text { pequeña } \\
\text { escala }\end{array}$ & 18,933 & $1,441,108$ & $13,329,255$ & 0.22 \\
\hline $\begin{array}{l}\text { Solar en } \\
\text { mediana } \\
\text { escala }\end{array}$ & 73,462 & $13,536,510$ & $75,499,542$ & 0.2 \\
\hline Total & 117,560 & $18,243,698$ & $128,020,629$ & \\
\hline
\end{tabular}

En resumen, a partir de datos obtenidos de la CRE, se estima que existen instalados en el país alrededor de $208 \mathrm{MW}$, incluyendo los sistemas de pequeña, mediana escala (Generación distribuida) y los sistemas de más de $0.5 \mathrm{MW}$ (Generadores). La Figura 1.14 muestra un diagrama a bloques de la potencia fotovoltaica instalada tanto en sistemas centralizados como en sistemas distribuidos. 


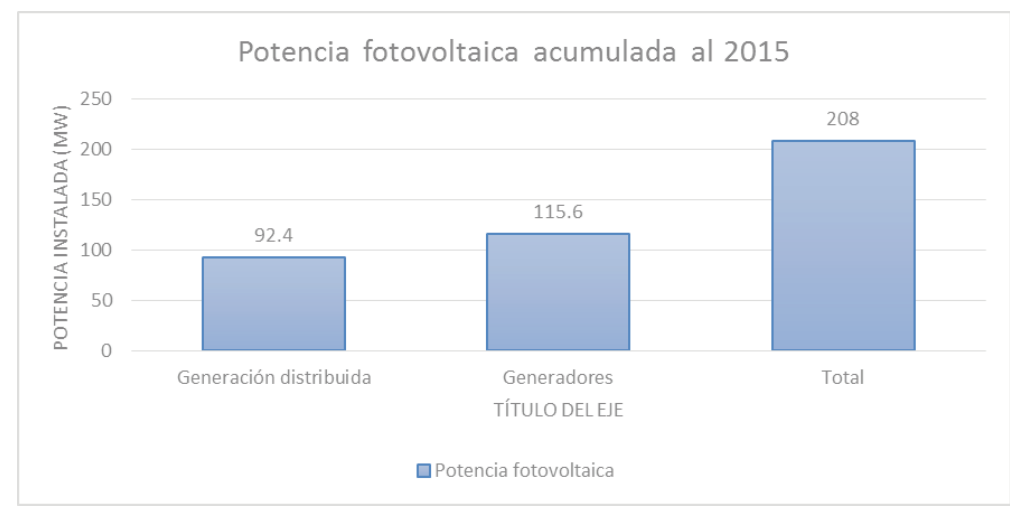

Figura 1.14: Potencia fotovoltaica instalada acumulada a finales de 2015.

Los valores reportados por la CRE, no incluyen los sistemas fotovoltaicos autónomos. Según datos obtenidos de la $\mathrm{CFE}^{6}$, dicha entidad ha instalado alrededor de 42 mil módulos en los últimos 10 años en pequeñas comunidades rurales alejados de las grandes urbes.

\subsection{Prospectiva económica}

Los GFV's han sido identificados como una tecnología de rápido crecimiento con un potencial de aplicación alto. Por ser modular, puede ser usada en muchas aplicaciones. El mayor obstáculo para su uso en gran escala es el alto costo de inversión inicial ya que, con precios al público para la tecnología que pueden fluctuar desde usd $\$ 0.55$ a usd $\$ 0.65$ por $\mathrm{Wp}[21]$, un SFV interconectado a la red de $1.0 \mathrm{kWp}$ con una generación promedio diaria de $4.0 \mathrm{kWh}$ [22], puede implicar una inversión inicial alrededor de usd $\$ 2,500.00$, por lo que muy pocos usuarios podrían adquirir dichos dispositivos. El precio promedio internacional más bajo para módulos mayores de 100 Wp es de usd $\$ 0.55 /$ Wp para la tecnología de silicio monocris-

6 http://www.cfe.gob.mx/ConoceCFE/1_AcercadeCFE/Paginas/Que-es-CFE.aspx 
talino, usd $\$ 0.53 / \mathrm{W}$ p para módulos de silicio policicristalino, y usd $\$ 0.6 / W p$ para módulos de película delgada [23].

Al evaluar el costo de la electricidad producida por los $G F V$ 's mediante modelos económicos basados en el tiempo de vida útil de la tecnología, se puede determinar que éste se encuentra entre usd $\$ 0.11$ hasta usd $\$ 0.305$ por $\mathrm{kWh}$ para diferentes tamaños y configuraciones de sistemas y localidades [24], que al compararse con el costo de la electricidad convencional, resulta ser de 1.5 a 6 veces más cara. Como resultado, el uso de los $G F V$ 's ha estado limitado principalmente a aplicaciones en las que el costo de introducción de la red eléctrica convencional y del consumo de la electricidad es alto, o bien, donde es necesario un generador limpio, silencioso y confiable. Este es el caso de áreas remotas (electrificación rural, telecomunicaciones, bombeo de agua, señalización, etc.) o para amortiguar los picos de consumo altos en fábricas o edificios. Sin considerar el costo inicial de inversión, la popularidad de la tecnología fotovoltaica se basa en su fácil uso, confiabilidad, relativo bajo mantenimiento y la disponibilidad del recurso solar. Debido a que son modulares, los sistemas fotovoltaicos pueden ser dimensionados para satisfacer las necesidades exactas de energía del usuario, disminuyendo el costo global del sistema e incrementando el rendimiento del mismo. Conforme aumentan las necesidades energéticas del usuario, el tamaño del sistema (potencia) se puede incrementar.

Otro factor que hacen atractivos a los GFV `s desde el punto de vista energético y ambiental es el corto tiempo en que dichos generadores retornan la energía usada para fabricarlos, conocido comúnmente como tiempo de retorno energético EPBT (por sus siglas en inglés: energy payback time). Asumiendo un periodo de 30 años de desempeño a un $80 \%$ de la potencia especificada, la tasa de retorno energético no es mayor de 3 años, aun así para la tecnología que demanda más energía como lo es las celdas de silicio monocrialino [25]; es 
decir, la energía requerida para producir el sistema no excede al $10 \%$ de la energía total generada por el mismo durante su tiempo de vida de operación.

Se espera que el mercado de los generadores fotovoltaicos se expanda rápidamente cuando la electricidad generada pueda ser colocada, en la red pública, a costos que sean comparables con los costos de generación de electricidad por medio de combustibles fósiles (entre usd $\$ 0.08$ y usd $\$ 0.10$ por kWh para aplicación residencial; entre usd $\$ 0.05$ y usd $\$ 0.07$ por $\mathrm{kWh}$ para venta en el servicio público). Este punto puede alcanzarse a mediano plazo con la tecnología del silicio cristalino solo si la demanda del mercado se incrementa en un $35 \%$ [26] trayendo como consecuencia una reducción de los costos de fabricación de los sistemas fotovoltaicos; o bien, con nuevas tecnologías emergentes de semiconductores de película delgada.

Es claro que para fomentar el uso de la $T F V$, es necesario contar con esquemas de financiamiento y estímulos fiscales que propicien el incremento en su demanda e implementación y puesta en operación de proyectos energéticos basados en $G F V$ 's. Sin embargo, aún sin dichos esquemas, por ser una tecnología de larga duración con garantías de hasta de 25 años con tiempos de operación estimados de más de 50 años, ésta induce a posibles usuarios a considerar inversiones en el presente que garanticen la producción de su energía eléctrica en el futuro.

Sin considerar la reducción en costos de fabricación debido a factores de demanda, científicos e ingenieros en todo el mundo están trabajando sobre el desarrollo de celdas solares con una mejor razón costo/desempeño. Esto se puede hacer aumentando la eficiencia de conversión de los GFV's, reduciendo su costo de elaboración, o la aplicación de nuevos materiales basados en películas delgadas. Es importante notar que aparte del mejoramiento en el proceso de elaboración, el escalamiento de la producción en grandes volúmenes es un 
requisito importante para la reducción de costos, tal y como lo afirma Shyam Mehta en su artículo PV Technology and Cost Outlook, 2013-2017 [27].

\subsection{El binomio de generación limpia: sol-TFV}

La TFV formada por dispositivos de estado sólido llamados celdas solares genera la electricidad debido a sus características de absorción de la luz solar. El proceso de generación, como se ha especificado anteriormente, es silencioso, no consume combustibles fósiles, no genera desechos contaminantes ni gases de efecto invernadero, de aquí que sea considerada una tecnología limpia de muy bajo impacto ambiental. La Figura 1.15 representa el espíritu del Binomio de Generación de Energía Limpia: energía solar y tecnología fotovoltaica.

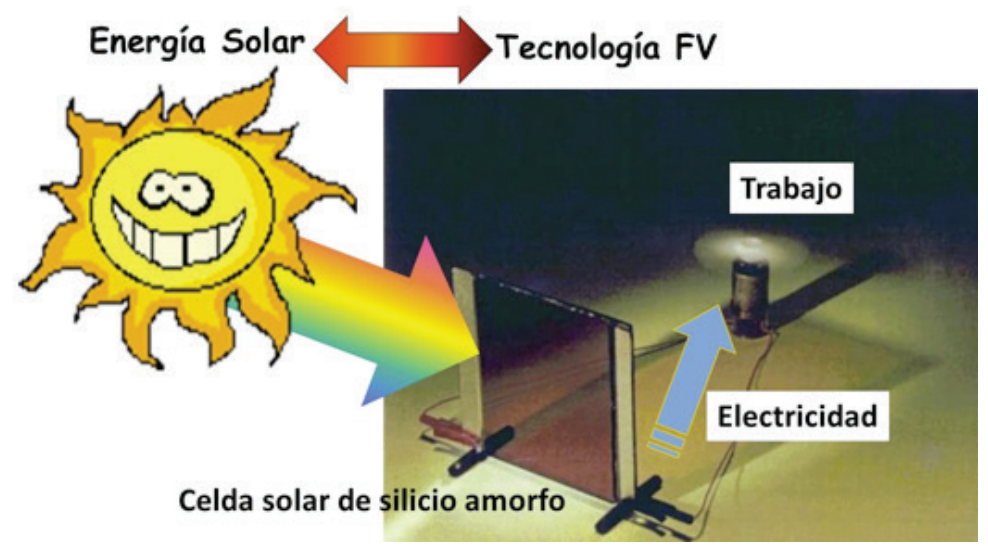

Figura 1.15: Concepción del Binomio de Generación de energía limpia: Energía Solar y Tecnología Fotovoltaica.

La magnitud de la Potencia Eléctrica Generada $\left(\mathrm{P}_{\mathrm{G}}\right)$, medida comúnmente en unidades de Watt, depende de la eficiencia de conversión de la $T F V$ y de la intensidad de la potencia de la radiación solar recibida en su superficie $\left(\mathrm{P}_{\text {Sol }}\right)$, ambos conceptos relacionados por la expresión representada en la Ec. 1.1. 


$$
\eta=\mathrm{P}_{\mathrm{G}} / \mathrm{P}_{\text {Sol }}=\mathrm{P}_{\mathrm{G}} / G S \quad \text { Ec. } 1.1
$$

donde $G$ es la irradiancia medida en $\mathrm{W} / \mathrm{m}^{2}$ y $S$ la superficie activa de la TFV

La Ec. 1.1 se muestra gráficamente en la Fig. 1.16 en donde se ha considerado una superficie $S$ de $1.0 \mathrm{~m}^{2}$ cubierta con una $T F V$ que capta la radiación solar incidiendo con una densidad de potencia $G$ de $1.0 \mathrm{~kW} / \mathrm{m}^{2}$. Si la $T F V$ tiene un $15 \%$ de eficiencia de conversión, entonces de los 1,000 W de potencia solar recibida en un metro cuadrado se generan 150 $\mathrm{W}$ de potencia eléctrica en corriente directa.

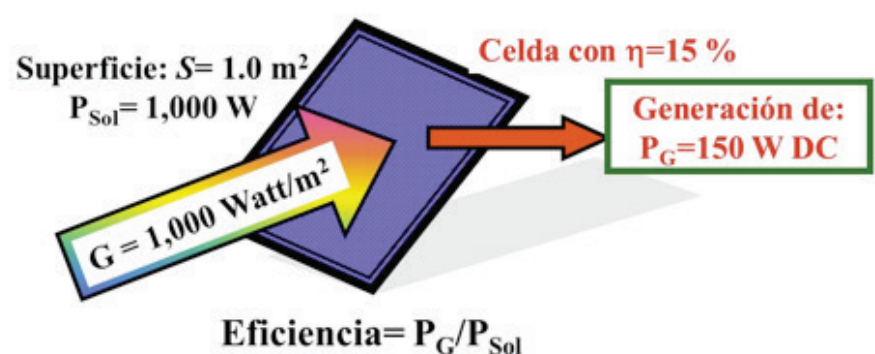

Figura 1.16: Diagrama representativo del concepto de la eficiencia de conversión.

Consecuentemente, la energía eléctrica generada durante un día específico, con determinado número de horas de luz de día u horas sol, es proporcional a la magnitud de la energía solar disponible en la localidad en dicho día. Por tal motivo, para determinar la cantidad de energía que puede generar una superficie cubierta con cierta $T F V$ es necesario saber cuál es la magnitud de la energía solar que se dispone en el sitio de instalación. En el siguiente Capítulo se proporcionará los conceptos básicos de la radiación solar así como la estimación del recurso solar nacional.

El esfuerzo realizado por particulares, el gobierno, las diferentes instituciones académicas, organismos no gubernamentales, y otros actores sociales con respecto al fomento y 
uso de la tecnología $F V$ han permitido la creación de muchos proyectos desde unos cuantos Watt hasta proyectos con potencias de $\mathrm{MW}$, teniéndose a la fecha una potencia pico instalada estimada en $250 \mathrm{MW}$ y proyectándose para el año 2017 una estimación adicional de $500 \mathrm{MW}$ tanto para sistemas aislados como para sistemas interconectados a la red [20]. Esta demanda creciente está motivando que existan regulaciones mexicanas que garanticen la calidad, seguridad y confiabilidad tanto de la $T F V$ como los equipos y partes que componen al BOS.

Se espera que el mercado de los generadores fotovoltaicos se expanda rápidamente derivado de la reducción de costos de la misma y la conciencia social sobre el uso de tecnologías amigables para el ambiente. Sin embargo, el sustento e incremento del número de proyectos fotovoltaicos depende de personal técnico capacitado que los fomente, impulse y mantenga. El propósito de estas actividades de capacitación es despertar el interés en los usuarios, técnicos, proveedores, etc., en el uso y adopción de la tecnología fotovoltaica la cual representa la mejor alternativa para la diversificación energética que será requerida por nuestro país en un futuro muy próximo.

\section{Referencias}

1. Nichos de Mercado para Sistemas Fotovoltaicos en Conexión a la Red Eléctrica en México": CONUE-SENER 2009. Documento elaborado por GTZ por encargo del Ministerio Federal de Cooperación Económica y Desarrollo de la República de Alemania.

2. "Programa de Fomento de Sistemas fotovoltaicos, PROSOLAR", Programa Energía Sustentable de la Cooperación Técnica entre México y Alemania. SENER-GIZ, 20 de julio de 2012.

3. Obtenidos de listas de precios de proveedores internacionales en la red electrónica: www.solarbuzz.com; cotización de 
la compañía SOLARTEC: Energía Renovable www.solartec. mx; la compañía ERDM S.A. de C.V. fabricante mexicano, oferta sus productos a un precio aproximado de $\$ 1.10$ usd por Watt pico (ver http://www.erdmsolar.com/shop/).

4. El año del Dragón: Producción de células solares en 2011"; Photon: La Revista Fotovoltaica, 4/2012, pag. 30-47, abril 2012.

5. "The Prospects for Low-Cost Photovoltaic Electricity", David E. Carlson, BP Solar, October 2007.

6. "PV Technology and Cost Outlook 2013-2017"; Shyam Mehta, Solar Marquet Research, June 17, 2013.

7. Estimación realizada por A. Sánchez Juárez y Jorge Islas Samperio del Instituto de Energías Renovables de la UNAM, 2012.

8. Prospectiva de la Tecnología Solar Fotovoltaica para la Generación de Electricidad Agredano Jaime; Instituto de Investigaciones Eléctricas, División de Energías Alternas. Gerencia de Energías No Convencionales. Anexo VII Balance de energía 2007; ANES.

9. Yasuhiro Matsumoto, Agredano Jaime, Sanchez-Juarez A., Urbano Antonio, "PV status in Mexico". Vol. XXXII Semana Nacional de Energía Solar: ANES 2008, 20-24 Oct. Mérida, Yuc. No Versión CD, Pp. Único, SFV-13-1, SFV-13-7; Y. Matsumoto, J. Agredano, A. Sanchez Juarez, and J. A. Urbano; "Awakening PV in Mexico"; 17th Internacional PhotovoltaicScience and EngineeringConference; No. 5P-P3-57; pag 880-881. December 3-7, 2007, Fukuoka, Japan;

10. "Estudio del Mercado de las Fuentes de Energía Renovable en el Sector Agropecuario: Electrificación de Agronegocios con Tecnología Fotovoltaica, realizado por A. Sánchez-Juárez, para ConEstadística/ANES por encargo del FIRCO-SAGARPA, mayo 2006. 
11. Resolución RES/176/2007 Comisión Reguladora de Energía, Publicada en el Diario Oficial de la Federación el 27 de Junio de 2007, Primera Sección.

12. Resolución RES/054/2010 Comisión Reguladora de Energía, Publicada en el Diario Oficial de la Federación el 8 de abril de 2010, Primera Sección.

13. Ley del Impuesto sobre la Renta (ISR) la posibilidad de deducción del $100 \%$ en un solo ejercicio de maquinaria y equipo para la generación de energía proveniente de fuentes renovables con la obligación de operar por lo menos 5 años, aplicable al sector productivo.

14. Programa de Energías Renovables para la Agricultura, 2000-2008, www.firco.gob.mx

15. "Nichos de Mercado para Sistemas Fotovoltaicos en Conexión a la Red Eléctrica en México": CONUE-SENER2009. Documento elaborado por GTZ por encargo del Ministerio Federal de Cooperación Económica y Desarrollo de la República de Alemania.

16. "Datos propios obtenidos de información periodística y visita a los sitios"; Aarón Sánchez Juárez

17. Información extraída de la base de datos que tiene el FIRCO de los sistemas instalados mediante el programa PDRS-FIRCO (Anexo I).

18. "Programa de Fomento de Sistemas fotovoltaicos, PROSOLAR", Programa Energía Sustentable de la Cooperación Técnica entre México y Alemania. SENER-GIZ, 20 de julio de 2012.

19. "RES 119/2012: Reglas Generales de Interconexión al SEN para Generadores o Permisionarios con Fuentes de Energías Renovables o Cogeneración Eficiente"; Diario Oficial de la Federación el 22 de mayo de 2012.

20. “América Latina: Estimación de potencia FV instalada en 2012"; Photon: La Revista Fotovoltaica, 4/2012, pag. 15, abril 2012. 
21. Rango de valores para México obtenidos de listas de precios de compañías mexicanas que pertenecen a la Asociación Mexicana de Proveedores de Energías Renovables (www-amper.org).

22. Energía estimada con un recurso solar promedio diario de $5.0 \mathrm{kWh} / \mathrm{m}^{2}$ con un rendimiento del $80 \%$ para la tecnología.

23. Obtenidos de listas de precios de proveedores internacionales en la red electrónica: www.solarbuzz.com

24. Valores calculados con el método del valor presente neto.

25. Ver trabajo de: V. Fthenakis and E. Alsema; "Photovoltaics energy payback times, greenhouse gas emissions and external cost:2004-early 2005 status"; Progress in Photovoltaics, V 14 No.3, pp275-280, 2006.

26. Estimaciones realizadas suponiendo un incremento en el mercado del 35\% anual: David E. Carlson; "The Prospect for Low-cost Photovoltaic Electricity"; BPSolar october $16,2007$.

27. "PV Technology and Cost Outlook 2013-2017"; Shyam Mehta, Solar Marquet Research, June 17, 2013. 


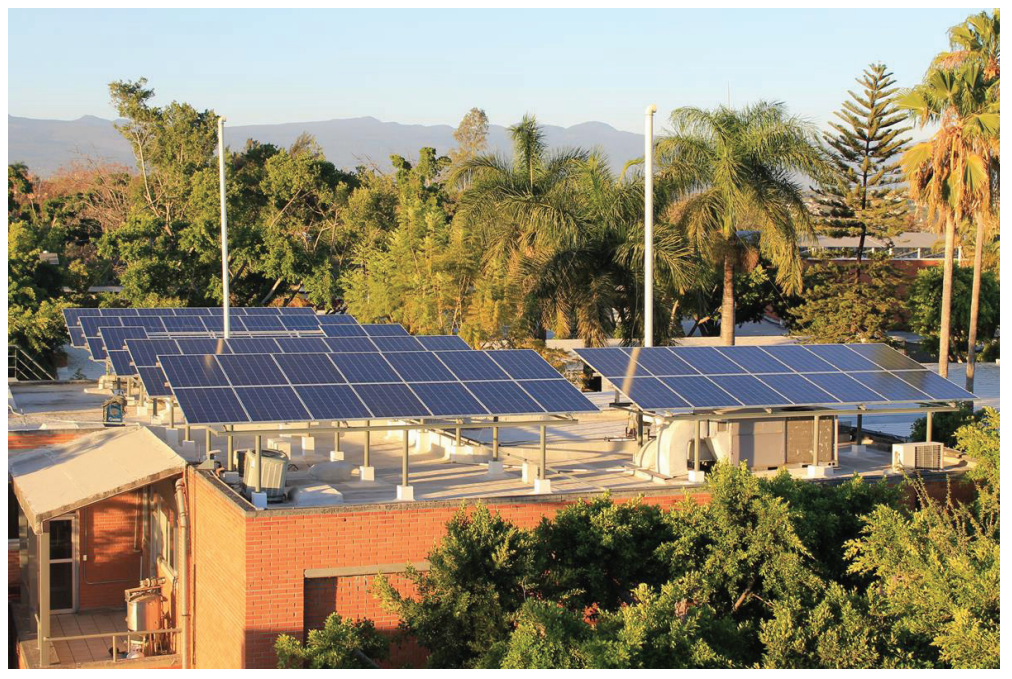

Sistema Fotovoltaico Demostrativo dentro del Proyecto FORDECyT No. 190603 "Estudio sobre el uso de la energía solar en aplicaciones residenciales, industriales y comerciales en diferentes estados del país", con la participación de la Universidad Nacional Autónoma de México a través de su Instituto de Energías Renovables

Sistema Fotovoltaico interconectado a la Red de Distribución Local del Edificio Laboratorio de Hidrógeno en el Instituto de Energías Renovables de la UNAM, ubicado en la calle Priv de Xochicalco s/n Col. Centro, CP 62580, Temixco, Morelos. SFV-I de $22.0 \mathrm{~kW}$ de potencia pico compuesto por dos AFV de 10.92 kW y dos inversores trifásicos de 10.0 kW cada uno. 


\section{2 \\ CONCEPTOS BÁSICOS DE ENERGİA SOLAR}

\subsection{Introducción}

El Sol es considerado el dador de vida en la Tierra ya que, a través de su energía y por procesos de absorción natural, se han creado: los vegetales que son la base fundamental de alimentación del mundo animal; los ríos y lagunas debido a procesos de evaporación del agua de mar y su respectiva condensación, líquido fundamental para la subsistencia; la formación y sustentación de corrientes de aire; e incluso, ha participado de alguna manera en la formación de combustibles fósiles. Claro está, lo anterior ha sido debido a un efecto acumulativo de la energía que ha enviado el Sol a la Tierra desde la formación del universo. Pero, ¿Cómo se propaga la energía proveniente del Sol?, ¿Cuál es su potencia radiada? ¿Cómo podemos hacer uso de ella? ¿Cuál es el recurso que se dispone para alguna aplicación específica?.

El objetivo de éste capítulo es introducir al lector en los conceptos básicos de la Energía Solar y dar los conocimientos necesarios para solucionar las preguntas planteadas.

\subsection{La luz solar}

El Sol es una fuente inagotable de energía. Gracias a las reacciones nucleares que en él se llevan a cabo, nuestro planeta 
recibe un flujo de energía muy grande. Este llega a la Tierra en forma de radiación electromagnética, con un espectro que abarca longitudes de onda, $\lambda$, desde $0.2 \mu \mathrm{m}$ hasta $2.6 \mu \mathrm{m}$; la que comúnmente se le llama luz solar.

Es importante establecer que la luz solar que nuestros ojos observan, llamado el espectro del visible, solo abarca un intervalo muy pequeño del espectro de las ondas electromagnéticas, siendo su rango desde $0.4 \mu \mathrm{m}$ hasta $0.7 \mu \mathrm{m}$. La Tabla 2.1 muestra el rango de valores de la longitud de onda asociada a los colores que los ojos humanos captan [2]. Así, al considerar el rango de longitudes de onda que forman a la energía solar, se puede establecer que ésta se compone de ondas electromagnéticas dentro del rango del ultravioleta (UV), visible e infrarrojo (IR).

Tabla 2.1: Rangos de longitud de onda expresada en micras en donde están definidos los colores.

\begin{tabular}{|c|c|c|}
\hline $\begin{array}{c}\text { Rango de longitud de } \\
\text { onda }\end{array}$ & Valor medio & Color \\
\hline $0.38-0.43$ & 0.41 & Violeta \\
\hline $0.43-0.5$ & 0.47 & Azul \\
\hline $0.5-0.57$ & 0.55 & Verde \\
\hline $0.57-0.6$ & 0.58 & Amarillo \\
\hline $0.6-0.64$ & 0.61 & Naranja \\
\hline $0.64-0.77$ & 0.66 & Rojo \\
\hline
\end{tabular}

Aunque solo "vemos" una porción de ésta radiación electromagnética, la existencia de las otras componentes, el ultravioleta y el infrarrojo, se ponen de manifiesto por su efecto en los cuerpos donde incide. Cuando éstas son absorbidas, los cuerpos se calientan. Así que el fenómeno de absorción de radiación implica fenómenos de calentamiento.

Los fenómenos ópticos que presentan la luz solar, transmisión y reflexión, se explican muy claramente al considerar el carácter ondulatorio de ésta. Sin embargo, cuando la 
luz interactúa con los sólidos, se llevan a cabo una serie de fenómenos que no es posible explicarlos usando conceptos de ondas. Albert Einstein demostró que la luz se comporta como un conjunto de "paquetes o cuantos", llamados actualmente fotones cuya energía está definida por la Ec. 2.1,

$$
\mathrm{E}_{\mathrm{ph}}=1.2048 / \lambda, \quad \text { Ec. } 2.1
$$

donde $\lambda$ es la longitud de onda asociada al fotón medida en micras (una micra, $\mu \mathrm{m}$, es la milésima parte de un milímetro), y la energía del fotón, $\mathrm{E}_{\mathrm{ph}}$, se mide en unidades de electrón-volt $(\mathrm{eV})$, que es la cantidad de energía que se requiere para acelerar un electrón a través de una diferencia de potencial de un volt.

\subsection{Irradiancia e irradiación}

Ya que la luz solar es una forma de energía, las unidades de medición para ésta corresponderán a las de energía. En el sistema internacional la unidad de energía es el joule, J. Se establece el concepto de intensidad de la radiación ó irradiancia solar, simbolizada por $G$, como la energía radiante por unidad de área por unidad de tiempo que atraviesa una superficie imaginaria de área $S$, perpendicular a la dirección de propagación de la onda. La relación entre dichas cantidades se expresa en la Ec. 2.2:

$$
\boldsymbol{G}=\mathrm{E} / \mathrm{St}
$$

siendo E la magnitud de energía radiante que llega a la superficie determinada en un tiempo determinado.

Como la energía $\mathrm{E}$ es el producto de la potencia $\mathrm{P}$ por el tiempo, $\mathrm{E}=\mathrm{Pt}$, entonces, la irradiancia $G$ estará dada por la Ec.2.3, o sea,

$$
G=\mathrm{P} / S,
$$

Si la potencia P se mide en Watt (W) y el área $S$ en metros cuadrados $\left(\mathrm{m}^{2}\right)$, entonces la unidad para la irradiancia es: $\mathrm{W} / \mathrm{m}^{2}$. 
Se establece el concepto de irradiación como la densidad de energía acumulada o recibida en la unidad de tiempo, es decir, es la irradiancia acumulada sobre la superficie en la unidad de tiempo. Si $\boldsymbol{H}_{\mathrm{S}}$ simboliza a la irradiación y t el tiempo medido en segundos (s), entonces:

$$
H_{\mathrm{S}}=\mathrm{Gt}, \quad \text { Ec. } 2.4
$$

y la unidad para la irradiación es: $\mathrm{W} \mathrm{s} / \mathrm{m}^{2}=\mathrm{J} / \mathrm{m}^{2}$

1 Joule $=(1 \mathrm{~W}) \boldsymbol{x}(1 \mathrm{~s})$

1 Joule $(1 \mathrm{~J})$ es la cantidad de energía que consume o produce una máquina con una potencia de 1 Watt en un segundo.

Si se expresa el tiempo en horas, $\mathrm{h},(1.0 \mathrm{~h}=3,600 \mathrm{~s})$, entonces la unidad para la irradiación es: $\mathrm{Wh} / \mathrm{m} 2$.

Usando transformaciones de unidades, la irradiación puede ser expresada en Langley ó BTU, estando relacionadas unas con otras por las igualdades siguientes:

$1000 \mathrm{Wh} / \mathrm{m} 2=$ Langley $/ 85.9=316.96 \mathrm{BTU} / \mathrm{ft} 2=3.6 \mathrm{MJ} /$ $\mathrm{m} 2$

Generalmente, el valor de la irradiación se reporta como una acumulación de energía promedio durante un periodo de tiempo (día, mes, estacional, anual); por ejemplo

$2.0 \mathrm{kWh} / \mathrm{m} 2=2,000 \mathrm{Wh} / \mathrm{m} 2$ al día.

$60.0 \mathrm{kWh} / \mathrm{m} 2$ al mes

$5.0 \mathrm{kWh} / \mathrm{m} 2$ promedio diario anual.

A la magnitud de la irradiancia recibida fuera de la atmósfera, considerando la distancia Tierra- Sol constante, se le llama la constante solar, y se simboliza por GSol. Un valor aceptado para la "constante solar" es 1,353 $\pm 21 \mathrm{~W} / \mathrm{m} 2$ (valor estándar NASA/ASTM 1977) [1, 3, 4], aunque otros autores consideran en sus modelos un valor de $1,367 \mathrm{~W} / \mathrm{m} 2$ [5]; es decir la constante solar tiene una magnitud de:

$$
G_{\mathrm{Sol}}=1,353 \mathrm{~W} / \mathrm{m}^{2} \quad \text { Ec. } 2.5
$$


El hecho de que no haya un valor único para GSol se debe a que la distancia Tierra-Sol no es constante; además, la radiación solar disminuye con la distancia a través de la ley del inverso al cuadrado. Al ser elíptica la trayectoria, la distancia Tierra- Sol varía $1.7 \%$ durante el año, y los valores de la irradiancia extraterrestre medida fuera de la atmósfera, o "constante solar", no será tan constante y variará según el día del año.

\subsection{Efectos de atenuación}

Al incidir la luz solar sobre la Tierra, parte de ella es reflejada, dispersada y absorbida por la atmósfera terrestre. Otra fracción de ella llega a la superficie de la Tierra en donde es absorbida y reflejada, generando una serie de fenómenos físicos. El proceso de absorción de la radiación solar se pone de manifiesto debido al calentamiento (aumento de temperatura) que experimentan los objetos, cosas o seres vivientes sobre los cuales incide la luz solar. Cualquier objeto o cosa sobre los cuales inciden los rayos de la luz solar puede ser llamado captador solar. Para que sea posible usar la Energía Solar es necesario tener un Captador Solar. Su función será la de recibir y absorber la energía del Sol que llega en forma de luz solar.

Debido a los procesos de absorción, reflexión y dispersión que se llevan a cabo en la atmósfera, la irradiancia que llega a la superficie de la Tierra es menor que el valor GSol; es decir, se atenúa en su trayecto hacia la superficie terrestre. El grado de atenuación dependerá de la longitud de la trayectoria que recorre la radiación a través de la atmósfera y del medio por el cual atraviesa. Como éste medio es aire, el grado de atenuación dependerá del espesor de la masa de aire, m. En realidad m es el espesor de la trayectoria que sigue un rayo solar, a través de la atmósfera, para alcanzar la superficie de un captador situado sobre la superficie terrestre. En la Fig. 2.1 se muestra una representación esquemática idealizada del concepto de Espesor de la Masa de Aire, el cual esta asignado al espesor de la atmósfera representada por el rayo BC. Ahí 
se ha considerado que la capa atmosférica es homogénea y de espesor constante.

Por convención, se dice que un captador recibe una radiación solar con Masa de Aire igual a la unidad, lo que se especifica como AM1 (Air Mass One), cuando el captador está a nivel del mar y el Sol se encuentra en el cenit del captador. Lo anterior significa una estandarización igual a la unidad para la masa de aire cuando los rayos solares caen perpendicularmente a la superficie del captador. Si no se considera la curvatura de la Tierra, y para ángulos cenitales menores de $60^{\circ}$, el concepto de masa de aire se establecerá por la relación entre la hipotenusa y el cateto adyacente al ángulo cenital definido en la Fig. 2.1, es decir,

$$
m=\mathrm{BC} / \mathrm{AC}=1 / \cos \Theta_{\mathrm{Z}}, \quad \text { Ec. } 2.6
$$

y se representará como AMm. Así, la expresión AM1 se obtiene con un ángulo Symbol ${ }_{z}=0^{\circ}$ y significa que el Sol está en el cenit del captador y que la distancia que recorren los rayos solares hacia el captador es mínima. La expresión AM2 se obtiene para un ángulo $\Theta_{z}=60^{\circ}$. AM0 significa que se está hablando de la radiación extraterrestre.

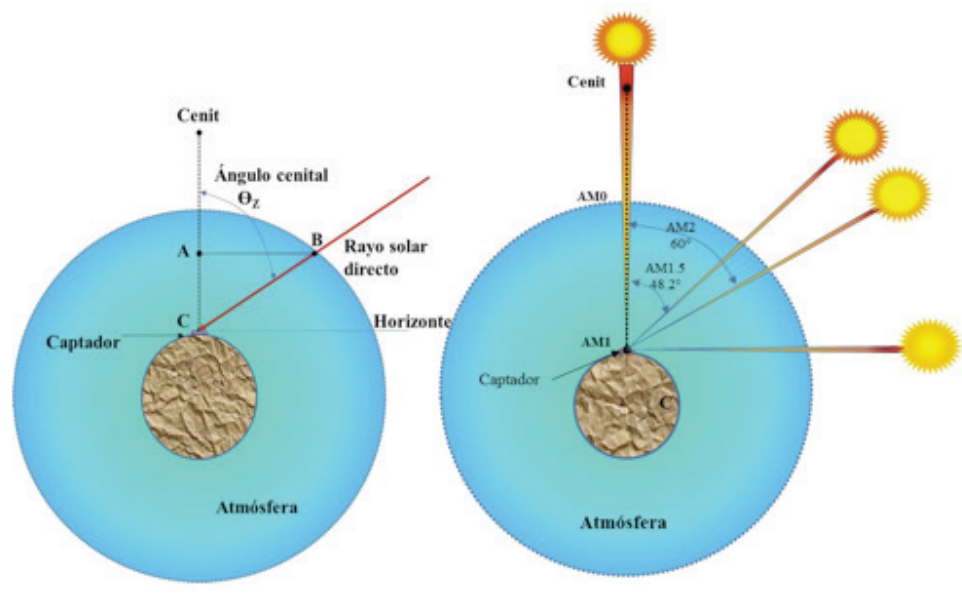

Figura 2.1: Establecimiento del concepto de Masa de Aire. 
La distribución de la intensidad de la radiación solar respecto de la longitud de onda de la radiación electromagnética, llamado Espectro de la Radiación Solar, fuera de la atmósfera, se muestra en la Figura 2.2. Al entrar en la atmósfera y dependiendo del espesor de la Masa de Aire, la intensidad de la radiación solar se atenúa por los procesos de dispersión y absorción atmosférica y en consecuencia, el espectro de la radiación solar cambia de forma. La Fig. 2.2 muestra la distribución de la radiación solar para dos diferentes masas de aire además de la extraterrestre. Se observa que para AM1, el valor máximo de la irradiancia mostrada en éste espectro es de $956.2 \mathrm{~W} / \mathrm{m}^{2}$ bajo condiciones de $20 \mathrm{~mm}$ de vapor de agua, 3.4 $\mathrm{mm}$ de ozono y una atmósfera relativamente clara.

\subsection{Radiación directa, difusa y global}

La radiación solar sale del Sol en todas direcciones, viaja en línea recta a la velocidad de la luz y su intensidad disminuye de forma inversamente proporcional al cuadrado de la distancia al foco emisor. Debido a esto, se dice que la radiación solar fuera de la atmósfera está compuesta de rayos por lo que se le asigna un carácter directo, es decir, viaja directamente del foco emisor al captador, recibiendo el nombre de radiación directa normal.

Sin embargo, cuando ésta entra a la atmósfera, las partículas suspendidas (el aire, el ozono, las moléculas de agua, polvo, etc.), interactúan con los rayos directos del Sol absorbiéndolos, difractándolos, y reflejándolos. En consecuencia, un captador recibe en su superficie radiación solar de dos tipos: irradiancia directa GB e irradiancia difusa GD. La directa, ya ha sido definida como aquella radiación que llega al captador sin sufrir algún cambio de dirección en su trayectoria, desde el foco emisor hacia éste. La difusa, es la radiación que recibe o "ve" el captador como aquella que viene de la bóveda celeste. Ella está compuesta por dos componentes, la 
refractada y la reflejada. A la suma de las radiaciones directa y difusa se le conoce con el nombre de radiación global $G G$. En la Figura 2.3 se muestra un esquema representativo de dichas radiaciones.

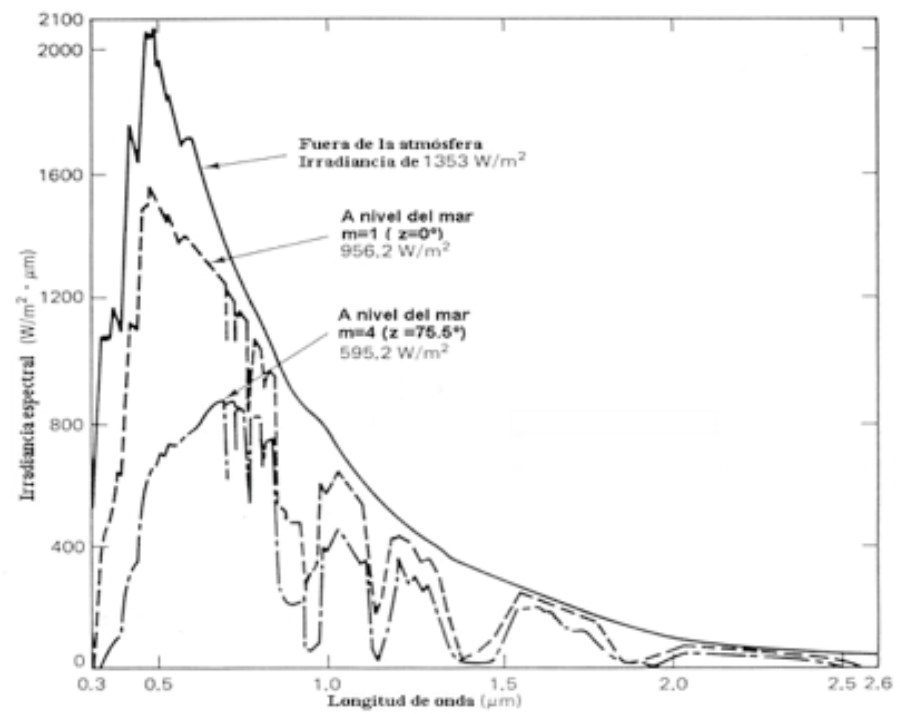

Figura 2.2: Distribución espectral de la radiación solar con diferentes masa de aire (adaptada de referencia [12]).

Al considerar los efectos de atenuación que sufre la radiación directa al ingresar en la atmósfera se ha determinado que, durante un día completamente claro y sin partículas suspendidas, estando el Sol en el cenit del observador y al nivel del mar, la máxima irradiancia directa que se puede recibir en el captador es ligeramente menor de $1000 \mathrm{~W} / \mathrm{m}^{2}$ (ver Figura 2.2 espectro AM1). 


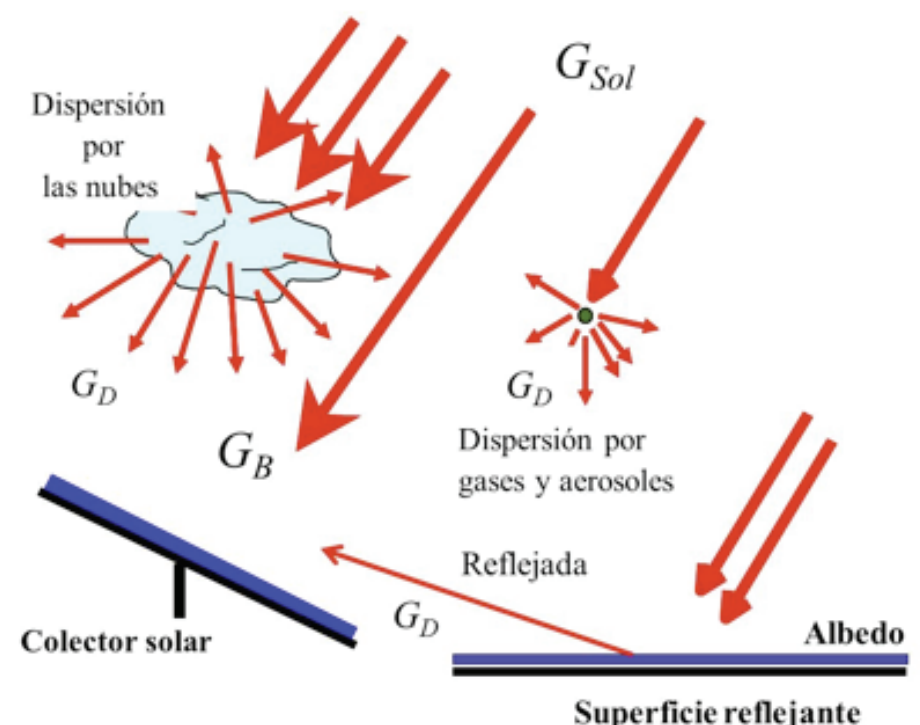

Figura 2.3: Irradiancia Global, directa y difusa sobre un captador: $G_{G}=G_{B}+G_{D}$

Desde un punto de vista operacional, los ingenieros dedicados a la aplicación de la energía solar han tomado como convención que, bajo las condiciones anteriores, el valor para la máxima irradiancia directa que puede recibir un captador sea de $1000 \mathrm{~W} / \mathrm{m}^{2}$. A éste valor se le conoce como el pico de la radiación solar, representado por $G_{P}$.

A medida que se aumenta en altura sobre el nivel del mar, el espesor de la masa de aire disminuye, se reducen los efectos de atenuación y en consecuencia, la irradiancia directa sobre el captador tendrá valores ligeramente superiores al pico. En la práctica rara vez se miden valores de radiación directa superiores a $1050 \mathrm{~W} / \mathrm{m}^{2}[1,4,5]$. Fuera de la atmósfera, el valor máximo de la irradiancia directa es el de la constante solar.

En un día despejado, la irradiancia global que recibe un captador tendrá como componente mayor la radiación directa $G_{\mathrm{B}}$, mientras que, en un día nublado, la componente mayor será la radiación difusa $G_{\mathrm{D}}$. La Figura 2.4 muestra el comportamiento hipotético de la irradiancia global, directa y difusa 
para un día despejado, recibida en un captador colocado horizontalmente. Aquí los valores se han normalizado al $100 \%$ de la irradiancia, es decir, a $1000 \mathrm{~W} / \mathrm{m}^{2}$.

En una gráfica de irradiancia contra tiempo, el área definida bajo la curva es la energía acumulada en el tiempo correspondiente, y en consecuencia, proporcionará el valor de la irradiación, cuyo conjunto de valores en un periodo dado determinará el Recurso Solar de la localidad.

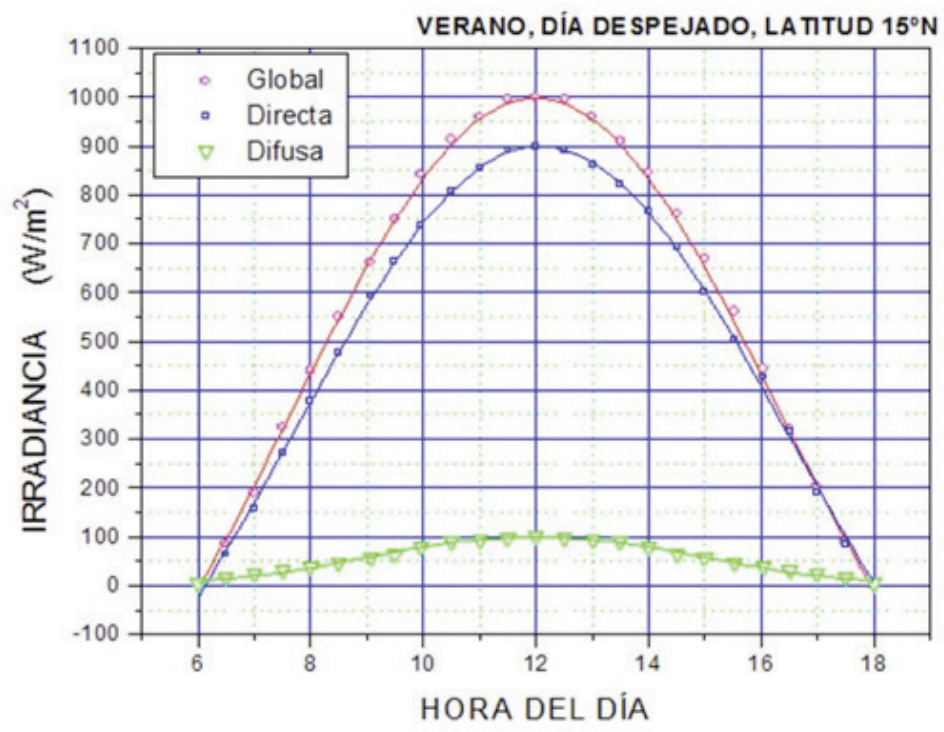

Figura 2.4: Comportamiento hipotético de la irradiancia para un día despejado, sin sólidos en suspensión, sin absorción molecular, normalizada al $100 \%$ para un captador horizontal.

La cantidad de irradiancia que se recibe en un captador solar, y en consecuencia, la energía acumulada, dependerá de la manera en que éste "ve" a la radiación solar. Es claro que si los rayos inciden perpendicularmente a él, la irradiancia recibida será máxima y su magnitud dependerá del tamaño (superficie) del captador.

En forma general, la magnitud captada dependerá del tamaño del captador y del ángulo que sustente la superficie y 
los rayos solares. Si llamamos $i$ al ángulo que forma la normal a la superficie del captador y la radiación directa $G_{\mathrm{B}}$ normal a la superficie horizontal, entonces la irradiancia $G_{\mathrm{C}}$ recibida sobre la superficie inclinada del captador de forma normal (vertical) será:

$$
\mathrm{G}_{\mathrm{C}}=\mathrm{G}_{\mathrm{B}} \cos 1 \text {. }
$$

La Figura 2.5-a muestra una representación geométrica del arreglo y del captador bajo esas condiciones. Esta representación es la misma si se considera que el captador está horizontal y la radiación directa forma un ángulo $i$ con la normal (recta vertical a una horizontal) a la superficie del captador. Este caso se representa en la Figura 2.5-b. La irradiancia recibida en la superficie horizontal, $G_{\mathrm{H}}$, está dada por,

$$
G_{\mathrm{H}}=\mathrm{G}_{\mathrm{B}} \cos 1 \text {. }
$$

Ec. 2.8

La Figura 2.5-C proporciona la relación entre áreas de un captador y su sombra cuando los rayos del Sol caen perpendicularmente sobre el captador.

Ya que la Irradiancia solar recibida en la superficie de la Tierra depende de la manera en que el captador solar "ve" al Sol durante su trayectoria diaria y anual (transito solar), y también de las condiciones atmosféricas, la cantidad de energía captada, en un sitio en particular, dependerá de las condiciones meteorológicas del lugar y del tránsito solar.

De esta manera, la Irradiación o Recurso Solar en el Estado de Sonora será diferente al del Estado de Veracruz; o bien, la Irradiación en los Altos del Estado de Chiapas será diferente a la de sus costas. Sabemos por ejemplo que el Estado de Sonora es un estado desértico, sin nubes, y en consecuencia su irradiación será alta; sin embargo, en los Altos del Estado de Chiapas se presentan muchos nublados, por lo cual, la irradiación será menor comparada con la del Estado de Sonora. 


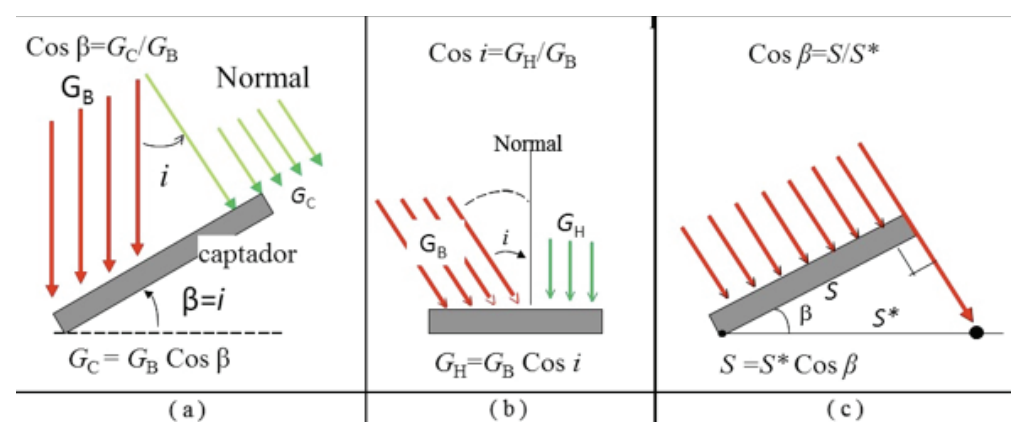

Figura 2.5: Rayos directos interceptados por un captador. En (a) y (b) se tiene un diagrama esquemático mostrando los rayos solares que llegan a un captador. En (c) se muestra la proyección ó sombra de la superficie del captador sobre la horizontal cuando los rayos inciden perpendicularmente a su superficie.

La irradiación de un sitio en particular acumulada diariamente, ó expresada como un promedio diario semanal, o mensual, o anual, se le define con el nombre de Recurso Solar. Las unidades que se usan comúnmente para éste concepto son unidades de energía por unidad de área, por lo que éstas serán, en el SI, J/m². También suele expresarse en otras unidades tales como: $\mathrm{kWh} / \mathrm{m}^{2} ; \mathrm{MJ} / \mathrm{m}^{2} ; \mathrm{Btu} / \mathrm{ft}^{2}$; y Langley.

\section{6.- El concepto de hora pico}

Para la aplicación del Recurso Solar en los Sistemas Fotovoltaicos, los ingenieros de diseño han convenido en usar otra unidad de medición de energía para especificar la irradiación.

Si se considera que un captador horizontal puede recibir una irradiancia directa aproximada de $1,000 \mathrm{~W} / \mathrm{m}^{2}$ bajo las condiciones de día claro, al nivel del mar y estando el Sol en el cenit del captador, entonces por convención a dicha cantidad se le ha llamado pico de la irradiancia. En consecuencia, si un captador recibe hipotéticamente un pico de irradiancia durante una hora, a la cantidad de energía recibida se ha convenido llamarla hora solar-pico, o simplemente hora-pico. Así, la transformación de unidades es: 


$$
1 \text { h- } p=1 \text { hora-pico }=1,000 \mathrm{Wh} / \mathrm{m}^{2}
$$

Ya que el área bajo la curva de irradiancia contra tiempo es la irradiación, entonces desde el punto de vista geométrico, el Recurso Solar en un día expresado en horas-pico corresponde al área de un rectángulo cuya base es el número de horas en que supuestamente el captador ha estado recibiendo una irradiancia con una intensidad pico de $1,000 \mathrm{~W} / \mathrm{m}^{2}$.

Con la anterior definición se tendrá que, para conocer las horas-pico que un determinado sitio tiene como Recurso Solar, se dividirá el valor de la irradiación entre el pico de la irradiancia $\left(1,000 \mathrm{~W} / \mathrm{m}^{2}\right)$; por ejemplo para una irradiación de $8.0 \mathrm{kWh} / \mathrm{m}^{2}$ se tendrá una equivalencia de 8 horas solares pico. La Figura 2.6 muestra éste práctico concepto de unidad de energía. Así, las horas-pico son las horas en que el captador estuvo aparentemente recibiendo el valor pico de la irradiancia.

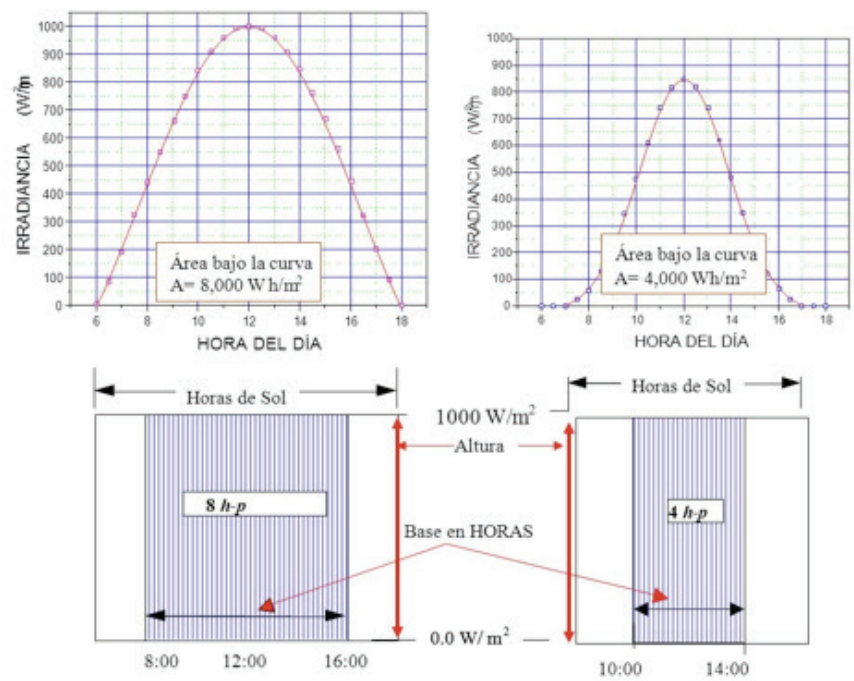

Figura 2.6: El concepto de hora-pico como unidad de energía para la irradiación o recurso solar. 


\subsection{Aparatos para medir la radiación solar}

La manera de establecer la magnitud de la radiación solar en un sitio determinado, sobre la superficie terrestre, es mediante mediciones directa de ésta. Esto se puede hacer mediante varias formas, unas cualitativas y otras cuantitativas. Las cualitativas permiten tener una idea de cómo es la radiación solar más no su magnitud. El heliógrafo es un aparato que mide las horas de Sol más no la magnitud de la irradiancia. Las cuantitativas proporcionan la magnitud de la irradiancia e irradiación con precisiones que dependen del aparato que se usa para medirla. Las unidades más comunes para establecer la magnitud de la irradiación solar son las siguientes:

1 Langley $/ \mathrm{h}=1 \mathrm{cal} / \mathrm{cm}^{2} \mathrm{~h}=3.687 \mathrm{Btu} / \mathrm{ft}^{2} \mathrm{~h}=11.63 \mathrm{Wh} / \mathrm{m}^{2}$

Dado que la irradiancia solar global tiene dos componentes, la directa y la difusa, los aparatos de medida deben diseñarse para identificar las magnitudes de cada una. La irradiancia global se mide con un instrumento llamado piranómetro ${ }^{7}$. Este aparato mide el flujo de radiación solar o irradiancia que se recibe en una superficie horizontal absorbente de forma directa y difusa. También, se pueden usar celdas solares como instrumentos de medida de la radiación solar debido principalmente a que al absorber a la luz solar, la corriente de corto circuito generada por la celda es directamente proporcional a la intensidad de la radiación solar; y aunque la sensibilidad y el rango espectral de las celdas solares es bajo comparado con la de los piranómetros, su costo, sencillez y fácil manejo (sólo se requiere de un multímetro de buena calidad) las han hecho muy populares para medir la irradiancia "in situ". La Figura 2.7 muestra un conjunto de 4 fotografías de piranómetros que se usan comúnmente $[8,9]$ para cuantificar la radiación solar.

$7 \quad$ Ver ejemplo de construcción de un piranómetro en: http://www. kippzonen.es/News.aspx?id=575\#.WMsJi281 4Y 

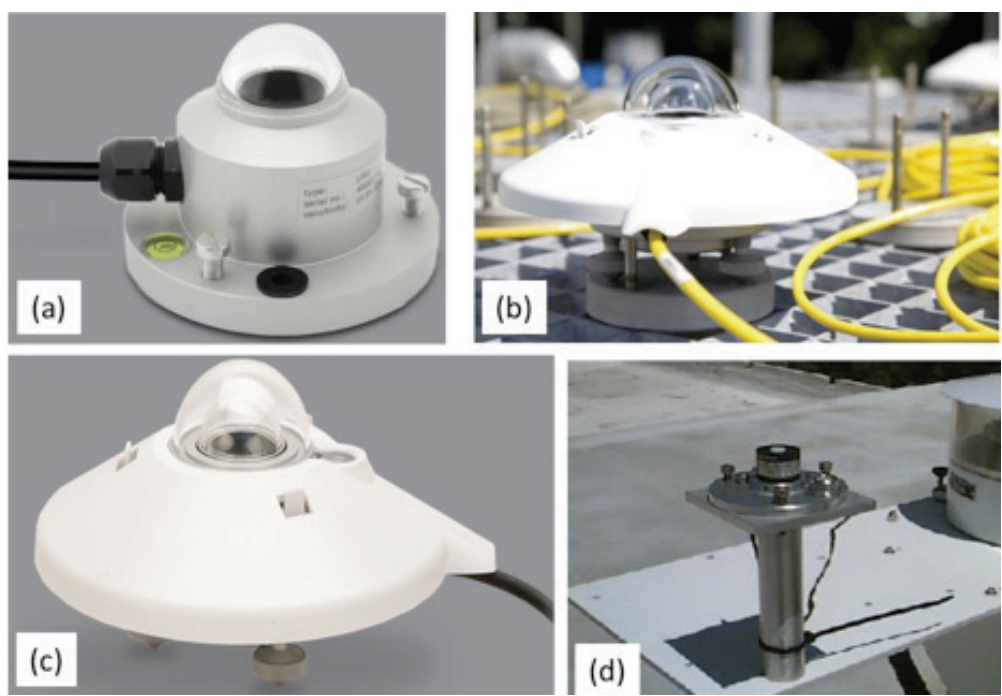

Figura 2.7: Piranómetros de uso común. Los mostrados en (a, b y c), usan una termopila para sensar la radiación solar. El mostrado en (d ) utiliza como sensor a una celda solar de silicio cristalino.

Para medir la radiación directa se usa otro instrumento llamado pirheliómetro de incidencia normal, o simplemente pirheliómetro. En éste instrumento, la superficie absorbedora está montada dentro de un tubo, en su fondo, y por el otro extremo del tubo se tiene una apertura con un cono de aceptación de $5.8^{\circ}$ que sólo permite la entrada de radiación que sea paralela a las paredes del tubo. Para que éste instrumento pueda medir la radiación directa a lo largo del día es necesario montarlo en un dispositivo electromecánico que siga al Sol. La Figura $2.8[8,9]$ muestra unas fotografías de dicho aparato. Por otra parte, la radiación difusa también se puede medir. Una manera de hacerlo es usando un piranómetro colocado horizontalmente y arriba de éste se coloca una banda opaca a la luz solar. Esta banda absorbe los rayos directos al piranómetro produciendo una sombra sobre éste, de tal manera que la única radiación que recibe es debido a la componente difusa. El inconveniente de éste equipo es que cada día hay que 


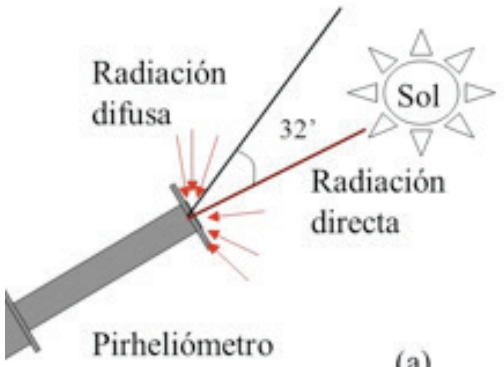

(a)

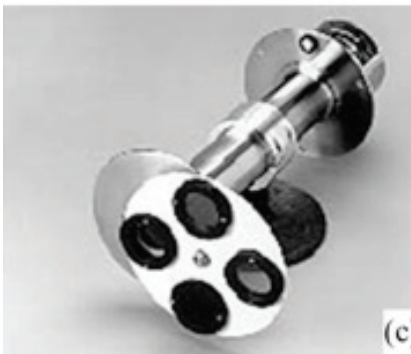

(c)

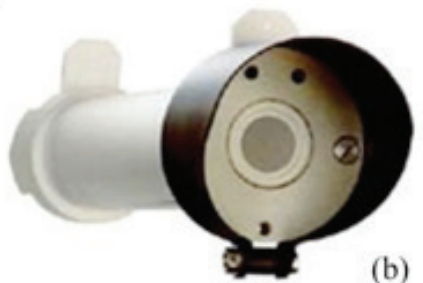

(b)

Figura 2.8: Pirheliómetros comerciales. En (d) se muestra un pirheliómetro montado en un seguidor solar.

La necesidad más creciente de establecer tecnologías que usan la Energía Solar ha motivado que desde hace más de 10 años varias instituciones se hayan abocado a colocar estaciones de medición de radiación solar con el objeto de establecer un mapa del Recurso Solar Nacional. Actualmente el Instituto de Geofísica de la UNAM a través del Observatorio de Radiación Solar se ha abocado la tarea de coordinar y calibrar los instrumentos de medida usados para la cuantificación de recurso solar. En el Instituto de Energías Renovables de la UNAM se encuentra una de estas estaciones. La Figura 2.9 muestra una fotografía de tal estación. Normalmente cada estación tiene por lo menos dos piranómetros operando. Uno encargado de medir la irradiancia global $G_{G}$ y el otro la difusa $G_{D}$, que en el caso mostrado en dicha figura, se mide con un piranómetro con banda de sombreado. 


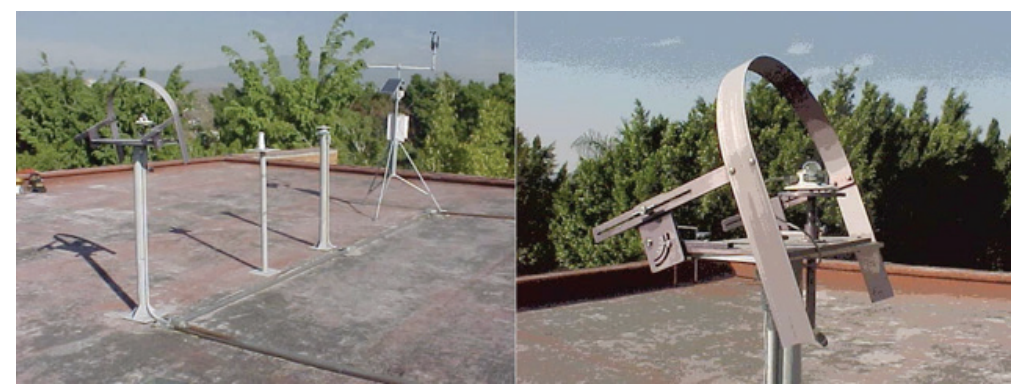

Figura 2.9: Estación meteorológica instalada en el IER-UNAM ubicada en Temixco, Mor.

\subsection{Datos de dadiación solar en México}

La radiación solar incidente en la superficie de la Tierra es el resultado de complejas interacciones de energía entre la atmósfera y la superficie. En una escala global, los gradientes latitudinales de la radiación son causados por la geometría de la Tierra, su rotación y revolución alrededor del Sol. En una escala regional y local, es la climatología del lugar así como el terreno (relieve) los factores que modifican la distribución de la radiación. La variabilidad de la elevación, la inclinación de la superficie, orientación y sombreado causado por las características del terreno provocan un fuerte gradiente local.

Ya que la generación de electricidad por medio de sistemas fotovoltaicos depende del Recurso Solar de la localidad en donde se piense instalar dichos sistemas, es necesario medir o estimar la irradiación. Independientemente de la forma en que se mide o estima el Recurso Solar, todos los valores de irradiación son expresados como promedios diarios mensuales, por estación o anualmente; y corresponden a valores globales o totales obtenidos con captadores horizontales. Estos valores se simbolizarán por EH. Los valores son condensados en mapas de radiación solar, en donde a través de líneas de igual valor se proporciona el valor del Recurso Solar. 
Las unidades que se usan comúnmente para el Recurso Solar o irradiación son: kWh/m²; $\mathrm{MJ} / \mathrm{m}^{2}$; Btu/ $/ \mathrm{ft}^{2}$; y Langley. Los factores de transformación entre unas y otras unidades son las siguientes:

$1 \mathrm{kWh} / \mathrm{m}^{2}=$ Langley $/ 85.9=316.96 \mathrm{Btu} / \mathrm{ft}^{2}=3.6 \mathrm{MJ} / \mathrm{m}^{2}$

Los datos de radiación solar para México han sido estimados y medidos por varias instituciones. El trabajo pionero de varios investigadores [14-19] y trabajos posteriores realizados en diferentes instituciones [20,21] han permitido tener a la fecha un banco de datos de radiación solar cuyos valores han sido estimados y calculados con una precisión del $5 \%$ [22]. La radiación solar que incide sobre una región determinada se suele representar en mapas mensuales y anuales de irradiación solar. El procedimiento más comúnmente usado para la elaboración de estos mapas es mediante la interpolación-extrapolación de series temporales de medidas de radiación solar en superficie, realizadas con piranómetros en puntos geográficos específicos. Otra alternativa para la generación de mapas con datos de radiación solar, son los modelos empíricos y físicos, que de igual forma, utilizan la interpolación de superficie como método de generalización de los datos de irradiación solar [14].

La Figura 2.10 muestra dos mapas del recurso solar para la República Mexicana en donde se han colocado isolineas que proporcionan los valores numéricos en unidades de horas solares pico (o bien, $\mathrm{kWh} / \mathrm{m}^{2}$ ). El que se muestra a la izquierda, Figura II(a), es la información que el FIRCO-SAGARPA especificó que usaran los proveedores, vendedores, e integradores de Sistemas Fotovoltaicos, que deseaban participar, en la venta, suministro e instalación de sistemas fotovoltaicos para homologar las propuestas económicas, en los diferentes programas de apoyo al campo para los proyectos productivos agropecuarios. El que se muestra a la derecha, Figura II(b), fue extraído de una publicación de Sandia National Laboratories. En ambos mapas, las isolíneas que se encuentran grafica- 
das corresponden a las horas-pico de Irradiación Global Horizontal promedio diaria al año. En dicha figura, los números representan las horas solares pico de las localidades; es decir, por ejemplo, $6 \mathrm{hsp}=6,000 \mathrm{Wh} / \mathrm{m}^{2}$.

Es práctica común también proporcionar la información del Recurso Solar de las localidades mediante tablas de datos. En el Anexo II se presentan tablas de valores de irradiación para las ciudades capitales de los Estados de la República Mexicana estimados a partir de la referencia [21]. Los valores corresponden a la irradiación solar global sobre un captador cuya superficie está horizontal

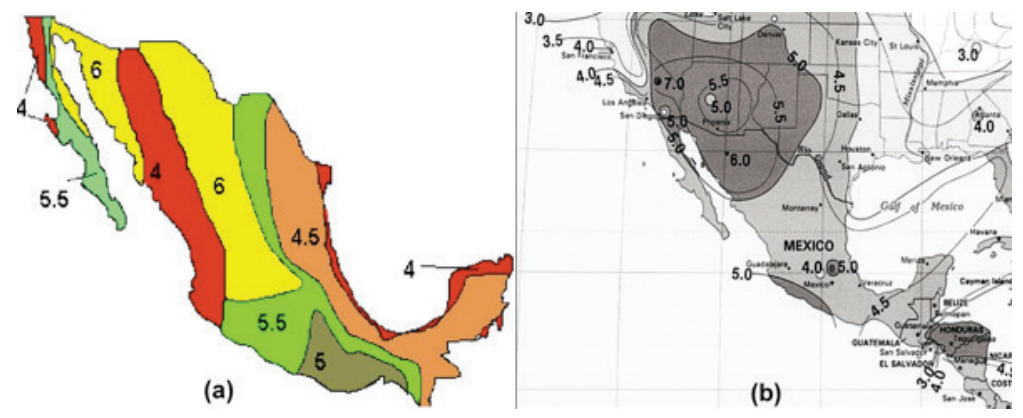

Figura 2.10: Mapas de radiación solar. Los valores indicados están en horas-pico y corresponden a la Irradiación Global Horizontal promedio diaria al año.

Es un hecho que cualquiera de las dos alternativas anteriores, en las que la información de radiación solar se representa en mapas o datos, pueden contener una gran incertidumbre, la cual está asociada a la metodología de cálculo o metodología de medición y resulta insuficiente para dimensionar y diseñar sistemas para el aprovechamiento de la energía solar, básicamente porque la interpolación de superficie no permite la observación de los aspectos microclimáticos de la radiación solar [23] (Zelenka, A. et al. 1999); sin embargo, proporcionan una idea del recurso disponible.

En México, es el Servicio Meteorológico Nacional (S.M.N.) el organismo que desde 1999, ha venido midiendo la radia- 
ción solar global de manera rutinaria y sistemática, gracias a la instalación de estaciones meteorológicas automatizadas (EMAS). El número de estaciones se ha venido incrementando año con año, por lo que hoy en día hay cerca de 400 estaciones cubriendo gran parte del territorio nacional. Desafortunadamente, la gran mayoría de ellas con pocos años de operación y su mantenimiento rutinario es deficiente (sin calibración periódica).

\subsection{Bases de datos de radiación solar}

Se puede obtener en cerca de 130 sitios de la red de Estaciones Meteorológicas Automatizadas (EMAS) del Servicio Meteorológico Nacional, información que nos permite conocer con suficiente resolución temporal (10 min) las características y comportamiento de la radiación global. Estos datos experimentales son necesarios y muy valiosos para probar y verificar las metodologías satelitales, sin embargo, es información limitada en cuanto a su resolución espacial, ya que la información de cada estación se refiere un solo punto en el espacio. Tampoco se conocen las características de los componentes directo normal y difuso de la radiación solar. Se cuenta con algunos programas de cómputo como el METEONORM que proporcionan datos de radiación solar a partir de mediciones terrenas, sin embargo los datos obtenidos para México son bastante imprecisos debido a que a diferencia de Europa y Estados Unidos, se tiene muy pocas estaciones meteorológicas que midan radiación. De la misma manera hay fuentes públicas que proveen de datos de radiación solar como es el caso de la NASA (http://www.eosweb.larc.nasa.gov/cgi-bin/sse-grid.cgi) pero su resolución es de $40 \mathrm{~km}$ x $40 \mathrm{~km}$ lo que impide tener un dato correcto para localidades específicas.

También se tiene disponible mapas de radiación solar para México que se pueden obtener del Inventario Nacional de Energías Renovables de la Secretaría de Energía (SENER), 
e información sobre valores y mapas editados por el Laboratorio de Radiación Solar del Instituto de Geofísica de la Universidad Nacional Autónoma de México (ver el sitio http://www. geofisica.unam.mx/radiacion_solar/atlas.php).

Además, existen trabajos de investigación, realizada por académicos, centrados en el estudio y manejo de información de los datos de radiación solar para México. Cabe destacar el documento editado por Solartronic8 S.A. de C.V. titulado "Irradiaciones global, directa y difusa, en superficies horizontales e inclinadas, así como irradiación directa normal, para la República Mexicana" 2003 SOL/DT-001-03, en donde se explica los conceptos relacionados con la radiación solar; así mismo, esta compañía oferta al público mediante el sitio web www.heliogis.com información de la radiación solar global con una resolución de 10 km x10km; además, es distribuidora de la base de datos Meteonorm, que contiene información climática para 8'325 localidades de todo el mundo, incluye además un sofisticado software de interpolación que permite conocer la información climática, incluidos los datos de radiación solar, para cualquier punto en la superficie terrestre.

Con el propósito de mejorar la resolución espacial, se usan interpolaciones a partir de los datos medidos en las estaciones meteorológicas, sin embargo, dado que se presentan grandes cambios en distancias cortas como consecuencia de la topografía y orografía del país, sólo mediante la utilización de la información enviada por los satélites meteorológicos se puede realizar una cuantificación económicamente viable y con la resolución tanto espacial como temporal requerida.

De ésta manera, para poder estimar la producción energética de una Planta Solar Fotovoltaica es necesario tener datos de radiación solar con una resolución espacial mejor que la que se dispone actualmente en las bases de datos pública.

8 www.solartronic.com 
Afortunadamente, el desarrollo tecnológico y la información enviada por los satélites meteorológicos, permite en la actualidad conocer con suficiente resolución -espacial y temporal- la intensidad de la radiación solar prácticamente en cualquier punto de la superficie terrestre. El desarrollo de los sistemas de información geográfica (SIG) plantea la posibilidad de generar este tipo de mapas empleando las relaciones existentes entre el movimiento aparente solar en la esfera celeste y el relieve de un terreno determinado. Por otro lado, poder calcular instalaciones fotovoltaicas bajo una base de datos de radiación estandarizada a nivel nacional da al usuario final una certeza para poder intercomparar las diferentes ofertas de tecnología que se le pueden presentar. A continuación se presenta direcciones electrónicas en donde es posible encontrar datos de radiación solar, que en algunos casos son públicas.

Base de Datos para el recurso solar se pueden encontrar en las siguientes fuentes:

- World Radiation Data Center; sitio http://wrdc-mgo.nrel. gov

- NASA: Surface Meteorology and Solar Energy; http:// eosweb.larc.nasa.gov/sse

- National Renewable Energy Laboratory, NREL Geospatial Data Science; www.nrel.gov/gis/solar.html

- Solar and Wind Energy Resource Assessment (SWERA); http://swera.unep.net

- Servicio SoDa (Solar Radiation Data); http://www.soda-is. com

- Estaciones Meteorológicas Automáticas (EMAS) del Servicio Meteorológico Nacional; http://smn.cna.gob.mx/ productos/emas

- Inventario Nacional de Energías Renovables, Secretaría de Energía (SENER); http://inere.energia.gob.mx/version4.5/

- Software; Meteonorm; http://www.meteonorm.com 
La base de datos que se ha usado con mayor frecuencia debido a su disponibilidad pública es la de la NASA; www/ eosweb.larc.nasa,gov/sse. De hecho, muchos proyectos energéticos sustentados en la energía solar toman como base los datos de esta fuente de información.

En la actualidad, la mejor alternativa para obtener datos de radiación solar la ofrecen los satélites geoestacionarios como GOES porque se puede extraer información sobre la radiación solar para grandes áreas geográficas, con resolución temporal de hasta 15 minutos y resolución espacial de hasta $1 \mathrm{~km}[24,25]$. Con los modelos actuales, el procesamiento de los datos de satélite y las mediciones de la radiación solar son algo comparables, con incertidumbres absolutas en la medición del orden de 25 a $100 \mathrm{~W} / \mathrm{m}^{2}$ (Myers 2003).

\subsubsection{Trayectoria solar y sombras}

La Tierra tiene dos tipos de movimiento: uno alrededor de su eje dando lugar al día y a la noche (movimiento rotacional); y el otro, alrededor del Sol (movimiento traslacional) siguiendo una trayectoria elíptica. Esta trayectoria forma un plano imaginario llamado la eclíptica.

Ya que el eje de rotación de la Tierra forma un ángulo de $23.5^{\circ}$ con respecto al plano de la eclíptica, un observador situado sobre la superficie de la Tierra verá que el Sol se declina diariamente con un ángulo d que varía entre $-23.5^{\circ}$ y $+23.5^{\circ}$ según la época del año. A éste ángulo se le llama la declinación solar. Entonces al efectuar su movimiento traslacional, esta inclinación produce las 4 estaciones del año (Ver Figura 2.11) 


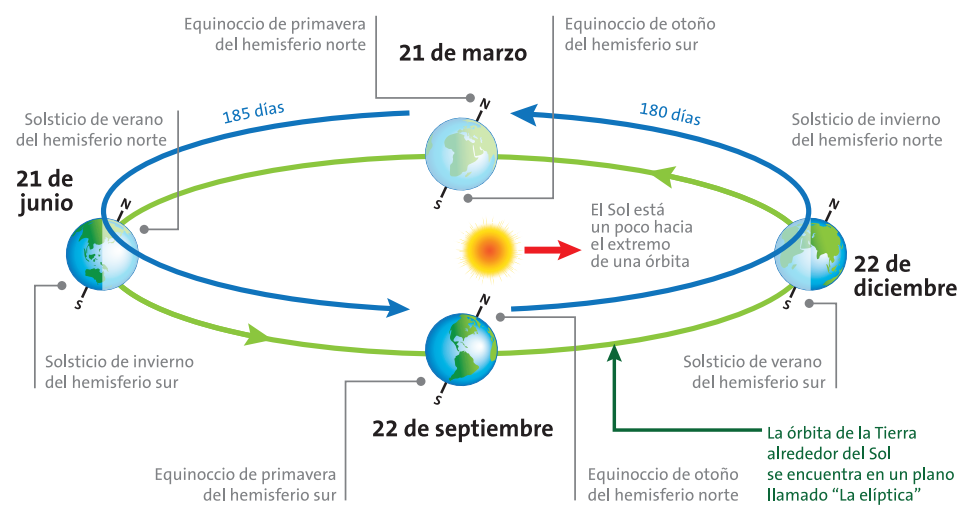

Figura 2.11: Ángulo de inclinación de eje terrestre y las estaciones del año.

La posición de cualquier observador sobre la superficie terrestre puede ser localizada con dos coordenadas llamadas longitud y latitud. La latitud, L, es el ángulo sustentado por las líneas rectas que van desde el centro de la Tierra hacia el Ecuador y el observador. Éste varía de $0^{\circ}$ para un observador situado en el Ecuador, hasta $90^{\circ}$ para un observador situado en los Polos. Como hay dos polos terrestres, Sur y Norte, habrá que referenciar como latitud Norte cuando el observador esta entre el Ecuador y el Polo Norte; y latitud Sur, aquella medida hacia el Polo Sur.

Debido a la declinación solar $\delta$, un observador situado en el Hemisferio Norte observa que el Sol siempre se declina hacia el Sur, con un ángulo de elevación o altura solar, simbolizado por $\alpha$ (letra griega de uso común para éste ángulo), que toma un valor mínimo en el solsticio de invierno y máximo en el solsticio de verano. Además, es más grande cuanto más cerca esté él observador del Ecuador.

Así, al medio día solar, el ángulo de elevación $\alpha$ está dado por la relación

$$
\alpha=\left(90^{\circ}-\mathbf{L}\right)+\delta
$$


donde $\delta$ toma valores desde $-23.5^{\circ}$ hasta $0^{\circ}$ desde el solsticio de invierno hasta el equinoccio de primavera, y desde $0^{\circ}$ hasta $+23.5^{\circ}$ desde el equinoccio de primavera al solsticio de verano; de ahí, regresa con un valor de $+23.5^{\circ}$ para el solsticio de verano, hasta llegar a $0^{\circ}$ para el equinoccio de otoño, y desde ese día del año con un valor de $0^{\circ}$ hasta $-23.5^{\circ}$ para el día del solsticio de invierno.

La posición aparente del Sol para un observador, desde el amanecer hasta el anochecer, describe una curva llamada la Trayectoria Solar. La posición del Sol, para cualquier día y hora del año, puede calcularse mediante ecuaciones proporcionadas por la geometría solar; sin embargo, se tienen programas de dominio público que calculan la trayectoria solar solamente proporcionando la latitud y longitud de donde se encuentra ubicado el observador.

La Figura 2.12 muestra las trayectorias solares aparentes para un observador situado en el Hemisferio Norte a una Latitud de $40^{\circ}$ (trayectoria color negro) y para una Latitud de $16^{\circ}$ (trayectoria color rojo) durante los días cuando se lleva a cabo los solsticios de verano e invierno. Se puede observar lo siguiente:

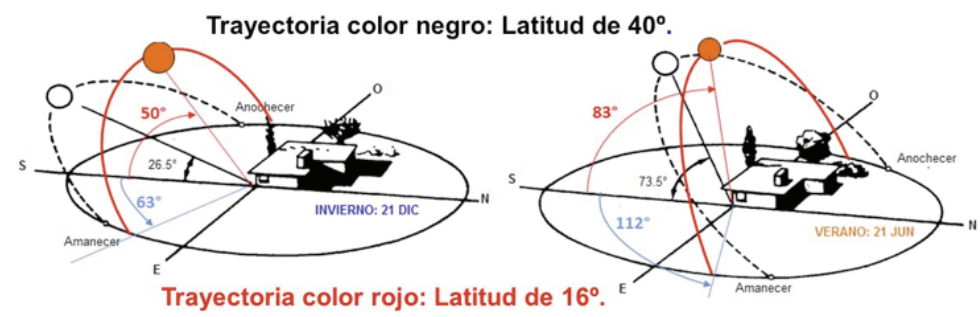

Figura 2.12: Trayectorias solares para los días en que se lleva a cabo los solsticios, para dos sitios con latitud diferente.

a) Entre más grande sea la Latitud del sitio, el ángulo de elevación solar es menor: Para el 21 de Diciembre se tiene: $\mathrm{a}=26.5^{\circ}$ para una $\mathrm{L}=40^{\circ}$; $\mathrm{a}=50^{\circ}$ para una $\mathrm{L}=16^{\circ}$. 
Para el 21 de Junio se tiene: $\mathrm{a}=73.5^{\circ}$ para una $\mathrm{L}=40^{\circ}$; y $\mathrm{a}=83^{\circ}$ para una $\mathrm{L}=16^{\circ}$ (aplicación directa de la Ec. 2.9)

b) Entre mayor sea la latitud del lugar, la sombra de los objetos es más grande.

c) La sombra que proyectan los objetos cercanos al observador son más largas en invierno que en verano.

d) Por trigonometría simple, el día en que los objetos presentan la mayor sombra es el 21 de diciembre.

Dentro del software de acceso gratuito que son de mucha utilidad para conocer las trayectorias solares está el SunChart (http://solardat.uoregon.edu/SunChartProgram.html). La gráfica de la Figura II-13 muestra una gráfica polar obtenida de dicho software en donde se muestran las trayectorias solares, obtenidas para los días 21 de cada mes, para un sitio ubicado a una Latitud de $20^{\circ} 59^{\prime}$

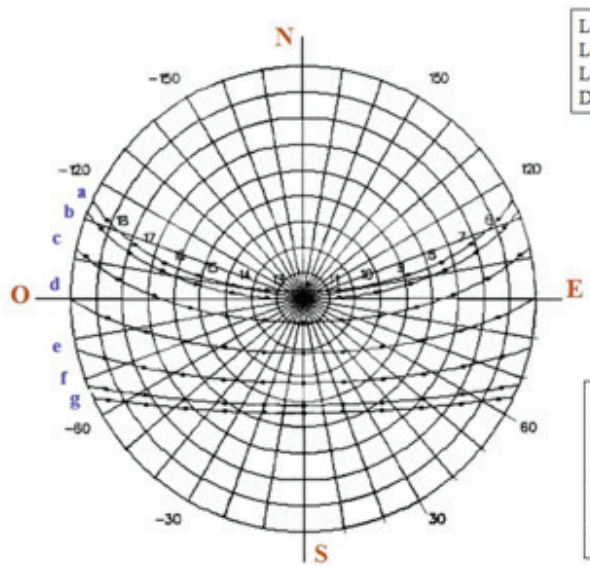

Figura 2.13: Trayectorias solares para una latitud de 2059' calculadas usando el programa SunChart.

Un observador situado en el Hemisferio Norte verá el Sol siempre declinado hacia el Sur, por lo que para recibir la máxima irradiancia, el captador debe estar orientado hacia el Sur, y para que los rayos caigan lo más perpendicular a él, el captador deberá de estar inclinado. Si $\beta$ es el ángulo que forma 
la superficie del captador con la horizontal, L el ángulo que determina la latitud del lugar, y sea $\boldsymbol{i}$ el ángulo de incidencia del rayo solar sobre el captador inclinado medido a partir de la recta perpendicular a la superficie (cenit del captador), al mediodía solar, el valor del ángulo i está regido por la relación:

$$
\boldsymbol{i}=|(\mathbf{L}-\beta)-\delta| \quad \text { Ec. } 2.10
$$

En el caso que se exija que los rayos solares incidan perpendicularmente sobre la superficie del captador, se tendrá que el ángulo de incidencia vale cero $\left(\boldsymbol{i}=0^{\circ}\right)$ y entonces

$$
\delta=\mathbf{L}-\beta
$$

Ec. 2.11

Si el captador está inclinado a un ángulo igual al valor de la latitud del lugar, es decir, $\mathrm{L}=\beta$, el ángulo de incidencia del rayo solar i variará cada día del año con un valor igual al de la declinación $\delta$. El rayo caerá perpendicularmente al captador para el día en que $\delta=0^{\circ}$, es decir en el equinoccio de Primavera y Otoño. En el solsticio de Verano estará a $23.5^{\circ}$ arriba del cenit del captador, mientras que en el solsticio de Invierno, estará a $23.5^{\circ}$ abajo del cenit del captador. Un bosquejo de tales ángulos se muestra en la Fig. 2.14.

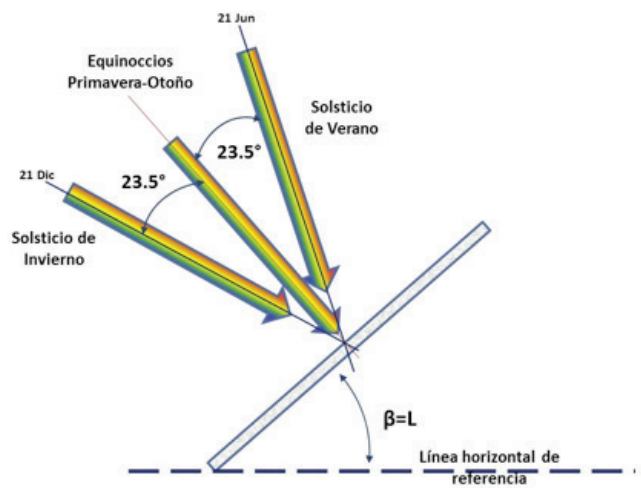

Figura 2.14: Posición que adquieren los rayos solares y un captador cuando su ángulo de inclinación es igual al de la latitud del lugar. 
Uno de los factores principales por los que las tecnologías solares no son aprovechadas al máximo es la proyección de sombras, generándose éstas debido a obstáculos que se interponen entre los rayos del Sol y los captadores. Para realizar un estudio del análisis de sombras es conveniente conocer las trayectorias solares, las cuales dependen de la latitud del sitio en cuestión y del día del año. Ya se ha establecido que para sitios localizados en el Hemisferio Norte, el día más desfavorable corresponde al 21 de Diciembre, ya que para ese día el Sol presenta la declinación menor, la altura solar angular (ángulo $\alpha$ ) es mínima, y las sombras generadas por los objetos será de mayor longitud.

La determinación de sombras proyectadas sobre los captadores debido a obstáculos próximos a éstos se efectúa en el sitio de instalación, observando el entorno desde el punto más bajo del captador, tomando como referencia la línea NorteSur. Si la altura solar para el sitio es $\alpha$, al hacer un barrido visual de Este a Oeste, con un ángulo $\alpha$ alrededor de la línea de referencia, no deberán verse obstáculos frente a los captadores.

Con respecto a la instalación de arreglos de captadores solares, la separación mínima entre ellos se establece de tal forma que la parte superior de un captador no sombree a la fila de captadores situados atrás de él. Para determinar la distancia óptima de separación se tendrá que calcular la sombra que produce determinado captador con un ángulo de inclinación $\beta$ y cuya longitud sea L. En la Fig. 2.14 se muestra un diagrama esquemático de tal situación.

La altura solar mínima para el 21 de Diciembre, al mediodía solar está dada por la relación,

$$
\alpha=90^{\circ}-|\mathbf{L}-\delta|
$$

De la Figura 2.15 se tiene que la sombra tiene una distancia $\mathbf{D}=\mathbf{d}_{1}+\mathbf{d}_{2}$. Sea $x$ la altura del extremo superior del captador. Si se aplican funciones trigonométricas en los dos trián- 
gulos mostrados en la figura se obtiene que la sombra tendrá una longitud dada por:

$$
\mathbf{D}=\mathbf{L}(\cos \beta+\operatorname{sen} \beta / \tan \alpha)
$$

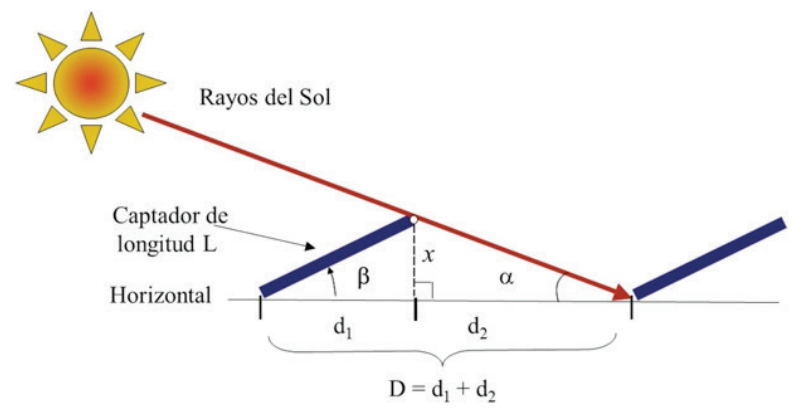

Figura 2.15: Sombra proyectada por un colector sobre la superficie horizontal.

\subsection{La orientación del captador}

Los análisis realizados en las secciones anteriores llevan a intuir que existe una orientación del captador, respecto de la trayectoria solar aparente, para la cual, se puede captar la máxima irradiancia. Esto se puede apreciar muy fácilmente en la Figura 2.16. Aquí se ha representado a la irradiancia como una "densidad" de rayos paralelos que llegan a la superficie de la Tierra.

Si se considera un captador cuya longitud mida X unidades, entonces dependiendo de la orientación del captador, éste puede interceptar un máximo de rayos o ninguno. Si el captador yace horizontalmente, su longitud sólo intercepta a "8 rayos" (Figura 2.16-a). Al aumentar la inclinación del captador hacia los rayos solares, el número de intercepción aumenta hasta llegar a un máximo de "13 rayos", cuando éstos caen de forma perpendicular en el captador (Figura 2.16-b). Al incrementar más el ángulo de inclinación, el número de rayos 
interceptados disminuye, siendo 11 para cuando la superficie es perpendicular a la horizontal (Figura 2.16-c), llegando hasta cero rayos interceptados cuando la superficie es paralela a los rayos solares (Figura 2.16-d).

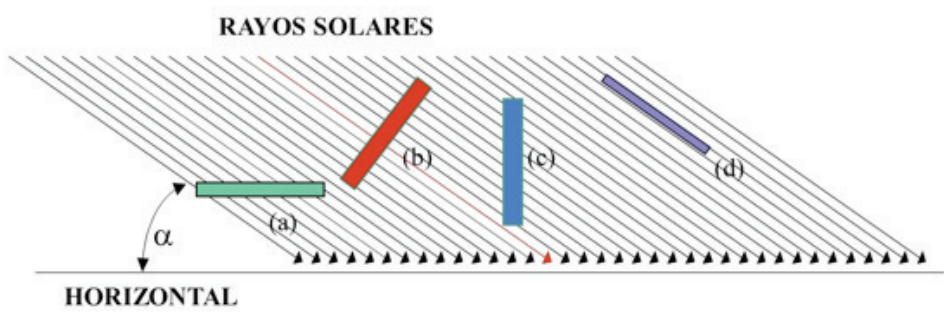

Figura 2.16: Rayos solares incidiendo sobre superficies con diferente inclinación.

Si el captador esta fijo, la máxima radiación directa se obtiene si los rayos solares inciden perpendicularmente sobre la superficie del captador (ángulo de incidencia $\iota=0^{\circ}$ respecto del cenit al captador), lográndose sólo en un instante del día. Éste instante depende de la orientación azimutal del captador.

Si el captador está orientado hacia el Sur, el instante de la máxima radiación directa sobre el captador será el mediodía solar, y la energía recibida (irradiación global) se acumulará desde el amanecer hasta el anochecer.

Si el captador está orientado hacia el Este (su ángulo azimutal es de $-90^{\circ}$ medido desde el Sur), la radiación directa sólo se recibirá en su superficie durante medio día, y el resto del día, el captador solo recibirá radiación difusa.

Si el captador está orientado hacia el Oeste, del amanecer hasta el mediodía solar, el captador recibirá solamente la componente difusa de la irradiancia, y a partir de ese instante, el captador empieza a recibir componentes de la irradiancia directa. 
En estos casos, se deduce que la máxima irradiación diaria recibida en un captador que estará fijo se obtiene cuando el captador está orientado e inclinado hacia el Sur, es decir, debe tener un cierto ángulo de inclinación y su ángulo azimutal debe ser cero.

Al considerar la manera en que la orientación afecta la cantidad de irradiación acumulada en un captador se puede establecer lo siguiente:

e) En un captador fijo en el Hemisferio Norte, la irradiación diaria acumulada se puede maximizar si el captador está orientado hacia el Sur y con un ángulo de inclinación que garantice que los rayos solares caigan perpendicularmente a su superficie al mediodía solar; la cual se obtiene cuando el ángulo de inclinación del captador, $\beta$, es igual al valor de la latitud del lugar, $\Lambda$, es decir: $\mathbf{L}=\beta$.

f) Por otra parte, si se pretende maximizar una temporada del año, por ejemplo Invierno, el ángulo de inclinación debe ser: $\beta=\Lambda+15^{\circ}$.

g) Si se desea maximizar verano, el ángulo debe ser: $\beta=\mathrm{L}-15^{\circ}$. La Figura 2.17-a muestra una representación cualitativa de la variación en los valores diarios de la irradiación recibida en un captador localizado en el trópico de Cáncer $\left(\mathrm{L}=23.45^{\circ} \mathrm{N}\right)$, mientras que en la Figura 2.17- $\beta$ se observa los efectos de la variación de $\pm 15^{\circ}$ sobre los valores normalizados en $\beta=\mathrm{L}$. 

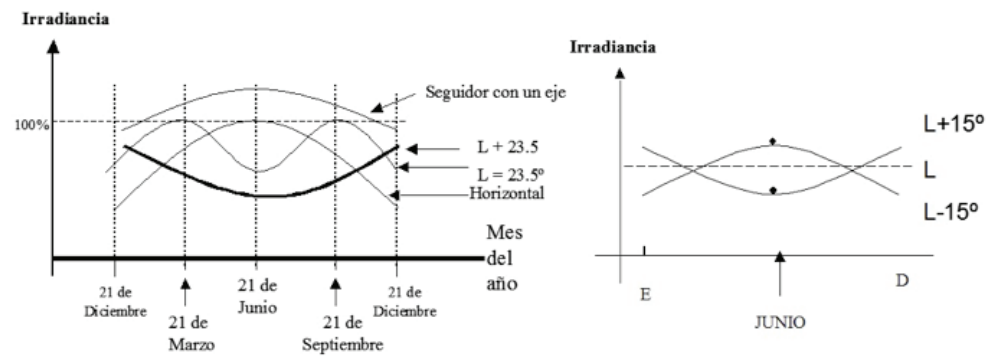

Figura 2.17: Gráficas cualitativas del comportamiento de la irradiancia global sobre un captador inclinado orientado hacia el Sur y localizado sobre el Trópico de Cáncer $\left(\mathrm{L}=23.45^{\circ} \mathrm{N}\right)$. En (a) se muestra el efecto del ángulo de inclinación, y en (b) los efectos de la inclinación del captador sobre la irradiación recibida normalizada a la latitud del lugar.

h) La única manera de maximizar la irradiación diaria es a través de un captador en donde su ángulo azimutal varíe instantáneamente siguiendo al Sol. Esto sugiere que el captador debe tener una estructura con un sistema mecánico que permita seguir al Sol durante las horas del día. A dicha estructura se le llama seguidor solar de un solo eje, pudiendo ser sistemas de seguimiento pasivo o activo. En los activos el seguimiento se realiza por medio de un motor eléctrico de pasos controlados por sensores solares. El principio de funcionamiento de los seguidores pasivos es el equilibrio de momentos que actúa sobre un eje de giro. Al rastrear el Sol durante el día, la irradiación recibida en el captador puede ser hasta de un $30 \%$ más que la obtenida para un captador fijo.

i) La irradiación anual será máxima cuando la superficie del captador este en cada instante, durante el día y durante el año, perpendicular a los rayos solares. Esto se logra montando al captador en una estructura que sigua al Sol con dos ejes de movimiento: uno diario, el azimutal, y el otro cambiando cada día en la dirección cenital. Un captador con dos ejes de seguimiento acumula una irradiación 
que puede ser hasta un $60 \%$ más que la que se obtiene para un captador fijo.

Ya que se exige que los captadores estén orientados hacia el Sur, la pregunta es ¿Cómo se identifica la dirección del Sur? La manera natural es el considerar que durante los equinoccios de Primavera y Otoño, el Sol sale por el Este y se oculta en el Oeste. Si la mano derecha del observador apunta hacia el Este, su espalda apuntará hacia el Sur. Sin embargo, no se puede esperar hasta que lleguen los días del equinoccio. La otra forma de identificar el Sur en una localidad dada es por medio de un compás magnético (brújula) y el conocimiento de la declinación magnética del lugar.

Para no confundir al lector, a los polos identificados con una brújula se le llamaran polos magnéticos. La Figura 2.18 muestra el mapa isogónico de la República Mexicana [22]. Aquí se observan las líneas de igual campo magnético y su declinación correspondiente medida desde el Sur no magnético. Estas líneas significan que, al detectar el Norte Magnético (o el Sur magnético) mediante una brújula, el Sur solar estará desviado hacia el Este la cantidad de grados expresados en el mapa.

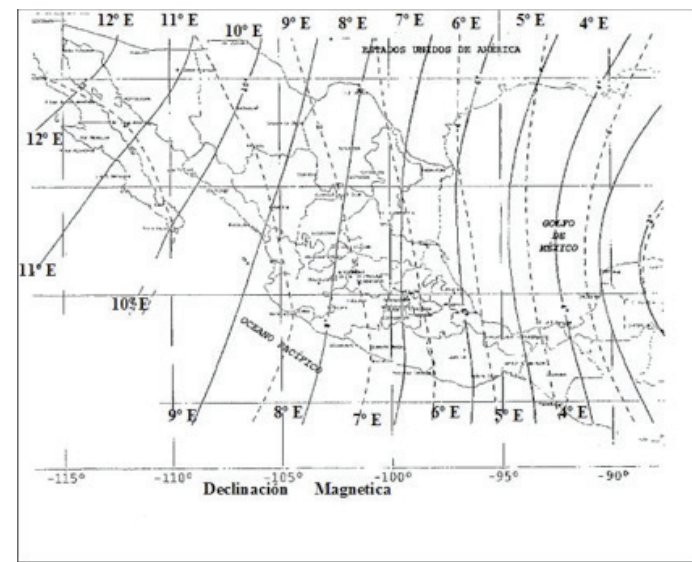

Figura 2.18: Mapa isogónico de la República Mexicana adaptado de la referencia [21]. 
Por ejemplo, para Temixco, Morelos, la declinación magnética es de $7^{\circ} \mathrm{E}$. Al identificar el Norte magnético, el Sur solar estará ubicado a $7^{\circ}$ hacia el Este de la línea Sur-Norte magnético. La Figura 2.19 muestra una representación esquemática de la localización del Sur solar para una localidad con una declinación magnética de $13^{\circ} \mathrm{E}$.

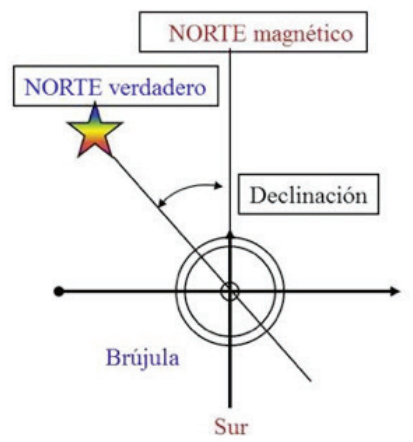

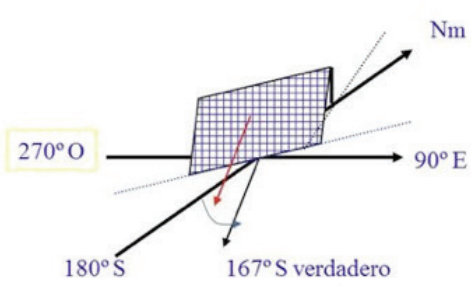

Ejemplo: Declinación Magnética $13^{\circ} \mathrm{E}$.

El Sur Verdadero está a $13^{\circ} \mathrm{E}$ del Sur magnético.

Si el captador se orienta con una brújula, el Sur verdadero estará a $167^{\circ}$.

Figura 2.19: Determinación del Sur Solar (Sur verdadero) mediante el uso de una brújula y el conocimiento de la declinación magnética.

\subsection{Generalidades}

En términos del ciclo de vida humano el Sol es una estrella que tiene una vida promedio muy grande. Así que la energía que envía a la Tierra puede considerarse como inagotable. Fuera de la atmósfera y a la distancia promedio Tierra-Sol, se recibe una irradiancia promedio de $1,353 \mathrm{~W} / \mathrm{m}^{2}$. A éste valor se le conoce con el nombre de la constante solar. Al ingresar la radiación solar en la atmósfera terrestre, ésta se absorbe, se refleja, se refracta y se transmite hacia la superficie terrestre, fenómenos que atenúan el valor de la irradiancia. Así, la radiación que incide sobre un captador está formada por dos componentes: la directa y la difusa. La suma de las dos forma el concepto de irradiancia global o total. 
Además de los efectos atmosféricos que atenúan la radiación solar, existen otros factores que reducen la captación de energía en un captador solar. Estos efectos son los geográficos: rotación y traslación de la Tierra, localización (altitud, longitud y latitud), temporada del año, y orientación relativa del captador.

La máxima radiación directa que incide sobre un captador horizontal durante un día claro, sin partículas suspendidas en el aire, a nivel del mar y estando el Sol en el cenit del captador es aproximadamente igual a $1000 \mathrm{~W} / \mathrm{m} 2$. A éste valor se le ha llamado el pico de la irradiancia. La contribución de la radiación difusa a la global bajo esas condiciones es muy poca y depende de los fenómenos de reflexión de los alrededores al captador. El valor de la irradiancia varía con respecto a la hora del día y al día del año. Los ángulos de orientación solar del captador respecto de los polos cardinales y de la superficie horizontal, permiten establecer relaciones aritméticas y modelos empíricos para calcular la irradiancia sobre la superficie terrestres para cualquier día y hora del año.

La energía acumulada en un captador durante un tiempo determinado (día, mes, año) define el concepto de irradiación. Esta es la energía disponible para su uso en alguna aplicación específica. La irradiación de un sitio determinado puede medirse mediante aparatos especiales o puede estimarse por medio de modelos empíricos o por medio de datos obtenidos de satélites. El conjunto de valores de irradiación de una región dada forman el Recurso Solar de dicha localidad.

Nuestro país, al estar dentro del cinturón solar terrestre, tiene muchas localidades donde el Recurso Solar es mayor de $\operatorname{los} 4,000 \mathrm{Wh} / \mathrm{m}^{2}$. Estos valores tan grandes sugieren la implementación de proyectos para obtener energía del Sol y transformarla en energía útil para el ser humano.

A manera de ejemplo, si el recurso solar de una localidad tiene un valor promedio diario mensual de $5 \mathrm{kWh} / \mathrm{m}^{2}$, entonces en un cuadrado de 10 m x 10 m (área típica para una 
azotea de casa de interés social) se recibirá una energía incidente Ei de

$$
\mathrm{E}_{\mathrm{i}}=\left(5 \mathrm{kWh} / \mathrm{m}^{2}\right) \times\left(100 \mathrm{~m}^{2}\right)=500 \mathrm{kWh} .
$$

Si se considera un dispositivo que transforme dicha energía en otra, por ejemplo electricidad, con una eficiencia modesta del 10\%, entonces la energía $\mathrm{E}$ disponible para realizar cualquier trabajo, valdrá

$$
\mathrm{E}=(500 \mathrm{kWh}) \times 0.1=50 \mathrm{kWh} .
$$

Ya que una casa de interés social, en zonas de clima cálido, tiene consumos eléctricos típicos de $5 \mathrm{kWh}$ por día, la energía que se generaría será la suficiente para abastecer ¡10 casas de ese tipo!.

Estas escalas se pueden ampliar tanto como el lector lo necesite. Pero es claro que se requiere de una tecnología que logre hacer esa transformación sin generar desechos contaminantes, que no haga ruido y que sea sencilla de operar y mantener para que el impacto socioeconómico sea alto. Dicha tecnología ya se tiene disponible en el mercado y es la Tecnología Fotovoltaica, la que se explicará en los siguientes capítulos.

\section{Referencias}

1. Sayigh A. A. M. Editor, Solar Energy Engineering, (1977), Academic Press.

2. White H. T., "Física Moderna”, V-I (1982), Editorial UTEHA.

3. Kreider J. F., Hoogendoorn C. J., y Kreith F., "Solar Design: Components, Systems, Economics", (1987) Editorial Hemisphere Publishing Corporation.

4. Kreith F. Y Freider J. K., "Principles of Solar Engineering", (1985) Editorial McGraw Hill.

5. J. A. Duffie, W. A. Beckman, "Solar Engineering of Thermal Processes", (1991) Second Edition, Editorial Wiley, New York. 
6. Rabl A., "Active Solar Collectors and Their Applications", (1985), Editorial Oxford University Press, New York.

7. Goswami D. Y., Kreith F., Kreider J. F., "Principles of Solar Engineering", (1999) 2nd edition, Editorial Taylor \& Francis, Philadelphia.Página electrónica: The Eppley Laboratory: www.eppleylab.comPágina electrónica: Kipp \& Zonen: www.kippzonen.com

8. Página electrónica: Campbell: www.campbellsc1.comStrahler Arthur N., The Earth Sciences, (1980) Second Edition, Editorial Harper and Row.Sheng H. J., "Solar Energy Engineering", (1988), editorial Prentice-Hall. Inc.Goswani D. Y., "Principles of Solar Engineering", (2000) Second Edition, EditorialEstrada-Cajigal, V., "Datos de radiación solar en la República Mexicana, alcances y limitaciones", (1992). La Revista Solar, 21, pp. 10-19.Almanza R. y López S., "Radiación Solar en la república Mexicana mediante datos de insolación", Series del Instituto de Ingeniería, (1975) UNAM, No. 357.

9. Servicio Meteorológico Nacional, "Normales climatológicas, periodo 1941-1970”, México (1976).

10. Servicio Meteorológico Nacional, "Normales climatológicas, periodo 1951-1980", México (1990).

11. Secretaría de Agricultura y recursos Hidráulicos, "Atlas del Agua", México (1976).

12. Galindo E. 1., Valdés B. M., "México: Atlas de Radiación Solar", Reimpresión 1991, Editor: J. Quintanilla, Programa Universitario de Energía, UNAM.

13. Almanza S. R., Estrada-Cajigal R. V., Barrientos A. J., "Actualización de los mapas de Irradiación Global Solar en la República Mexicana", (reimpresión 1992), Series del Instituto de Ingeniería, UNAM, (1983) No. 543.

14. Estrada-Cajigal R. V., "Datos de Radiación Solar para México", (1994), Reporte Interno LES94-0503-103, Centro de Investigación de Energía, UNAM.

15. Cartas del Instituto de Geofísica. 
16. Zelenka, A., Perez, R., Seals, R. and Renné, D. (1999). Effective accuracy of satellite-derived hourly irradiances. Theor. Appl. Climatol., 62, 199-207.

17. Hammer, A., Heinemann, D., Hoyer, C., Kuhlemann, R. y otros (2003). Solar energy assessment using remote sensing technologies. Remote Sensing of Environment 86, 423-432.

18. Polo, J., Zarzalejo, L. F. y Ramírez, L. (2008). Solar Radiation Derived from Satellite Images, pp. 449-460. Contenido en: Modeling Solar Radiation at the Earth Surface. Editado por: Viorel Badescu. Springer-Verlag. 


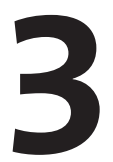

\section{LA TECNOLOGÍA FV Y SU PROSPECTIVA FUTURA DE DESARROLLO}

\subsection{Introducción}

Una de las formas en que el ser humano puede aprovechar la energía solar es por medio de la conversión directa de la luz solar en electricidad mediante el "Efecto Fotovoltaico" (FV). Ésta transformación es una de las formas más prometedoras que han surgido para generar energía eléctrica limpia usando fuentes de energía renovable. Los dispositivos donde se lleva a cabo la transformación de luz solar en electricidad se les conoce con el nombre de celdas solares y son las unidades mínimas de conversión fotovoltaica con las cuales se fabrican los llamados Generadores Fotovoltaicos (GFV). A la integración de generadores fotovoltaicos con dispositivos para el uso, almacenamiento y acondicionamiento de energía y aparatos consumidores de electricidad (cargas eléctricas) se les llama Sistemas Fotovoltaicos. Pero, ¿que son las celdas solares, como trabajan y como se pueden usar?. Estas son preguntas que serán respondidas durante el desarrollo de éste capítulo. Aquí se analizarán los Principios de la Conversión Fotovoltaica para dar al lector las herramientas necesarias para comprender y operar la tecnología fotovoltaica. 


\subsection{Efecto fotovoltaico y parámetros eléctricos}

La conversión de la luz solar en electricidad, a través del fenómeno físico conocido como "efecto fotovoltaico," se realiza en un dispositivo fabricado con semiconductores en donde se absorbe la luz solar y ésta es convertida en electricidad del tipo corriente continua o directa (c.c. o bien c.d.), sin ningún proceso intermedio. A la unidad mínima de conversión de luz solar en electricidad se le ha llamado "celda solar" y representa la base para la formación de estructuras de potencia eléctrica o GFV. A los diferentes materiales con que se basa la fabricación de celdas solares forman lo que se conoce con el nombre de Tecnologías Fotovoltaicas.

El Efecto Fotovoltaico $(F V)$ se puede definir como la generación de una fuerza electromotriz (diferencia de tensión eléctrica o voltaje) en las terminales de un dispositivo debido a la absorción de la luz solar. Bajo estas condiciones, si se le conecta una carga, se producirá una corriente eléctrica que será capaz de realizar un trabajo en ella. La corriente producida es proporcional al flujo luminoso recibido en el dispositivo (ver Figura 3.1).

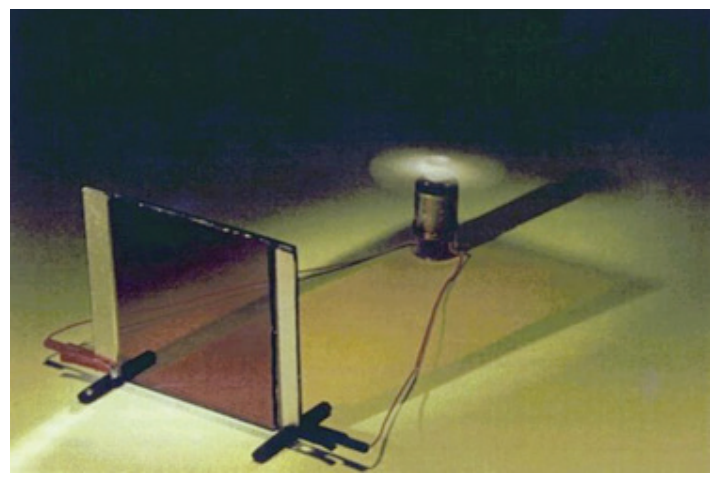

Figura 3.1: Evidencia física del Efectro FV en una celda solar semitransparente de silicio amorfo, la cual esta conectada a un motor que tiene acoplado una hélice.

En una celda solar, el efecto $F V$ se presenta como la generación de voltaje en sus terminales cuando está bajo ilumi- 
nación. Si a las terminales de la celda solar se le conecta un aparato eléctrico, por ejemplo, un motor, entonces ésta cierra el circuito, la tensión fotogenerada impulsa una corriente eléctrica a través de ella y el motor se pondrá a girar debido al trabajo que ejerce la corriente al fluir por el embobinado de éste (ver esquema en la Figura 3.1). Esto representa la evidencia física del efecto fotovoltaico.

Las características eléctricas de una celda solar se obtienen bajo condiciones estandarizadas internacionalmente, llamadas las Condiciones Estándares de Prueba, STC (por sus siglas en inglés: Standard Test Conditions) las cuales son las siguientes:

a) Someter a la celda solar a una iluminación con una irradiancia de $1,000 \mathrm{~W} / \mathrm{m}^{2}$; es decir,

b) $G_{\mathrm{p}}=1.0 \mathrm{~kW} / \mathrm{m}^{2}=100 \mathrm{~mW} / \mathrm{cm}^{2}$

c) El Espectro de la Radiación Solar debe corresponder a una Masa de Aire AM1.5

d) La Temperatura de operación de la celda solar debe mantenerse a $25^{\circ} \mathrm{C}$; es decir:

e) $\mathrm{T}_{\mathrm{C}}=25^{\circ} \mathrm{C}$

Los parámetros eléctricos de una celda solar bajo iluminación se representan esquemáticamente en la Figura 3.2 y Figura 3.3 y estos son:
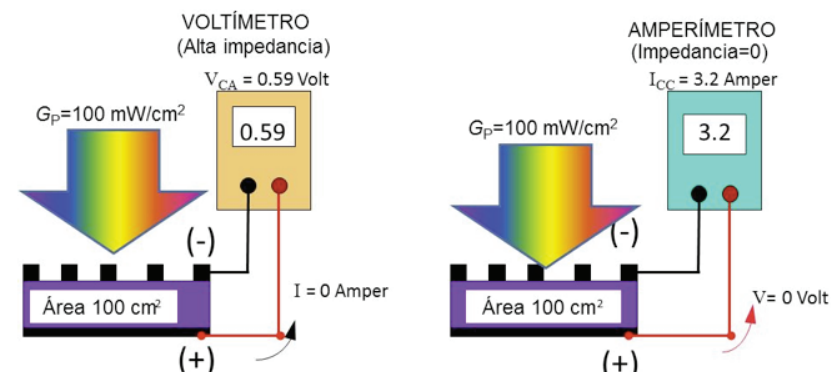

Figura 3.2: Representación esquemática de los parámetros eléctricos de una celda solar. 
a) El voltaje a circuito abierto $\left(V_{C A}\right)$, es el máximo voltaje que genera la celda solar.

b) La densidad de corriente de corto circuito $\left(J_{C C}\right)$, o corriente de corto circuito $\left(I_{C C}=J_{C C} / S\right.$ siendo $S$ la superficie activa de la celda solar), es el valor máximo que genera la celda solar.

c) Máxima Potencia, $\mathrm{P}_{\mathrm{M}}$ : Cuando se acopla una "carga eléctrica" a las terminales de una celda solar sometida a iluminación, la celda solar entregará potencia eléctrica a la carga en términos de la Ley de Ohm, es decir, el voltaje de operación de la "carga", diseñado por su fabricante respectivo, debe tener un valor comprendido entre 0 y el valor del $\mathrm{V}_{\mathrm{CA}}$ de la celda para que ésta funcione, si esto no se cumple, la “carga” no entregará trabajo. Así, el punto de operación de la "carga" estará determinado por su resistencia eléctrica $\mathrm{R}_{\mathrm{L}}$, y la corriente de operación $I_{O P}$ estará determinada por la Ley de Ohm: $I_{O P}=\left(1 / \mathrm{R}_{\mathrm{L}}\right) V_{O P}$ Así, al variar el valor de la resistencia de la "carga", $\mathrm{R}_{\mathrm{L}}$, se pueden tener un número muy grande de puntos de acoplamiento entre la potencia que entrega la celda solar y la potencia de diseño de la carga eléctrica. Si se grafica en un diagrama $I$ vs $V$ los valores del voltaje y corriente de operación para cada punto de acoplamiento, se tendrá una curva como la mostrada en la Figura 3.3. De todos los puntos de acoplamiento, solo hay uno y solo un para el cual, el producto del voltaje por la corriente de operación es máximo; es decir, la celda solar entrega su máxima potencia a la "carga".

En consecuencia, si el voltaje para la máxima potencia se denota por $V_{M}$ y la corriente para la máxima potencia se denota por $I_{M}$, entonces $\mathrm{P}_{\mathrm{M}}=V_{M} I_{M}$; 

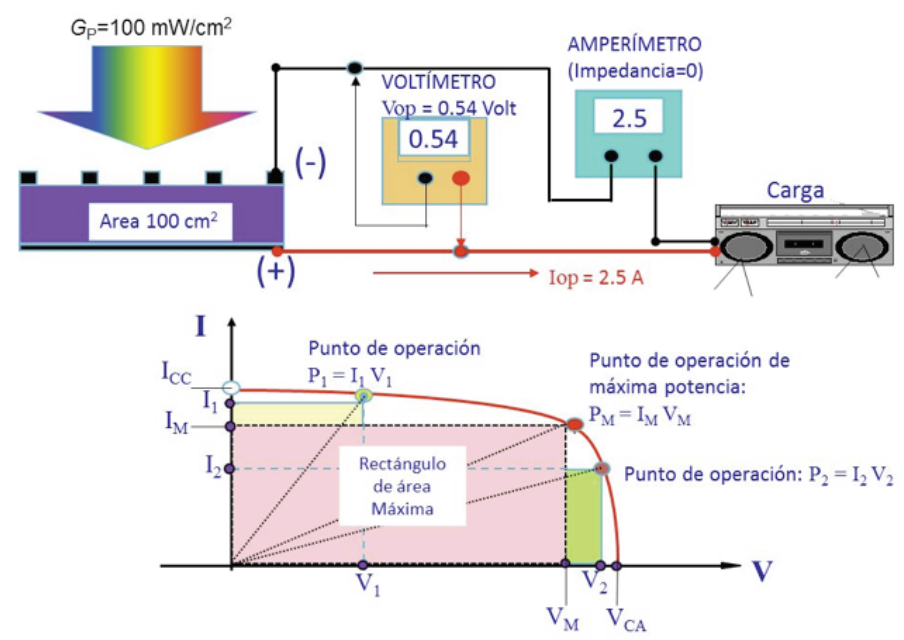

Figura 3.3: Celda solar acoplada a una "carga eléctrica" definiendo puntos de operación con na potencia $\mathrm{P}=\mathrm{VI}$

d) La eficiencia de conversión, $\eta$, definida como la razón de la máxima potencia generada $\mathrm{P}_{\mathrm{M}}$ entre la potencia de la radiación solar incidente $\mathrm{P}_{\mathrm{I}}$, definida como el producto de la irradiancia $G$ por la superficie $S$ de la celda solar.

\begin{tabular}{|c|c|}
$\substack{\eta=P_{M} / P_{I} ; \\
\text { o bien } \\
\eta=P_{M} / G \times S}$ & Ec. 3.1 \\
\hline
\end{tabular}

e) El Factor de Forma $\boldsymbol{F F}$ de la curva de generación I vs V definida como $\boldsymbol{F F}=\mathrm{P}_{\mathrm{M}} / I_{C C} V_{C A}$

La potencia eléctrica generada en una celda solar es pequeña, por lo que, para incrementar ésta, es necesario interconectarlas entre sí para formar los módulos fotovoltaicos, los que a su vez, se identifican por sus parámetros eléctricos $V_{C A}, I_{C C}, V_{M}, I_{M} \mathrm{y}_{\mathrm{M}}$.

Cuando a la celda se le hace incidir una radiación solar con una potencia igual al Pico de la Irradiancia, GP=1.0 kW/ $\mathrm{m}^{2}$, la potencia máxima que genera la celda se le llama la potencia pico, que es el parámetro con el cual se comercializa la tecnología fotovoltaica. 
La tecnología de elaboración de celdas solares está basada en materiales semiconductores monocristalinos, policristalinos y amorfos, los cuales, dependiendo del tipo de semiconductor, se pueden elaborar en película delgada (del orden de $1 \mu \mathrm{m}$ de espesor) o gruesas (del orden de cientos de micra de espesor).

Se encuentran en el mercado diferentes tipos de celdas y módulos solares; pero a nivel de investigación, donde se busca obtener de la celda solar la máxima potencia manteniendo los costos de elaboración al mínimo, hay una gama amplia de materiales semiconductores y estructuras en desarrollo.

\subsection{Tecnologías de celdas solares: historia y su estado de desarrollo}

La historia del Efecto Fotovoltaico comienza en 1839 cuando E. Becquerel observó "la generación de corriente eléctrica en una reacción química inducida por luz". Varias décadas después, en 1870s, un efecto similar fue observado en sólidos, en especial en selenio. En 1930, Lange, Schottky and Grondhal reportan eficiencias de conversión del $2 \%$ en celdas basadas en Se y $\mathrm{Cu}_{2} \mathrm{O}$. Sin embargo, se tuvo que esperar al avance de la ciencia, en especial en Física Cuántica, para dar una explicación fundamental del fenómeno fotovoltaico. Posteriormente, el desarrollo de la teoría del Rectificador de Estado Sólido (diodo) llevado a cabo por Mott y Schottky a principios de la década de 1940s y el invento del transistor por Bardeen, Brattain y Shockley en 1949, abrieron el camino al establecimiento de la primera celda solar de silicio cristalino de eficiencia aceptable. Este desarrollo se llevó a cabo en 1954 en los Laboratorios Bell y fue realizado por Chapin, D.M. y colaboradores [1] los que reportaron una eficiencia de conversión, de energía solar a electricidad, del 6\%.

Las celdas solares no tuvieron que esperar mucho tiempo para encontrar una aplicación. El año 1958 fue testigo del 
lanzamiento del Vanguard I, primer satélite que usó celdas solares para generar su energía eléctrica. De hecho, el comienzo del programa espacial de los Estados Unidos Americanos inició la primera mayor aplicación de las Celdas Solares y de los Sistemas Fotovoltaicos.

Desafortunadamente, las celdas solares eran muy caras, en el rango de cientos de dólares el Watt-pico. El alto costo y la falta de un mercado terrestre relegaron a las celdas solares fotovoltaicas al "estado" de dispositivos únicamente para investigación y curiosidad de laboratorio. Sin embargo, los dispositivos fotovoltaicos demostraron que son ideales para generar electricidad en el espacio: no requieren mantenimiento, no producen desechos y la generación de electricidad solo depende del Sol. Las investigaciones llevadas a cabo a principios de los 1970s mejoraron la eficiencia de conversión y lograron reducir su peso, factor importante para los satélites. De esta manera, grandes arreglos fotovoltaicos pudieron usarse en los satélites, tal como el del Skylab.

A raíz de la crisis petrolera en los años 1970s, los programas de desarrollo e investigación en celdas solares para aplicación terrestre comienzan en gran escala, y en relativo corto tiempo, se logran tremendos avances en aumento de eficiencia y reducción de costos. En la Tabla 3.1 se muestra un esbozo de lo que ha sido el progreso de la tecnología fotovoltaica. 
Tabla 3.1: Reseña histórica de la tecnología fotovoltaica.

\section{Progreso de la tecnología fotovoltaica}

1839 Descubrimiento del Efecto Fotovoltaico por E. Becquerel

Estudios del Efecto Fotovoltaico en sólidos por $\mathrm{H}$. Hertz

1870s Celdas solares basadas en selenio con el $1 \%$ al $2 \%$ de eficiencias de conversión.

Primera celda solar de silicio cristalino desarrollada en los Laboratorios Bell, USA. $6 \%$ de eficiencia de conversión en celdas

1954 solares basadas en silicio cristalino [1].

Celdas solares basadas en CdS son reportadas por Reynolds y colaboradores.

El programa espacial en USA inicia la primera mayor aplicación de celdas solares.

1958 El Vanguard I primer satélite espacial con tecnología fotovoltaica para la generación de electricidad.

La crisis mundial petrolera y el aumento en los costos de la energía propiciaron el interés de reducir costos en la tecnología fotovoltaica para aplicaciones terrestres y el desarrollo de nuevos materiales semiconductores.

Reducción de precios en módulos fotovoltaicos basados en silicio Usd \$/watt pico

\begin{tabular}{|l|l|l|l|l|l|}
\hline 1958 & $1965-74$ & 1980 's & 1990's & $\begin{array}{c}\text { Actualmente } \\
(2017)\end{array}$ & año 2020 \\
\hline$\cong 1500$ & $\cong 200$ & $\cong 20$ & $\cong 7-10$ & $\cong 0.60$ & $<0.30 ? ?$ \\
\hline
\end{tabular}

Eficiencias de conversión en módulos fotovoltaicos comerciales

$$
5 \text { al } 22 \%
$$

Récord de eficiencia de conversión en celdas solares experimentales

29.8\% A 38.8\% En celdas solares de unión múltiple basadas en $\mathrm{GaAs}{ }^{9}$

Por otra parte, gracias al avance en la tecnología de fabricación de semiconductores en película delgada, actualmente se tienen una variedad muy amplia de dichos materiales que han sido considerados, con base a sus características ópticas

9 Martin A. Green, Keith Emery, Yoshihiro Hishikawa, Wilhelm Warta and Ewan D. Dunlop; "Solar Cell Efficiency Tables (version 48)"; Prog. Photovolt: Res. Appl. 2016; 24:905-913 
y eléctricas, como buenos candidatos para formar una celda solar. Entre estos, el que recibió un fuerte impulso en la investigación y desarrollo tecnológico fue el silicio amorfo hidrogenado (a-Si:H). Se desarrollaron celdas a nivel experimental y comercial demostrándose que su proceso de fabricación es más barato en comparación con el silicio cristalino (x-Si); sin embargo su eficiencia es menor con valores máximos del $10.2 \%$ para una unión simple, y hasta $13.6 \%$ para una triple unión. A nivel comercial la eficiencia para una triple unión llega al 12.3\%. El inconveniente de éste material es la degradación debido al conocido efecto Staebler-Wronski, sin embargo, la compañía United Solar Ovonics ha elaborado celdas de triple unión ${ }^{10}$ con eficiencias del $13.6 \%$. Actualmente el uso de estas celdas solares es muy común ya que se les puede encontrar en relojes, calculadoras, sistemas de señalización y hasta módulos con 64 Watt de potencia, con garantía de fábrica por 20 años, con los que se puede dimensionar sistemas de potencia. La Figura 3.4 muestra fotografías del silicio en sus diferentes configuraciones sólidas: monocristal, policristal y amorfo.

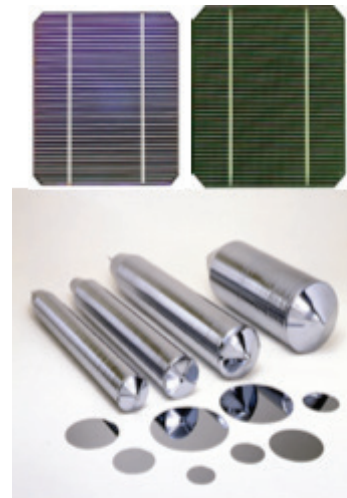

(a)

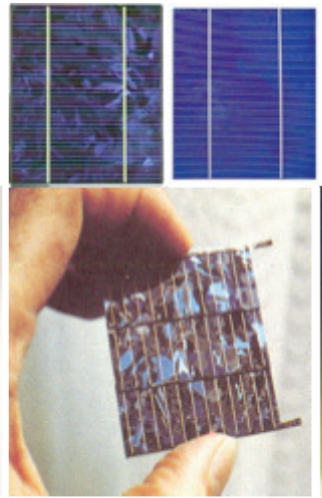

(b)

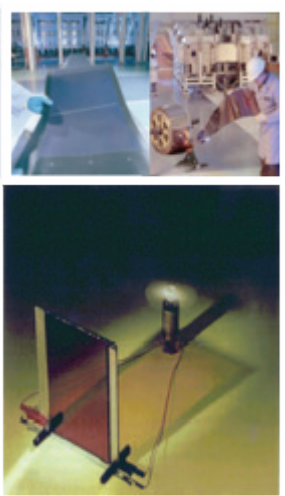

(c)

10 Valor tomado de www.uni-solar.com y nota anterior 
Figura 3.4: Silicio para celdas solares. (a) muestra lingotes y obleas de monocristales; (b) una oblea policristalina mostrando la configuración tipo mosaico del material; y (c) abajo, celda de silicio amorfo monocapa, mostrando su transparencia; arriba: celdas triple unión.

Otros compuestos semiconductores en película delgada que han sido considerados para aplicaciones fotovoltaicas son el teluro de cadmio (CdTe) y el cobre-Indio-Galio diselenio (CIGS). Las celdas solares elaboradas con estos compuestos presentan grandes expectativas de aplicación comercial ya que las eficiencias experimentales reportadas son del $21 \%$ en ambos casos. Las dos tecnologías están disponibles comercialmente aunque con eficiencias menores a las experimentales $(10.7 \%, 13.4 \%$, y $9 \%$, respectivamente) y satisfacen la combinación requerida de bajo costo y eficiencia de conversión aceptable. La Figura 3.5 muestra un par de fotografías de las tecnologías de CdTe y CIGS y las estructuras representativas de dichos dispositivos.

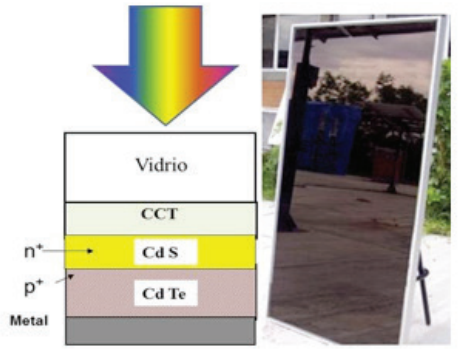

(a)
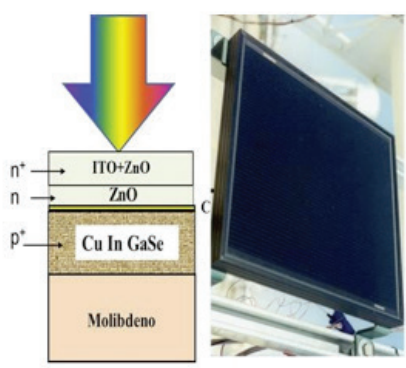

(b)

Figura 3.5: (a) parte superior, un corte transversal de la estructura de las celdas de CdTe, y a un lado, una fotografía de un módulo comercial de CdTe. (b) la parte de arriba, un corte transversal de la estructura de una celda solar de CulnGaSe ${ }_{2}$, mientras que a un lado, una fotografía para un módulo comercial de CulnGaSe ${ }_{2}$.

Por otra parte, se ha impulsado mucho la investigación y desarrollo tecnológico en celdas solares combinadas con el objeto de incrementar la eficiencia de conversión. Como ejemplo tenemos la celda solar HIT (Heterojunction with an Intrinsic Thin layer) desarrollada por SANYO con la que han logrado 
eficiencias experimentales del $22 \%$, mientras que en su línea de producción comercial han llegado al $20.2 \%$ de eficiencia (ver estructura en Figura 3.6-a). Aún más, esta compañía ha lanzado al mercado celdas bifaciales usando dicha tecnología para las que han alcanzado eficiencias hasta el $24.2 \%{ }^{11}$.

En el caso de mejoras en la tecnología de silicio monocrisytalino (m-Si), la aplicación de capas pasivadoras, superficies texturizadas en ambas caras de la oblea del m-Si y contactos traseros como los implementados por SunPower, han permitido alcanzar hasta el $23 \%$ de eficiencia en celdas de laboratorio (ver estructura en Figura 3.6-b). Y por el mismo camino, BP Solar con su celda "Saturno" la que utiliza contactos enterrados frontales y superficie texturizada, les han permitido alcanzar el $20.1 \%$ de eficiencia en celdas de laboratorio (ver estructura en Figura 3.6-c).
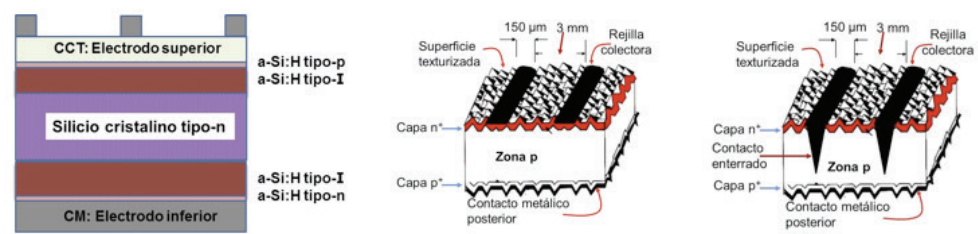

Figura 3.6: Mejoras realizadas a nivel laboratorio que han incrementado la eficiencia de conversión en celdas solares basadas en silicio cristalino.

Existen otra clase de celdas solares basadas en monocristales de compuestos semiconductores tales como arsenuro de galio (GaAs) o fosfuro de indio ( $\mathrm{InP})$, materiales cuya elaboración es muy cara pero que satisfacen los requerimientos de alta eficiencia y bajo peso (GaAs presenta el récord de más alta eficiencia 28.8\%), características que las hacen ideales para las aplicaciones espaciales. Para este tipo de aplicacio-

11 Datos provistos por el fabricante en: http://us.sanyo.com/industrial/solar. 
nes, donde se busca bajo peso y alta eficiencia, la relación costo/beneficio es pequeña.

También se ha impulsado líneas de investigación y desarrollo tecnológico en celdas fotoquímicas basadas en tintes sensitivos, como las desarrolladas por Sharp, entre otros laboratorios, para las cuales se ha logrado una eficiencia del $11.9 \%$ en área pequeña $\left(1.0 \mathrm{~cm}^{2}\right)$ y hasta $10.7 \%$ para un mini módulo de $26.5 \mathrm{~cm}^{2}$ de área. El programa Japonés ha considerado como meta para el 2030 llegar al $15 \%$ de eficiencia en áreas de $1 \mathrm{~cm}^{2}$, y en producto comercial al $8 \%$ para áreas de $900 \mathrm{~cm}^{2}$.

Por otra parte, las celdas solares basadas en Perovskitas como el cristal $\mathrm{CH}_{3} \mathrm{NH}_{3} \mathrm{PbI}_{3-\mathrm{x}} \mathrm{Cl}_{\mathrm{x}}$, como absorbedor, depositado sobre $\mathrm{TiO}_{2}$, han mostrado eficiencias del $19.7 \%$

Con respecto a materiales orgánicos como lo son los polímeros semiconductores, se han realizado notables esfuerzos de investigación que han permitido elaborar celdas solares con eficiencias alrededor de $11.2 \%$. Aunque muy modesta, las celdas solares orgánicas muestran un potencial de aplicación alto debido a los bajos costos del dispositivo.

Otra forma de incrementar el rendimiento de generación de potencia eléctrica en términos de un área de captación es por medio de la concentración de luz solar sobre el captador. El efecto neto de un sistema $F V$ con concentración solar (C-FV) se observa en la reducción del costo de la generación de electricidad producida y el aumento en la densidad de potencia. Esta característica hace muy atractivo el uso de concentradores solares (CS) sobre las celdas solares, unidad base de un sistema $F V$, para crear sistemas de generación de potencia eléctrica de mayor densidad energética y menor costo comparados con aquellos que no usan tales dispositivos. En consecuencia, el resultado de concentrar la luz en una celda solar es

12 S Dsas, B Yang, G Gu, PC Joshi et al; "high- performance flexible perovskite solar cells by using a combination of ultrasonic spray-coating and low thermal budget photonic curing"; CS Photonics, 2015, 2(6), pp 680-686 
reducir el costo de generación de potencia eléctrica. La Figura 3.7 muestra dos fotografías de la tecnología de sistemas de concentración de potencia con aplicación para interconexión con la red.

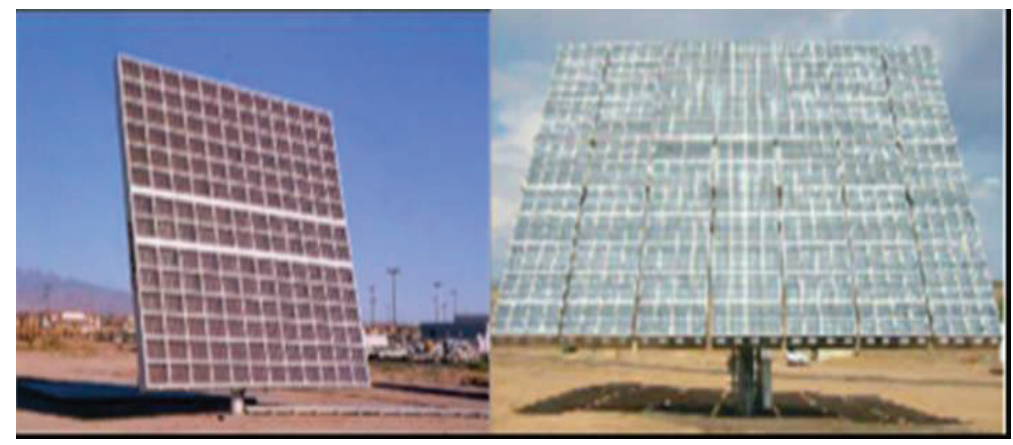

Figura 3.7: Fotografías de la tecnología C-FV. En la derecha se tiene la tecnología desarrollada por la compañía AMONIX.

Aunque el desarrollo de concentradores solares para aplicaciones fotovoltaicas inició con los trabajos realizados a fines de los años 70's en Sandia Nacional Lab, seguido después por muchos esfuerzos a nivel mundial, el Estado del Arte Actual de los sistemas $\mathrm{C}_{-} \mathrm{FV}^{13}$ incluye desarrollos en sistemas de concentración lineal y puntual, y una gama amplia de razones de concentración geométrica.

Sin considerar los logros en las eficiencias actuales para celdas solares de concentración, se puede afirmar que los sistemas C-FV son una tecnología en vías de madurar. Se han realizado muchas variantes a los sistemas y pocos experimentos que determinen la mejor alternativa o solución para la elección de un sistema C-FV. La industrialización de tales sistemas se está impulsando a través de varios esfuerzos académicos y gubernamentales. Sin embargo, el impacto comercial de los sistemas C-FV ha sido muy pobre comparado con los sistemas

13 G. Salas, D. Pachon, 1. Anton; "Test, rating and specifications of PV concentrator components and systems"; 2002 C-Rating project Book 1 NNE-1999-00588 
FV's convencionales. Hay varias razones para eso, pero la más importante, es que el costo fijo de un sistema C-FV es grande y solo se justifica en instalaciones arriba de cierta potencia, generalmente dada por análisis económico del balance energético. En consecuencia, el nicho de aplicación de los sistemas C-FV ha sido en sistemas de alta potencia conectados a la red convencional de energía eléctrica, mercado en el cual, los sistemas de concentración ya han estado penetrando ${ }^{14}$.

Para una actualización al 2016 de las eficiencias de celdas solares experimentales y de módulos fotovoltaicos, el lector puede referirse al artículo de Martin Green y colaboradores: Martin A. Green, Keith Emery, Yoshihiro Hishikawa, Wilhelm Warta and Ewan D. Dunlop; "Solar Cell Efficiency Tables (version 48)"; Prog. Photovolt: Res. Appl. 2016; 24:905-913

\subsection{Principios de la conversión fotovoltaica}

La materia está constituida por átomos, los cuales a su vez están formados por dos partes bien diferenciadas: el núcleo, dotado de una carga eléctrica positiva y los electrones, con carga eléctrica negativa que compensa la del núcleo, formando de esta manera un conjunto eléctricamente neutro. Los electrones más externos se conocen como electrones de valencia. Por su estado, los materiales se clasifican en sólidos, líquidos y gases; y con respecto a sus propiedades eléctricas, hay conductores, aislantes y semiconductores.

Los semiconductores son utilizados en la fabricación de las celdas solares porque la energía que liga a los electrones de valencia al núcleo es similar a la energía que poseen los fotones que constituyen a la luz solar. Por lo tanto, cuando la luz solar incide sobre el semiconductor (usualmente silicio), sus fotones suministran la cantidad de energía necesaria

14 Compañías que fabrican sistemas FV's de concentración se encuentra en: http:/ peswik1.com/index.php/Directory:Concentrated_Solar_Power 
a los electrones de valencia para que se rompan los enlaces y queden libres para circular por el material. Por cada electrón que se libera (carga negativa), aparece un hueco (ausencia de carga negativa), los que se comportan como partículas con carga positiva (+). Cuando en el semiconductor se generan pares electrón-hueco debido a la absorción de la luz, se dice que hay una fotogeneración de portadores de carga negativos y positivos, los que contribuyen a disminuir la resistencia eléctrica del material. Este es el principio básico de operación de las fotoresistencias.

Por otra parte, mediante la ingeniería de materiales se pueden introducir átomos ajenos a un semiconductor, los que son conocidos como impurezas. Dentro de éstas, hay aquellas que al enlazarse a los átomos nativos, ceden electrones "libres" al material, cambiando el estado neutral de carga hacia un comportamiento negativo, por lo que son conocidos como semiconductores tipo-N. Hay otras impurezas atómicas que al enlazarse con los átomos nativos dejan enlaces incompletos o "huecos", creándose una carga aparente positiva debido a una ausencia de electrones, apareciendo un comportamiento positivo, por lo que son conocidos como semiconductores tipo-P. Con semiconductores tipo-N y tipo-P se forman las celdas solares.

En la Figura 3.8, se muestra una estructura simple de una celda solar en donde se ilustra el principio básico de la conversión fotovoltaica.

La celda solar consiste en una unión de dos capas de materiales semiconductores uno tipo p y el otro tipo n con contactos eléctricos en la parte superior y en la inferior. El espesor de éste sándwich puede variar, desde menos de una micra para el caso de semiconductores muy absorbentes (caso del silicio amorfo, CdTe, CIGS), hasta unos cientos de micra para el caso de semiconductores de baja absorción (caso del silicio cristalino). La unión entre las capas n (lado negativo) y p (lado posi- 
tivo) es la responsable de que se forme un campo eléctrico interno Ei que radica principalmente en la unión.

Cuando la energía de los fotones, hn (radiación luminosa) es absorbida por los semiconductores se generan, en exceso de su concentración en equilibrio, pares de portadores de carga eléctrica, electrones y huecos, los cuales deben de ser separados para poder usar la energía que cada uno representa. Estos portadores fotogenerados viajan bajo un gradiente de concentración hacia la unión en donde son separados por efecto del campo eléctrico El. Esta separación envía electrones fotogenerados a la capa n y huecos fotogenerados a la capa p, creándose una diferencia de potencial entre las superficies superior e inferior de las capas (ver Figura 3.8).

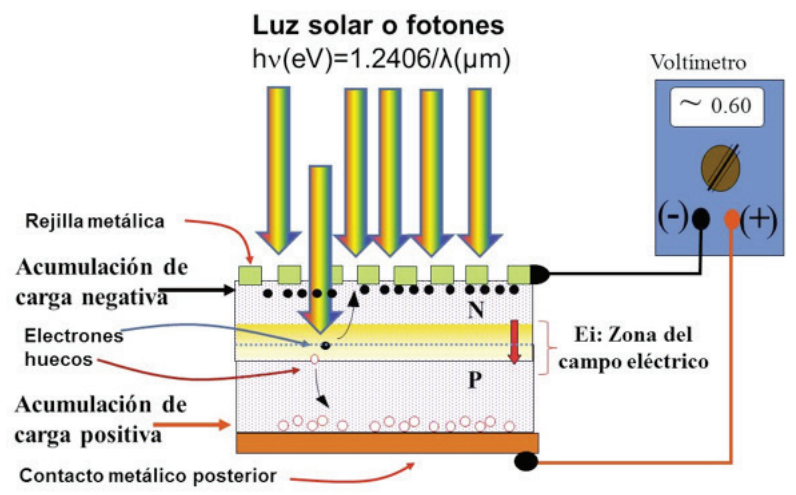

Figura 3.8: Representación esquemática de una celda solar y del efecto fotovoltaico.

La acumulación de cargas en las superficies del dispositivo da como resultado un voltaje eléctrico medible externamente. La unidad de medición es el Volt. Este voltaje fotogenerado es lo que se conoce como el Efecto Fotovoltaico (FV). Si se establece un circuito eléctrico externo entre las dos superficies, los electrones acumulados fluirán a través de él regresando a su posición inicial. Este flujo de electrones forma lo que se llama la corriente fotogenerada o fotovoltaica. 
Bajo condiciones de circuito abierto, el Efecto FV genera una diferencia de potencial $\mathrm{V}_{\mathrm{CA}}$ entre la parte superior y la inferior de la estructura. Bajo condiciones de corto circuito, el proceso genera una corriente eléctrica $\mathrm{I}_{\mathrm{CC}}$ que va de la parte positiva a la negativa (dirección convencional para la corriente eléctrica).

\subsection{La celda solar de silicio cristalino}

Las celdas solares comerciales se fabrican con lingotes de silicio de alta pureza (material muy abundante en la arena). El lingote es rebanado en forma de placas delgadas llamadas obleas. El espesor típico usado es del orden de $300 \mathrm{~nm}(0.3$ $\mu \mathrm{m})$. Una fracción muy pequeña de tal espesor (del orden de $0.5 \mu \mathrm{m})$ es impregnado con átomos de fósforo para formar la capa tipo-N. El resto de la oblea es impregnado con átomos de boro para formar la capa tipo-P. Estas capas unidas forman el campo eléctrico (voltaje interno construido) que se necesita para la separación de los portadores que se fotogenerarán. Dada la diferencia de espesores de las capas, el campo eléctrico ínter construido, Ei, dentro de la oblea aparece cerca de la superficie que recibe la luz del sol.

La celda cuenta con dos terminales que se conectan a un circuito externo para extraer la corriente eléctrica producida. La cara de la oblea expuesta a la luz, capa N, posee un enrejado metálico muy fino (titanio/paladio/plata), cubriendo del 5 al $10 \%$ de área de la oblea y cuya función es colectar los electrones fotogenerados. Esta capa corresponde a la terminal negativa. Sobre este enrejado está conectado uno de los conductores del circuito exterior. La otra cara es recubierta totalmente con una capa metálica, usualmente de aluminio. Esta corresponde a la terminal positiva ya que en ella se acumulan las cargas positivas. Sobre esta capa está conectado el otro conductor del circuito exterior. 
Para disminuir las pérdidas por reflexión la cara de la celda expuesta a la luz se recubre con una capa antirreflectora, usualmente óxido de talio o de titanio, la que también sirve como una capa anticorrosiva; o bien, se texturiza. El tipo de compuesto usado como capa antirreflectora y el tratamiento superficial sobre la capa n son los que contribuyen a definir el color característico de las celdas solares, visto por reflexión (ver Figura 3.9).

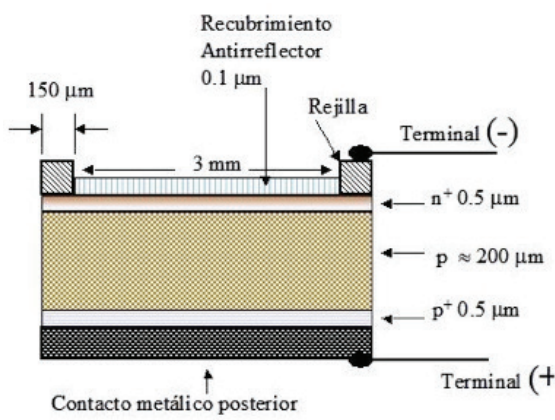

(a)

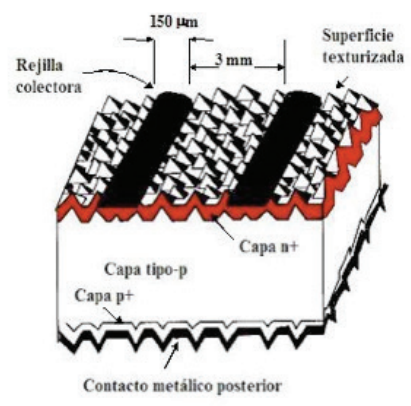

(b)

Figura 3.9: Celda solar comercial de silicio cristalino. (a) diagrama esquemático de la estructura. (b) un corte transversal de la celda solar mostrando la texturización de la capa frontal. Esta celda tiene una apariencia negra bajo luz normal debido a que casi no refleja la luz solar.

\subsection{Parámetros eléctricos de una celda solar}

Una celda solar expuesta a la luz genera electricidad; es decir, en las terminales eléctricas externas del dispositivo aparece un voltaje que puede ser medido con un voltímetro. Si a las terminales de salida se conecta una resistencia $\mathrm{R}_{\mathrm{L}}$ simulando una carga, entonces por el circuito circulará una corriente eléctrica limitada por la Ley de Ohm.

Para conocer el comportamiento eléctrico de la celda solar en la obscuridad y bajo iluminación, consideremos el circuito eléctrico mostrado en la Figura 3.10 y Figura 3.11. 
La Figura 3.10 muestra tanto el dispositivo experimental para determinar las características eléctricas de la celda solar bajo oscuridad, el comportamiento de la corriente que circula por la celda cuando se le aplica, a las terminales de la celda, un voltaje de polarización directa e inversa (típico desde -1.0 hasta +1.0 Volt) y el circuito eléctrico equivalente. Para cada voltaje aplicado en ese rango, se mide la caída de tensión $\mathrm{V}$ en las terminales de la celda y al mismo tiempo, la corriente I que circula por el circuito. Estas medidas se hacen usando el amperímetro y el voltímetro mostrados en la figura.

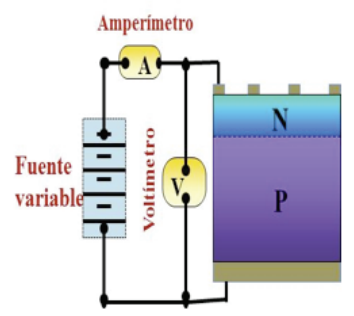

(a)

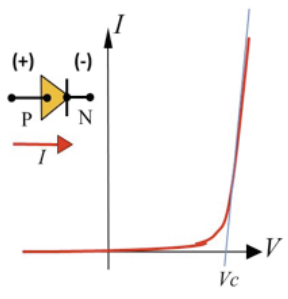

(b)

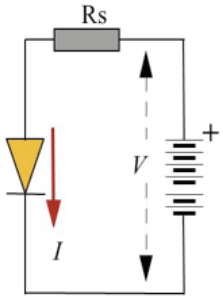

(c)

Figura 3.10: (a) Dispositivo experimental; (b) Curva I vs V de la celda solar en oscuridad; (c) Circuito equivalente.

El comportamiento I vs V de la celda solar en oscuridad, mostrado en la Figura 3.10(b) corresponde al de una unión rectificadora p/n llamada comúnmente Diodo. En dicha figura se muestra el símbolo común que representa a un diodo en un diagrama eléctrico. Tomado esto en consideración, la Figura 3.10(c) muestra el circuito eléctrico equivalente del dispositivo experimental. De éste se tiene que la Ecuación que describe el comportamiento I vs $\mathrm{V}$ puede ser establecida como: 


$$
\left.I=I_{0} \operatorname{Exp}\left[q\left(V-I \mathrm{R}_{\mathrm{S}}\right) / A \mathrm{KT}\right)-1\right]
$$

$\mathrm{O}$ bien, definiendo la densidad de Ec. 3.2 corriente $J$ como la razón de la corriente entre el área de la sección transversal total con superficie $S_{T}$, se tiene,

$$
\left.J=J_{0} \operatorname{Exp}\left[q\left(V-J S_{T} \mathrm{R}_{\mathrm{S}}\right) / A \mathrm{KT}\right)-1\right]
$$

En la ecuación anterior, $I_{0}$ es la corriente inversa de saturación $\left(J_{0}\right.$ propiedad intrínseca de la unión $\left.\mathbf{p} / \mathbf{n}\right), \boldsymbol{q}$ la carga elemental del electrón $\left(q=1.6 \times 10^{-19} \mathrm{C}\right), \mathrm{R}_{\mathrm{S}}$ la resistencia intrínseca de la unión $\mathbf{p} / \mathbf{n}, \boldsymbol{A}$ una constante que proporciona información de la calidad de la unión, $\mathrm{K}$ la constante de Boltzman $\left(\mathrm{K}=1.38 \times 10^{-23} \mathrm{~J} / \mathrm{K}\right)$ y $\mathrm{T}$ la temperatura absoluta $(\mathrm{K})$. Para el caso de una unión $\mathbf{p} / \mathbf{n}$ ideal se tiene que $\mathrm{R}_{\mathrm{S}}=0$ y $A=1$.

Cuando a la celda solar se le somete a una iluminación constante, generalmente se le aplican las condiciones $S T C$, manteniendo el mismo dispositivo experimental, se observa que la curva $I$ vs $V$ que describe el comportamiento de la corriente $I$ circulando por el circuito, cae al cuarto cuadrante del plano cartesiano $I-V$, cortando a los Ejes Voltaje y Corriente en un punto, respectivamente. Dichas intersecciones crean una "área" entre los ejes $I$ y $V$ y la curva $I v s ~ V$. Esta "área" es potencia eléctrica. La Figura III-11 muestra el dispositivo experimental de la celda solar bajo iluminación, el comportamiento eléctrico de la corriente $I$ cuando se le aplica un voltaje de polarización a las terminales de la celda, y el circuito equivalente.

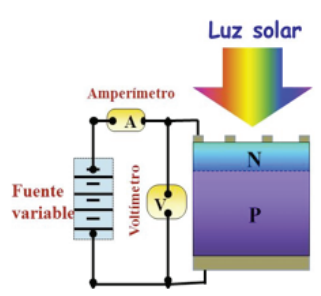

(a)

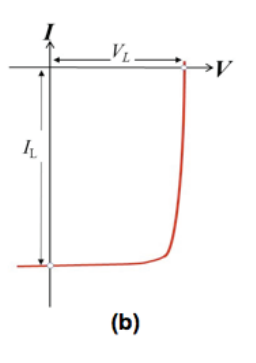

(b)

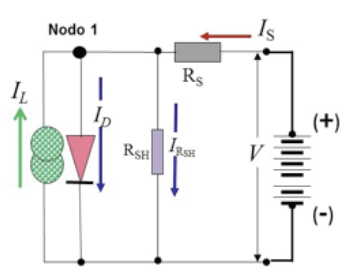

(c) 
Figura 3.11: (a) Dispositivo experimental para medir el comportamiento $I$ $\boldsymbol{v} \boldsymbol{V}$ de una celda solar bajo iluminación; (b) Comportamiento $\boldsymbol{I} \boldsymbol{v} \boldsymbol{V} \boldsymbol{V}$ bajo iluminación; (c) Circuito equivalente

La profundidad a la cual baja la curva define un punto de intersección con el eje vertical que corresponde exclusivamente a la corriente que genera la celda solar bajo iluminación o corriente fotogenerada, la cual se ha simbolizado por $I_{L}$. En todas las celdas solares, no importa de qué materiales este hecha, la magnitud de la corriente de iluminación es directamente proporcional a la magnitud de la irradiancia $G$ o potencia de la radiación solar.

Considerando el circuito equivalente y analizando las corrientes que inciden en el Nodo 1 , se tiene que el comportamiento de la corriente de salida $I_{S}$ se puede expresar como:

$$
\begin{array}{l|l}
I_{S}=I_{D}-I_{L}+I_{\mathrm{RSH}} & \text { Ec. } 3.2 \\
\text { donde } \left.\quad I_{D}=I_{0} \operatorname{Exp}\left[q\left(V-I_{S} \mathrm{R}_{\mathrm{S}}\right) / A \mathrm{KT}\right)-1\right] ; & \\
I_{\mathrm{RSH}}=\left(V+I_{S} \mathrm{R}_{\mathrm{S}}\right) / \mathrm{R}_{\mathrm{SH}} &
\end{array}
$$

O bien, definiendo la densidad de corriente $J$ como la razón de la corriente a la superficie total activa $S_{\mathrm{T}}$ de la celda, se tiene:

$$
\begin{array}{l|l}
J_{S}=J_{D}-J_{L}+J_{\mathrm{RSH}} & \text { Ec. } 3.3 \\
\text { donde } \left.J_{D}=J_{0} \operatorname{Exp}\left[q\left(V-J_{S} \mathrm{R}_{\mathrm{S}} S_{\mathrm{T}}\right) / A \mathrm{KT}\right)-1\right] ; & \\
J_{\mathrm{RSH}}=\left(V+J_{S} \mathrm{R}_{\mathrm{S}}\right) / \mathrm{R}_{\mathrm{SH}} &
\end{array}
$$

Los parámetros eléctricos de una celda solar bajo iluminación definidos en la Sección 3.2 se establecen de la siguiente manera:

a) Condiciones de Circuito Abierto. Las terminales de la celda NO están conectadas ni a la Fuente Variable ni tampoco a alguna resistencia externa. NO hay flujo de corriente al exterior, por lo cual $I_{S}=0\left(J_{S}=0\right)$; en consecuencia, de la Ec. 3.2 (Ec. 3.3), la tensión eléctrica que aparece en las terminales de la celda será $V_{L}$, es decir, 
la Tensión o Voltaje a Circuito Abierto $V_{C A}$, y está dada por:

$$
V_{C A}=(A \mathrm{KT} / \mathrm{q}) \operatorname{Ln}\left[\left(J_{L}+J_{O}\right) / J_{O}\right]
$$

El Voltaje a Circuito Abierto, $V C A$, es el máximo voltaje que genera la celda bajo las condiciones de medición, y su valor depende, además de la temperatura, de la función logaritmo de las magnitudes de $J L$ y $J O(I L$ e $I 0)$ según la Ec. 3.3.

b) Condiciones de Corto Circuito.- Las terminales de la celda se corto circuitan, en consecuencia el voltaje de salida es cero $(V=0), \mathrm{R}_{\mathrm{S}}$ es despreciable, el diodo no está polarizado, y en consecuencia, la corriente de corto circuito $I_{C C}$ será la corriente de iluminación $I_{L}$; por lo cual,

$$
I_{C C}=I_{L}=\boldsymbol{b} G
$$

o bien, en términos de la densidad de corriente

$$
J_{C C}=J_{L}=\boldsymbol{B} G
$$

c) donde " $\boldsymbol{b}$ " (" $\boldsymbol{B}$ ") es una constante de proporcionalidad que proporciona la linearidad con la magnitud de $\boldsymbol{G}$.

d) La Corriente de Corto Circuito o Corriente de iluminación, $I_{C C}$, es la máxima corriente que genera la celda bajo las condiciones de medición

e) Máxima Potencia de Generación.- La curva mostrada en la Figura 3.11(a) está formada por un conjunto de puntos de la forma ( $\mathrm{Vi}$, Ii), cuyo producto proporciona la Potencia Generada $P i$ en dicha combinación, es decir, $P i=V i x 2$. La Figura 3.12(a) proporciona la gráfica $P v s$ $V$ que muestra la curva característica del comportamiento de la Potencia Generada $P$ contra el Voltaje de salida $V$. Dicha curva muestra que hay un punto $(V, P)$ para el cual, la potencia es máxima, es decir, hay uno y solo un valor de $V$, simbolizado en este caso como $V_{M P}$ para 


$$
\mathrm{FF}=I_{M P} V_{M P} / I_{C C} V_{C A}
$$

El valor máximo para el FF es la unidad. Celdas solares de alta eficiencia tienen un factor de forma máximo de 0.85 . Celdas de baja eficiencia tienen valores menores de 0.5 .

La forma geométrica de la curva $I v s V$ de la celda solar mostrada en la Figura 3.12(b) sugiere que, en el caso ideal con $\mathrm{FF}=1$, la celda solar se comporta como una fuente de voltaje a corriente constante (comportamiento a la izquierda del punto $\mathrm{P}_{\mathrm{MP}}$, y como una fuente de corriente a voltaje constante. Y como todo generador de potencia eléctrica tendrá asociada una resistencia interna. Ya que la resistencia interna de una fuente de corriente se representa por una resistencia en paralelo $\left(\mathrm{R}_{\mathrm{SH}}\right)$, y el de una fuente de voltaje con una resistencia en serie $\left(R_{S}\right)$, el circuito eléctrico de una celda solar real es el que se presenta en la Figura 3.13.

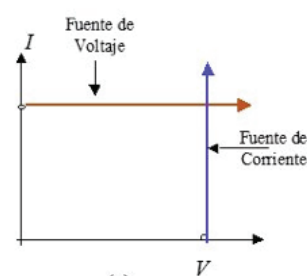

(a)

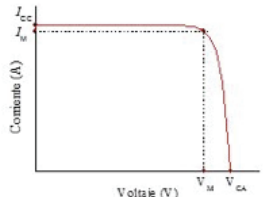

(b)

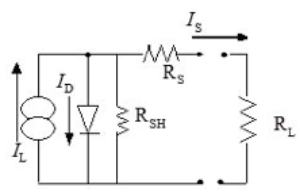

(c)

Figura 3.13: Curvas $\boldsymbol{I}$ vs $\boldsymbol{V}$ para fuentes de fuerza electromotriz. En (a) se muestra las correspondientes a las fuentes de corriente y voltaje constante; en (b) la de una celda solar; y en (c) el circuito equivalente de una celda solar.

En la Figura 3.13(a) se muestra la combinación de una fuente de corriente y de voltaje, en la Figura 3.13(b) la curva $I$ vs $V$ de la celda solar, y en la Figura 3.13(c) se muestra el circuito equivalente de la celda solar.

Así, bajo condiciones de iluminación, la celda solar se comporta como un generador de potencia, mientras que, durante la noche, se comportará como un recibidor de poten- 
cia, estando representado por el símbolo del diodo rectificador de corriente.

\subsection{Efecto de la irradiancia, superficie de captación, temperatura y sombreado}

Con el objeto de que los fabricantes de celdas solares reporten las características eléctricas de sus productos de una manera estandarizada, especialmente la eficiencia de conversión, se ha convenido en usar, como parámetros de caracterización fotovoltaica los valores que corresponden a las Condiciones Estándares de Prueba ó Medición (STC por sus siglas en inglés: Standard Test Conditions): Luz solar con una intensidad de $1000 \mathrm{~W} / \mathrm{m}^{2}\left(100 \mathrm{~mW} / \mathrm{cm}^{2}\right)$ con un espectro correspondiente a una masa de aire AM1.5, incidiendo normalmente sobre la celda, y manteniendo a ésta a una temperatura de celda de $25^{\circ} \mathrm{C}$.

\section{7.a. El efecto de la intensidad luminosa.}

En todas las celdas solares la corriente fotogenerada $I_{L}$ es proporcional a la irradiancia $G$ y bajo condiciones de corto circuito, ésta corriente se le ha llamado corriente de corto circuito (Ec. 3.5). La Figura 3.14 muestra una simulación del comportamiento típico de la curva I vs V para diferentes valores de la irradiancia $G$. Para trazarla se consideró que la temperatura de la unión es de $25^{\circ} \mathrm{C}$ y que la celda presenta las características siguientes: Densidad de corriente bajo iluminación $J_{\mathrm{L}}=44 \mathrm{~mA} / \mathrm{cm}^{2}$; área efectiva de la celda $S_{\mathrm{E}}=100 \mathrm{~cm}^{2}$, y valores de irradiancia comprendidos entre $200 \mathrm{~W} / \mathrm{m}^{2}$ hasta $1200 \mathrm{~W} / \mathrm{m}^{2}$.

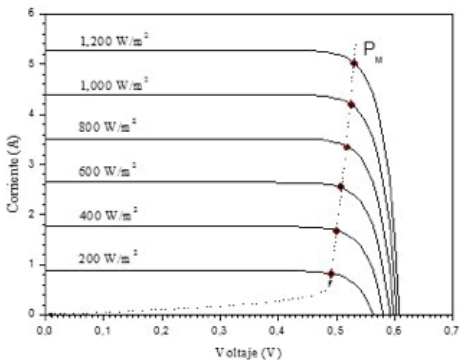

(a)

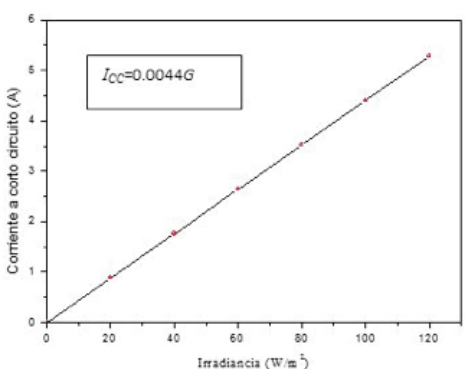

(b) 
Figura 3.14: Efecto de la irradiancia sobre las características eléctricas $\boldsymbol{I} \boldsymbol{v} \boldsymbol{V}$. En (a) se muestra la forma de las curvas; y en (b) el comportamiento lineal de $I_{C C}$ con G.

Como se puede observar en la Figura 3.14(a), el valor de $I_{L}$ o corriente de corto circuito $\left(I_{C C}\right)$, disminuye gradualmente en la misma proporción que lo hace la irradiancia $G$. Dicha característica entre ambas cantidades se muestra en la Figura 3.14(b), donde la constante de proporcionalidad $\boldsymbol{b}$ (Ec. 3.5) vale $0.0044 \mathrm{Am}^{2} / \mathrm{W}$.

En la Figura 3.14(a) se observa que el voltaje a circuito abierto, $V_{C A}$, decrece ligeramente al decrecer la irradiancia. Esto es debido a que si $G$ decrece, $I_{L}\left(J_{L}\right)$ también decrece, y dado que $V_{C A}$ depende proporcionalmente del factor $\operatorname{Ln}\left(1+J_{L} /\right.$ $\left.J_{0}\right)$, según se establece en la Ec. 3.4, al decrecer $J_{L}$, decrece el valor de la función logarítmica y en consecuencia la magnitud para el valor de dicho voltaje (ver Figura 3.14a).

Este mismo efecto se observa en el voltaje para el punto de máxima potencia $\left(P_{M P}\right)$. El voltaje que define $P_{M P}$ para cada curva, en ésta simulación, varía en un rango desde $0.48 \mathrm{~V}$ para una $G=200 \mathrm{~W} / \mathrm{m}^{2}$, hasta $0.53 \mathrm{~V}$ para $G=1200 \mathrm{~W} / \mathrm{m}^{2}$, es decir, del orden de $0.05 \mathrm{~V}$ que es solamente un $10 \%$ del $V_{M P}$ obtenido para $G=1000 \mathrm{~W} / \mathrm{m}^{2}$.

El comportamiento lineal de la corriente fotogenerada (o corriente a corto circuito) con la irradiancia, hacen de las celdas solares dispositivos aceptables para medir la intensidad de la luz.

Por otra parte, la eficiencia de la celda puede considerarse "constante" con los cambios en el valor de la irradiancia ya que ha sido definida como el cociente de la potencia de salida entre la potencia de la radiación luminosa. Para fines prácticos se puede establecer que la eficiencia de la celda no cambia al variar la irradiancia.

\section{7.b. Efecto de la superficie de captación}


Dado que a mayor área de captación mayor es la potencia luminosa recibida, entonces bajo condiciones de irradiancia constante y temperatura de la celda constante, el valor de la corriente fotogenerada $\left(I_{\mathrm{L}}\right)$ y de la Potencia Máxima $\left(\mathrm{P}_{\mathrm{MP}}\right)$, de una celda solar dependerá del tamaño de su área o superficie total activa, $S_{T}$. Esto queda implícito debido a los conceptos de densidad de corriente $J=I / S$ y densidad de potencia luminosa (irradiancia: $G=\mathrm{Psol} /$ Scaptador).

Ya que se tiene una relación directamente proporcional entre $I_{\mathrm{L}}$ y el área $S_{T}$; una celda solar de $50 \mathrm{~cm}^{2}$, generará la mitad de la corriente que aquella celda que tiene $100 \mathrm{~cm}^{2}$ de área. Sin embargo, independientemente del tamaño, para celdas solares del mismo material y lote de fabricación, es de esperarse que el $V_{C A}\left(\mathrm{y}\right.$ el $\left.V_{\mathrm{MP}}\right)$, no dependan del área o superficie de la celda ya que esa es una característica propia de la unión p/n. La Figura 3.15 muestra una tabla de valores para los parámetros eléctricos de una celda típica de silicio policristalino con diferentes superficies $S$, así como una fotografía de cada una de ellas.

\section{CARACTERÍSTICAS}

Valores típicos a $1 \mathrm{~kW} / \mathrm{m}^{2}$ y $25^{\circ} \mathrm{C}$

\begin{tabular}{|c|c|c|c|c|c|}
\hline & & & Celda & $\begin{array}{c}1 / 2 \\
\text { Celda }\end{array}$ & $\begin{array}{c}1 / 4 \\
\text { Celda }\end{array}$ \\
\hline $\begin{array}{c}\text { Voltaje a } \\
\text { cto. abierto }\end{array}$ & $V_{\mathrm{CA}}$ & (V) & 0.6 & 0.6 & 0.6 \\
\hline $\begin{array}{c}\text { Corriente de } \\
\text { corto cto }\end{array}$ & $I_{\propto}$ & (A) & 2.9 & 1.45 & 0.72 \\
\hline $\begin{array}{c}\text { Pot. máx. } \\
( \pm 10 \%)\end{array}$ & $\mathrm{P}_{\mathrm{M}}$ & (W) & 1.35 & 0.60 & 0.3 \\
\hline $\begin{array}{c}\text { Voltaje a } \\
\text { Pot. máx. }\end{array}$ & $V_{\mathrm{M}}$ & (V) & 0.47 & 0.47 & 0.47 \\
\hline $\begin{array}{c}\text { Corriente } \\
\text { a Pot. máx. }\end{array}$ & $I_{\mathrm{M}}$ & (A) & 2.6 & 1.3 & 0.65 \\
\hline Peso & & (g) & 6 & 3 & 1.5 \\
\hline
\end{tabular}

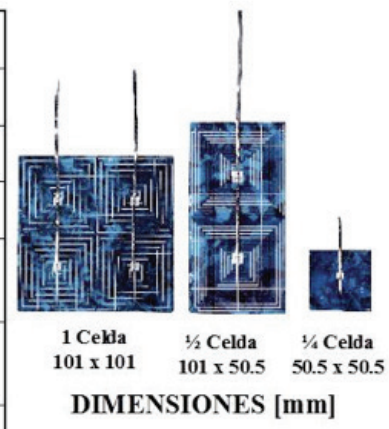

Figura 3.15: Efecto del tamaño de la celda sobre las características eléctricas.

\section{7.c. Efecto de la temperatura}


Las celdas solares al estar expuestas al Sol se calientan como cualquier captador solar. Este aumento en la temperatura afecta las características eléctricas de ellas. La Figura 3.16 muestra el comportamiento simulado de los parámetros eléctricos de una celda solar ideal de silicio cristalino en función de la temperatura de la celda, Tc. Se observa que $I_{C C}$ aumenta ligeramente mientras que el $V_{C A}$ está disminuyendo en una razón muy grande. Este fenómeno es más pronunciado en unas celdas, como es el caso del silicio, que en otras, como es el caso de las celdas basadas en telurio de cadmio o de arseniuro de galio (GaAs).

Para celdas de silicio cristalino el coeficiente de temperatura para $I_{C C}$, dado como el cambio en su valor respecto de un cambio en $\mathrm{T},\left(\mathrm{d} I_{\mathrm{CC}} / \mathrm{dT}\right)$, tiene un valor aproximado de $10-30 \mu \mathrm{A} / \mathrm{cm}^{2}$; mientras que, el coeficiente de temperatura para el $V_{\mathrm{CA}}$, definido como $\mathrm{dV}_{\mathrm{CA}} / \mathrm{dT}$ tiene valores entre 2.0 hasta $2.3 \mathrm{mV} /{ }^{\circ} \mathrm{C}$.

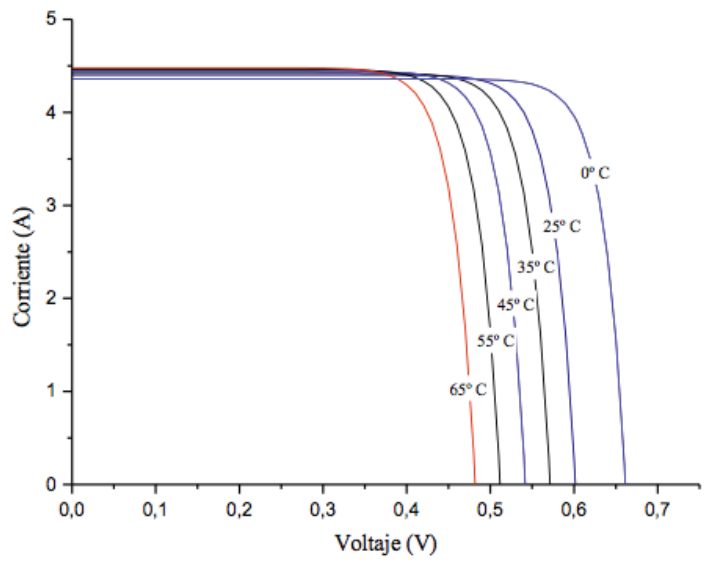

Figura 3.16: Efecto de la temperatura sobre los parámetros eléctricos de la celda solar.

La ligera ganancia en $I_{\mathrm{CC}}$ y la disminución en $V_{\mathrm{CA}}$ cuando la temperatura de la celda aumenta, trae como consecuencia que sus efectos se vean reflejados tanto en la potencia gene- 
rada por la celda como en su eficiencia. En la Tabla 3.2 se muestran los valores de los coeficientes de temperatura para el $V_{\mathrm{CA}}, I_{\mathrm{CC}}$, potencia y eficiencia para el caso de una celda de silicio cristalino.

Tabla 3.2: Coeficientes de temperatura para silicio cristalino

\begin{tabular}{|c|c|c|c|}
\hline Parámetro & Símbolo & Efecto & Valor \\
\hline $\begin{array}{c}\text { Corriente } \mathrm{a} \\
\text { corto circuito }\end{array}$ & $\mathrm{d} l_{\mathrm{cC}} / \mathrm{dT}$ & Aumenta & $10 \mathrm{a} 30\left(\mu \mathrm{A} / \mathrm{cm}^{2}\right)$ por $\cong \mathrm{C}$ \\
\hline $\begin{array}{c}\text { Voltaje a } \\
\text { circuito } \\
\text { abierto }\end{array}$ & $\mathrm{d} V_{\mathrm{CA}} / \mathrm{dT}$ & Disminuye & $2.0 \mathrm{a} 2.4 \mathrm{mV}$ por $\cong \mathrm{C}$ \\
\hline Potencia & $\mathrm{dP} / \mathrm{dT}$ & Disminuye & $\sim 0.4 \%$ por $\cong \mathrm{C}$ \\
\hline Eficiencia & $\mathrm{d} \eta / \mathrm{dT}$ & Disminuye & $\sim 0.4 \%$ por $\cong \mathrm{C}$ \\
\hline
\end{tabular}

La Figura 3.17 muestra fotografías de las diferentes tecnologías comerciales para aplicaciones terrestres así como las características eléctricas de las mejores celdas experimentales. Los valores indicados fueron obtenidos del artículo Ref: Martin A Green, Keith Emery et al.: "Solar cells efficiency tables (version 39)", Prog. Photovolt: Res. Appl. 2012; 20 : $12-20 .{ }^{15}$
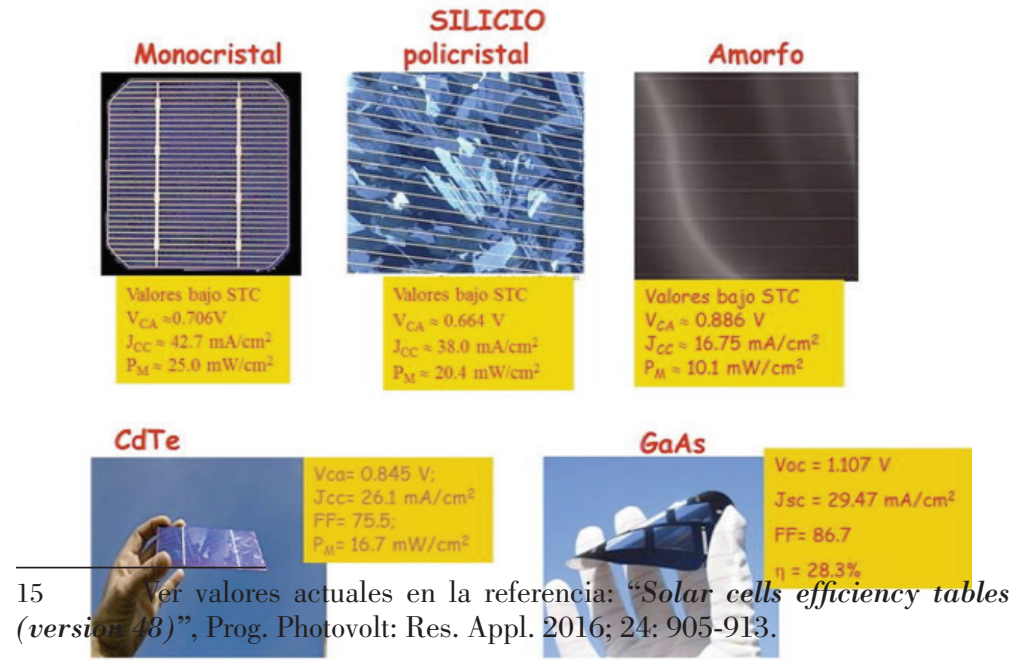
Figura 3.17: Características eléctricas de las mejores celdas experimentales.

\section{7.d.- Efecto del sombreado sobre una celda solar}

Dado que a menor área de captación menor es la potencia luminosa recibida, entonces bajo condiciones de irradiancia constante y temperatura de celda constante, una celda con parte de su superficie sombreada, no proporcionará la misma potencia que cuando está sin sombrear.

Para analizar este fenómeno supóngase que se tiene una celda solar de superficie unitaria, independientemente de cual sea su tamaño, y que ésta pueda considerarse como la integración de fracciones de celdas de área pequeña (superficie de tamaño X) conectadas en paralelo (fracciones de superficie de la celda unitaria tan pequeña como se desee o tan grande como se requiera). Cada fracción de la celda unitaria generará una potencia equivalente a su fracción del área total según se ha establecido en la Sección 3.7-b.

Cuando una fracción determinada $\mathrm{X}$ de la celda unitaria se sombrea, ésta deja de generar potencia eléctrica y se convierte en una resistencia de carga, la cual por la Ley de Ohm, va a consumir una fracción de la potencia generada.

La fracción sombreada $X$ de la celda dejará de generar corriente eléctrica $\left(I_{L}\right)$ de manera proporcional al área de la sombra ya que la densidad de corriente, propiedad intrínseca de la celda, está dada como $J=I / S$. Así que el valor de la corriente fotogenerada $\left(I_{L}\right)$ dependerá del tamaño del área o superficie sin sombrear. Si se define como superficie activa $S$ la diferencia entre la superficie total unitaria $\left(S_{T}=1\right)$ y la superficie sombreada $\left(S_{D}=\mathrm{X}\right)$; es decir, $S=S_{T}-S_{D}$, o bien $S=1-\mathrm{X}$, entonces:

- Caso de la Densidad de Corriente de corto circuito $J_{C C}$ o corriente fotogenerada $I_{L^{-}}$Como se debe de satisfacer la Ec. 3.5, entonces se ha determinado que existe una relación directamente proporcional entre $I_{L}$ y la superficie 
activa $S$ de la celda solar sin sombrear. Ya que $S=1-X$, entonces

Si $J_{C C}=J_{L}=C G$ y $J_{L}=I_{L} / S$, entonces
\begin{tabular}{rl|l}
$I_{L}=$ & $\boldsymbol{b} \boldsymbol{G} \boldsymbol{S}=\boldsymbol{b} \boldsymbol{G}\left(S_{T}-S_{D}\right) ;$ & Ec. 3.7 \\
& $\boldsymbol{o}$ bien \\
$I_{L}=\boldsymbol{b} \boldsymbol{G}(1-\mathrm{X})$ &
\end{tabular}

donde $\boldsymbol{b}$ es una constante particular de la celda la que está asociada a la geometría de ésta y a la distribución de la rejilla metálica de colección.

La Ecuación anterior establece que si X es la magnitud de la superficie sombreada de una celda solar de superficie total activa unitaria $\left(S_{T}=1\right)$, entonces la corriente fotogenerada $I_{L}$ o de corto circuito $I_{C C}$ disminuye proporcionalmente al valor de la magnitud de la superficie sombreada X.

- Caso del Voltaje a Circuito abierto $V_{C A}$. Considérese que la celda unitaria $S_{T}$ se divide hipotéticamente en dos secciones: una con sección $S_{D}$ de superficie X y otra con sección $S$ con superficie igual a la diferencia de la celda unitaria menos $S_{D}$, es decir, con superficie $S_{T}-S_{D}=1-\mathrm{X}$; y que ambas secciones estén conectadas en paralelo. Ambas secciones son de hecho, celdas solares con diferentes áreas que, al estar conectadas en paralelo, bajo condiciones de iluminación y temperatura de celda constantes, ambas generan la misma tensión eléctrica a circuito abierto. Un diagrama esquemático de tal situación se muestra en la Figura 3.18
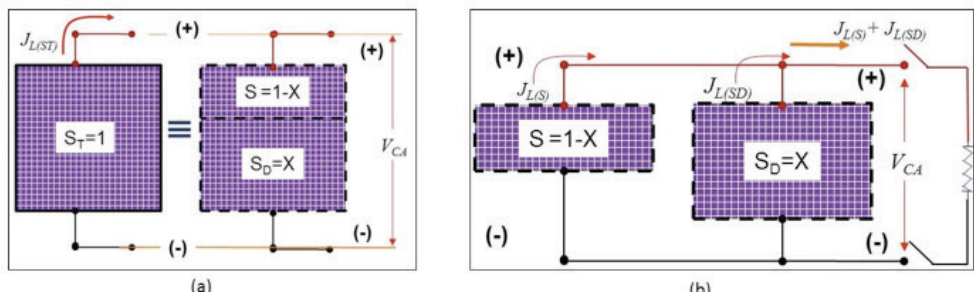
Figura 3.18: Representación esquemática de la partición de la celda solar unitaria en dos secciones: Una sección $S_{D}$ con superficie $X$, y la otra sección $\mathrm{S}$ con superficie (1-X).

De la Ec. 3.4 se tiene:

$V_{C A}\left(S_{T}\right)=(A \mathrm{KT} / \mathrm{q}) \operatorname{Ln}\left[\left(1+\left(J_{L(S T)} / J_{O(S T)}\right)\right]\right.$ para la celda unitaria $S_{T}$

$V_{C A}(S)=(A \mathrm{KT} / \mathrm{q}) \operatorname{Ln}\left[\left(1+\quad\left(J_{L(S)} / J_{O(S)}\right)\right]\right.$ para la celda de sección $S$.

$V_{C A}\left(S_{D}\right)=(A \mathrm{KT} / \mathrm{q}) \operatorname{Ln}\left[\left(1+\left(J_{L(S D)} / J_{O(S D)}\right)\right]\right.$ para la celda unitaria $S_{D}$

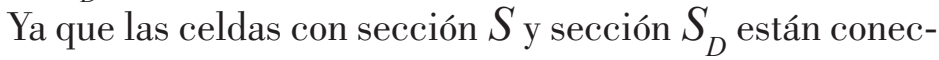
tadas en paralelo, la densidad de corriente de iluminación o corto circuito de la celda unitaria $S_{T}$ estará dada como la suma de las corrientes de iluminación o corto circuito de las dos secciones; es decir,

$J_{L}\left(S_{T}\right)=J_{L(S)}+J_{L(S D)} ;$ y $J_{0}\left(S_{T}\right)=J_{O(S)}+J_{O(S D)}$; en consecuencia, el $V_{C A}$ de la celda unitaria se puede escribir como:

$V_{C A}\left(S_{T}\right)=(A \mathrm{KT} / \mathrm{q}) \operatorname{Ln}\left[\left(1+\left(J_{L(S)}+J_{L(S D)}\right) /\left(J_{o(S)}+J_{o(S D)}\right)\right]\right.$

Si la sección $S_{D}$ se sombrea, ésta no genera corriente eléctrica y sus parámetros eléctricos son cero; por lo tanto:

$J_{L(S D)}=0$ pero $J_{O(S D)}$ no es cero ya que es la corriente inversa de saturación de la unión $\mathbf{p} / \mathbf{n}$ asociada a la sección sombrada que no depende de si la celda está o no bajo iluminación. En consecuencia se tiene que:

$V_{C A}\left(S_{T}\right)=(A \mathrm{KT} / \mathrm{q}) \operatorname{Ln}\left[\left(1+\left(J_{L(S}\right) /\left(J_{0}\right)\right]\right.$

$\mathrm{y}$ en términos de la superficie sombreada de magnitud $\mathrm{X}$, se tiene que

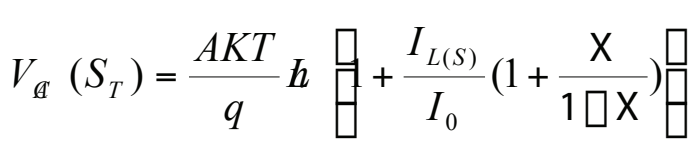

La Ec. 3.8 especifica que si una porción de superficie $\mathrm{X}$ de la celda solar unitaria se sombrea, su $V_{C A}$ disminuye proporcionalmente a la función logaritmo natural, cuyo 
argumento, está relacionado con la corriente que produce la sección iluminada $S$ cuyo valor es $I_{L(S)}=I_{C C(S)}$ y la razón geométrica entre la superficie sombreada $X$ y la no sombreada (1-X).

Ahora bien, la sección de la celda sin sombrear (superficie $1-X)$ ve a la sección de la celda sombreada (superficie $\mathrm{X}$ ) como una resistencia y la magnitud del voltaje dado por la Ec. 3.8 va a polarizar, en sentido inverso, dicha sección y si su valor es del orden del voltaje de compuerta VC del diodo de dicha celda, circulará una corriente absorbiendo potencia eléctrica. Es claro que la magnitud de la corriente que absorberá dependerá de la resistencia eléctrica total del diodo con un valor máximo dado por la magnitud de la corriente de iluminación de la sección de lña celda sin sombrear $\left(I_{L S}\right)$

Para corroborar lo antes dicho, se ha medido el comportamiento $I$ vs $V$ de una celda solar de silicio policristalino con dimensiones de $156 \mathrm{~mm}$ x $156 \mathrm{~mm}$ con una superficie $S$ de $243.36 \mathrm{~cm}^{2}$, cuyo valor será tomado como unitario; es decir, es la celda solar unitaria. Dicha celda se dividió en fracciones y cada fracción se cubrió con un material totalmente opaco para dejar porciones de la celda sin sombrear.

La curva típica de generación $I$ vs $V$ para las celdas con superficie iluminada de $243.36 \mathrm{~cm}^{2}, 6 / 7 ; 0.5$, y $1 / 7$ de dicha superficie, fue obtenida con un trazador de curvas $I v s$ $V$ bajo condiciones estándares de prueba $(G=1,000 \mathrm{~W} / \mathrm{m} 2$ y $\mathrm{T}_{\mathrm{C}}=25^{\circ} \mathrm{C}$ ) y se muestra en la Figura 3.19 para cada caso. Los parámetros eléctricos de dichas celdas se presentan en una tabla de valores insertada en dicha figura. 


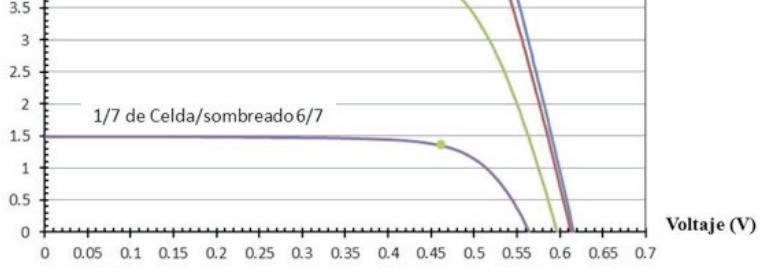

Figura 3.19: Efecto del tamaño de la celda sobre las características eléctricas.

Al graficar los parámetros eléctricos mostrados en la tabla que aparece en la Figura 3.19 con respecto a la superficie activa de la celda $S$, gráfica que aparece en la Figura 3.20, que en el caso de la corriente de corto circuito $I_{C C}$ y la Potencia Máxima $\mathrm{P}_{\mathrm{MP}}$, se llega a las siguientes conclusiones:

a) La corriente de corto circuito $I_{C C}$ (corriente fotogenerada $\left.I_{L}\right)$ así como la corriente para el punto de la máxima potencia $\left(I_{M P}\right)$ disminuyen su magnitud de manera proporcional, desde el valor que corresponde a la Superficie unitaria totalmente iluminada, respecto del área sombreada X; siguiendo lo establecido en la Ec. 3.7

b) Las constantes de proporcionalidad tienen una magnitud de $b_{1} G=8.4545 \mathrm{~A} / \mathrm{cm}^{2}$, y $b_{2} G=7.663 \mathrm{~A} / \mathrm{cm}^{2}$, para $I_{C C}$ e $I_{M P}$, respectivamente, siendo $G$ la irradiania pico.

c) La Potencia Máxima $\mathrm{P}_{\mathrm{MP}}$ que genera la celda también disminuye de manera proporcional al tamaño de la superficie sombreada de la celda X, o bien, si $S$ es la superficie activa de la celda unitaria $\left(S=S_{T}-S_{D}\right), \mathrm{P}_{\mathrm{MP}}$ es directamente proporcional a $S$, es decir

d) $\mathrm{P}_{\mathrm{MP}}=\mathrm{a} \mathrm{S}=\mathrm{a}\left(\mathrm{S}_{\mathrm{T}}-\mathrm{S}_{\mathrm{D}}\right)=\mathrm{a}(1-\mathrm{X})$,

e) donde la constante de proporcionalidad tiene una magnitud de $a=3.352 \mathrm{~W} / \mathrm{cm}^{2}$.
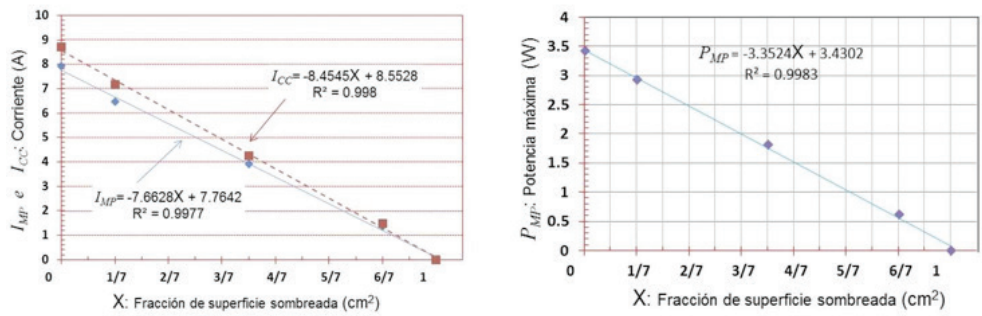
Figura 3.20: Comportamiento de la corriente de corto circuito, la corriente en el punto de la máxma potencia y la potencia máxima para una celda solar con diferente superficie de captación: celda unitaria, 6/7, 1/2, 1/7 y 0 de superficie iluminada. Se observa el decrecimiento proporcional respecto del área sombreada $\mathrm{X}$.

f) Por otra parte, en la Figura 3.19 se observa que al incrementar la superficie $X$ de la sección sombreada $\left(\mathrm{S}_{\mathrm{D}}\right)$ de la celda unitaria, el voltaje a circuito abierto $V_{C A}$ disminuye. Esto se debe principalmente tanto al acoplamiento en paralelo de las fracciones sombreadas como al hecho de que $I_{L(S)}$ de la sección de la celda sin sombrear, disminuye proporcionalmente debido al sombrado, y dado que $V_{C A}$ es una función logarítmica de $I_{L(S)}$, al disminuir ésta corriente, se tienen también una disminución en el $V_{\mathrm{CA}}$. Este decremento está regido por la Ec. 3.8. La Figura 3.21 muestra el comportamiento tanto del $V_{C A}$ como del $V_{M P}$ de la celda bajo estudio. Dicha figura muestra un ligero incremento en el $V_{M P}$ debido que el Punto de la Máxima Potencia se traslada hacia voltajes mayores conforme la forma de la curva tiene hacia el eje horizontal, tal y como se observa en la Figura 3.19.

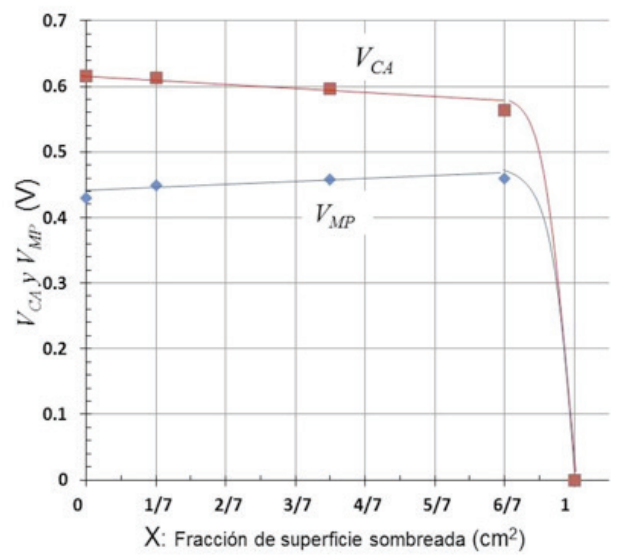


Figura 3.21: Comportamiento tanto del VCA como del VMP de una celda unitaria a la que se le esta sombreando una sección de superficie $S$.

\subsection{Notas finales}

Las celdas solares transforman la luz en electricidad de una manera silenciosa ya que no hay partes mecánicas, al no usar combustibles fósiles para su operación no generan desechos contaminantes, y prácticamente, no requieren de algún operador para su funcionamiento.

Las celdas solares trabajan muy bien con la radiación directa, pero también lo hacen con la radiación difusa y en días nublados. Su respuesta es inmediata ante los cambios en la irradiancia. Presentan el inconveniente de que si se sombrean completamente no generan electricidad. Tiene un buen número de cualidades que las hacen candidatos óptimos para generar electricidad de una manera limpia y confiable. Sin embargo, para obtener una energía útil para la mayoría de las aplicaciones, la potencia generada por las celdas solares es muy pequeña, de aquí la necesidad de crear con ellas estructuras que produzcan la suficiente potencia para una aplicación práctica. 


\section{4}

\section{LOS CONVERTIDORES FOTOVOLTAICOS}

\subsection{El módulo fotovoltaico}

La corriente y el voltaje generado son muy pequeños para una aplicación práctica, por lo que para poder ofrecer una alternativa de aplicación, se debe de fabricar nuevas estructuras basadas en la unidad mínima de conversión. La asociación de celdas solares interconectadas de alguna manera es necesaria para incrementar tanto el voltaje como la corriente generada. Esta asociación formará una nueva estructura conocida como el módulo fotovoltaico (MFV), y de aquí en adelante se referirá simplemente como módulo.

La celda solar es un generador que se comporta tanto como fuente de corriente y fuente de voltaje, siendo la electricidad generada del tipo directo. Por las Leyes Kirchhoff para circuitos eléctricos se sabe que si fuentes de fuerza electromotriz idénticas son conectadas en serie, o en paralelo, se tendrá,

g) "Las conexiones tipo serie entre fuentes de fuerza electromotriz incrementan el voltaje de salida, siendo su magnitud igual a la suma de los voltajes de cada una de las fuentes, manteniendo la corriente constante".

h) "Las conexiones tipo paralelo entre fuentes de fuerza electromotriz incrementan la corriente de salida, siendo su 
magnitud igual a la suma de las corrientes de cada una de las fuentes, manteniendo el voltaje constante".

El requisito de identidad para las celdas solares es una característica que en los procesos de fabricación masiva no es sencillo lograr; por lo que los fabricantes, al realizar la construcción de su MFV, deben tener mucho control en la elección de cada uno de los elementos que participarán en la formación de esa nueva estructura.

Cuando celdas no idénticas se conectan para formar un MFV, se generan importantes problemas que están asociados a desbalances eléctricos y térmicos generados por la falta de acoplamiento entre ellas. Sin embargo, aunque se haya garantizado que las celdas individuales tengan idénticas características eléctricas, siempre existirá la probabilidad de que alguna de ellas quede sombreada parcialmente, implicando inmediatamente que aparecerá un desbalance eléctrico y térmico.

El efecto principal de estos problemas se manifiesta en el hecho de que un MFV o varios de ellos trabajarán como receptores de potencia y consumirán, en lugar de producir, parte de la potencia generada por los otros módulos en el arreglo. Como consecuencia se calentarán, existiendo la posibilidad de que se formen los llamados "puntos calientes" que dañan irreversiblemente a la celda en donde se produce, y en consecuencia, al MFV.

Si se tienen $N$ celdas con las mismas características eléctricas (celdas idénticas), entonces se tiene lo siguiente:

\section{1.a. Conexión SERIE de celdas idénticas}

La Conexión en Serie de celdas eléctricamente idénticas se realiza al conectar la terminal positiva de una celda con la terminal negativa de la siguiente, y así sucesivamente (ver Figura 4.1). Esta conexión crea un dispositivo que genera la misma corriente que produce cada celda y con un voltaje de salida, $V_{S}$, igual a la suma de los voltajes individuales de cada 
una de ellas; en consecuencia, la conexión en serie de celdas solares incrementa el voltaje de salida $\mathrm{V}_{s}$; por lo tanto:

Para $N$ celdas idéntica conectadas en serie, $V_{S}=N V$ siendo $V$ el voltaje que genera cada celda.

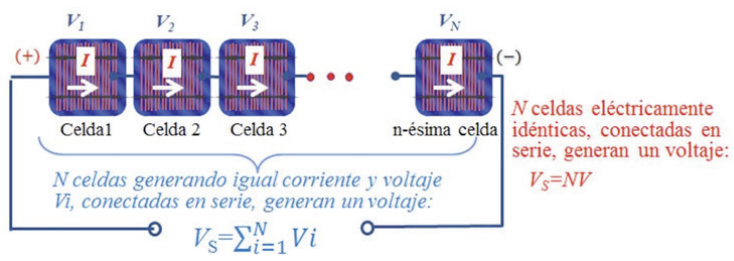

Figura 4.1: Diagrama esquemático que muestra la conexión en serie de celdas solares.

\section{1.b. Conexión paralelo de celdas idénticas}

La Conexión en Paralelo de celdas eléctricamente idénticas se realiza al conectar todas las terminales positivas de cada celda en el mismo punto y todas las terminales negativas de cada celda en otro punto (ver Figura 4.2). Esta conexión crea un dispositivo que genera el mismo voltaje que produce cada celda y con una corriente de salida IS igual a la suma de las corrientes individuales de cada una de ellas; en consecuencia la conexión en paralelo de celdas solares incrementa la corriente de salida $\mathrm{I}_{\mathrm{s}}$; por lo que:

Para $N$ celdas conectadas en paralelo, $I_{S}=N I$, siendo $I$ la corriente producida en cada celda.

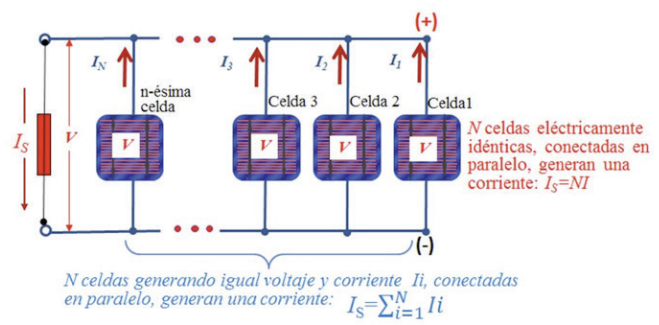

Figura 4.2: Diagrama esquemático que muestra la conexión en paralelo de celdas solares 
Resumiendo: Celdas eléctricamente idénticas conectadas en serie incrementan el voltaje de la asociación, conservando una corriente que es igual a la corriente de cualesquiera de una de ellas; mientras que celdas eléctricamente idénticas conectadas en paralelo, incrementan la corriente manteniendo un voltaje que es igual al voltaje generado por cualesquiera de una de ellas de la asociación.

\section{1.c. Conexión de celdas no identicas y los diodos de protección}

Si se tienen N celdas conectadas en serie, y una de ellas genera una corriente inferior a las demás debido a un defecto de fabricación o por efecto de alguna sombra que la cubra parcial o totalmente, a la que se le llamará "celda mala", entonces bajo condiciones cercanas a corto circuito (la carga eléctrica a conectar tiene una resistencia de carga RL cercana a cero), dicha celda quedará polarizada inversamente con un voltaje igual a la suma de todos los voltajes de las otras celdas restantes, actuará como un elemento resistivo y la potencia que disipará será igual al producto de la corriente que producen las otras celdas multiplicado por el voltaje de polarización. Lo anterior hará que la celda se caliente formándose lo que se conoce como "punto caliente". En éste caso, la corriente de la conexión en serie estará controlada por la "celda mala", y su magnitud será inferior a la de las celdas buenas.

Si se tienen $\mathrm{N}$ celdas conectadas en paralelo, y una de ellas genera un tensión eléctrica (voltaje) inferior a las demás debido a un defecto de fabricación o por efecto de alguna sombra que la cubra totalmente, a la que se le llamará "celda mala", entonces bajo condiciones cercanas al circuito abierto, (la carga eléctrica a conectar tiene una resistencia de carga RL muy grande), dicha celda actuará como un "sumidero", quedará polarizada inversamente y por ella circulará una corriente de retorno igual a la suma de las corrientes de las otras celdas restantes. Esto hará que la celda disipe 
una potencia dada por el producto del voltaje de la conexión en paralelo por la magnitud de la corriente de retorno. Si la corriente de retorno es mayor a la ampacidad (capacidad de conducción de la electricidad) de la celda, ésta se quemará! En éste caso, la tensión eléctrica o voltaje de la conexión estará controlada por la "celda mala" y su magnitud será inferior a la de las celdas buenas.

Para disminuir el efecto del desacoplamiento eléctrico de las celdas solares los fabricantes de módulos introducen caminos de alivio ("by pass") para evitar la inyección de voltaje o corriente en una celda de menor eficiencia. Estos caminos de alivio se construyen usando diodos rectificadores que propician la conducción en un sentido dependiendo de su polarización eléctrica.

4.1.c1.- Diodos de paso.- Para reducir los efectos de la polaridad invertida en celdas no idénticas conectadas en serie, se coloca un diodo en paralelo con ésta celda para permitir el paso de la corriente de la serie, sin que se vea reducida por la celda de menor corriente. Por su función, a estos diodos se les llama diodos de paso.

4.1.c2.- Diodos de bloqueo.- Por otra parte, para la configuración en paralelo, se agrega un diodo en serie con la celda de menor eficiencia para evitar la inyección de corriente en polaridad invertida. Este diodo bloquea dicha corriente, por lo cual recibe el nombre de diodo de bloqueo.

Colocar diodos a nivel de celda no es muy práctico, por lo que la protección contra polaridades invertidas y puntos calientes se debe hacer a nivel del módulo fotovoltaico.

Por lo anterior, al construir el módulo el fabricante debe evitar la conexión de celdas no idénticas para minimizar el efecto de la polaridad invertida y puntos calientes. Desafortunadamente en los lotes de producción no es posible obtener celdas perfectamente idénticas. No obstante, se pueden minimizar los efectos del desacoplamiento eléctrico si se consi- 
dera que, la mayoría de las celdas de silicio producidas en un mismo lote, generan el mismo voltaje a circuito abierto. Celdas con muy poca diferencia en el $V_{\mathrm{CA}}$ (menos del 2\%), no producen efectos muy pronunciados de polaridad invertida cuando se conectan en paralelo.

Sin embargo, las celdas de un mismo lote pueden tener diferentes valores para la corriente a corto circuito, y no podrían usarse para formar una configuración serie. Por esa razón, los módulos fotovoltaicos son construidos con celdas solares que tienen prácticamente la misma corriente a corto circuito; es decir, se seleccionan con una dispersión de valores menores del 1\% para minimizar los efectos del desacoplamiento eléctrico y disminuir los puntos calientes inherentes a él.

\section{1.d. Construcción o fabricación del módulo fotovoltaico}

Los Módulos Fotovoltaicos (MFV) se fabrican siguiendo estándares o normas nacionales o internacionales. Respecto de éstas, las más conocidas son:

- UL1703 Standard for Flat-Plate Photovoltaic Modules and Panels. Norma nacional de Estados Unidos, la cual se relaciona con los requerimientos que deben cumplir los materiales de construcción, la manera de medir el desempeño eléctrico y las pruebas a las que se somete al producto para determinar su seguridad y durabilidad.

- IEC61730-1 Photovoltaic (PV) module safety qualification - Part 1: Requirements for construction. Norma Internacional emitida por la International Electrotechnical Commission, la cual proporciona los requerimientos que deben cumplir los materiales que integran al módulo para proveer seguridad eléctrica y operación mecánica.

- NMX-J-618/1-ANCE-2010 Norma Mexicana homologación de la norma IEC 61730-1. 
De ésta manera, en la construcción de los MFV's se consideran los siguientes aspectos para tener un producto durable, confiable y seguro:

a) Fragilidad.- Ya que las celdas son muy frágiles, deben protegerse contra posibles golpes mecánicos que las romperían.

b) Degradación.- También, deben protegerse contra las condiciones ambientales para evitar procesos de corrosión y absorción de agua que producen la degradación de las celdas.

c) Aislamiento eléctrico.- Ya que se genera electricidad, el MFV debe ser construido de tal manera que no se tenga ni fugas de corriente ni de tensión eléctrica.

Para cumplir lo anterior, las celdas que integrarán al MFV, conectadas eléctricamente, se encapsulan para formar la estructura llamada módulo fotovoltaico (MFV). Este conjunto de celdas deben estar convenientemente conectadas, de tal forma que reúnan las condiciones óptimas para su integración en sistemas de generación de energía, siendo compatibles con las necesidades y los equipos estándares existentes en el mercado.

La Figura 4.3 muestra un corte esquemático de las principales componentes del módulo. Consiste prácticamente de un conjunto de celdas, conectadas generalmente en serie, de tal manera que produzcan el voltaje y la corriente requerida por la aplicación específica. Las celdas son soportadas en un vidrio templado de alta transmitancia óptica o substrato rígido para darles rigidez mecánica; y a su vez, laminadas entre dos polímeros para aislarlas contra la humedad y protegerlas del clima. Por la parte trasera y sobre el polímero posterior, se fijan las cajas de conexión eléctrica para la terminal positiva y negativa, la que provee, el punto eléctrico del circuito de salida en donde se conectarán los cables que llevarán la electricidad a la carga específica. Este laminado es colocado en un 
marco metálico, provisto de hoyos de fijación, que permiten colocarlo en una estructura que provee la orientación respectiva del módulo.

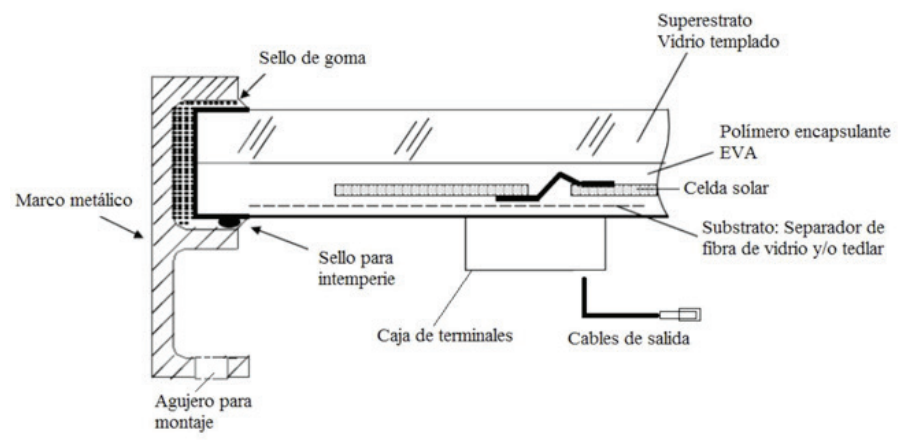

Figura 4.3: Corte transversal de un módulo fotovoltaico se en donde muestra las principales partes de él.

La Fig. 4.4 muestra una fotografía de un módulo típico de silicio cristalino y el símbolo que se usa convencionalmente para representar al módulo en un diagrama eléctrico fotovoltaico.

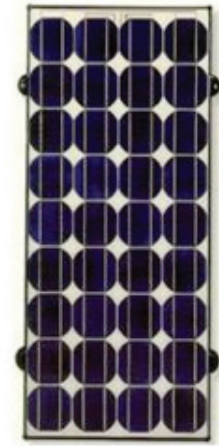

(a)

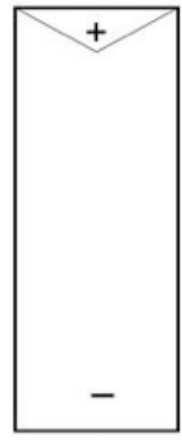

(b)

Figura 4.4: En (a) se muestra una fotografía de un módulo típico de silicio cristalino, y en (b) el símbolo convencional para módulos fotovoltaicos. 
Los módulos FV debe tener la característica de ser libres de mantenimiento durante muchos años en las condiciones ambientales para las cuales sean diseñados. El objetivo es crear estructuras con un tiempo de vida promedio mayor que el de la garantía. El vidrio y el encapsulante frontal para el laminado, comúnmente Etil Vinil Acetate (EVA), deben ser transparentes a la radiación solar en el rango de longitudes de onda en donde el silicio tiene su respuesta espectral (0.35 a $1.2 \mu \mathrm{m})$. Dicha característica no debe disminuirse por las exposiciones prolongadas a la radiación solar y al clima. Así, el vidrio debe tener buena resistencia al impacto contra granizos, granos de arena arrastrados por el viento, e inclusive contra golpes accidentales. La superficie del vidrio debe ser dura, resistente a la abrasión, lisa y plana para garantizar la auto limpieza por medio de la lluvia, viento o rocío. No debe tener relieves que faciliten la acumulación superficial de lluvia, polvo o cualquier otra materia sólida.

Para mantener la temperatura de operación lo más baja posible y maximizar su desempeño, el módulo debe diseñarse para tener una baja absorción del espectro de la radiación luminosa que no se aprovecha, y poder disipar calor vía procesos de radiación, convección y conducción.

Los polímeros para el encapsulamiento deben ser resistentes a la permeabilidad de gases, vapor de agua y líquidos, cuya condensación dentro del módulo ocasionaría corrosión galvánica en los contactos eléctricos y en consecuencia cortos circuitos. Cualquier fuga en los sellos aumentaría la razón de absorción de gases beneficiando reacciones químicas adversas al dispositivo. El desprendimiento del laminado entre el vidrio y el encapsulante, o encapsulante y celdas, aumentan las pérdidas por reflexión. En consecuencia, tanto el vidrio como los polímeros no deben desprenderse bajo condiciones térmicas cicladas de frío y calor. Generalmente, el laminado debe garantizar un aislamiento contra altos voltajes, los cuales pueden alcanzarse al conectar en serie varios módulos. 
Las celdas que formarán un módulo deben seleccionarse con características eléctricas casi idénticas: menos del $1 \%$ de dispersión para los valores de corriente a corto circuito y del voltaje a circuito abierto. Las conexiones eléctricas entre ellas deben ser dobles para garantizar la confiabilidad de la conexión.

El módulo debe ser lo suficientemente rígido para soportar las frágiles celdas y darles protección durante los procesos de traslado e instalación. Debe ser capaz de absorber pequeñas imperfecciones o distorsiones en la estructura, aguantar las vibraciones producidas por vientos débiles y soportar fuertes vientos, nieve, hielo y tolvaneras. Además deben ser fáciles de montar, interconectar, y reemplazar. Los tornillos de montaje, terminales eléctricas, cajas de conexión y conectores deben ser anticorrosivos.

Ya que la eficiencia de un módulo dependerá de la radiación solar que su área intercepte, el factor de compactación de las celdas en el módulo debe ser lo más alto posible. Es obvio que celdas cuadradas producen una compactación mayor que celdas circulares, sin embargo, si el área no es una limitante, no existe una restricción respecto del factor de compactación.

La Tabla 4.1 muestra las normas que deben satisfacer las partes y componentes que integran a un módulo fotovoltaico para satisfacer los requerimientos de calidad exigidos em su construcción.

\begin{tabular}{|l|l|l|l|}
\hline COMPONENTE & NORMA QUE APLICA & COMPONENTE & NORMA QUE APLICA \\
\hline $\begin{array}{l}\text { ETIQUETA DE } \\
\text { IDENTIFICACIÓN }\end{array}$ & $\begin{array}{l}\text { NMX-J-618/1-ANCE-2010 } \\
\text { (IEC 61730-1); UL 1703; } \\
\text { UNE-EN-50380 (2003) }\end{array}$ & $\begin{array}{l}\text { TERMINAL DE CONEXIÓN/SALIDA } \\
\text { POSITIVA Y NEGATIVA }\end{array}$ & $\begin{array}{l}\text { NMX-J-618/1-ANCE-2010 (IEC 61730-1); } \\
\text { UL 1703 }\end{array}$ \\
\hline $\begin{array}{l}\text { ENCAPSULANTES/ } \\
\text { POLIMEROS }\end{array}$ & $\begin{array}{l}\text { NMX-J-618/1-ANCE-2010 } \\
\text { (IEC 61730-1); } \\
\text { UL 1703 }\end{array}$ & CABLES DE SALIDA & NMX-J-618/1-ANCE-2010 (IEC 61730-1); \\
\hline SUPERESTRATO & $\begin{array}{l}\text { NMX-J-618/1-ANCE-2010 } \\
\text { (IEC 61730-1); } \\
\text { UL 1703 }\end{array}$ & CONECTOR EN CABLES & $\begin{array}{l}\text { NMX-J-618/1-ANCE-2010 (IEC 61730-1); } \\
\text { UL 1703; UL-SU 6703; UL746C }\end{array}$ \\
\hline DIODOS DE PASO & NO HAY & CAIA DE CONEXIÓN & $\begin{array}{l}\text { NMX-J-618/1-ANCE-2010 (IEC 61730-1); } \\
\text { UL 1703; UL746C }\end{array}$ \\
\hline
\end{tabular}

Tabla 4.1: Requerimientos normativos a satisfacer por las componentes de MFV's para su fabricación 


\section{1.e. Número óptimo de celdas en un módulo y potencia}

Ya que el MFV está integrado por celdas solares eléctricamente idénticas conectadas en serie, la Potencia Máxima, $\mathrm{P}_{\mathrm{MP}}$, que puede generar dicha integración está determinada como la suma de la potencia máxima de cada una de las celdas, y ésta a su vez, depende del área de la celda. Ahora bien, no hay un consenso de cuál es el número óptimo de celdas que debe tener un MFV, en consecuencia, tampoco hay un consenso de cuál debe ser la potencia óptima de ellos. Uno de baja potencia ocupa menos área que otro de mayor potencia. Desde un punto de vista de instalación es más rápido instalar módulos de potencia grande que de potencia baja, pero son más fáciles de manipular los de potencia baja que los de alta.

Actualmente existen en el mercado una amplia variedad de potencias que van desde unos cuantos watt hasta módulos de $360 \mathrm{~W}$; y así mismo, es posible encontrar módulos fotovoltaicos construidos con 18, 36, 54, 60, 72, 80, y 96 celdas conectadas en serie; sin embargo, esta selección sobre el número de celdas conectadas en serie no ha sido al azar, y ésta ha dependido de la aplicación masiva de la tecnología FV. Así, en los inicios de las aplicaciones fotovoltaicas (70's-90's), la demanda estaba enfocada en el ámbito rural, con sistemas con almacenamiento electroquímico basados en baterías tipo automotriz de plomo-ácido a $12 \mathrm{~V}$ nominales, o bien para sistemas de bombeo fotovoltaico. Sin embargo, con la aparición de los acondicionadores de potencia para la interconexión a la red, las aplicaciones en el ámbito urbano no se hicieron esperar. Lo más importante es que el MFV o una conexión en serie de éstos, debe proporcionar la tensión que requiere la "carga" eléctrica.

En la Figura 4.5 se muestra un diagrama a bloques de las dos posibles configuraciones en que se puede acoplar un módulo a una "carga" eléctrica. 


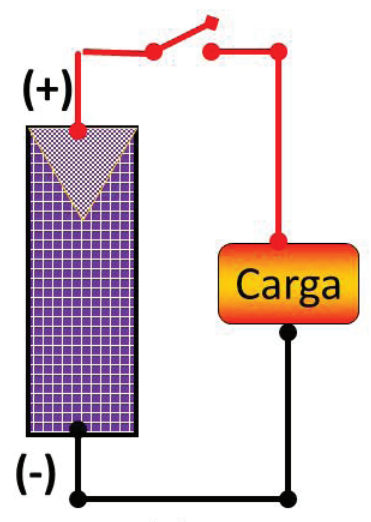

(a)

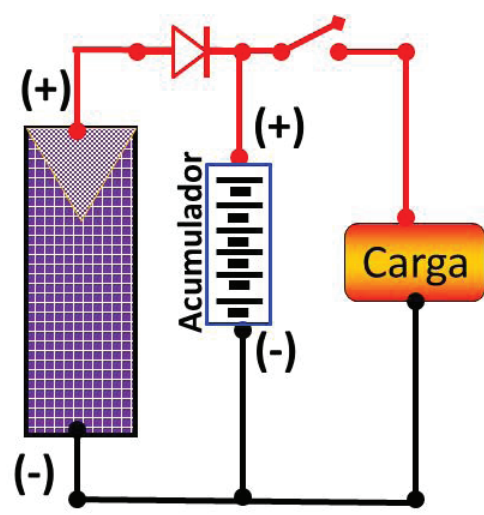

(b)

Figura 4.5: Configuración de conexión eléctrica entre módulos y cargas. En (a) se muestra la conexión directa. En (b) la conexión a través de un acumulador de energía.

En el caso en que el MFV se conecte directamente a la "carga" (Figura 4.5-a), éste debe generar, el voltaje mínimo necesario para que la carga opere. Lo anterior significa que las características eléctricas de la carga (curva $I-V$ ) que exige cierto rango de voltaje, es la que define el número de celdas del módulo. Lo ideal es que el acoplamiento MFV-“carga” se realice en el Punto de la Máxima potencia de generación del MFV. Una "carga" cuyo voltaje nominal sea de 15 volt necesitará un módulo que genere en el punto de máxima potencia el mismo voltaje $\left(V_{M P}=15 \mathrm{~V}\right)$. Si la "carga" requiere de 30 $\mathrm{V}$, se necesitarán dos MFV conectados en serie que generen, cada uno, un $V_{M P}=15 \mathrm{~V}$; y así sucesivamente; y en este caso, el MFV que genere un $V_{M P}=15 \mathrm{~V}$ será el módulo base para construir el Arreglo Fotovoltaico; pero también, para el caso de la "carga" que requiere $30 \mathrm{~V}$, se puede acoplar un MFV que genere un $V_{M P}=30 \mathrm{~V}$.

La conexión directa MFV-“carga” es la conexión más simple, si hay Sol, se genera electricidad y la carga opera. Si no hay Sol, no hay generación de electricidad y la carga no opera. 
Ya que las celdas solares solo generan electricidad durante el día, y ésta se usa a cualquier hora, la energía generada debe ser almacenada en un acumulador de energía. Los sistemas de almacenamiento pueden ser electroquímicos o hidráulicos. En el caso del almacenamiento hidráulico lo que se almacena es agua en contenedores con cierta energía potencial, la cual, es usada cuando el agua se traslada por gravedad a los sitios de consumo. Sin embargo, para operar "cargas" eléctricas de forma despachable, se requiere de electricidad, y en consecuencia, es necesario almacenarla en sistemas electroquímicos. La Fig. 4.5-b muestra la conexión más simple entre el módulo, el acumulador electroquímico (Ac.) y la "carga" eléctrica

La tecnología de acumuladores electroquímicos más madura, de alta diseminación mundial debido a la industria automotriz, es la basada en la celda electroquímica de plomo-ácido, formada por una placa de plomo, otra de bióxido de plomo, un electrolito formado por ácido sulfúrico al 37\% y un contenedor plástico. El voltaje nominal, $V_{N}$, de ésta celda es igual a $2 \mathrm{~V}$. Cuando la celda está completamente cargada (100\% de carga) tiene un voltaje a circuito abierto de $2.12 \mathrm{~V}$, y cuando esta descargada ( $0 \%$ de carga) es de 1.98 V. Seis celdas conectadas en serie forman lo que comúnmente se conoce como acumulador de $12 \mathrm{~V}$, dispositivo muy popular llamado "batería" usado en la industria automotriz. La capacidad de almacenamiento de un acumulador es proporcional al número de placas en cada celda.

Para el caso de un acumulador tipo automotriz $\left(V_{\mathrm{N}}=12\right.$ V), el voltaje final de carga máximo recomendado es de 15.24 $\mathrm{V}$ (2.54 V por celda para seis celdas en serie). Si la razón de carga es lenta, el voltaje final de carga máximo es de $14.7 \mathrm{~V}$ (2.45 $\mathrm{V}$ por celda). El voltaje final de descarga en una batería de éste tipo es de $11.4 \mathrm{~V}$ (1.90 V por celda). Con el objeto de satisfacer los voltajes de carga en un acumulador, los fabri- 
cantes de celdas solares han decidido construir los módulos fotovoltaicos conectando 36 celdas en serie. ¿Por qué?

Para contestar la pregunta anterior se considerará dos cosas: una el voltaje de la celda, y la otra, la magnitud de la corriente. Aunque el valor de $V_{M P}$ en celdas solares comerciales de silicio está limitado por la calidad del proceso de fabricación, con valores comprendidos entre el rango de 0.454 a $0.51 \mathrm{~V}$, se va a suponer, para fines didácticos que cada celda de silicio genera un $V_{M P}=0.5 \mathrm{~V}$. Por otra parte, dado que la cantidad de corriente que genera una celda al $100 \%$ de la irradiancia depende de su área, las razones de carga en un acumulador de plomo ácido serán catalogadas como lentas.

$\mathrm{Si}$ se pretende dar un voltaje para cargar acumuladores de $12 \mathrm{~V}$ nominales, que requiere un voltaje de carga de 14.7 $\mathrm{V}$, el módulo debe generar, en su punto de máxima potencia, un voltaje del orden de $15 \mathrm{~V}$. Así que el mínimo número de celdas a conectar en serie es $30(0.5 \mathrm{~V}$ x $30=15 \mathrm{~V})$. Ya que el acumulador es el que demanda el acoplamiento, el módulo nunca operará en su punto de máxima potencia, pero dada la forma de la curva $I-V$ del módulo (ver Figura 4.7), el acumulador se acoplará en la zona en que el módulo se comporta como fuente de voltaje bajo condiciones STC (ver Fig. 3.13).

Si se considera una irradiancia constante, al inicio de la carga, el acumulador tratará de sacar la máxima corriente del módulo iniciando la carga a un voltaje cercano a los $11.4 \mathrm{~V}$ (caso de un acumulador descargado). Conforme se va acumulando corriente, el voltaje se incrementa y el acoplamiento exige que la corriente de inyección disminuya. El acumulador se acoplará ahora en puntos cercanos al voltaje $V_{M P}$ para garantizar su plena carga y la inyección de corriente se reducirá conforme la batería alcanza su máximo voltaje de carga. El flujo de corriente disminuye cuando el voltaje es de 14.7 V. Este es un principio de autorregulación controlado por la impedancia del acumulador (ver Fig. 4.6). 
Sin embargo, bajo dichas condiciones, el módulo de 30 celdas, conocido como módulo autorregulable, no es capaz de llenar al $100 \%$ a un acumulador debido a las pérdidas de potencia por temperatura, cableado y circuitos de protección. Debido a esto, los fabricantes de módulos asocian más celdas en serie para compensar las pérdidas de temperatura y cableado en un sistema fotovoltaico. El número de celdas óptimo es de 36.

La Figura 4.6(a) muestra un diagrama esquemático del acoplamiento directo entre un MFV y un acumulador/carga eléctrica, mientras que en la Figura 4.6(b) las curvas características I vs $\mathrm{V}$ de un MFV de 36 celdas obtenidas con una irradiancia pico a diferente temperatura de la celda y las zonas de acoplamiento para inyectar carga eléctrica al acumulador/ batería. Ya que dicho acoplamiento se realiza en el rango desde $11.2 \mathrm{~V}$ (voltaje de batería descargada) hasta $15.4 \mathrm{~V}$ (voltaje de gasificación, $100 \%$ de carga), de aquí que al módulo de 36 celdas en serie se le asigna un voltaje nominativo de $12 \mathrm{~V}$.

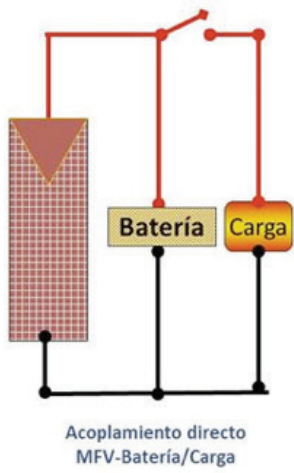

(a)

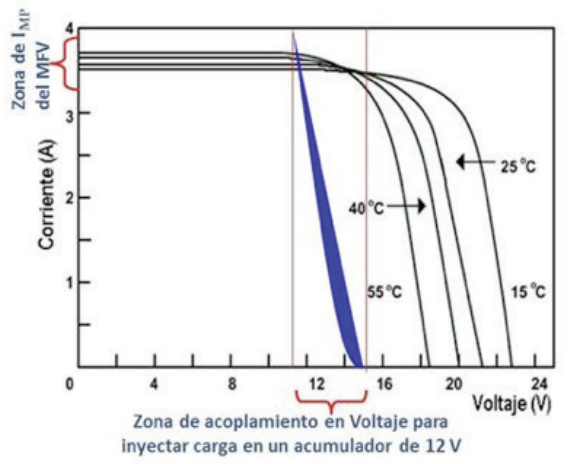

(b)

Figura 4.6: Acoplamiento directo entre un MFV y un acumulador.- En (a) se muestra un diagrama esquemático del acoplamiento; en (b) se tiene la curva $\boldsymbol{I}$ - $\boldsymbol{V}$ típica de un MFV de 36 celdas en serie en donde se muestran las zonas para tensión y corriente del acoplamiento MFV-Acumulador de $12 \mathrm{~V}$. 
Por lo antes dicho, aunque el rango de voltaje de los MFV fabricados con 36 celdas en serie disponible comercialmente es desde 0 hasta el $V_{C A}$ cuyo valor típico actual está en el rango de 21 a $26 \mathrm{~V}$, cuando se acoplan en acumuladores de 12 $\mathrm{V}$, se dice que su voltaje nominal, $V_{\mathrm{N}}$, es de $12 \mathrm{~V}$. La razón es la siguiente

Debido a que se pretende tener una compactación máxima, la forma geométrica del módulo usada por los fabricantes es rectangular. En un rectángulo, 36 celdas en 3 columnas de 12 renglones, o 4 columnas de 9 renglones son las óptimas. Así que como oferta comercial, para cargar baterías a $12 \mathrm{~V}$ nominales, se ofertan MFV de 36 celdas con diferentes potencias

Actualmente, la oferta comercial de MFV de silicio cristalino incluye productos con mayor número de celdas. Se tienen de 54, $6072,80,96$ y hasta 120 celdas conectadas en serie o una combinación serie/paralelo. Las de mayor demanda debido a sus aplicaciones domésticas, comerciales e industriales en sistemas fotovoltaicos interconectados a la red son las de 60 celdas conectadas en serie; y para las Granjas Solares o Plantas de Generación Eléctrica Fotovoltaica de gran escala se usan MFV con más de 72 celdas conectadas en serie.

\section{2.- Parámetros eléctricos de un módulo}

El comportamiento eléctrico de los módulos está dado por las curvas de corriente contra voltaje (curva $I$ vs $V$ ) o potencia contra voltaje (curva P vs $V$ ) que los caracteriza. La curva de potencia se genera multiplicando la corriente y el voltaje en cada punto de la curva $I$ vs $V$. La Figura 4.7 se muestran respectivamente curvas $I$ vs $V$ y $\mathrm{P}$ vs $V$ para un módulo fotovoltaico típico. Bajo condiciones estándares de prueba, 1.0 $\mathrm{kW} / \mathrm{m}^{2}$, temperatura de celda de $25^{\circ} \mathrm{C}, \mathrm{AM} 1.5$, cada modelo de módulo tiene una curva característica $I$ vs $V$ (o P vs $V)$. 


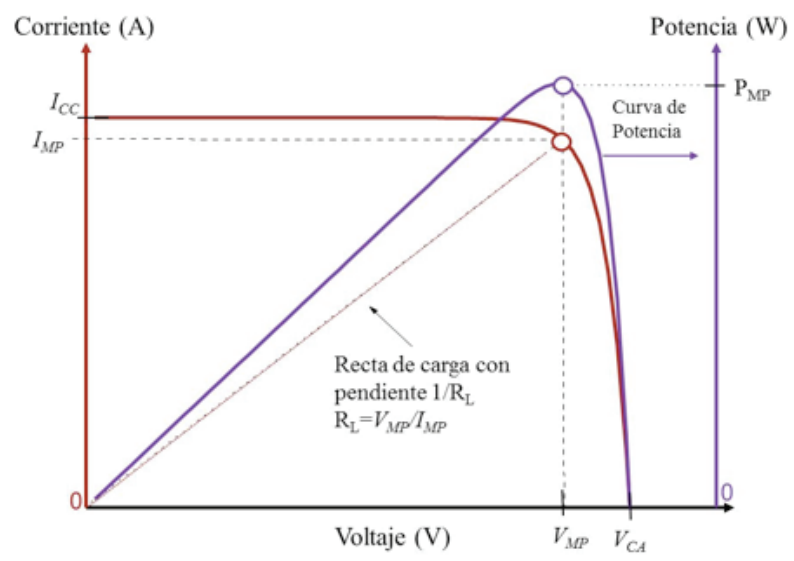

Figura 4.7: Curvas I vs V y P vs V identificando los parámetros eléctricos de un módulo fotovoltaico.

En la curva de potencia contra voltaje, existe un valor de voltaje, el $V_{M P}$ para el cual la potencia es máxima. La potencia máxima del módulo se le simboliza por $\mathrm{P}_{\mathrm{MP}}$ proporcionando la capacidad de generación y cuando la irradiancia con la que se le ilumina es de $1.0 \mathrm{~kW} / \mathrm{m}^{2}, \mathrm{P}_{\mathrm{MP}}$ recibe el nombre de Potencia Pico, $\mathrm{P}_{\mathrm{P}}$ del módulo. Esta es la potencia nominal con la que se vende el módulo. Así que un módulo especificado como de 50 Watt pico significa que entrega $50 \mathrm{~W}$ a una irradiancia de $1000 \mathrm{~W} / \mathrm{m}^{2}$. Con el valor de $\mathrm{P}_{\mathrm{MP}}$ se evalúa la eficiencia de conversión del módulo.

La Potencia Pico queda definida por una pareja de valores de corriente y voltaje, $I_{\mathrm{MP}}$ y $V_{\mathrm{MP}}$, los que definen, a través de la Ley de Ohm, una resistencia de carga $R_{L}$ cuyo valor es

$$
\mathrm{R}_{\mathrm{L}}=V_{M P} / I_{M P^{*}} \quad \text { Ec. } 4.1
$$

Cuando una carga eléctrica con resistencia $R_{L}$ se conecta al módulo, la transferencia de energía del módulo a la carga es máxima, y se dice que $I_{\mathrm{MP}}$ y $V_{\mathrm{MP}}$ corresponden a la corriente y voltaje de operación de la carga eléctrica. Sin embargo, en aplicaciones reales no siempre sucede que la resistencia de la carga eléctrica es $\mathrm{R}_{\mathrm{L}}$. En la Figura 4.8 se muestra un conjunto de curvas de igual potencia ( $I V=$ constante) que interceptan 
a la curva $I$ vs $V$ en dos puntos, cada uno de ellos definiendo una resistencia de carga.

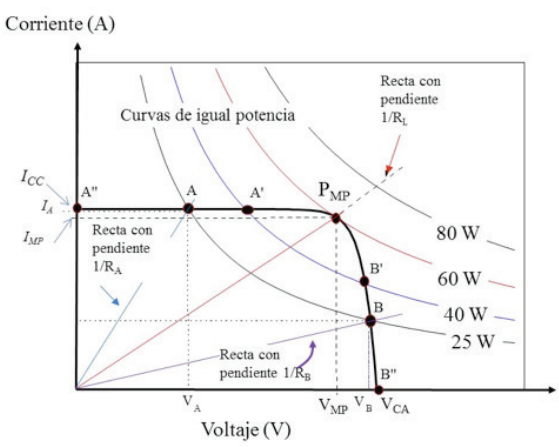

Figura 4.8: Curvas isopotenciales sobre una curva $\boldsymbol{I}$ vs $\boldsymbol{V}$ de un MFV. Se muestran puntos de intersección entre las curvas que denotan sitios de acoplamiento entre el MFV y resistencias de carga.

Tanto en los puntos de intersección entre las curvas de potencia y la curva $I-V$ (puntos A y B con una potencia de 25 W; A'y B' con una potencia de $40 \mathrm{~W}$ ) se tiene un acoplamiento en donde la transferencia de potencia del MFV a la "carga" no es la que corresponde al Punto de la Máxima Potencia (punto $P_{M P}=60 \mathrm{~W}$ ), el módulo opera lejos del punto de máxima potencia y la potencia entregada $\mathrm{P}_{\mathrm{OP}}$ se reduce significativamente; en consecuencia se tendrán pérdidas de energía. Bajo estas condiciones, el Rendimiento R en el acoplamiento módulo-carga eléctrica se puede establecer como:

$$
\mathrm{R}=\mathrm{P}_{\mathrm{OP}} / P_{M P} \quad \text { Ec. } 4.2
$$

Así, para una misma curva isopotencial, eso significa que habrá dos valores de resistencias para las cuales la celda entregará la misma potencia, una con menor voltaje que la otra. Se observa también que la curva de potencia máxima solo intercepta a la curva $I v s V$ en un solo punto, el $P_{M P}$, que es el de potencia máxima.

En este punto el lector debe de preguntarse que conviene más, una carga que opere a mayor voltaje o a menor voltaje, ya 
que en ambos casos la potencia será la misma. A mayor voltaje se requiere de menos corriente para satisfacer la potencia, y a menor corriente, menor es la potencia disipada en los cables eléctricos de conducción. Lo inverso sucede cuando el acoplamiento se realiza con menor voltaje. De aquí que se preferirá que las "cargas" operen al mayor voltaje posible. Sin embargo, estarán fuera del punto de operación de la máxima potencia de generación y el Rendimiento $\mathrm{R}$ en el acoplamiento será menor que aquella que se lograría trabajando en el punto $P_{M P}$.

El lector también debe de considerar que siempre que sobre una celda incida luz, aparece imaginariamente la curva $I$ vs $V$; y cuando se le conecta un aparato eléctrico con una resistencia intrínseca, $\mathrm{R}$, (su resistencia de carga) habrá un acoplamiento celda-resistencia (aparato) en un cierto valor de $V$, exigiendo una corriente $I$ para su operación; y la potencia, sólo dependerá del valor de R. Bajo éstas condiciones, a la caída de voltaje $V$ en la carga eléctrica y a la corriente $I$ que fluye a través de ella se les llaman voltaje y corriente de operación.

Si el nivel de irradiancia y la temperatura permanecen constantes, entonces dependiendo del valor de $\mathrm{R}$, la celda operará como una fuente de corriente constante o como una fuente de voltaje constante. Si R es pequeña, el acoplamiento se realizará en la región A'A" de la curva en la Figura 4.8 y la celda trabajara como fuente de corriente constante con un valor casi igual al de ICC. Si R es grande, el acoplamiento se realizará en la región B’B" de la curva en la Figura 4.8 y la celda trabajará como fuente de voltaje constante con un valor casi igual al del VCA.

Otros parámetros de importancia son: la corriente de corto circuito, $I_{C C}$, que es la corriente máxima generada por el módulo para cero potencia; y el voltaje de circuito abierto, $V_{\mathrm{CA}}$, máximo voltaje producido por el módulo.

Para fines de dimensionamiento y diseño fotovoltaico, se usaran los valores de $V_{M P}$ e $I_{M P}$ para determinar el tamaño en 
potencia pico que debe tener un AFV que satisfaga cierto requerimiento energético; mientras que, los valores de $I_{C C}$ y $V_{C A}$ servirán para el diseño eléctrico de la instalación FV.

\subsection{Certificación de módulos}

La potencia máxima o "tamaño" de los módulos comerciales varía entre unos cuantos Watt hasta 510 Watt. El voltaje $V_{M P}$ de los módulos fluctúa dependiendo del número de celdas conectadas en serie y de la tecnología con la que se fabricaron. Independientemente de la tecnología, los valores de los parámetros eléctricos de un módulo fotovoltaico los debe proporcionar el fabricante mediante una etiqueta de identificación colocada en la parte posterior del módulo. A la información vertida en dicha etiqueta se le conoce con el nombre de valores de placa.

Para que los valores de placa proporcionados por los fabricantes sean aceptables como verídicos y que el usuario pueda confiar que el producto es seguro, es decir, que no presenta riesgos para la salud, los módulos deben tener el certificado de conformidad de producto emitido por un Organismo Nacional de Certificación acreditado en términos de la Ley LFMN (Ley Federal de Metrología y Normalización) y su reglamento. En caso de no existir infraestructura en el país, los módulos deben estar certificados por un organismo NCB (National Certification Body), miembro del grupo IECEE, CB Scheme, así como contar con el informe de pruebas emitido por un laboratorio (CBTL Certification Body Testing Laboratory) que sea acreditado bajo ISO/IEC 17025. El esquema mostrado en la Figura 4.9 presenta las pruebas a las que son sometidos los módulos fotovoltaicos a través de las cuales se reconoce su desempeño energético, seguridad y durabilidad. 
Según la revista Photon ${ }^{16}$, a nivel mundial hay 23 Laboratorios de Ensayo certificados bajo el esquema CB Certification Body y 25 Entidades Certificadoras, dentro de las cuales, las más conocidas en nuestro país son:

a) UL: Underwriter Laboratories que es una entidad norteamericana de Certificación y Sociedad de Verificación que tiene Laboratorios de Ensayo en San Jose Ca. USA, Suzhou China, Zeppelinheim Alemania y socios de tercera parte por ejemplo Mississauga Laboratory-Bodycote Materials Testing Canada Inc en Canada, en donde se evalúan la conformidad de producto de acuerdo a las normas IEC y UL; y

b) TÜV Rh PS: TÜV Rheinland Product Safety GmbH que es una entidad certificadora del TÜV Rheinland Group con un Laboratorio de Ensayo en Norteamerica, dos en Asia, 4 en Europa.
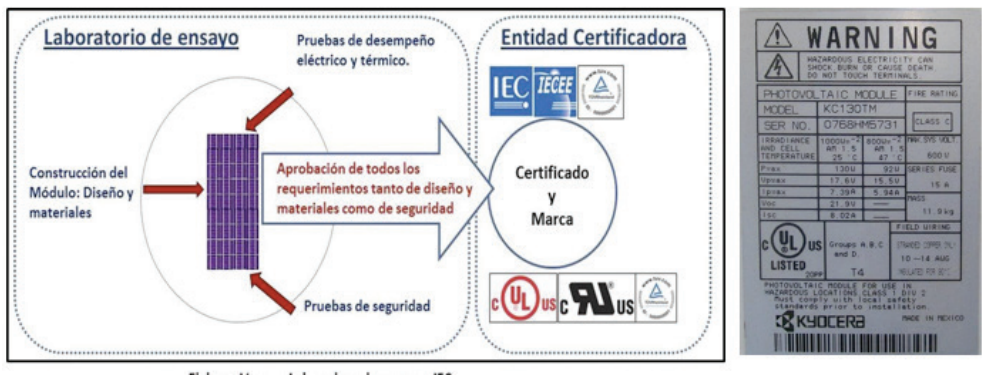

Figura 4.9: Esquema y pruebas que debe satisfacer un MFV para su certificación y un ejemplo de una etiqueta de identificación con el sello UL.

Es importante considerar que cumplir con las pruebas de seguridad a las que son sometidas los módulos es una garantía de que el producto es confiable, durable y seguro; por lo cual, siempre se recomienda el usar módulos que estén certificados.

Un módulo que genera más de $30 \mathrm{VDC}$, presenta riesgos potenciales de choque eléctrico, y en consecuencia, debe ser manipulado con toda la precaución posible.

16 "Laboratorios de Ensayo"; Photon la Revista Fotovoltaica, No. 5 Mayo 2009; p 62-p76. 
La Tabla 4.2 muestra las características eléctricas de placa para varios módulos de silicio cristalino fabricados por las marcas que se enuncian. En el Anexo IV se presenta una tabla más completa de la oferta comercial de módulos FV.

Tabla 4.2: Características eléctricas de módulos fotovoltaicos comerciales de silicio bajo condiciones estándares de medición (1000 W/m², AM1.5, $25 \div C)$.

\begin{tabular}{|c|c|c|c|c|c|c|c|c|c|}
\hline Marca & Modelo & Tipo & $\begin{array}{c}\text { No. } \\
\text { Celdas }\end{array}$ & $\begin{array}{l}V_{N} \\
(V)\end{array}$ & $\begin{array}{l}P_{P} \\
(W)\end{array}$ & $\begin{array}{l}V_{C A} \\
(V)\end{array}$ & $\begin{array}{l}I_{C C} \\
\text { (A) }\end{array}$ & $\begin{array}{l}V_{M P} \\
(V)\end{array}$ & $\begin{array}{l}I_{M P} \\
\text { (A) }\end{array}$ \\
\hline \multirow{4}{*}{$\begin{array}{c}\text { Shell } \\
\text { (Siemens, } \\
\text { Arco Solar) }\end{array}$} & SM110 & $M-X$ & 72 & $12 / 24$ & 110 & $21.7 / 43.5$ & $6.9 / 3.45$ & $17.5 / 35.0$ & $6.3 / 3.15$ \\
\hline & SP75 & $M-X$ & 36 & $12 / 6$ & 75 & $21.7 / 10.9$ & $4.8 / 9.6$ & $17.0 / 8.5$ & $4.4 / 8.8$ \\
\hline & SM50-H & $M-X$ & 33 & 12 & 50 & 19.8 & 3.35 & 15.9 & 3.15 \\
\hline & SM46 & $M-X$ & 30 & 12 & 46 & 18.0 & 3.35 & 14.6 & 3.15 \\
\hline BPSOLAR & BP275F & $M-X$ & 36 & 12 & 75 & 21.4 & 4.75 & 17.0 & 4.45 \\
\hline \multirow[t]{5}{*}{ HELIOS } & $\mathrm{H} 20$ & $M-X$ & 40 & 12 & 20 & 22.4 & 1.4 & 18.0 & 1.1 \\
\hline & KC140 & P-X & 36 & 12 & 140 & 22.1 & 8.68 & 17.7 & 7.91 \\
\hline & $\mathrm{KC220}$ & P-X & 54 & & 220 & 33.2 & 8.98 & 26.6 & 8.28 \\
\hline & $\mathrm{KC} 240$ & $\mathrm{P}-\mathrm{X}$ & 60 & & 240 & 36.9 & 8.59 & 29.8 & 8.06 \\
\hline & KC320 & $\mathrm{P}-\mathrm{X}$ & 80 & & 320 & 49.5 & 8.6 & 40.1 & 7.99 \\
\hline SOLAREX & MSX60 & $\mathrm{P}-\mathrm{X}$ & 36 & 12 & 60 & 21.1 & 3.8 & 17.1 & 3.5 \\
\hline
\end{tabular}

\subsection{Efecto de la intensidad luminosa}

Los cambios en la magnitud en la irradiancia $(G$ medida en $\mathrm{W} / \mathrm{m}^{2}$ ) producen cambios en las características eléctricas del módulo. Ya que el módulo lo forman un cierto número de celdas eléctricamente idénticas conectadas en serie (o en paralelo), la forma de las curvas $I-V$ de un módulo será la misma que para una celda. La Figura 4.10 muestra una simulación de las curvas $I-V$ para un módulo con una Potencia Pico de $75 \mathrm{~W}$. En ésta simulación se observa que partir de la gráfica $V_{C A} v \boldsymbol{s}$, si se considera como valor máximo del $V_{\mathrm{CA}}$ aquel valor generado para una $G=1,000 \mathrm{~W} / \mathrm{m}^{2}$, al disminuir el valor de G, la magnitud del $V_{C A}$ tiende a disminuir siguiendo la Ec. 3.4; sin embargo, el decrecimiento es poco en el rango para $G$ entre 200 y $1000 \mathrm{~W} / \mathrm{m}^{2}$, pudiendo decir que aún con un valor bajo de irradiancia, el MFV ya genera una tensión eléctrica $V_{C A}$ con un valor cercano a aquel que genera al $100 \%$ de la irradiancia (ver Figura 4.10-b). 


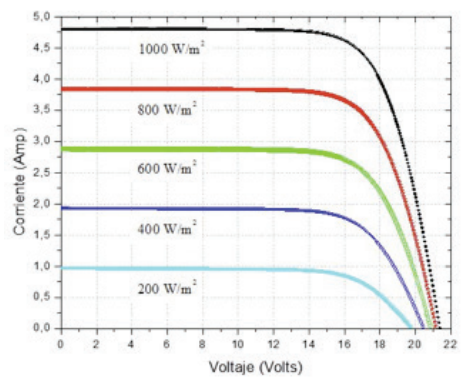

(a)

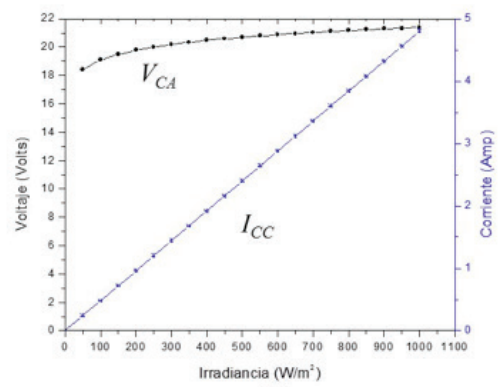

(b)

Figura 4.10: En (a) se muestra las características I-V de un módulo con diferentes valores de irradiancia $(T c=25 \circ \mathrm{C})$; mientras que en $(b)$ se presenta el comportamiento de la $I_{c C}$ y $V_{C A}$ del módulo en función de la magnitud de la irradiancia.

La característica anterior hace "ver" a los MFV como dispositivos de voltaje "casi" constante en la zona a la derecha del punto de máxima potencia. Si una carga eléctrica se acopla a éste voltaje, ella funcionará desde muy temprano de la mañana hasta muy tarde, cercano al ocaso.

De la Figura 4.10-b eje izquierdo, se observa que la forma en que cambia la corriente de corto circuito (corriente de iluminación $I_{L}$ ) es proporcional al valor de la irradiancia. Dado que la corriente que genera un módulo con celdas conectadas en serie es igual a la corriente que genera una celda individual, entonces el efecto de la irradiancia sobre el módulo es el mismo que para una celda individual. De aquí que si $I_{\mathrm{CC}(\mathrm{m})}$ es la corriente de corto circuito del módulo, entonces

$$
I_{\mathrm{CC}(\mathrm{m})}=\boldsymbol{b} \boldsymbol{G}
$$

donde la constante $\boldsymbol{b}$, con unidades (A $\left.\mathrm{m}^{2} / \mathrm{W}\right)$, se determina mediante una regla de tres simple al conocer el valor de la corriente a corto circuito bajo condiciones STC ( $G=1000 \mathrm{~W} /$ $\mathrm{m}^{2}$ ), es decir,

$$
\mathrm{b}=\frac{I_{\mathrm{CC}(\mathrm{m})}(\mathrm{STC})}{1000} \quad \text { Ec. } 4.4
$$


La relación anterior permite tener una manera de determinar si un módulo está generando la corriente especificada por el fabricante, o estimar que corriente dará el módulo bajo una irradiancia conocida. Ya que al $100 \%$ de la irradiancia (G) el módulo debe generar la corriente $I_{\mathrm{CC}(\mathrm{m})}$ especificada en la placa, al medir simultáneamente el valor de $\boldsymbol{G}$ y el valor de $I_{\mathrm{CC}}$, en un instante dado, se puede normalizar el valor real de la corriente de corto circuito y compararla con la placa. Este es uno de los procedimientos que se realizan en "campo" o sitio de instalación para verificar los datos de placa del módulo el cual es llamado normalización.

\subsection{Efecto de la temperatura}

Las celdas solares al estar expuestas al Sol se calientan como cualquier captador solar. Este aumento en la temperatura afecta las características eléctricas de ellas. La Fig. 4.11 muestra el comportamiento simulado de los parámetros eléctricos de una celda solar ideal en función de la temperatura de la celda, Tc. Se observa que $I_{\mathrm{CC}}$ aumenta ligeramente mientras que el $V_{C A}$ está disminuyendo en una razón muy grande. Este fenómeno es más pronunciado en unas celdas, como es el caso del silicio, que en otras, como es el caso de las celdas basadas en arseniuro de galio (GaAs) y Teluro de Cadmio.

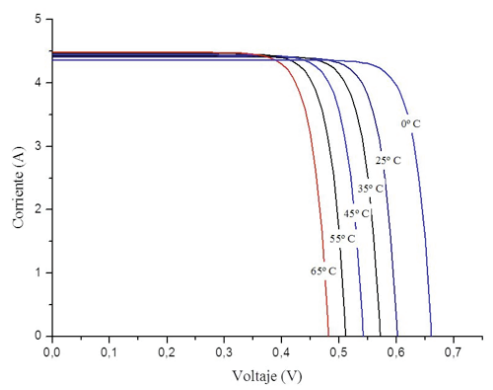

Figura 4.11: Efecto de la temperatura sobre los parámetros eléctricos de la celda solar. 
Para celdas de silicio cristalino el coeficiente de temperatura para $I_{C C}$, dado como el cambio en su valor respecto de un cambio en $\mathrm{T},\left(\mathrm{d} I_{C C} \mathrm{dT}\right)$, tiene un valor aproximado de 10-30 $\mu \mathrm{A} / \mathrm{cm}^{2}$. Sin embargo, el coeficiente de temperatura para el $\mathrm{V}_{\mathrm{CA}}$, definido como $\mathrm{d} V_{C A} / \mathrm{dT}$ tiene un valor negativo de 2.3 $\mathrm{mV} /{ }^{\circ} \mathrm{C}$.

La ligera ganancia en $I_{\mathrm{CC}}$ y la disminución en $V_{C A}$ cuando la temperatura de la celda aumenta, trae como consecuencia que sus efectos se vean reflejados tanto en la potencia generada por la celda como en su eficiencia. En la Tabla 4.3 se muestran los valores de los coeficientes de temperatura para el $V_{C A}, I_{C C}$, potencia y eficiencia para el caso de una celda de silicio cristalino.

Tabla 4.3: Coeficientes de temperatura para celdas de silicio cristalino.

\begin{tabular}{|c|c|c|c|}
\hline PARÁMETRO & SÍMBOLO & EFECTO & VALOR \\
\hline $\begin{array}{c}\text { Corriente } a \\
\text { corto circuito }\end{array}$ & $\mathrm{d} l_{c C} / \mathrm{dT}$ & Aumenta & 10 a $30(\mu \mathrm{A} / \mathrm{cm} 2)$ por $\circ \mathrm{C}$ \\
\hline $\begin{array}{c}\text { Voltaje a } \\
\text { circuito abierto }\end{array}$ & $\mathrm{d} V_{C A} / \mathrm{dT}$ & Disminuye & 2.0 a $2.4 \mathrm{mV}$ por $\circ \mathrm{C}$ \\
\hline Potencia & $\mathrm{dP} / \mathrm{dT}$ & Disminuye & $\sim 0.4 \%$ por $\circ \mathrm{C}$ \\
\hline Eficiencia & $\mathrm{d} \eta / \mathrm{dT}$ & Disminuye & $\sim 0.4 \%$ por $\circ \mathrm{C}$ \\
\hline
\end{tabular}

Pero ¿̨cuál es la temperatura que alcanza un módulo y de quien depende su valor?. La respuesta a este tipo de preguntas sólo es posible contestarlas empíricamente.

La temperatura que puede alcanzar una celda solar en un módulo, cuando está en operación (a la que se le llamará temperatura de operación de la celda, $\mathrm{T}_{\mathrm{C}}$ ), depende de la irradiancia $(\boldsymbol{G})$, temperatura ambiente (Tamb), velocidad de viento y del tipo de encapsulamiento, a través del cual se disipa el calor. Una relación empírica que establece la temperatura que alcanzará un módulo, bajo condiciones de equilibrio térmico, en función de la irradiancia $G$ que recibe, a una velocidad de viento de $1 \mathrm{~m} / \mathrm{s}$ está dada por: 


$$
\mathrm{T}_{\mathrm{C}}=\mathrm{Tamb}+\mathrm{C}_{1} G, \quad \text { Ec. } 4.5
$$

donde $\mathrm{C}_{1}$ es una constante empírica, llamada la constante de propagación de temperatura, que depende del tipo de módulo (fabricante) y que se obtiene a partir de la temperatura que adquieren las celdas solares, que integran al MFV, cuando éste es sometido a las siguientes condiciones de operación:

$G=800 \mathrm{~W} / \mathrm{m}^{2} ; \mathrm{Tamb}=20^{\circ} \mathrm{C}$; velocidad de viento $\mathrm{v}=1.0 \mathrm{~m} / \mathrm{s}$ y espectro de la radiación solar correspondiente a una Masa de Aire AM1.5.

Bajo estas condiciones, cuando el MFV está en equilibrio termodinámico, se mide la temperatura que alcanzan las celdas solares, y a dicho valor, se le llama "Temperatura de la celda bajo condiciones de operación", (NOCT por sus siglas en inglés: Normal Operation Cell Temperature), y se le suele representar como $\mathrm{T}_{\text {NOCT }}$

Considerando lo anterior y dado que los MFV's nunca operarán bajo las condiciones STC, se ha convenido proporcionar a los usuarios sus parámetros eléctricos bajo las condiciones NOCT. Para esto, $\mathrm{T}_{\text {NOCT }}$ se mide cuando las celdas del MFV alcanza su equilibrio termodinámico con condiciones de trabajo dadas con una irradiancia de $800 \mathrm{~W} / \mathrm{m}^{2}$, manteniendo al MFV en un ambiente con una temperatura de $20^{\circ} \mathrm{C}$ y haciéndole fluir una corriente de aire con una velocidad 1.0 $\mathrm{m} / \mathrm{s}$. Con dichas condiciones, se miden los parámetros eléctricos del dispositivo.

Con el valor de $\mathrm{T}_{\text {NocT }}$ proporcionado por el fabricante del módulo, la constante de propagación $\mathrm{C}_{1}$ está dada por la relación:

$$
\mathrm{C}_{1}=\left(\mathrm{T}_{\text {NOCT }}-20\right) / 800 \quad \text { Ec. } 4.6
$$

Habiendo determinado la temperatura de operación del módulo, es muy simple determinar los valores de sus parámetros eléctricos. Aunque los fabricantes proporcionan los valores de los coeficientes de temperatura de sus productos $\left(\mathrm{d} V_{C A} /\right.$ 
$\left.\mathrm{dT} ; \mathrm{d} I_{C C} / \mathrm{dT}, \mathrm{d} P / \mathrm{dT}, \mathrm{d} \eta / \mathrm{dT}\right)$, para tener una idea del valor de los parámetros eléctricos del módulo, bastaría con considerar los coeficientes que aparecen en la Tabla 4.3.

En consecuencia, el efecto de la absorción de la irradiancia, la temperatura ambiente, y la manera que el módulo disipa el calor debido a los fenómenos de convección propiciados por una corriente de aire, ocasionan un incremento en la temperatura de las celdas (Tc) del módulo. Por lo cual, para valores de Tc arriba de la de referencia $\left(\mathrm{Tc}_{(\mathrm{STC})}=25^{\circ} \mathrm{C}\right)$, el módulo pierde potencia a una razón dado por el coeficiente de temperatura $\mathrm{d} P / \mathrm{dT}$, el cual debe ser proporcionado por el fabricante.

De ésta forma, un módulo trabajando a una temperatura ambiente Tamb y con una irradiancia $G$, se calentará a una temperatura $\mathrm{T}_{\mathrm{C}}$ dada por la relación

$$
\mathrm{T}_{\mathrm{C}}=\mathrm{Tamb}+\mathrm{C}_{1} \boldsymbol{G} \text {; }
$$

y el gradiente de incremento en la temperatura será:

$$
\Delta \mathrm{T}=\mathrm{T}_{\mathrm{C}}-\mathrm{T}_{(\mathrm{STC})} \quad \text { Ec. } 4.7
$$

El porcentaje de las pérdidas por temperatura en la Potencia Pico, $\mathrm{PP}_{P}$, estarán dadas por:

$$
\mathrm{P}_{P}=(\mathrm{d} P / \mathrm{dT}) \times \Delta \mathrm{T} \% \quad \text { Ec. } 4.8
$$

Y la Potencia Pico, $P_{P}(\mathrm{Tc})$, generada cuando el módulo está caliente a la temperatura de la celda $\mathrm{T}_{\mathrm{C}}$ será:

$$
P_{P}\left(\mathrm{~T}_{\mathrm{C}}\right)=P_{P}(\mathrm{STC})-P_{P}(\mathrm{STC}) \times \mathrm{P} P_{P} \%=P_{P}(\mathrm{STC})\left[1-\mathrm{P} P_{P}\right] \text {; y como }
$$
consecuencia

$$
P_{P}\left(\mathrm{~T}_{\mathrm{C}}\right)=P_{P}(\mathrm{STC})\left[1-\mathrm{P} P_{P}\right] \text {; o bien } P_{P}\left(\mathrm{~T}_{\mathrm{C}}\right) / P_{P}(\mathrm{STC})=\left[1-\mathrm{P} P_{P}\right] \text {; }
$$

Si a la expresión $\left[1-\mathrm{P}_{P}\right.$ ] se le llama el Rendimiento Térmico del módulo, simbolizado por $\mathrm{R}_{\mathrm{T}}$, entonces: 


$$
\mathrm{R}_{\mathrm{T}}=\left[1-\mathrm{P} P_{P}\right] ; \quad \text { Ec. } 4.9
$$

y en consecuencia la Potencia Pico del MFV

cuando esta caliente será

$$
P_{P}\left(\mathrm{~T}_{\mathrm{C}}\right)=\mathrm{R}_{\mathrm{T}} P_{P}(\mathrm{STC})
$$

El Rendimiento Térmico de un módulo no es un valor constante ni absoluto, depende de la temperatura de la celda que es función de la temperatura ambiente y de la magnitud de la irradiancia, en consecuencia se puede estimar un valor promedio, en términos de valores promedios para los parámetros mencionados anteriormente.

Ejemplo: Considere al fabricante de módulos KYOCERA. El producto modelo KD320GX-LPB genera bajo STC una potencia pico $P_{P}=320 \mathrm{~W}$, la temperatura de la celda bajo condiciones NOCT es de $\mathrm{T}_{\text {NOCT }}=45^{\circ} \mathrm{C}$ y su coeficiente de temperatura $\mathrm{d} P / \mathrm{dT}=-0.45 \% /{ }^{\circ} \mathrm{C}$, se requiere calcular la potencia instantánea que se generará cuando la temperatura ambiente es $\mathrm{Tamb}=30^{\circ} \mathrm{C}$ y se presenta una irradiancia de $1,000 \mathrm{~W} / \mathrm{m}^{2}$.

Con los datos del fabricante se determina que el coeficiente de propagación de temperatura de dicho módulo es de $\mathrm{C}_{1}=3.125 \times 10^{-2} \mathrm{~m}^{2 \circ} \mathrm{C} / \mathrm{W}$ y en consecuencia las celdas del módulo adquirirán una temperatura $\mathrm{T}_{\mathrm{C}}=61.2^{\circ} \mathrm{C}$.

El gradiente de temperatura, respecto a la temperatura estándar es:

$\Delta \mathrm{T}=\mathrm{T}_{\mathrm{C}}(\mathrm{Tamb})-\mathrm{T}_{\mathrm{C}}(\mathrm{STC})=61.2^{\circ} \mathrm{C}-25^{\circ} \mathrm{C}=36.2^{\circ} \mathrm{C}$

Las pérdidas por temperatura en la potencia están dados por el coeficiente de temperatura del módulo, valor que es proporcionado por el fabricante que, en este caso es: $\mathrm{d} P / \mathrm{dT}=(-$ $0.45 \%) /{ }^{\circ} \mathrm{C}$; por lo cual, el porcentaje de pérdida de la potencia pico es:

$P P_{P}=(-0.45 \%) \times(\Delta \mathrm{T})=(-0.45 \%) \times(36.2)=16.29 \% ; \mathrm{y}$ entonces $\mathrm{P} P_{P}=16.29 \%$ de la potencia pico. Así, el Rendimiento Térmico del módulo es: 
$\mathrm{R}_{\mathrm{T}}=\left(1-\quad P P_{P} \%\right)=100 \%-16.29 \%=83.71 \% ; \quad$ o $\quad$ bien, $\mathrm{R}_{\mathrm{T}}=0.8371$

En consecuencia, cuando el módulo está caliente generará una potencia $P_{P}\left(\mathrm{~T}_{\mathrm{C}}\right)$ dada por:

$$
P_{P}\left(\mathrm{~T}_{\mathrm{C}}\right)=\quad P_{P}(\mathrm{STC})-\quad P_{P}(\mathrm{STC}) \mathrm{x} \quad \quad P_{P}=320-
$$

$(320 \times 16.29 / 100)=267.9 \mathrm{~W}$; o bien,

$$
P_{P}\left(\mathrm{~T}_{\mathrm{C}}\right)=P_{P}(\mathrm{STC}) \times R_{\mathrm{T}}=320 \times 0.8371=267.9 \mathrm{~W}
$$

Dado que la magnitud de los coeficientes de temperatura depende del fabricante y con el objeto de tener un marco de referencia de valores para los mismos y para las distintas tecnologías, se realizó una búsqueda de información para los módulos disponibles comercialmente y crear una tabla de valores promedio para los tres coeficientes de temperatura para las diferentes tecnologías. La Tabla 4.4 muestra los valores promedios determinados a partir de los valores de las ofertas comerciales. En dicha tabla se puede observar que la tecnología que presenta las menores pérdidas por efecto de la temperatura es la híbrida de a-si/m-Si (HIT), siguiendo por la tecnología de CdTe. La tecnología que tiene las mayores pérdidas es la de m-Sl.

Tabla 4.4: Valores promedio para los coeficientes de temperatura de las ofertas comerciales para las diferentes tecnologías FV's.

\begin{tabular}{|c|c|c|c|c|c|c|c||}
\hline \hline \multirow{2}{*}{$\begin{array}{c}\text { COEFICIENTES DE } \\
\text { TEMPERATURA } \\
\% /{ }^{\circ} \mathrm{C}\end{array}$} & \multicolumn{6}{|c||}{ TECNOLOGIAS FOTOVOLTAICAS COMERCIALES } \\
\cline { 2 - 8 } & $\mathrm{m}-\mathrm{Si}$ & $\mathrm{p}-\mathrm{Si}$ & $\mathrm{m} / \mathrm{a}-\mathrm{Si}$ & $\mathrm{a}-\mathrm{Si}$ & $\mathrm{CdTe}$ & $\mathrm{CIGS}$ & $\mathrm{CIS}$ \\
\hline Potencia: $\mathrm{\gamma}=\mathrm{d} P / \mathrm{dT}$ & -0.51 & -0.4 & -0.24 & -0.36 & -0.25 & -0.38 & -0.45 \\
\hline $\mathrm{VCA}: \beta=\mathrm{d} V_{C A} / \mathrm{d} T$ & -0.36 & -0.34 & -0.3 & -0.36 & -0.25 & -0.29 & -0.43 \\
\hline ICC: $\alpha=\mathrm{d} /{ }_{C} d \mathrm{dT}$ & 0.061 & 0.06 & 0.07 & 0.16 & 0.04 & 0.01 & 0.013 \\
\hline
\end{tabular}

Con dichos valores, la pérdida en la potencia pico en función de la temperatura ambiente, para una localidad específica, evaluada con una irradiancia pico $\left(\mathrm{G}=1.0 \mathrm{~kW} / \mathrm{m}^{2}\right)$, para las diferentes tecnologías se muestra en la Tabla 4.5. Se constata que la mayor pérdida la presenta la tecnología de silicio monocristalino. 
Tabla 4.5: Perdidas en la potencia pico en función de la temperatura ambiente para una $\mathrm{G}=1.0 \mathrm{~kW} / \mathrm{m}^{2}$.

\begin{tabular}{|c|c|c|c|c|c|c|c||}
\hline \hline $\begin{array}{c}\text { TEMPERATURA } \\
\text { AMBIENTE } \\
\left({ }^{\circ} \mathrm{C}\right)\end{array}$ & \multicolumn{7}{|c||}{ PÉRDIDAS EN LA POTENCIA PICO (\%) } \\
\cline { 2 - 8 } & $\mathrm{m}-\mathrm{Si}$ & $\mathrm{p}-\mathrm{Si}$ & $\mathrm{m} / \mathrm{a}-\mathrm{Si}$ & $\mathrm{a}-\mathrm{Si}$ & $\mathrm{CdTe}$ & $\mathrm{CIGS}$ & $\mathrm{CIS}$ \\
\hline 45 & 22.9 & 19.2 & 10.8 & 16.2 & 11.2 & 19.5 & 21.1 \\
\hline 40 & 20.4 & 17.2 & 9.6 & 14.4 & 10.0 & 17.5 & 18.9 \\
\hline 35 & 17.8 & 15.2 & 8.4 & 12.6 & 8.7 & 15.6 & 16.6 \\
\hline 30 & 15.3 & 13.2 & 7.2 & 10.8 & 7.5 & 13.7 & 14.4 \\
\hline 25 & 12.7 & 11.2 & 6.0 & 9.0 & 6.2 & 11.8 & 12.1 \\
\hline
\end{tabular}

Los porcentajes de pérdida en la potencia mostrados en la Tabla 4.5 se pueden usar para estimar por omisión, el valor del Rendimiento Térmico $\mathrm{R}_{\mathrm{T}}$ de cada tecnología.

\subsection{El voltaje de diseño bajo condiciones de operación}

Se ha dicho que los MFV de silicio cristalino se pueden fabricar conectando un número determinado de celdas en serie para dar un voltaje de carga para acumuladores de $12 \mathrm{~V}$ nominales. Se especificó que dicho número debe ser mayor de 30 celdas. Ahora, se considerará el efecto de la temperatura sobre el desempeñó de esos módulos.

Para esto, considérese que todos los módulos de silicio cristalino tienen un coeficiente de temperatura negativo en el voltaje de $2.3 \mathrm{mV} /{ }^{\circ} \mathrm{C}$ y una temperatura de celda en operación de $45^{\circ} \mathrm{C}\left(\mathrm{T}_{\text {NoCT }}=45^{\circ} \mathrm{C}\right)$. Se analizará que voltajes son los esperados en el punto de máxima potencia a una irradiancia del $80 \%\left(G=800 \mathrm{~W} / \mathrm{m}^{2}\right)$. Por conveniencia se definirá como clima frío, clima templado, clima cálido y clima caliente, aquellos cuya temperatura ambiente promedio diaria en verano no sea mayor de $5^{\circ} \mathrm{C}, 15^{\circ} \mathrm{C}, 25^{\circ} \mathrm{C}$ y $35^{\circ} \mathrm{C}$, respectivamente. La Tabla 4.6 muestra los valores del voltaje en el punto de máxima potencia de módulos con 30, 33 y 36 celdas, así como el valor medido bajo STC. 
Los valores condensados en la Tabla 4.6 permiten establecer ciertas aseveraciones importantes respecto del acoplamiento módulo-acumulador-carga. Para esto supongamos que las caídas de voltaje en los cables de conexión módulo-acumulador-carga, es del orden de $0.36 \mathrm{~V}$ (3\% del voltaje nominal de $12 \mathrm{~V})$.

Tabla 4.6: Valores del voltaje en el punto de máxima potencia, $\mathrm{V}_{\mathrm{MP}(\mathrm{m})}$ para módulos de 30, 33 y 36 celdas en serie en función de la temperatura ambiente. Los valores están redondeados a una cifra decimal. El valor de la irradiancia considerada es de $800 \mathrm{~W} / \mathrm{m}^{2}$. Entre paréntesis aparece el voltaje a circuito abierto del módulo.

\begin{tabular}{||c|c|c|c|c|c|c||}
\hline \multicolumn{2}{|c|}{ MÓdULO $\mathrm{x}-\mathrm{Si}$} & \multicolumn{4}{c|}{ TEMPERATURA AMBIENTE } \\
\hline No. de celdas & $\mathrm{d} V_{\mathrm{MP}(\mathrm{m})} / \mathrm{dT}$ & $25^{\circ} \mathrm{C}$ & $5^{\circ} \mathrm{C}$ & $15^{\circ} \mathrm{C}$ & $25^{\circ} \mathrm{C}$ & $35^{\circ} \mathrm{C}$ \\
\hline 30 & $69 \mathrm{mV} /{ }^{\circ} \mathrm{C}$ & $14.6(18)$ & $14.3(17.7)$ & $13.6(17.0)$ & $12.9(16.3)$ & $12.2(15.6)$ \\
\hline 33 & $76 \mathrm{mV} /{ }^{\circ} \mathrm{C}$ & $15.9(19.8)$ & $15.5(19.4)$ & $14.8(18.7)$ & $14.0(17.9)$ & $13.2(17.1)$ \\
\hline 36 & $82 \mathrm{mV} /{ }^{\circ} \mathrm{C}$ & $17.4(21.7)$ & $17.0(21.3)$ & $16.2(20.5)$ & $15.4(19.7)$ & $14.5(18.8)$ \\
\hline
\end{tabular}

Así, se puede establecer 4 situaciones especiales para seleccionar el módulo de mejor desempeño para la aplicación específica:

a) El módulo de 30 celdas proporciona un voltaje de carga aceptable para acumuladores en localidades de clima frío o templado (en clima templado $V_{M P}=13.6-0.36=13.24 \mathrm{~V}$ ). Para otro tipo de clima, el acumulador se acoplaría al módulo en la zona de voltajes mayores del $V_{M P}$, lejos del punto de máxima potencia, trayendo como consecuencia un sistema de carga con valores bajos de corriente de inyección hacia el acumulador, y en consecuencia, perdiendo potencia generada. Si el proyectista no considera ésta pérdida de potencia, el sistema en general estará desbalanceado energéticamente, habrá más energía consumida y como conclusión, la batería no se cargará.

b) El razonamiento anterior se puede aplicar para los módulos de 33 celdas que sean instalados en zonas calientes $\left(V_{M P}\right.$ $=13.2-0.36=12.84 \mathrm{~V})$. Este módulo se recomienda aplicar- 
lo en proyectos en donde la temperatura ambiente máxima sea $25^{\circ} \mathrm{C}$.

c) El módulo de 36 celdas se puede aplicar en todo tipo de climas. Es recomendado sobre todo para sitios en donde la distancia módulo-acumulador sea grande (del orden de 15 metros). Se hará más énfasis en éste aspecto cuando se analice el diseño de sistemas fotovoltaicos.

d) Por otra parte, el voltaje de máxima potencia del módulo de 36 celdas, cuando está caliente, se sitúa alrededor de un voltaje promedio de 15 volt, es decir, $V_{M P(\mathrm{~m})}($ caliente) » 15 V. Éste módulo es recomendado para los sistemas de bombeo, ya que los fabricantes de sistemas de bombeo fabrican sus motores eléctricos con voltajes nominales en múltiplos de 15 Volt.

De lo anterior se puede establecer que los módulos de 36 celdas son adecuados para cualquier tipo de aplicación, ya sea en conexión directa o acoplados con acumuladores. Y en todos los casos bajo condiciones reales de operación el voltaje de acoplamiento se situará alrededor de los 15 volt, o en múltiplos de éste número para MFV conectados en serie.

En consecuencia, para los módulos fabricados con 33 o 36 celdas en serie (o bien de 72 celdas en serie considerando que el valor $\mathrm{V}_{\mathrm{N}}$ será del doble para el de 36 celdas en serie), se puede establecer el concepto de voltaje nominal de un módulo, $V_{\mathrm{N}(\mathrm{m})}$ bajo las siguientes consideraciones:

a) Dado que el voltaje nominal de los acumuladores de plomo-ácido de 6 celdas es $12 \mathrm{~V}$, se acostumbra a decir que los módulos fotovoltaicos de 33-36 celdas tiene un voltaje nominal de $12 \mathrm{~V}\left(\mathrm{~V}_{\mathrm{N}}=24 \mathrm{~V}\right.$ para los módulos de 72 celdas en serie). Esto se aplica comúnmente en los conceptos de diseño para sistemas con voltaje nominal menor o igual a $48 \mathrm{~V}$.

$V_{\mathrm{N}(\mathrm{m})}=12 \mathrm{~V}$ para acumuladores cuyo voltaje nominal sea múltiplo de $12 \mathrm{~V}$; 
b) Ya que la mayoría de los fabricantes de bombas fabrican sus equipos con voltajes nominales que son múltiplos de $15 \mathrm{~V}$, en un sistema de bombeo en donde el módulo se acoplará directamente a la carga sin acumulador de electricidad, se dice que el módulo de 36 celdas tiene un voltaje nominal de $15 \mathrm{~V}$.

$V_{\mathrm{N}(\mathrm{m})}=15 \mathrm{~V}$ para bombas cuyo voltaje nominal sea múltiplo de $15 \mathrm{~V}$.

Sin embargo, con el objeto de disminuir la cantidad de módulos que habría que conectar en serie para proporcionar voltajes mayores de $12 \mathrm{~V}$, los fabricantes de módulos también construyen MFV's de 72 celdas conectadas en serie, para proporcionar voltajes nominales de 24 volt para bancos de baterías a $24 \mathrm{~V}$ nominales, o en el caso de acoplamiento directo (sin baterías), para motores que trabajen con voltajes nominales múltiplos de 30 volt (60, 90, 120 volt nominales).

Con el concepto de módulo fotovoltaico se establece la unidad con la cual se comercializa la tecnología FV. Estos fueron diseñados en un principio como dispositivos cargadores de baterías de $12 \mathrm{~V}$ nominales corriente directa (CD), así que debían producir electricidad con un voltaje efectivo alrededor de $15.0 \mathrm{~V}$ a la carga. Para esto, en el caso de celdas de silicio cristalino, cuyo $V_{C A}$ es alrededor de $0.6 \mathrm{~V}$ (ver Tabla 4.1 ), se han usado 36 celdas conectadas en serie para fabricar módulos $\mathrm{FV}$, con un $V_{C A} \cong 21.0 \mathrm{~V}$, que proveen el voltaje necesario para cargar eficientemente a la batería. Sin embargo, para otras tecnologías, como es el caso del silicio amorfo a-Si triple unión, con un $V_{C A}=2.297 \mathrm{~V}$ por celda, sólo se requieren 10 de ellas conectadas en serie para tal propósito $\left(V_{C A}=22.97 \mathrm{~V}\right)$.

En la actualidad, la aplicación específica de un MFV está dada por el voltaje de operación de la carga, la que define el voltaje nominal de la tecnología; y por esta razón, hay actualmente en el mercado una gama amplia de módulos con diferentes características eléctricas. Dentro de éstos destacan los 
diseñados para cargar baterías a 12 VCD nominales o múltiplos de éste valor (casi todos los de silicio cristalino se han fabricado para tal propósito); los diseñados para su uso en sistemas de bombeo de agua con voltaje nominales de 60 y 120 V CD (caso especial el de los módulos bicapas de a-Si fabricados por BPSolar; y los de CdTe fabricados por First Solar; estos dos últimos son diseño especial para las bombas Grundfos); y los diseñados para aplicaciones de interconexión de la red, fabricados con 54, 60, 72, 80, 96 celdas conectadas en serie. En éste último caso, ya que el voltaje residencial en el continente americano es de 127/220 VAC, y que para la interconexión a la red se requiere de un inversor $\mathrm{CD} / \mathrm{CA}$, cuyo voltaje de alimentación en corriente directa depende de la configuración propia del fabricante del mismo, el número de módulos conectados en serie se deben cuantificar en función del voltaje de alimentación del inversor.

\subsection{Arreglos fotovoltaicos}

En muchas aplicaciones la potencia generada por el módulo no basta para activar una carga eléctrica, por ésta razón y usando la ventaja de que la generación de electricidad es de corriente directa, los módulos se pueden conectar en serie o en paralelo para incrementar la potencia de trabajo, y formar una nueva estructura llamada el arreglo fotovoltaico. Es importante considerar que para formar los arreglos fotovoltaicos, los módulos deben tener características eléctricas idénticas para evitar la formación de los llamados "puntos calientes".

\section{7.a. Incrementando el voltaje}

La conexión en serie de módulos idénticos dará un arreglo con un voltaje de salida dado como la suma de los voltajes de cada módulo. Si se considera que se tiene N módulos idénticos conectados en serie, las características eléctricas de ésta nueva asociación, a la que se le llamará panel fotovoltaico 
o cadena, tendrán como voltaje, la suma de cada uno de los voltajes de los módulos; y como corriente, la misma corriente que genera un módulo. Para fines nemotécnicos sólo se considerarán 4 módulos idénticos. La Fig. 4.12 muestra la conexión de estos 4 módulos en serie.

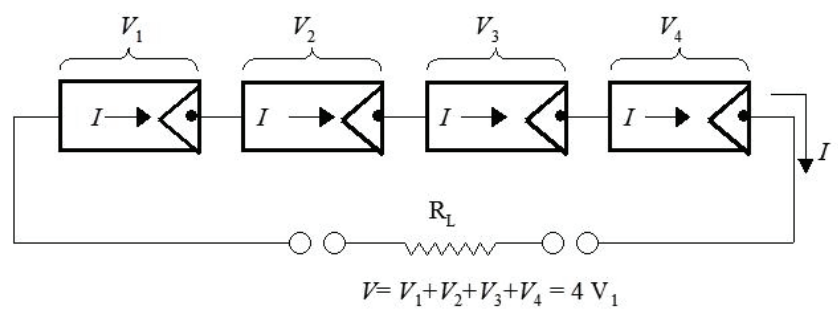

Figura 4.12: Conexión en serie de 4 módulos idénticos.

Así, si se llama $V_{C A}(1), I_{C C}(1)$, al voltaje a circuito abierto y corriente a corto circuito, respectivamente del módulo 1; y así sucesivamente para los otros módulos, entonces las características eléctricas de la asociación tipo serie, para módulos idénticos, estará dadas por:

$$
V_{C A}(S)=4 V_{C A}(1) \text {. }
$$

La corriente a corto circuito de la asociación serie, $I_{C C}(\mathrm{~S})$, es igual al valor de la corriente a corto circuito de cualquiera de los 4 módulos ya que éstos tienen el mismo valor por ser módulos idénticos, de donde:

$$
I_{C C}(S)=I_{C C}(1)=I_{C C}(2)=I_{C C}(3)=I_{C C}(4) \text {. }
$$

Si se conecta una carga eléctrica con resistencia de carga $\mathrm{R}_{\mathrm{L}}$, entonces el voltaje de operación de la carga, $V_{\mathrm{OP}}(\mathrm{S})$, estará dado como la suma de los voltajes de acoplamiento de la carga eléctrica en cada uno de los módulos; es decir, si $V_{1}, V_{2}, V_{3}, V_{4}$, son esos voltajes, entonces

$$
V_{O P}(S)=V_{1},+V_{2}+V_{3}+V_{4} .
$$


Como las celdas son idénticas, la corriente de operación de la carga eléctrica en cada celda será la misma que la de la asociación en serie, de donde

$$
I_{\mathrm{OP}}(\mathrm{S})=I_{1}=I_{2}=I_{3}=I_{4}=I
$$

\section{7.b. Incrementando la corriente}

Ya que celdas solares idénticas conectadas en paralelo forman una asociación cuya corriente de salida es igual a la suma de las corrientes individuales de cada celda, la conexión en paralelo de módulos fotovoltaicos idénticos formará una asociación cuya corriente de salida será igual a la suma de las corrientes individuales de cada módulo. La Fig. 4.13 muestra una representación esquemática de la conexión en paralelo de módulos idénticos. Para fines nemotécnicos sólo se han considerado 4 módulos, pero el razonamiento se aplica para cualquier número de módulos conectados en serie. La condición es que todos ellos tengan idénticas características eléctricas.

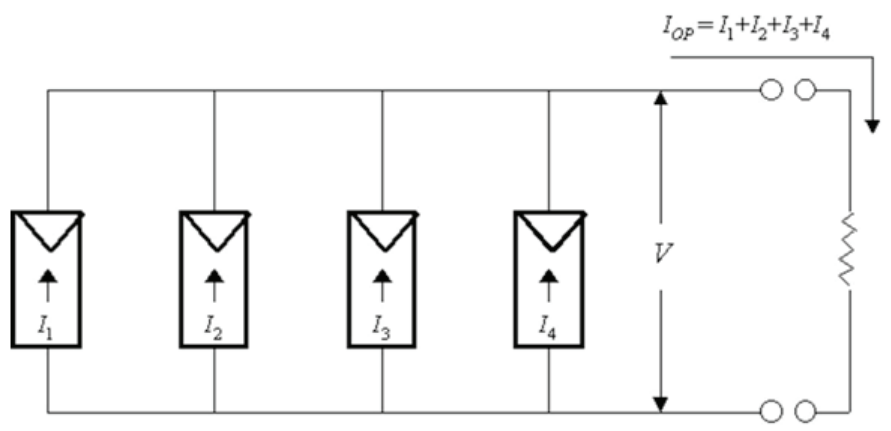

Figura 4.13: Diagrama esquemático de la conexión en paralelo de módulos idénticos.

Si $\mathrm{V}_{\mathrm{CA}}(\mathrm{P})$ es el voltaje a circuito abierto de la asociación en paralelo, entonces

$$
V_{C A}(\mathrm{P})=V_{C A}(1)=V_{C A}(2)=V_{C A}(3)=V_{C A}(4) .
$$

Si $I_{C C}(\mathrm{P})$ es la corriente a corto circuito de la asociación en paralelo, entonces

$$
I_{C C}(\mathrm{P})=4 I_{C C}(1)
$$


Si se conecta una carga $R_{L}$ a la asociación entonces se tendrá que la corriente de operación de la carga, $I_{\mathrm{OP}}$ estará dada

$$
I_{\mathrm{OP}}=I_{1}+I_{2}+I_{3}+I_{4}
$$

donde $I_{1}, I_{2}, I_{3}$, e $I_{4}$ son la corriente de operación que consume la carga cuando se conecta a cada módulo individualmente.

Para evitar el flujo de corriente en la dirección opuesta cuando se conectan módulos en serie y en paralelo, se utilizan diodos de bloqueo en todos los paneles o cadenas de módulos conectados en paralelo; y los diodos de paso, en todos los módulos conectados en serie. Estos dispositivos proporcionan un camino de alivio para evitar que circule corriente por un panel o un módulo sombreado (sombra de nubes o de objetos). Un módulo sombreado no genera energía, por lo cual, los demás módulos lo verán como un punto de resistencia. En consecuencia, fluirá corriente hacia él convirtiéndose en un punto caliente del arreglo; aumentará su temperatura y se degradará aceleradamente.

\section{7.c.- El arreglo fotovoltaico}

Cuando la potencia demandada es alta, se recomienda primero analizar qué tipo de sistema es el que se alimentará. En el caso de acoplamiento directo módulos-carga, se identifica cual es el rango de voltaje en el que operará la carga eléctrica para que, con una combinación en serie de módulos, sea suministrado el voltaje de operación. Recuerde que los módulos conectados en serie forman una estructura llamada panel.

Si el módulo se acopla con acumuladores de 12 volt nominales, recordando que para garantizar el $100 \%$ de carga se requiere de un voltaje del orden de 14.4 volt, entonces por cada acumulador en serie se requiere de un módulo de 36 celdas. Esta regla básica es válida para sistemas con voltajes nominales de hasta 48 Volt. La Fig. 4.14 muestra la conexión serie y paralelo de módulos acoplados con acumuladores. 


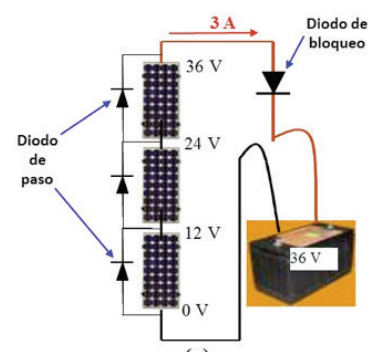

(a)

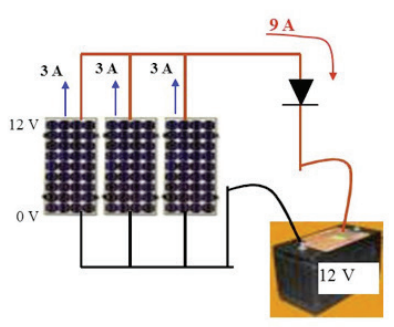

(b)

Figura 4.14: Diagrama esquemático de la conexión entre módulos y un acumulador. En (a) se tiene la conexión en serie, y en (b) la conexión en paralelo.

Generalmente, bajo la configuración de acoplamiento directo, las cargas son motores eléctricos conectados a dispositivos mecánicos que producen trabajo, como es el caso de las bombas para extraer agua. Valores de voltaje de operación menores de 17 volt pueden ser alimentados con un solo módulo; valores mayores de 22 volt y menores de 34 volt se alimentan con dos módulos; y así sucesivamente. En ésta configuración la carga se acoplará al módulo con un voltaje demandado por su propia impedancia eléctrica. Ya que el voltaje de máxima potencia de un solo módulo de 36 celdas, cuando está caliente y cercano a las condiciones normales de operación, es aproximadamente 15 Volt, los fabricantes de dichos motores los hacen ajustando la impedancia eléctrica con rangos de valores cercanos a ese valor. De ésta manera pretenden garantizar que el módulo y la carga trabajarán en puntos cercanos a la máxima potencia generada por aquel. Por la razón anterior, los fabricantes de bombas para aplicaciones fotovoltaicas asignan un voltaje nominal a sus cargas en múltiplos de 15 volt.

Habiendo estimado el número de módulos necesarios para proporcionar el voltaje de operación y formar el panel o cadena $\mathrm{FV}$, es necesario estimar cuantos paneles se requieren conectar en paralelo para que la corriente producida multiplicada por la irradiación (irradiancia acumulada al día), genere 
la energía eléctrica que consumirá la carga acoplada durante el día.

La estructura formada con los paneles conectados en paralelo recibe el nombre de arreglo fotovoltaico (AFV). La Fig. 4.15 muestra el diagrama esquemático de un AFV en donde se han colocado los diodos de paso y de bloqueo para disminuir la probabilidad de los puntos calientes.

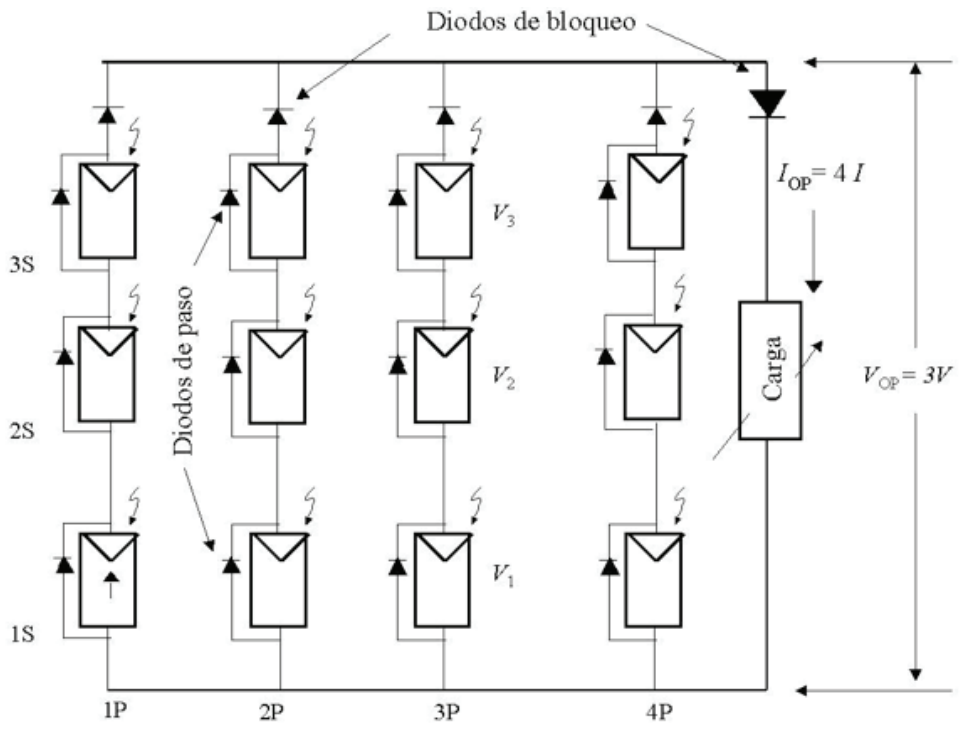

Figura 4.15: Un AFV compuesto por 3 módulos en serie, los que forman el panel para proporcionar el voltaje de operación, y 4 paneles conectados en paralelos para proporcionar la potencia. La configuración así formada se especifica como $35 \times 4 P$.

La configuración eléctrica de dicho arreglo está formada por 3 módulos conectados en serie (formando el panel que dará el voltaje de operación de la carga), y 4 paneles o cadenasconectados en paralelo, que generarán la corriente necesaria que consumirá la carga. Dicha configuración suele especificarse como 3Sx4P (3 módulos en serie y 4 paneles en paralelo). 
Si cada módulo entrega un voltaje $V$ y una corriente $I$, en la carga se tendrá:

Voltaje de operación $V_{\mathrm{OP}}=3 V$;

con una corriente de operación $I_{\mathrm{OP}}=4 I$; y en consecuencia, $P=12$ VI

Es importante aclarar que los arreglos fotovoltaicos deben de construirse usando módulos cuyas características eléctricas sean idénticas para evitar los desbalances eléctricos y la probabilidad de formación de los puntos calientes.

Así, se ha llegado a formar toda una configuración de módulos llamada el arreglo fotovoltaico cuya base de formación es la celda solar. La Fig. 4.16 muestra un diagrama esquemático de los componentes fundamentales del AFV el cual puede tener potencias desde unos cuantos watt hasta potencias del orden de Megawatt.

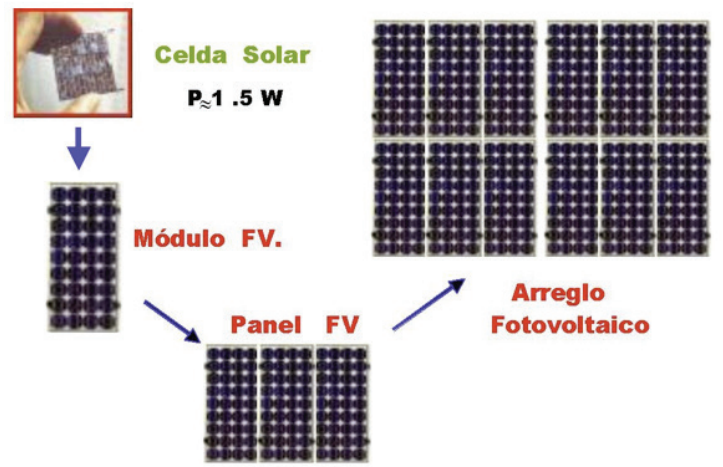

Figura 4.16: Desde unos cuantos Watt hasta Megawatt

\subsection{Energía generada por un módulo}

La energía generada por un módulo, panel o arreglo FV no sólo depende de la potencia del módulo individual, si no que depende de la cantidad de radiación solar disponible en el sitio así como de factores geográficos y de orientación. A la cantidad de radiación solar que recibe una localidad se le 
conoce como el Recurso Solar, $H$, el que está definido como la energía disponible calculada al integrar la variación de la irradiancia $(\boldsymbol{G})$ en las horas solares. Generalmente $\boldsymbol{H}$ se expresa en Joule $/ \mathrm{m}^{2}$, pero para aplicaciones FV's se usan las unidades de $\mathrm{Wh} / \mathrm{m}^{2}$, o bien "hora-pico", h-pico, entendiéndose como la cantidad de horas en que hipotéticamente el sol entregó el $100 \%$ de la Irradiancia $\left(1,000 \mathrm{~W} / \mathrm{m}^{2}\right)$.

Para dar una idea de la cantidad de energía que pueda generar un módulo, supóngase que se tiene una carga que se acoplará al módulo en su punto de máxima potencia. Como el módulo estará expuesto al sol, su potencia se verá reducida debido al calentamiento. Al considerar éste valor, la energía generada por el módulo se obtiene mediante el producto del recurso solar, expresado en horas pico, por la potencia del módulo cuando éste está caliente. La Tabla 4.7 muestra los valores de energía máxima que proporcionarían los módulos considerados si es que se tiene el recurso solar dado.

De dicha tabla se puede observar que un mismo módulo genera valores diferentes de energía debido a valores diferentes del recurso solar. Considerando la tabla anterior, un arreglo fotovoltaico con configuración 3Sx4P de módulos de $50 \mathrm{Wp}$ por ejemplo, con un recurso promedio diario anual de $4.3 \mathrm{Wh} / \mathrm{m}^{2}$ (4.3 h-pico), generará una energía promedio diario anual de 2,270.4 Wh, con un voltaje nominal de $36 \mathrm{~V}$ para cargar acumuladores; o bien, con un voltaje nominal de $45 \mathrm{~V}$ para acoplarse a un sistema de bombeo.

Tabla 4.7: Energía generada por módulos comerciales de silicio cristalino en función del recurso solar, en el punto de máxima potencia.

\begin{tabular}{|c|c|c|c|c|c|c|}
\hline \multirow{4}{*}{$\begin{array}{c}P_{P} \text { bajo STC: } \\
\mathrm{G}=1000 \mathrm{~W} / \mathrm{m}^{2} \\
\text { Tc }=25^{\circ} \mathrm{C}\end{array}$} & \multirow{4}{*}{$\begin{array}{c}P_{P} \\
\mathrm{G}=1000 \mathrm{~W} / \mathrm{m}^{2} ; \mathrm{y} \\
\mathrm{T} \mathrm{c}=55^{\circ} \mathrm{C}\end{array}$} & \multicolumn{5}{|c|}{$\begin{array}{l}\text { RECURSO SOLAR (HORAS-PICO) } \\
\text { Promedio diario anual }\end{array}$} \\
\hline & & Primavera & Verano & Otoño & Invierno & Anual \\
\hline & & 4.7 & 4.3 & 4.0 & 4.2 & 4.3 \\
\hline & & \multicolumn{5}{|c|}{ Energía producida al día por módulo (Wh) } \\
\hline $50 \mathrm{~W}$ & $44 \mathrm{~W}$ & 206.8 & 189.2 & 176 & 184.8 & 189.2 \\
\hline $60 \mathrm{~W}$ & $52.8 \mathrm{~W}$ & 248.2 & 227.0 & 211.2 & 221.8 & 227.0 \\
\hline $75 \mathrm{~W}$ & $66 \mathrm{~W}$ & 310.2 & 283.8 & 264.0 & 277.2 & 283.8 \\
\hline $100 \mathrm{~W}$ & $88 \mathrm{~W}$ & 413.6 & 378.4 & 352.0 & 369.6 & 378.4 \\
\hline
\end{tabular}




\subsection{Orientación óptima del arreglo fotovoltaico}

Los módulos deben de montarse en estructuras que permitan orientar su superficie hacia los rayos solares. Dado que la máxima captación de energía solar recibida en un captador se realiza cuando los rayos caen perpendicularmente sobre la superficie de éste, la máxima generación de electricidad producida por un módulo, se llevará a cabo cuando el módulo siga al Sol durante el día y durante el año. Esto significa montar al módulo en una estructura con seguimiento en dos ejes, lo cual sólo se puede dar usando motores eléctricos y un sistema de orientación computarizado. En el caso de arreglos de baja potencia, aunque la ganancia en energía puede ser hasta del 50\%, el costo involucrado en el seguidor puede ser alto comparado con la ganancia de energía que se obtendría. Por otra parte, en el medio rural, sin atención de algún operario especializado, estos sistemas no presentan mucha confiabilidad.

La otra alternativa de obtener más energía generada al día es mantener el módulo o arreglo a un ángulo de elevación fijo, y seguir al Sol diariamente. La ganancia en este tipo de seguidores es del orden del 30\%. Este tipo de seguimiento se puede hacer de una manera pasiva o con un motor eléctrico. Desafortunadamente en ambos casos, el sistema de seguimiento puede ser más caro que el $30 \%$ adicional de energía que produciría el arreglo montado en éste tipo de estructuras. La Fig. 4.17 muestra una fotografía típica de un seguidor solar pasivo. 


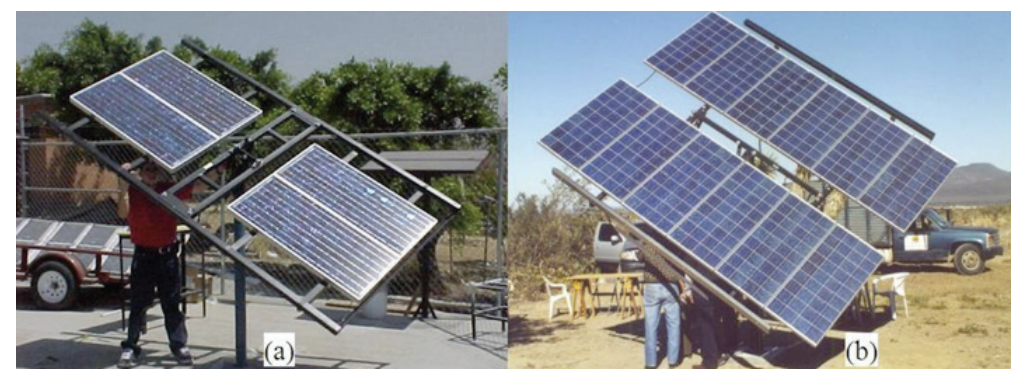

Figura 4.17: Seguidor solar pasivo. En (a) se muestra una estructura para 4 módulos; y en (b) una estructura para 12 módulos.

No se recomienda el uso de seguidores solares en sitios en donde se espera muchos días nublados ya que la energía generada es del mismo orden que aquella que se obtendría si el arreglo ó módulo estuviera fijo. Por ésta razón y la económica, es importante realizar el estudio energético con el fin de estimar la estructura óptima que garantice la mayor energía al menor costo.

Para arreglos o módulos montados en estructuras fijas, la orientación y el ángulo de inclinación de ella es de mucha importancia en la generación de energía. Se estableció que debido a la declinación solar, el módulo debe estar orientado hacia el Sur geográfico (o verdadero). Ahora, si se desea que el módulo genere la máxima energía promedio al año, el ángulo de inclinación, $\beta$, del módulo o arreglo, provisto por la estructura, debe ser igual al valor de la latitud, L, del lugar; es decir,

Máxima energía captada al año solo si $\beta=\mathrm{L}$

Sin embargo, existen temporadas del año en las que se desea beneficiar la energía generada en esa época. Con dicha condición, se debe de garantizar que $\beta$ tenga un valor tal que los rayos incidan perpendicularmente a la superficie del arreglo. Esto se logra haciendo que

$$
\beta=\mathrm{L}-\delta
$$

siendo $\delta$ el valor de la declinación promedio en esa época del año. 
Para el caso de sistemas de bombeo la inclinación del arreglo debe de garantizar la máxima generación de energía con la que se tendrá la máxima producción de agua, en el mes con mayor demanda de agua, la que coincide con el estiaje.

Si se desea maximizar la generación de energía en el Invierno, la inclinación del arreglo debe estar dada por la relación

$$
\text { INVIERNO } \quad \beta=\mathrm{L}+15^{\circ}
$$

Para el caso de que se desee maximizar en verano, la inclinación del arreglo debe ser

$$
\text { VERANO } \quad \beta=\mathrm{L}-15^{\circ}
$$

\subsection{Los sistemas fotovoltaicos}

Se ha establecido que la tecnología FV se comercializa en unidades de diferentes tamaños llamadas "módulos fotovoltaicos", MFV, todos ellos referidas a la potencia máxima que pueden generar bajo condiciones estándares de prueba, existiendo desde unos cuantos Watt hasta cientos de Watt (actualmente, $320 \mathrm{~W}$ es la máxima potencia disponible en el mercado $\left.{ }^{17}\right)$.

Los MFV's presentan la característica única de que la electricidad que se genera es de tipo "directo" (corriente directa $\mathrm{CD})$, lo que permite su posible almacenamiento en acumuladores electroquímicos, como lo son las baterías de plomo-ácido.

Las aplicaciones de los MFV's solo están limitadas por la imaginación del diseñador. Ya que la electricidad que producen los MFV's es del tipo CD y se realiza durante las horas sol, sus aplicaciones aparentemente estarían limitadas a cargas en CD que operarían durante el día. Sin embargo, las características de generación eléctrica hacen de los MFV ideales para

17 Producto fabricado varias compañías.. 
cargar acumuladores eléctricos y que sean diseñados como cargadores de baterías. De hecho, los primeros MFV fueron diseñados para que la energía generada sea almacenada en baterías de plomo-ácido, u otro tipo de tecnología como lo son las baterías de niquel-cadmio ó hidruros metálicos. Con controladores electrónicos que regulan el estado de carga de las baterías, los MFV's pueden suministrar la energía que requieran un conjunto de aparatos eléctricos (cargas en CD) cuyo funcionamiento no estaría limitado a las horas solares, si no a discreción del usuario (noche y/o día), es decir, proporcionando el concepto de despachabilidad. Además, gracias al avance de la electrónica que ha permitido diseñar inversores de carga que transforman la CD en corriente alterna (CA), los sistemas MV's pueden usarse para alimentar cualquier tipo de carga eléctrica en CA.

La conjunción de AFV's con acondicionadores de energía (controladores de carga, inversores y electrónica de control), almacenamiento de carga, estructuras para el soporte y orientación del AFV, y los aparatos eléctricos a energizar constituyen lo que se conoce con el nombre de sistema fotovoltaico (SFV); siendo su función generar electricidad a un voltaje específico para su consumo en las cargas eléctricas consideradas. La Figura IV-17 muestra un diagrama esquemático de un SFV.

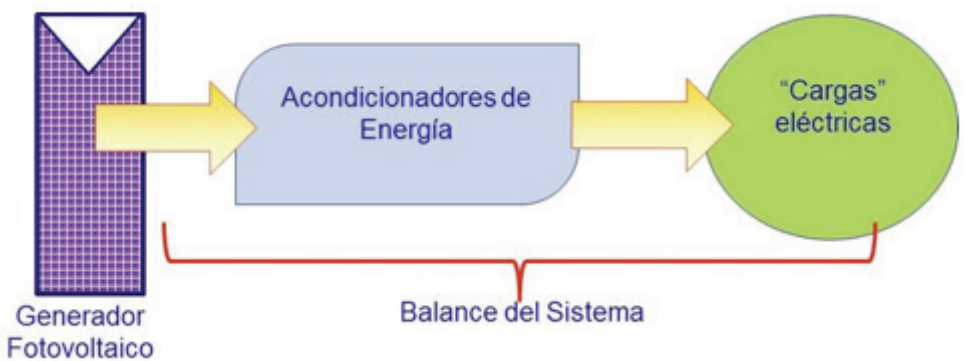

Figura 4.18: Diagrama esquemático de un SFV. 
Los SFV's en los que la única fuente de generación de electricidad es el MFV reciben el nombre de sistemas autónomos (SFV-A), los que pueden incluir cargas eléctricas en CD y/o CA, y que pueden ser sistemas con o sin almacenamiento de energía (con baterías o sin éstas). La Figura 4.19 muestra diagramas esquemáticos de las posibles arquitecturas de SFV-A sin almacenamiento electroquímico, que generalmente se usan cuando la "carga" eléctrica es un motor de corriente directa o alterna que únicamente funciona durante las "horas sol".
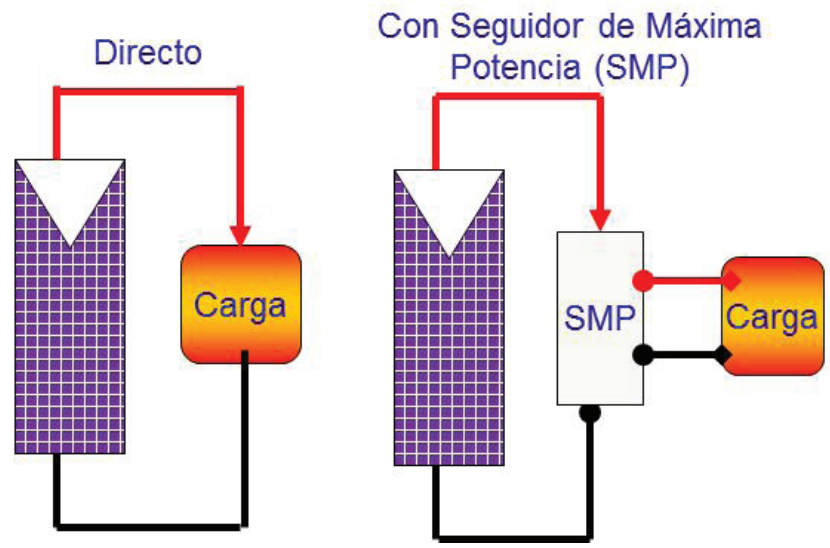

Figura 4.19: Arquitecturas típicas de un acoplamiento directo AFV- "carga" normalmente usadas en aplicaciones de ventilación y bombeo de agua.

Las arquitecturas anteriores sólo son aplicables en los sistemas de bombeo de agua y sistemas de ventilación basados en motores de corriente directa. Cuando se requiere extraer la máxima potencia del arreglo es necesario usar un circuito electrónico que acople la impedancia de la carga con el punto de máxima del arreglo FV.

Cuando las cargas en CD requieran de un voltaje constante para operar o se desea que trabajen durante cualquier hora del día, la energía se debe de almacenar en una acumulador de carga eléctrica. Además, cuando las cargas requieran corriente alterna (CA) para operar, es necesario usar un 
inversor que transforme la corriente directa en corriente alterna (Inversor CD/CA).

Y aún más, ya que algunos inversores $\mathrm{CD} / \mathrm{CA}$ pueden administrar otros generadores de electricidad, se pueden diseñar sistemas de generación de electricidad que operen con diferentes tecnologías. Estos sistemas energéticos en donde hay más de una fuente de generación de electricidad reciben el nombre de sistemas híbridos (SFV-H), pudiendo ser una combinación de AFV con motogenerador, y/ó generadores eólicos, y/o generadores microhidráulicos y/o la red eléctrica convencional y/o cualquier combinación entre ellas. La Figura IV-20 muestra las arquitecturas típicas de SFV's-A con almacenamiento electroquímico de energía y la arquitectura típica para SFV-H.
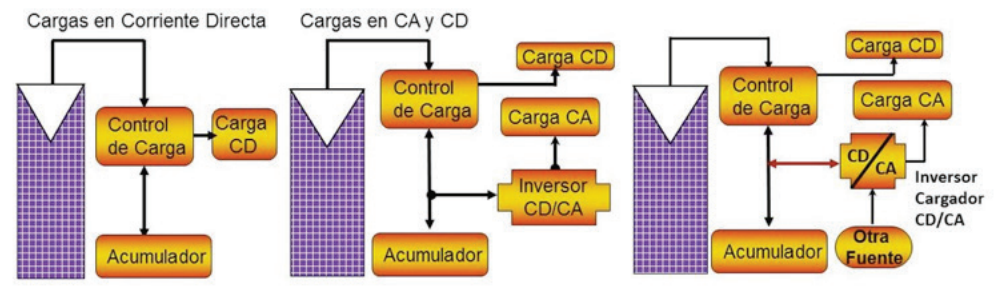

Figura 4.20: Arquitecturas típicas de SFV-A (izquierda y central) y SFV-H (derecha) con almacenamiento electroquímico. La Fuente de energía en el SFV-H puede ser un motogenerador, un sistema eólico, un sistema hidráulico, o cualquier otr fuente de energía que genere corriente alterna.

Dada la versatilidad actual de los acondicionadores de energía, se tienen en el mercado inversores que permiten el acoplamiento con la red eléctrica convencional ya que, a partir de su electrónica de control, están monitoreando la red eléctrica y efectúan una interacción efectiva aceptando el flujo de energía bidireccional desde el AFV hacia la red (inyección) en caso de mínimo ó nulo consumo por las cargas conectadas; o desde la red hacia las cargas (suministro) para el caso de baja generación del AFV. Este tipo de sistemas reciben el 
nombre de sistemas interactivos con la red (SFV-I). En la Fig. 4.21 se muestra un diagrama típico de la arquitectura de un sistema fotovoltaico interconectado (SFV-I).a una Red de Distribución Eléctrica Local, pudiendo estar la interconexión en Baja Tensión (menor de 1,000 V), Mediana Tensión (mayor de $1,000 \mathrm{~V}$ y hasta $69.0 \mathrm{kV}$ ); o bien conectado a una Red de Transmisión en Alta Tensión, lambas redes pertenecientes al Sistema Eléctrico Nacional.

Así un SFV-IR operará para complementar la energía que se demanda de la red por parte de los usuarios. Esta forma de operación es muy versátil, debido a que, entre otras cosas, cuando existe la radiación solar o durante las horas de luz, el usuario consume la energía solar producida por su sistema fotovoltaico, mientras que cuando no haya luz solar o ésta no sea suficiente, el usuario toma la energía faltante de la red eléctrica. Como resultado final, el productor disminuye el consumo eléctrico provisto por la CFE y en consecuencia su facturación eléctrica. Debido a estas características, cada vez más usuarios del servicio eléctrico público están interesados en cubrir parte de su demanda energética con la adopción de esta tecnología, y así obtener los beneficios económicos y ambientales, que permiten por un lado, un incremento en la rentabilidad económica, y por el otro, una reducción o abatimiento en los Gases de Efecto de Invernadero (GEI).

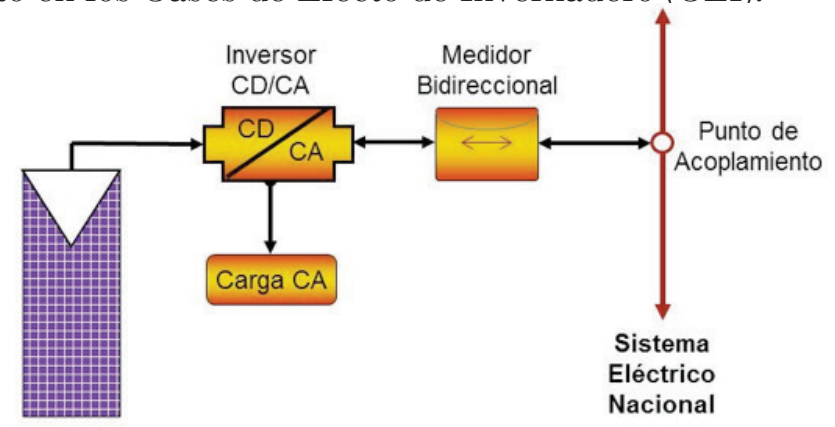

Figura 4.21: Arquitectura típica de un Sistema Fotovoltaico Interconectado (SFV-I). 
El diagrama mostrado en la Figura 4.21 representa las componentes principales de un Sistema Fotovoltaico Interconectado al Sistema Eléctrico Nacional (SEN). En dicho diagrama, SP1, SP2 y SP3 representa los sistemas de seguridad exigidos por la normatividad eléctrica; CEL es el circuito eléctrico local del usuario; M y MB representan sistemas de medición de energía eléctrica; y PI es el punto de interconexión en el Sistema de Distribución Local.

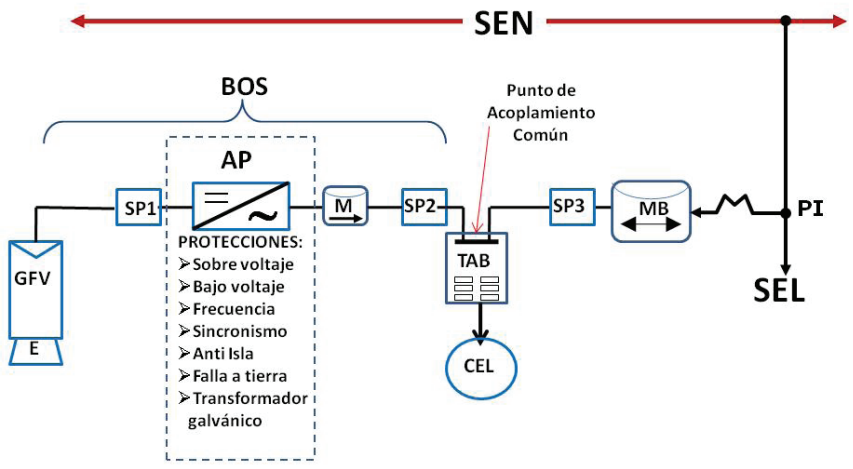

Figura 4.22: Diagrama de bloques de un Sistema Fotovoltaico Interconectado al SEN mostrando los dispositivos de seguridad requeridos por la normatividad eléctrica.

Por lo anterior el personal técnico que estará involucrado en actividades de toma de decisiones, supervisión, evaluador de proyectos, elaboración de proyectos y el calculista (dimensionador y diseñador) de sistemas FV's, deberá tener un amplio conocimiento de la tecnología disponible en el mercado para su correcta selección; debe conocer y manejar conceptos eléctricos que le permitan identificar y cuantificar el tipo de cargas eléctricas a las que se les suministrará energía incluyendo conceptos de voltaje de operación, corriente de consu- 
mo, potencia demanda, energía consumida; debe tener conocimientos de las limitaciones de la tecnología derivadas de la disponibilidad del recurso solar así como de las condiciones ambientales y geográficas; debe tener conocimientos de ingeniería eléctrica para elaborar diagramas y circuitos eléctricos que le permitan identificar las partes y componentes necesarias para garantizar la seguridad del usuario; debe conocer de estructuras mecánicas así como tener conocimientos de ingeniería civil para el diseño propio de cimentaciones, soportes y estructuras que garanticen la alta durabilidad, funcionalidad y alto rendimiento de la tecnología FV; debe conocer los conceptos básicos del recurso solar, como se mide y como se estima así como de las trayectorias solares y comportamiento del recurso solar a lo largo del año.

El personal técnico dedicado a la implementación, instalación, certificación técnica, operación y mantenimiento, además de conocer y manejar las herramientas y equipos de medición, debe conocer la normatividad eléctrica y las especificaciones técnicas de los sistemas, el funcionamiento de la tecnología FV, su identificación, los factores de riesgo y de seguridad, y todas las demás actividades y procedimientos de seguridad relacionados con el uso y manejo de la electricidad.

\subsection{Proyectos de aplicación y regulaciones existentes}

Los nichos de aplicación de la tecnología FV cubren prácticamente todos los ámbitos en donde se requiera electricidad para desarrollar actividades humanas. Se encuentran aplicaciones de ella en el ámbito rural, zonas urbanas, zonas remotas ó aisladas, y aplicaciones espaciales. Para el caso de nuestro país, las aplicaciones rurales son las que más se han fomentado por los diferentes organismos e instituciones debido a la falta de cobertura de la red eléctrica convencional. Este tipo de sistemas en donde el único generador es el FV han recibi- 
do el nombre de autosustentados $(S F V-A)$. Ejemplos típicos de estos sistemas han sido implementados por PEMEX, Secretaría de Marina, Secretaría de Comunicaciones, SEP, Secretaría de Desarrollo Social, TELMEX, compañías televisivas, entre otras, que han tenido necesidad de elaborar proyectos de desarrollo social ó técnico, en sitios apartados de la red eléctrica convencional, para los cuales la tecnología fotovoltaica ha sido la más apropiada. También, el uso de la tecnología FV en sistemas híbridos (SFV-H) aprovechando recursos energéticos como lo es el eólico y sistemas convencionales de motogeneración, se han estado fomentando para aquellos sitios aislados en donde la energía del viento puede aprovecharse, como ha sido el caso de San Juanico en Baja California Sur. Aunque desde 1977 a la fecha se han instalado del orden $20 \mathrm{MW}^{18}$, la carencia de especialistas, técnicos y promotores de tecnología con conocimiento a fondo de ella, no ha permitido su difusión y uso masivo, aunque sean grandes las necesidades de electricidad en el medio rural.

Además, ya que el entorno energético mundial está obligando a los gobiernos a establecer sistemas de generación de energía limpios en todos los ámbitos, las aplicaciones FV's interactivas con la red de distribución de electricidad convencional en el medio urbano, con proyectos de generación eléctrica que van desde unos cuantos Watt hasta kiloWatt, que se están fomentando fuertemente, abren un nicho de mercado en nuestro país que ha sido estimado del orden de 200 MW durante los próximos 5 años. De aquí que se espera una fuerte demanda de sistemas FV conectados a la red (SFVI) en un futuro muy próximo. En consecuencia, para garantizar la adopción, permanencia y largo tiempo de operación de los proyectos SFV-I se requiere y necesita personal técnico capacitado para el desarrollo, implementación, instalación

18 Y. Matsumoto, J. Agredano, A. Sanchez Juarez, and A. Urbano, Aweking PV in Mexico; presentado en el 17th Photovoltaic Specialist Energy Conference. Trabajo 5P-P3-57, Fukuoka, Japan, 2007 
y mantenimiento de proyectos de generación de electricidad basados en dicha tecnología.

Por otro lado, dado el esquema de regulación del sector eléctrico en nuestro país, los proyectos de generación de electricidad cuyo objetivo es la prestación de un servicio público solo pueden ser establecidos por la Nación la que generará, conducirá, transformará, distribuirá y abastecerá a los usuarios a través de sus diferentes organismos, Secretaría de Energía (SENER), Comisión Reguladora de Energía (CRE) y Comisión Federal de Electricidad (CFE). Sin embargo, La Ley del Servicio Público de Energía Eléctrica (LSPEE) contempla en el Art. 3 que la generación de energía para autoabastecimiento, cogeneración o pequeña producción; inclusive aquella generada por los productores independientes para su venta a la CFE, no se considera servicio público, pero la Ley de la CRE la facultad como el organismo regulador para las actividades de generación que no son servicio público.

Para el caso de los SFV-A aplicados al desarrollo social (iluminación domestica rural, comunicación, teleeducación, servicios médicos) y al desarrollo agropecuario (bombeo de agua, iluminación en invernaderos, picadoras, ordeñadoras y conservación de productos perecederos), no se han regulado debido a que son sistemas mucho muy pequeños (la máxima potencia instalada es de $10 \mathrm{kWp}$ ) comparado con aquellos catalogados en la LSPEE como pequeña producción (100.0 $\mathrm{kW}$ ); en consecuencia, se carece de instrumentos regulatorios provistos por la CRE. Actualmente, se cuenta con un conjunto de especificaciones técnicas ${ }^{19}$ que son observadas y aplicadas por los organismos institucionales, implementadores de programas de electrificación rural, que permiten al menos establecer criterios de selección de equipos y partes para

19 Especificaciones técnicas para sistemas $\mathrm{FVs}$ de iluminación doméstica rural; CFE 1998; Especificaciones Técnicas para sistemas de Bombeo de Agua con energía FV; FIRCO-SAGARPA 2002. 
garantizar larga duración de los sistemas a instalar y seguridad para los usuarios.

En el caso de los SFV-I, aunque los usuarios serán productores de electricidad catalogados en el esquema de autoabastecimiento, por el hecho de que estarán interactuando con la red eléctrica pública, energía suministrada por alguna de las dos compañías asignadas por el Estado para proporcionar el servicio público, la CRE deberá de tener marcos regulatorios que permitan identificar tanto calidad, operación y seguridad de aquellos SFV-I que se pretendan instalar.

Considerando lo anterior, se han emitido las siguientes leyes y la CRE ha aprobado los modelos de contrato para la Interconexión a la Red Eléctrica de sistemas FV de baja escala (máximo hasta $50.0 \mathrm{~kW}$ ), mediana escala (hasta $500.0 \mathrm{~kW}$ ) y cogeneración eficiente:

- Ley para el Aprovechamiento de Energías Renovables y el Financiamiento de la Transición Energética (LAERFTE), Noviembre 2008;

- Reglamento de la LAERFTE en 2009.

- Ley para el Aprovechamiento Sustentable de la Energía (LASE), Noviembre 2008;

- Reglamento de la LASE en 2009.

- Resolución RES/054/2010 Comisión Reguladora de Energía, Publicada en el Diario Oficial de la Federación el 8 de abril de 2010, Primera Sección:

a) Contrato de Interconexión para fuente de energía renovable o sistema de cogeneración en pequeña escala HASTA 30.0 kW (actualmente ampliado hasta 50.0 kW según se establece en el Manual de Interconexión de Centrales de Generación con Capacidad Menor a $0.5 \mathrm{MW})$;

b) Contrato de Interconexión para fuente de energía renovable o sistema de cogeneración en mediana escala; 
c) Contrato de Interconexión para centrales de generación de energía eléctrica con energía renovable o cogeneración eficiente (28-I-2010).

- Resolución RES 119/2012 Comisión Reguladora de Energía; Diario Oficial de la Federación el 22 de mayo de 2012: Reglas Generales de Interconexión al SEN para Generadores o Permisionarios con Fuentes de Energías Renovables o Cogeneración Eficiente".

- Manual de Interconexión de Centrales de Generación con Capacidad Menor a 0.5 MW, publicado en el Diario Oficial de la Federación el 15 de diciembre de 2016

Dadas la regulaciones emitidas y la tendencia a la alza del precio de los hidrocarburos, el incremento gradual del $\mathrm{CO}_{2}$ en la atmósfera, y la disminución en costos de la tecnología FV derivado de la producción masiva y la investigación, se estima que la demanda por parte de los industriales (la industria de servicios, manufactura, etc.) de SFV-I de mayor potencia será mayor en un periodo de tiempo corto (2015), en consecuencia, dichas aplicaciones tendrán que ser evaluadas, supervisadas y aprobados por la CRE a través de la CFE, la que para lograr su cometido de organismo regulador, tendrá que formar recursos humanos, con diferentes niveles de conocimiento, que les permita evaluar y supervisar, en todos los aspectos relacionados con la tecnología, desde el dimensionamiento, diseño, hasta la selección de equipos y materiales e instalación, de todos los proyectos que se presenten para su aprobación.

Por las razones antes dichas, los técnicos que serán asignados a la supervisión, evaluación y certificación de sistemas FV's deben tener habilidades y conocimientos, dependiendo de la función asignada, que les permita acciones que van desde procedimientos de selección, dimensionamiento y evaluación (evaluar y cuantificar las necesidades energéticas de los usuarios, evaluar y cuantificar el recurso solar regional, identificar la arquitectura óptima del sistema FV para su aplicación específica, dimensionar el tamaño del arreglo FV y esti- 
mar la energía a generar, analizar la factibilidad económica), hasta la entrega llave en mano del sistema, pasando por procedimientos que les permita: seleccionar el sitio de instalación; elegir la estructura (fija o con seguimiento), soporte y diseñar su cimentación; seleccionar la orientación óptima; conocer y aplicar la Norma Eléctrica para el diseño del cableado, selección de la partes y componentes para garantizar seguridad y durabilidad del sistema; y supervisar, cuantificar y certificar el desempeño y seguridad del sistema instalado.

Aunque estas notas no pretenden formar recursos humanos especializados en la tecnología fotovoltaica, su objetivo es divulgar la información relevante de ella con el objeto de que sea considerada como una alternativa energética que puede resolver problemas energéticos a futuro. 



\section{5 \\ DIMENSIONANDO SISTEMAS FOTOVOLTAICOS}

Se ha establecido que dependiendo de su aplicación, los SFV se pueden clasificar como autónomos (SFV-A), híbridos (SFV$\mathrm{H})$ e interconectados a la red eléctrica convencional (SFV-I). Dichos sistemas se integran por un conjunto de elementos que permiten generar, almacenar, acondicionar y distribuir, según sea el caso, la electricidad fotogenerada en los AFV's, al voltaje específico que requiere la "carga" eléctrica. Generalmente los Sistemas fotovoltaicos están compuestos del arreglo FV, la estructura, los acondicionadores y el almacenamiento de energía, los conductores eléctricos, los dispositivos de seguridad requeridos por la normatividad eléctrica respectiva (NOMM 001 SEDE 2012) y las cargas eléctricas.

Dependiendo del tipo de carga eléctrica (directa o alterna) y de su uso, los SFV-A pueden ser tan simples como la arquitectura de una conexión directa mostrada en la Fig. IV-19, o si se requiere almacenamiento electroquímico, una arquitectura como la mostrada en la Fig, IV-20. En forma general, si hay "cargas" que para operar requieren de corriente alterna, es necesaria la inclusión de un inversor de CD a CA (Inversor CD/CA) cuya función es proporcionar la potencia eléctrica que requiere el aparato para operarlas. Si solamente hay 
cargas en $\mathrm{CD}$, no se necesita el inversor. Las partes y componentes de un SFV-A pueden ser representadas por el diagrama esquemático de la Figura V.1. En ésta, las flechas indican el flujo de la electricidad a través de los conductores eléctricos requeridos

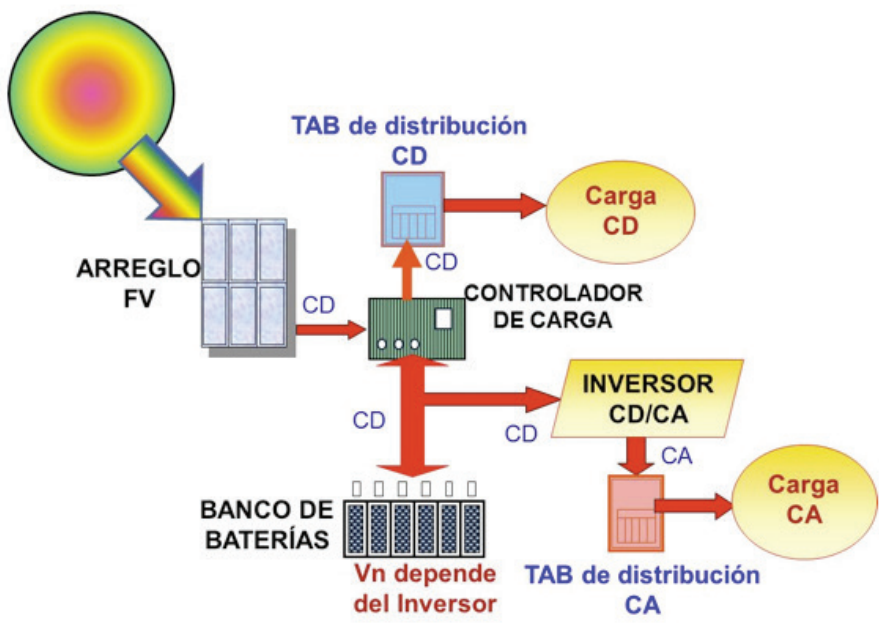

Figura 5.1: Arquitectura general de los sistemas fotovoltaicos autónomos.

En la Figura V.2 se muestra las partes y componentes de un SFV interconectado a la red eléctrica convencional (REC) del Sistema Eléctrico Nacional (SEN), a la tensión de trabajo requerida por las cargas eléctricas. Esta aplicación se ha usado muy intensamente a nivel mundial, y en nuestro país, ha estado tomando mucho auge derivado de la reducción de precios en la TFV, las nuevas regulaciones gubernamentales que están fomentando su uso, y la conciencia general a que debemos de contribuir a la disminución de los gases de efecto invernadero derivados de la quema de combustibles fósiles. En este tipo de aplicaciones, el Inversor CD(CA es un acondicionador de energía que tiene la función principal de sincronizarse con las características eléctricas de la RED (tensión y 
frecuencia), ya que se sincronizó, el inversor inyecta corriente a la RED en el Punto de Acoplamiento en Común (PAC) sin el requerimiento de proporcionar la potencia de consumo de las "cargas" eléctricas en CA

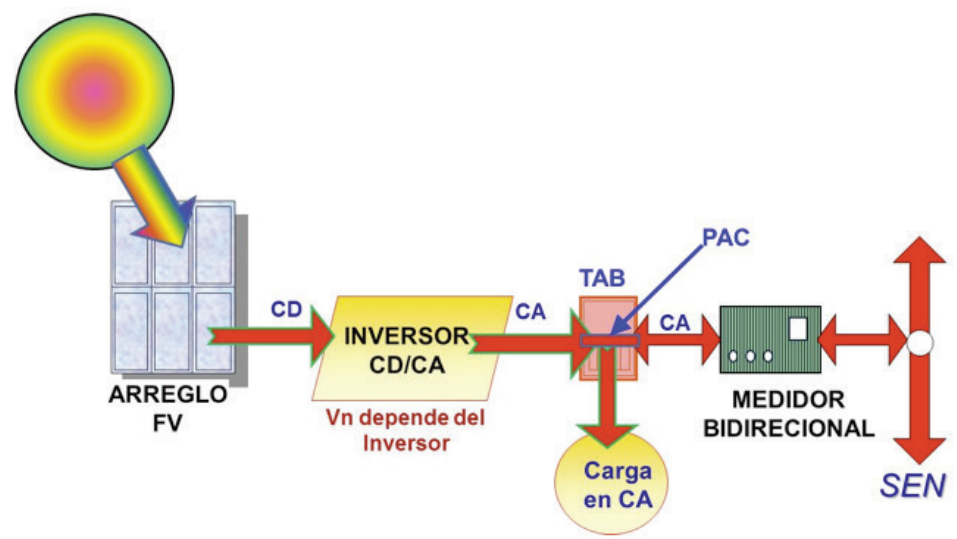

Figura 5.2. Arquitectura general para un SFV-I de baja escala (menos de $50.0 \mathrm{~kW}$ ) conectado en baja tensión a la REC. En ésta figura: TAB es el Tablero de Distribución de la red electrical local del usuario, y ahí, se sugiere instalar el Punto de Acoplamiento en Común (PAC) entre la RED, las "cargas" y el circuito de salida del SFV.

Nota: Tanto en la Figura V.1 como en la Figura V.2 no están representados los dispositivos de seguridad requeridos por las regulaciones normativas correspondientes.

Una vez que se ha seleccionado la aplicación del sistema fotovoltaico y se haya elegido la arquitectura correspondiente, se deberá de estimar el tamaño del arreglo FV que sea capaz de generar la electricidad que consumirá la carga durante el tiempo de su operación. A este proceso se le llama el Dimensionamiento Fotovoltaico y los principios básicos para realizar dicha estimación se proporcionan a continuación. 


\subsection{El dimensionamiento fotovoltaico}

$\mathrm{Al}$ proceso de estimar la Potencia Pico de un arreglo FV que satisfaga un requerimiento dado se le llama Dimensionamiento Fotovoltaico. Los requerimientos pueden ser energéticos, geométricos (superficie disponible), económicos, de desempeño, u otros. Independientemente cual sea el requerimiento, es necesario establecer un criterio entre el requerimiento y el parámetro eléctrico del arreglo fotovoltaico para llegar a la solución del problema.

\section{V.1 a. Requerimiento Energético: Balance de Energía}

Para éste requerimiento se quiere estimar el tamaño de un arreglo FV, en términos de su Potencia Pico, que generará la energía eléctrica requerida por un conjunto de "cargas" eléctricas; es decir, encontrar cual es la Potencia Pico óptima del arreglo FV que generará la energía necesaria que consumirá una "carga (s)" eléctrica para una aplicación específica en cierta localidad. Así mismo y si es necesario, se determina la capacidad del sistema de almacenamiento de energía, con base a los requerimientos de autonomía requeridos. En el caso de los SFV-A, dado que la electricidad que se genera depende del tamaño de la potencia pico fotovoltaica, del recurso solar de la localidad y de las condiciones ambientales; y dado que la energía que se produzca en exceso no produce algún beneficio económico para los usuarios, la potencia óptima a instalar deberá ser aquella que produzca la energía que sea requerida por las "cargas eléctricas" durante un periodo de tiempo establecido: al día, a la semana, al mes o al año. Esto lleva a establecer un criterio energético llamado el "balance de energía".

El criterio de balance de energía se puede escribir mediante la expresión siguiente:

"Energía generada igual a la energía consumida"

En la relación anterior, la energía consumida debe expresarse como un valor de consumo promedio al día, mientras 
que la energía generada se deberá de estimar al considerar las horas pico promedio diarias de la localidad.

Existen varios factores que el dimensionador debe conocer para estimar las energías a generar y a consumir. Dentro de éstos están los geográficos, tecnológicos y energéticos.

Los factores geográficos influyen en el Recurso Solar y el desempeño diario del arreglo $\mathrm{FV}$, mientras que los energéticos afectan directamente la estimación de la energía a consumir. Hay que tener presente las eficiencias de todos los elementos involucrados, desde que se genera la electricidad hasta que se consume. Dentro de los factores tecnológicos está el conocimiento de la tecnología que se usará tanto para generar la energía como para acondicionarla (seguidores de máxima potencia, controladores de carga, inversores). La Fig. V.3 muestra un diagrama de los requerimientos de conocimiento que el dimensionador debe tener para establecer un buen balance energético.

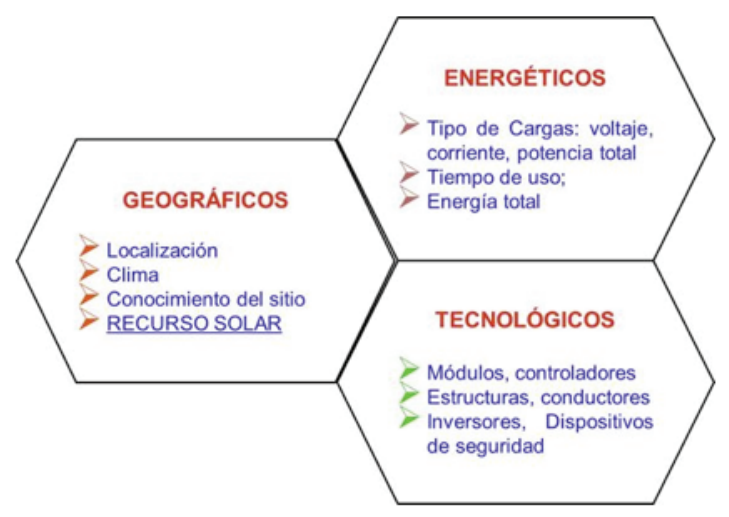

Figura 5.3: Factores imprtantes a conocer para realizar el proceso de dimensionamiento fotovoltaico

Teniendo eso presente es fácil llegar a escribir una relación algebraica, partiendo del balance de energía, entre la Energía Generada $\left(\boldsymbol{E}_{G}\right)$ por el arreglo FV y la energía total consumida por las cargas eléctricas del proyecto $\left(\boldsymbol{E}_{C L}\right)$ así 
como la energía que se consume por el manejo, acondicionamiento y uso de la energía, ambas en unidades de Watt-hora. Así se puede establecer que:

$$
E_{G}=E_{C L} / \eta_{\mathrm{ET}} \quad \text { Ec. V. } 1
$$

siendo $\eta_{\mathrm{ET}}$ la eficiencia eléctrica total global del sistema, cuyo valor se determina al multiplicar la eficiencia en las líneas de transmisión o pérdidas establecidas en el cableado $\left(\eta_{\mathbb{W}}\right)$, eficiencia en el controlador de carga $\left(\eta_{\mathrm{CC}}\right)$, eficiencia en el sistema de almacenamiento electroquímico $\left(\eta_{\mathrm{B}}\right)$, eficiencia del inversor $\left(\eta_{\text {INV }}\right)$ y la eficiencia de cualquier otro dispositivo electrónico que use y maneje o acondicione la energía generada. Los valores típicos por omisión propuestos son: eficiencia en las líneas de transmisión de la electricidad (eficiencia en el cableado) $\eta_{\mathbb{W}}=97 \%$; eficiencia en los acondicionadores de energía: controlador de carga $\eta_{\mathrm{cc}}=0.97$, eficiencia en el inversor $\eta_{I}=95 \%$; eficiencia del acumulador $\eta_{B}=85 \%$ (eficiencia Coulómbica en el acumulador $\eta_{\mathrm{cB}}=95-98 \%$; eficiencia en el voltaje de carga $88 \%$ ).

Ya que la energía generada por un $\mathrm{AFV}$ de $\mathrm{N}_{\mathrm{S}}$ módulos en serie (formando un panel o cadena) y por $\mathrm{M}_{\mathrm{P}}$ paneles en paralelo cada uno con una potencia pico $\boldsymbol{P}_{P}(\mathrm{MFV})$, en una localidad con un recurso solar $\boldsymbol{H}_{\mathrm{p}}$ (horas pico), y una temperatura ambiente media Tamb, está dada por:

$$
E_{G}=H_{\mathrm{P}}\left(\mathrm{N}_{\mathrm{s}} \times \mathrm{M}_{\mathrm{p}}\right) \times P_{P}(\mathrm{MFV}) \times \mathrm{R}_{\mathrm{T}},
$$

donde $\left(\mathrm{N}_{\mathrm{s}} \mathrm{xM}\right) \mathrm{x} P_{P}(\mathrm{MFV})=P_{P}(\mathrm{AFV}) ; \boldsymbol{H}_{\mathrm{P}}$ es el Recurso Solar de la Localidad; $\mathrm{R}_{\mathrm{T}}$, es el rendimiento térmico del módulo que, bajo condiciones NOCT, suele tomarse como 85\% para sistemas sin baterías; entonces a partir de la Ec. V.1 se tiene que: La Potencia Pico de un Arreglo Fotovoltaico $P_{P}(\mathrm{AFV})$ que genere la cantidad de energía que consumen las cargas eléctricas $\boldsymbol{E}_{C L}$ de un proyecto dado, está determinada por la expresión: 


$$
P_{p}(\mathrm{AFV})=\frac{\mathrm{E}_{\mathbb{C}}}{\mathrm{H}_{P} x \mathrm{~h}_{\mathbb{E}} \mathcal{R}_{T}}
$$

donde

$$
P_{P}(\mathrm{AFV})=\mathrm{N}_{\mathrm{T}} x P_{P}(\mathrm{MFV})
$$

siendo $\mathrm{N}_{\mathrm{T}}$ el número total de MFV que tienen una Potencia Pico $P_{P}(\mathrm{MFV})$ es decir, $\mathrm{N}_{\mathrm{T}}=\mathrm{N}_{\mathrm{s}} \times \mathrm{M}_{\mathrm{p}}$.

Dado que la energía consumida puede expresarse en términos de Watt-hora (Wh) ó de Amper-hora (Ah), existen dos criterios de dimensionamiento: el de Wh y el de Ah. A continuación se establecen ambos criterios.

\section{1.a1. Criterio de Amper-hora (Ah)}

Este criterio se recomienda aplicarlo a sistemas fotovoltaicos que tengan "cargas" eléctricas en CD con almacenamiento electroquímico cuyo voltaje nominal sea múltiplo de $12 \mathrm{~V}$

El valor del voltaje nominal de un sistema de almacenamiento electroquímico (acumuladores o baterías), especificado como $\mathrm{V}_{\mathrm{N}}(\mathrm{S})$, lo define la "carga" o aparato eléctrico con el voltaje nominal más grande. Se recomienda no combinar "cargas" que funcionen con corriente directa con aquellas que funcionen en corriente alterna, a menos de que sea estrictamente necesario.

Dado que el sistema de almacenamiento electroquímico más popular han sido las baterías automotrices de $12 \mathrm{VCD}$, basadas en la celda electroquímica de Pb-ácido, para cubrir la necesidad de "cargas" en CD para su aplicación, tanto para la industria automotriz como posteriormente para aplicaciones domésticas y de comunicación, los fabricantes de "cargas" eléctricas decidieron diseñar a éstas para que operen con tensiones nominales de 12 VCD o múltiplos de éste valor.

Considerando eso, la energía que consuma un aparato eléctrico se podrá expresar en términos de Ah (Amper-hora) a un voltaje nominal. Por ejemplo: una lámpara de corrien- 
te directa con una potencia nominal de $20 \mathrm{~W}$ consume una corriente de $1.7 \mathrm{~A}$, a un voltaje nominal de $12 \mathrm{~V}$. Si la lámpara está prendida durante 4 horas, la energía consumida será:

$$
E_{C}=(1.7 \mathrm{~A}) \times(4 \mathrm{~h})=6.8 \mathrm{Ah} @ 12 \mathrm{~V}
$$

Por otra parte, dado que los MFV de 36 celdas han sido diseñados para cargar baterías a 12 VCD y se les ha asignado un Voltaje Nominal $\mathrm{V}_{\mathrm{N}}(\mathrm{MFV})=12 \mathrm{VCD}$, al acoplarse a ellas, estarán inyectando una corriente casi igual a la corriente que define el punto de máxima potencia bajo condiciones estándares de medición (el valor de $I_{M P}$ dado por el fabricante), independientemente si el módulo está caliente o no (esto se representa gráficamente en la Figura 4.6); y en consecuencia, el Método de AH no considera las Pérdidas por Temperatura en el MFV; y asigna al criterio de dimensionamiento un valor de la unidad para el Rendimiento Térmico, es decir, $\mathrm{R}_{\mathrm{T}}=1$.

En los sistemas autónomos con almacenamiento en baterías, lo común es encontrar en el mercado cargas eléctricas que se alimentan con un voltaje que es múltiplo de $12 \mathrm{VCD}$; así que se puede decir que en este tipo de aplicaciones, el voltaje nominal del sistema $\mathrm{V}_{\mathrm{N}}(\mathrm{s})$ es múltiplo de 12 VCD; y de lo anterior, se puede establecer que el AFV estará formado por un panel o cadena FV compuesto de $\mathrm{N}_{\mathrm{S}}$ módulos de $12 \mathrm{~V}$ conectados en serie, por lo cual,

a) Número de MFV a conectarse en serie $\left(\mathrm{N}_{\mathrm{S}}\right)$ de $12 \mathrm{~V}$ nominales (módulos con 36 celdas conectadas en serie), que generan una corriente $I_{M P}$, está dado por:

$$
\mathrm{N}_{\mathrm{S}}=\frac{\left.\mathrm{V}_{\mathrm{N}} \mathrm{S}\right)}{2}
$$

donde $\mathrm{V}_{\mathrm{N}}(\mathrm{s})$ es el voltaje nominal del sistema.

b) La corriente requerida que debe generar el AFV para satisfacer el balence de energía, en el punto de la máxima potencia del AFV, $I_{M P}(\mathrm{AFV})$, estará dado por El núme- 
ro de paneles conectados en paralelo $\mathrm{M}_{\mathrm{p}}$, que generan una corriente $I_{M P}$, de donde, siguiendo la Ec. V.2 está dado por

$$
I_{\mathscr{H}}(\mathrm{AFV})=\frac{\mathrm{E}_{\mathbb{C}} \mathrm{F}_{\mathrm{S}}}{\mathrm{H}_{P} \mathrm{~h}_{\mathbb{E}}}
$$

donde $\eta_{\mathrm{ET}}=\eta_{\mathrm{W}} \eta_{\mathrm{cc}} \eta_{\text {Inv }} \eta_{\mathrm{cB}}$. En la expresión anterior, $\boldsymbol{E}_{C L}$ se debe expresar en Ah al voltaje nominal del sistema, Fs es un factor de sobredimensionamiento que el diseñador puede incluir si lo considera necesario (valor recomendado del 5\% 'de $\boldsymbol{E}_{C L}$ o bien Fs=1.05), e $I_{M P}$ es la corriente del AFV de 36 celdas seleccionado en el punto de máxima potencia bajo STC.

c) El número de paneles o cadenas conectados en paralelo $\mathrm{M}_{\mathrm{p}}$, que generan una corriente total $I_{M P}$, siguiendo la Ec. V.3, está dado por

$$
\mathrm{M}_{\mathrm{P}}=\frac{I_{M M}(\mathrm{AFV})}{I_{B I}(\mathrm{MFV})}
$$

De ésta manera, el Número Total $\left(\mathrm{N}_{\mathrm{T}}\right)$ de MFV esta dado por: $\mathrm{N}_{\mathrm{T}}=\mathrm{N}_{\mathrm{S}} \mathrm{x} \mathrm{M}_{\mathrm{P}}$; y la configuración eléctrica en la que se deben conectar será: $\mathrm{N}_{\mathrm{S}}$ (módulos en SERIE) x $\mathrm{M}_{\mathrm{P}}$ (cadenas en PARALELO)

\section{V.1.a2. Criterio de Watt-hora (Wh)}

Este criterio se recomienda aplicarlo a sistemas fotovoltaicos que tengan "cargas" eléctricas en CA con o sin almacenamiento electroquímico, y suele usarse cuando el voltaje nominal del sistema es mayor de 48 VCD y no se conoce explícitamente la corriente que consume cada una de las cargas, y también, para los sistemas interconectados a la red eléctrica convencional. La energía consumida ECL debe expresarse en Wh. Se sugiere que todas las cargas eléctricas operen con la 
misma tensión nominal, ya sea en corriente directa (múltiplo de 12) o en corriente alterna (VN=127 VCA@60Hz)

Tomando en consideración lo anterior, la potencia del arreglo fotovoltaico, $P_{P}(\mathrm{AFV})$, en unidades de Watt, está regida por la Ec. V.2

$$
P_{p}(\mathrm{AFV})=\frac{\mathrm{E}_{\mathbb{C}}}{\mathrm{H}_{P} x \mathrm{~h}_{\mathbb{E}} \mathcal{R}_{T}} ;
$$

donde $\eta_{\mathrm{ET}}$ es la eficiencia eléctrica total en el proceso de transferencia, manejo y almacenamiento de energía, y $\mathrm{R}_{\mathrm{T}}$ es el rendimiento térmico del módulo que, bajo condiciones NOCT, suele tomarse como $85 \%$ para sistemas sin baterías.

Al elegir el modulo a usar, cuya potencia pico bajo condiciones STC es $P_{P}(\mathrm{MFV})$. entonces el número total de módulos, $\mathrm{N}_{\mathrm{T}}$, está dado por el cociente entre la Potencia Pico del AFV dimensionado, $P_{P}(\mathrm{AFV})$, y la Potencia Pico del MFV elegido, $P_{P}(\mathrm{STC})$; es decir,

$$
\text { Ec. V.5 }
$$

$$
\begin{aligned}
& \mathrm{N}_{\mathrm{T}}(\text { módulos })=\frac{P_{(}(\mathrm{AFV})}{\mathrm{P}_{\mathrm{P}}(\mathrm{MFV})}, \quad \text { donde } \\
& \mathrm{N}_{\mathrm{T}}=\mathrm{N}_{\mathrm{S}} \mathrm{x} \mathrm{M}_{\mathrm{P}}
\end{aligned}
$$

Para determinar cuál debe ser la configuración en que deben conectarse los $\mathrm{N}_{\mathrm{T}}$ módulos, es necesario identificar cual es el Voltaje Nominal del Sistema Electroquímico, $\mathrm{V}_{\mathrm{N}}(\mathrm{S})$ o si no existe éste, cual es el Voltaje Nominal de la "carga" eléctrica que se acoplará al AFV. Así que tenemos los siguientes casos:

- "Cargas" en CD o CA con Inversor CD/CA con Almacenamiento Electroquímico.-

Las "cargas" eléctricas pueden ser aparatos o electrodomésticos que operan con $\mathrm{CD}$, o bien, "cargas" eléctricas o electrodomésticos que operan con CA, y en consecuencia se requiere de un inversor CD/CA. El Voltaje Nomi- 
nal del Sistema electroquímico, $\mathrm{V}_{\mathrm{N}}(\mathrm{S})$, lo determina la "carga" eléctrica de CD con la mayor tensión de alimentación (múltiplo de $12 \mathrm{~V}$ ), o bien, la tensión de alimentación en $\mathrm{CD}$ del inversor.

Para vigilar el "estado de carga" del sistema de almacenamiento (baterías) es necesario usar un Controlador de Carga para baterías, $\mathrm{CC}_{\mathrm{B}}$.

Dependiendo de MFV a usar, se presentan dos alternativas de acoplamiento:

Alternativa 1.- Se usan MFV de 36 celdas en serie, con un $\mathrm{V}_{\mathrm{N}}(\mathrm{MFV})=12 \mathrm{VCD}$; o MFV con 72 celdas en serie con un $\mathrm{V}_{\mathrm{N}}(\mathrm{MFV})=24 \mathrm{VCD}$.

En esta situación, el Número de Módulos a conectarse en Serie, $\mathrm{N}_{\mathrm{S}}$ (módulos), para formar el panel o cadena FV está dado por:

$$
\begin{aligned}
& \mathrm{N}_{\mathrm{S}}(\text { módulos })=\frac{\left.\mathrm{V}_{\mathbb{N}} \mathrm{S}\right)}{\mathrm{V}_{\mathrm{MFV}}(\mathrm{MF})} \quad \text { Ec. V.6 } \\
& \text {, con una Potencia Pico } \\
& P_{P}(\mathrm{MFV}) \text {; } \\
& \text { y el número de paneles o cade- } \\
& \text { nas conectados en parale- } \\
& \text { lo } \mathrm{M}_{\mathrm{P}} \text { será: } \\
& \mathrm{M}_{P}(\text { cadenas })=\frac{\mathrm{N}_{\mathrm{T}}}{\mathrm{N}_{\text {. }}} \text {, } \\
& \text { redondeando esta fracéión al } \\
& \text { número entero superior. }
\end{aligned}
$$

NOTA: el Controlador de Carga $\left(\mathrm{CC}_{\mathrm{B}}\right)$ a elegir debe ser tal que tensión de control para el Sistema de Almacenamiento Electroquímico y la tensión de acoplamiento con el AFV sea la nominal del MFV, ambas con valor fijo y múltiplo 
de $12 \mathrm{VCD}$, requiriéndose que voltaje de entrada FV sea igual al voltaje de salida hacia la batería. A este tipo de controladores se les puede llamar de "Tensión fija".

Alternativa 2.- Se usan MFV's integrados por cualquier TFV, que puede ser de silicio cristalino de 54, 60, 80, celdas, incluyendo a los de 36 y 72 celdas.

En esta situación se debe usar Controladores de Carga de Tensión Variable, $\mathrm{CC}_{\mathrm{TV}}$, con seguimiento del Punto de la Máxima Potencia (MPPT), por lo cual, éste se elige tal que la tensión de control hacia el Sistema de Almacenamiento Electroquímico sea el valor del $\mathrm{V}_{\mathrm{N}}(\mathrm{S})$, mientras que, la Tensión de Acoplamiento del controlador de carga $\left(\mathrm{CC}_{\mathrm{TV}}\right)$ con el AFV, este comprendida en el intervalo de alimentación de diseño del controlador, que típicamente está desde $12 \mathrm{~V}$ hasta $150 \mathrm{~V}$, valor máximo que corresponde al $V_{C A}$ de la cadena FV cuando la temperatura de la celda es la estándar $\left(\mathrm{T}_{\mathrm{C}}=25^{\circ} \mathrm{C}\right)$.

Si se denota por $\mathrm{V}_{\mathrm{ACO}}\left(\mathrm{CC}_{\mathrm{TV}}\right)$, la tensión de acoplamiento entre el AFV y el $\mathrm{CC}_{\mathrm{TV}}$, entonces:

al elegir al MFV, la tensión de acoplamiento debe ser múltiplo del voltaje de generación del MFV en el punto de la máxima potencia bajo STC, es decir, el $V_{M P}(\mathrm{MFV})$. Así, se tendrá que:

$$
\begin{aligned}
& \begin{array}{l}
\mathrm{N}_{\mathrm{S}}(\text { módulos })=\frac{\mathrm{V}_{\mathrm{Acd}}\left(\mathrm{CC}_{\nabla}\right)}{V_{\text {Poǵtencla }}(\mathrm{MFV})} \text { Pico } P_{P}(\mathrm{MFV}) ; \quad \text { Ec. V.7 }
\end{array} \\
& \text { y el número de paneles o cade- } \\
& \text { nas conectados en paralelo } \\
& \mathrm{M}_{\mathrm{P}} \text { será: } \\
& \mathrm{M}_{P}(\text { cadenas })=\frac{\mathrm{N}_{\mathrm{T}}}{\mathrm{N}_{\text {. }}}, \\
& \text { redondeando esta fraćción al } \\
& \text { número entero superior. }
\end{aligned}
$$


- "Cargas" en Corriente Alterna, sin almacenamiento de Baterías.-

Este puede ser el caso de sistemas de bombeo fotovoltaico o sistemas fotovoltaicos interconectados a la red electrica convencional.

Para poder acoplar un AFV a la "carga" eléctrica es necesario un inversor CD/CA, el cual requiere de una tensión eléctrica de alimentación en CD. La Tensión de acoplamiento AFV-Inversor la determina el inversor, así que, si denotamos por $\mathrm{V}_{\mathrm{ACO}}(\mathrm{Inv})$ al Voltaje de Acoplamiento AFV-Inv, entonces:

al elegir al MFV con una Potencia Pico, $P_{P}(\mathrm{MFV})$, la tensión de acoplamiento $\mathrm{V}_{\mathrm{ACO}}(\mathrm{Inv})$ debe ser múltiplo del voltaje para el punto de máxima potencia del MFV bajo STC, es decir, el $V_{M P}($ MFV). Así, se tendrá que el Número de Módulos a conectarse en Serie, $\mathrm{N}_{\mathrm{S}}$ (módulos) para formar el panel o cadena FV está dado por:

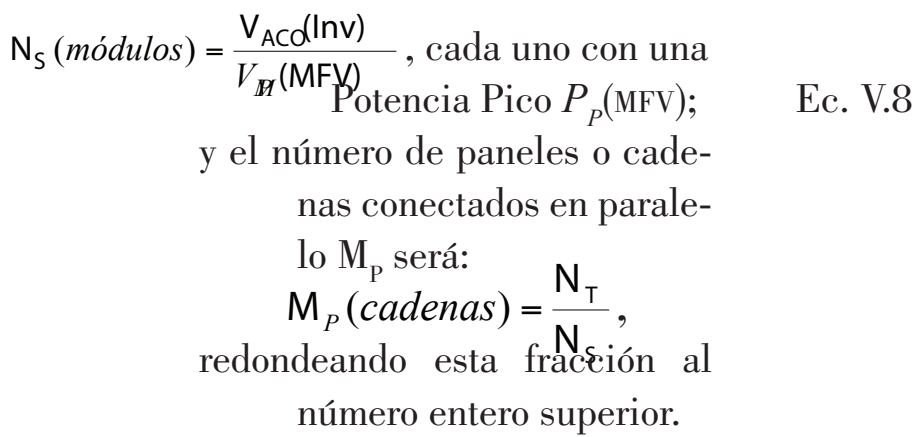

\section{V.1.b. Requerimiento Geométrico: Disponibilidad de área}

Cuando el proyecto no está basado en un requerimiento energético a satisfacer si no que está limitado por la superficie en donde será instalado el AFV, entonces la Potencia Pico a instalar dada una superficie $\mathrm{S}$ estará regida estrictamente por la eficiencia de conversión de la tecnología fotovoltaica elegida que cubrirá una superficie activa $\mathrm{S}_{\mathrm{A}}$ contenida en $\mathrm{S}$. 
Para el cálculo de la Potencia Pico del Arreglo Fotovoltaico, $P_{P}(\mathrm{AFV})$ que cubra una Superficie Activa $\left(\mathrm{S}_{\mathrm{A}}\right)$ se considera el hecho de que una celda solar, lo mismo que un Módulo Fotovoltaico (MFV), así como un Arreglo Fotovoltaico (AFV) que está formado por la conexión serie y paralelo de Módulos Fotovoltaicos (MFV), tienen asociada una eficiencia de conversión $\eta$ dada por el cociente de la Potencia de Salida $\left(P_{S}\right)$ entre la Potencia Solar Incidente $\left(\boldsymbol{P}_{E S}\right)$ que se recibe en la celda (o captador), siendo la $\boldsymbol{P}_{E S}$ el producto de la Irradiancia Global $G$ por la Superficie Activa $S_{A}$ :

El diseño de la instalación FV incluye muchos aspectos a considerar y entre ellos, la Superficie Total $\left(S_{T}\right)$ que ocupará el SFV, la cual incluye la superficie óptima requerida para instalar el o los arreglos fotovoltaicos que lo integran (Superficie Activa, $S_{A}$ ) más las superficies, que no generarán electricidad pero que se requiere para evitar el sombrado entre cadenas fotovoltaicas, así como las superficies necesarias para proveer el camino requerido a los sitios de instalación, que a su vez, servirán como caminos de mantenimiento. Debe considerarse las superficies en donde se construyan los cuartos que contengan los equipos necesarios para el acondicionamiento de energía, inversores, medios de transformación, medios de seguridad; y un cuarto especial para el monitoreo energético y ambiental de la planta eléctrica solar y de las condiciones ambientales.

Como en todo dispositivo que produce trabajo, la eficiencia de conversión $(\eta)$ de una celda solar que está recibiendo la luz solar con una magnitud $G$, se define como la razón entre la Potencia Eléctrica $\left(P_{S}\right)$ producida y la Potencia de la Radiación Solar Incidente $\left(\boldsymbol{P}_{E S}\right)$ que recibe; es decir,

$$
\square=\frac{P_{S}}{P_{\mathrm{B}}}
$$


Dado que los Módulos Fotovoltaicos (MFV) es un laminado de vidrio y polímeros que contienen las celdas solares conectadas en serie, se ha convenido en llamar Superficie Activa $\left(S_{A}\right)$ del módulo al área geométrica de éste, es decir, al producto de su largo con el ancho medidos exteriormente. Así, si un MFV tiene una superficie activa $S_{A}$ y recibe una irradiancia solar $G$, la potencia producida $P_{S}$ y la definición de eficiencia establece que (ver Figura V.4):

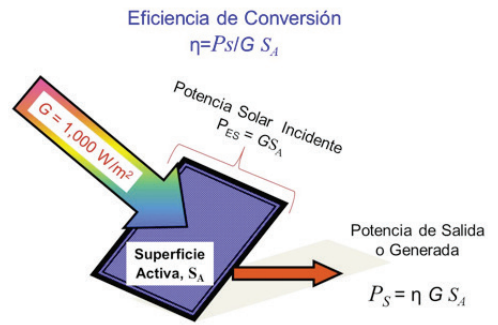

Figura V.4: Concepto de eficiencia de conversión en celdas solares, módulos y arreglos fotovoltaicos.

La relación anterior establece que, para cualquier tecnología FV, celda solar, MFV o AFV, con una eficiencia de conversión y ocupando una superficie activa conocida (largo por ancho), dado un valor para la irradiancia $G$, se tiene que la potencia de salida del AFV está dado por el producto de la eficiencia de conversión, el valor de la irradiancia y el valor de la superficie activa

Ya que la Potencia Pico $\left(P_{P}\right)$ de un MFV se mide bajo las condiciones estándares de prueba: someter al MFV a una irradiancia $G_{P}=1.0 \mathrm{~kW} / \mathrm{m}^{2}$, que es el valor pico de dicho parámetro, mantener la celda del MFV a una temperatura de $25^{\circ} \mathrm{C}$ y una Masa de Aire de 1.5, entonces la Potencia Pico, $P_{P}$, que puede generar un AFV integrado con MFV con una eficiencia de conversión $\eta$ y una superficie activa $S_{A}$, medida en $\mathrm{m}^{2}$ será de: 


$$
P_{P}(\mathrm{AFV})=\eta G S_{A} \quad \text { Ec. V.10 }
$$

De esta relación se observa que a menor eficiencia de conversión, menor es la potencia pico que se puede instalar en la superficie activa.

\subsection{Capacidad de almacenamiento en baterías}

La capacidad de almacenamiento de un Sistema Electroquímico o un Banco de Baterías, $\mathrm{C}_{\mathrm{BB}}$, se dimensiona en función de la energía consumida diariamente por las cargas eléctricas y la autonomía requerida en el sistema.

En un sistema FV la autonomía del banco de baterías se define como el número de días que funcionarán las cargas eléctricas con cero irradiación.

La unidad de medición para la capacidad de almacenamiento en un banco de baterías es el Amper-hora (Ah) expresado a un voltaje nominal $\left(\mathrm{V}_{\mathrm{B}}\right)$, es decir, se dice que la capacidad de una batería es de 100 Ah @ 12 V.

La expresión que se usa para estimar la capacidad de almacenamiento de un Banco de Baterías o Acumuladores, $\mathrm{C}_{\mathrm{BB}}$, que estará alimentando un conjunto de cargas eléctricas cuyo consumo de energía es $\mathrm{E}_{\mathrm{CL}}$, se expresa como

$$
C_{\mathbb{B}}=\frac{E_{C} A_{U}}{\left.V_{N} S\right) f_{U} F} \quad \text { Ec. V.11 }
$$

donde $\boldsymbol{E} \boldsymbol{c}_{L}$ se debe expresar en $\mathbb{W h}, \boldsymbol{A} \boldsymbol{u}$ es la autonomía expresada en días (se recomienda una autonomía no mayor de 3 días), $\mathrm{V}_{\mathrm{N}}(\mathrm{S})$ es el voltaje nominal del sistema (múltiplo de 12 V), $f_{u}$ es el factor de uso recomendado por el fabricante de la batería $\left(f_{u}=0.5\right.$ para baterías de placa delgada tipo automotríz; $\mathrm{f}_{\mathrm{u}}=0.8$ para baterías de placa gruesa o de tracción); $\mathrm{Fi}=1.05$ para batería de placa delgada y $\mathrm{Fi}=1.35$ para batería de placa gruesa. 
Si $\boldsymbol{E}_{C L}$ se expresa en Ah @ $\mathrm{V}_{\mathrm{N}}(\mathrm{s})$, entonces

$$
C_{B}=\frac{E_{c} A_{U}}{f_{U} F} @ V_{N}(s)
$$

Ec. V.12

Con dicha relación se determina el número total $\mathrm{N}_{\text {тв }}$ de baterías a instalar. Dicho número dependerá de la Capacidad de Almacenamiento $\mathrm{C}_{\text {BAT }}$ y voltaje nominal de la batería $V_{\text {BAT }}$ seleccionada.

Si $V_{\text {BAT }}$ es el voltaje de la batería seleccionada con una Capacidad de Almacenamiento $\mathrm{C}_{\mathrm{BAT}}$, entonces:

a) Número de Baterías conectadas en Serie: $\mathrm{N}_{\mathrm{S}}=\mathrm{V}_{\mathrm{N}}(\mathrm{s}) / \mathrm{V}_{\text {BAT }}$

b) Número de arreglos (de baterías en serie) conectados en paralelo: $\mathrm{M}_{\mathrm{P}}=\mathrm{C}_{\mathrm{BB}} / \mathrm{C}_{\mathrm{BAT}}$ redondeando la fracción al entero más próximo.

c) Arreglo de Baterías: $\mathrm{N}_{\mathrm{S}} \mathrm{x} \mathrm{M}_{\mathrm{P}}$

d) Numero Total de Baterías: $\mathrm{N}_{\mathrm{TB}}=\mathrm{N}_{\mathrm{S}} \mathrm{x} \mathrm{M}_{\mathrm{P}}$

\subsection{Ejemplos de dimensionamiento}

A continuación se presentan una serie de ejemplos que permiten visualizar la manera en que se pueden usar los criterios de dimensionamiento para requerimientos energéticos específicos. Dado que el tamaño del AFV se dimensiona con base en un requerimiento energético, el cual corresponde a un periodo específico que pertenece a un ciclo mensual, por temporada o anual, el proceso de dimensionamiento se debe hacer considerando los datos para el consumo energético de dicho periodo (un mes en particular, para una temporada del año, o para un consumo energético anual; es decir, se recomienda que los datos de la Energía que consumen las “cargas" eléctricas debe referirse, como un valor promedio diario del consumo mensual, o promedio diario del consumo por la temporada, o promedio diario de consumo anual. La recomendación se 
basa en el hecho de que en el proceso de dimensionamiento se usará el Recurso Solar de la localidad, el cual suele proporcionarse en las Bases de Datos de Radiación Solar como valores promedio diario mensual y valores promedio diario anual.

Ya habiendo identificado dicho periodo, se procede al dimensionamiento $\mathrm{FV}$ y a determinar la magnitud de la $\boldsymbol{P}_{\boldsymbol{P}}$ del AFV, valor que satisface el balance energético únicamente para el periodo elegido, y si el dimensionamiento fue realizado para un mes o temporada del año específica, para los otros meses o temporada no se cumplirá.

\section{3.a. Sistema autónomo en CD.}

Los usuarios de una casa rural del municipio de Cuautla, en el Estado de Morelos, han instalado un conjunto de cargas eléctricas que operan en corriente directa a $12 \mathrm{~V}$ nominales para los servicios de iluminación, recreación y refrigeración. Dentro de dichas cargas se tiene 6 lámparas fluorescentes de $20 \mathrm{~W}$ consumiendo $1.6 \mathrm{~A}$; un televisor de $80 \mathrm{~W}$ 6.4 A; y un refrigerador horizontal de $70 \mathrm{~W}$ que durante un día típico consume 40 Ah a 12 VCD. Los usuarios han estimado un consumo típico promedio diario anual de $105 \mathrm{Ah}$ al voltaje nominal. Si el recurso solar de la localidad, promedio diario anual, a la latitud del lugar es de $5.4 \mathrm{kWh} / \mathrm{m}^{2}$, y el módulo elegido es de la marca Kyocera, 36 celdas en serie, con una potencia pico $P_{P}(\mathrm{MFV})=135 \mathrm{~W}\left(V_{M P}=17.7 \mathrm{~V} ; I_{M P}=7.63 \mathrm{~A}\right)$, estimar

a) La Potencia Pico del Arreglo FV a instalar.

b) La arquitectura del Arreglo FV.

c) La capacidad de Almacenamiento del Banco de baterías.

Dado que todas las cargas operan con $12 \mathrm{VCD}$ nominales, el voltaje del sistema es $\mathrm{V}_{\mathrm{N}}(\mathrm{S})=12 \mathrm{VCD}$ y la arquitectura del sistema fotovoltaico es la que se muestra en la figura V.4: 


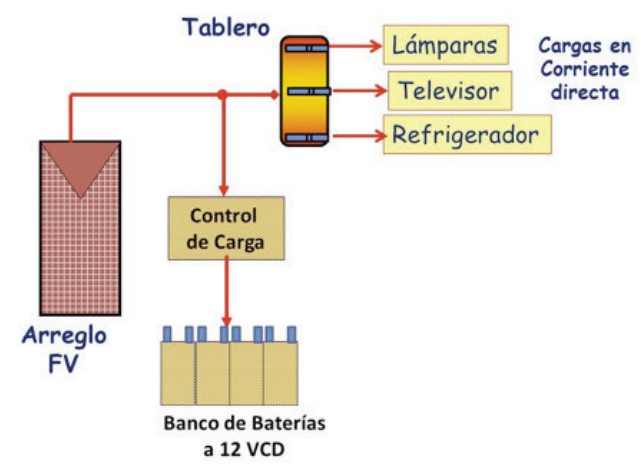

Figura V.5: Arquitectura del SFV autónomo del proyecto de electrificación

Considerando una eficiencia en el cableado de 0.97; una eficiencia Coulómbica del Banco de Baterías en 0.95; y una eficiencia en el Controlador de Carga de 0.97, la eficiencia eléctrica total del sistema por la transmisión, uso y acondicionamiento de la energía es de: $\eta_{\mathrm{T}}=0.894$.

Usando el método de Ah, la Corriente en el punto de la máxima potencia del AFV a instalar, integrado con MFV de 36 celdas está dado por:

$$
I_{M P}\left({ }_{\mathrm{AFV}}\right)=\mathrm{E}_{\mathrm{CL}} \mathrm{Fs} /\left(\boldsymbol{H}_{\mathrm{P}} \eta_{\mathrm{T}}\right) @ \mathrm{~V}_{\mathrm{N}}(\mathrm{s}) \mathrm{CD}
$$

Si Fs=1.05, $\mathrm{E}_{\mathrm{C}}=105 \mathrm{Ah} @ 12 \mathrm{VCD} ; \boldsymbol{H}_{P}=5.4$ horas pico; $\eta_{\mathrm{T}}=0.894$, entonces

$$
I_{M P}\left({ }_{\mathrm{AFV}}\right)=22.837 \mathrm{~A} @ 12 \mathrm{VCD}
$$

Ya que $P_{P}\left({ }_{\mathrm{AFV}}\right)=\mathrm{N}_{\mathrm{S}} \mathrm{x} \mathrm{M}_{\mathrm{P}} \mathrm{x} \quad I_{M P}(\mathrm{MFV}) @ 12 \mathrm{VCD} ; \quad$ y que $\mathrm{N}_{\mathrm{S}}=\mathrm{V}_{\mathrm{S}} / 12=12 / 12=1$; entonces

El número total $\mathrm{M}_{\mathrm{p}}$ de paneles conectados en paralelo será de:

$\mathrm{M}_{\mathrm{P}}=I_{M P}(\mathrm{AFV}) / I_{M P}(\mathrm{MFV}) @ 12 \mathrm{~V}$, se sigue que

$\mathrm{M}_{\mathrm{p}}=22.837 / 7.63=2.99 \cong 3$; @12; por lo tanto

La configuración del Arreglo Fotovoltaico, usando MFV de $135 \mathrm{~W}$ de potencia pico es: 1Sx3P.

Controlador de carga.- Dado que se deben conectar en paralelo $3 \mathrm{MFV}$, se requerirá de un Bus Metálico de Para- 
lelismo, y de ahí enviar el circuito de salida FV hacia el Controlador de Carga. Este debe tener una capacidad de conducción mayor que 3 veces la corriente en el punto de máxima potencia que genera el MFV considerado; es decir, mayor de 22.89 A. De la oferta comercial de Controladores de Carga, uno de $12 \mathrm{VCD}$ tanto a la entrada como a la salida de $30 \mathrm{~A}$ es el adecuado.

Banco de Baterías.- Si se elige una batería de plomo-acido de 115 Ah@12 VCD tipo automotriz $\left(\mathrm{C}_{\mathrm{BAT}}=115\right.$ Ah, $\left.\mathrm{V}_{\mathrm{B}}=12 \mathrm{VCD}\right)$, en donde el Factor de Uso es de 0.5, entonces la Capacidad del Banco de Baterías a instalar, $\mathrm{C}_{\mathrm{BB}}$, para una autonomía de 3 días debe tener una capacidad de: $\mathrm{C}_{\mathrm{BB}}=600$ Ah@12V.

No. de baterías en serie $\mathrm{N}_{\mathrm{S}}=\mathrm{V}_{\mathrm{N}}(\mathrm{S}) / \mathrm{V}_{\mathrm{BAT}}=12 / 12=1$; por lo tanto $\mathrm{N}_{\mathrm{S}}=1$.

Ya que la Capacidad de la Batería elegida es de 115 Ah, entonces:

No. de Baterías en Paralelo, $\mathrm{N}_{\mathrm{P}}=\mathrm{C}_{\mathrm{BB}} / \mathrm{C}_{\mathrm{BAT}}=600 / 115=5.2$.

Como no se pueden instalar 5.2 baterías, se redondea este número a 5; por lo cual, la configuración del Banco de Baterías es: 1Sx5P

Conclusión: De esta manera, para proporcionar la energía eléctrica diaria que requiere el usuario se necesitan 3 MFV de $135 \mathrm{~W}$ de potencia pico conectado eléctricamente en una configuración 1Sx3P, es decir, la cadena FV está integrada por un solo módulo y se deben conectar tres de ellos en paralelo. Así, la Potencia Pico del AFV es de 405 W. Por otra parte, el sistema de almacenamiento electroquímico, usando baterías de $12 \mathrm{VCD}$ con una capacidad de 115 Ah, estará integrado por 5 baterías conectadas eléctricamente en una configuración 1Sx5P, para dar una capacidad total de 575 Ah a 12 VCD nominales. 


\section{3.b. Sistema autónomo para cargas en CA}

La siguiente Tabla muestra el perfil de consumo eléctrico mensual de una casa en el medio urbano cuyas cargas eléctricas son electrodomésticos que operan a 127 VCA@60 Hz y cuyas potencias suman un total de 5,200 W. El usuario desea saber, si se desconecta de CFE, cual es la potencia pico del arreglo FV que le proporcione la energía que consume así como el banco de baterías adecuado a sus necesidades energéticas. El proyecto eléctrico está ubicado en la Ciudad de Temixco, Morelos, y los datos energéticos se muestran en la tabla adjunta. El Recurso Solar fue obtenido del sitio www. eosweb.larc.nasa.gov/sse para la localidad con coordenadas: 18.8397 Latitud Norte y 99.2353 Longitud Oeste.

Se requiere además, determinar él mes crítico para el cual se desarrollará el proceso de dimensionamiento y especificar cuál es el ángulo óptimo a la que deben estar los módulos para la captación de energía, y la Superficie Activa que ocupará el arreglo fotovoltaico.

Tabla V.1: Valores energéticos para el dimensionamiento fotovoltaico. El Recurso Solar corresponde a un captador inclinado a un ángulo de $18^{\circ}$.

\begin{tabular}{|c|c|c|c|c|c|}
\hline & $\mathbf{E}_{\mathrm{CL}}$ & $\mathbf{E}_{\mathrm{CL}}$ & \begin{tabular}{|c|}
$\begin{array}{c}\text { Recurso } \\
\text { Solar }\end{array}$ \\
\end{tabular} & Potencia & Temperatura \\
\hline Mes & $\begin{array}{c}\text { (kWh) al } \\
\text { mes }\end{array}$ & $\begin{array}{c}\text { (kWh) } \\
\text { promedio } \\
\text { diario } \\
\text { mensual }\end{array}$ & \begin{tabular}{|c|}
$\left(\mathrm{kWh} / \mathrm{m}^{2}\right)$ \\
Promedio \\
diario \\
mensual
\end{tabular} & $\begin{array}{c}\text { (W) } \\
\text { Efectiva } \\
\text { promedio } \\
\text { diaria }\end{array}$ & $\begin{array}{c}{ }^{\circ} \mathrm{C} \\
\text { Temperatura } \\
\text { media } \\
\text { máxima }\end{array}$ \\
\hline Ene & 403 & 13 & 6.27 & 2.073 & 27 \\
\hline Feb & 380.8 & 13.6 & 6.92 & 1.965 & 29 \\
\hline Mar & 449.5 & 14.5 & 7.31 & 1.984 & 30 \\
\hline $\mathrm{Abr}$ & 408 & 13.6 & 6.84 & 1.988 & 32 \\
\hline MAy & 415.4 & 13.4 & 6.15 & 2.179 & 34 \\
\hline Jun & 396 & 13.2 & 6.03 & 2.189 & 33 \\
\hline Jul & 452.6 & 14.6 & 6.27 & 2.329 & 32 \\
\hline Ago & 406.1 & 13.1 & 5.69 & 2.302 & 29 \\
\hline Sep & 381 & 12.7 & 5.46 & 2.326 & 29 \\
\hline Oct & 387.5 & 125 & 5.83 & 2.144 & 28 \\
\hline Nov & 414 & 13.8 & 6.22 & 2.219 & 27 \\
\hline Dic & 418.5 & 13.5 & 6.03 & 2.239 & 26 \\
\hline Anual & 4912.4 & 161.5 & 75.02 & 2.153 & \\
\hline $\begin{array}{c}\text { Promedio } \\
\text { Diario } \\
\text { Anual } \\
\end{array}$ & 13.46 & 13.46 & 6.25 & 2.153 & \\
\hline
\end{tabular}




\section{SOLUCIÓN:}

La solución será realizada a través de los siguientes pasos:

\section{1: Arquitectura del Sistema}

Ya que el usuario se desea desconectar de CFE, el proyecto FV corresponde a un Sistema Fotovoltaico Autónomo, y como se requiere de un sistema despachable de energía, el sistema tendrá almacenamiento electroquímico.

Como las cargas eléctricas son electrodomésticos que operan a $127 \mathrm{VCA}$, se requiere de un inversor CD/CA para transformar la electricidad de $\mathrm{CD}$ a $\mathrm{CA}$ con una tensión nominal de $127 \mathrm{~V} @ 60 \mathrm{~Hz}$

La Figura V.6 proporciona la arquitectura para el SFV-A que generará la energía requerida en el mes crítico o de diseño.

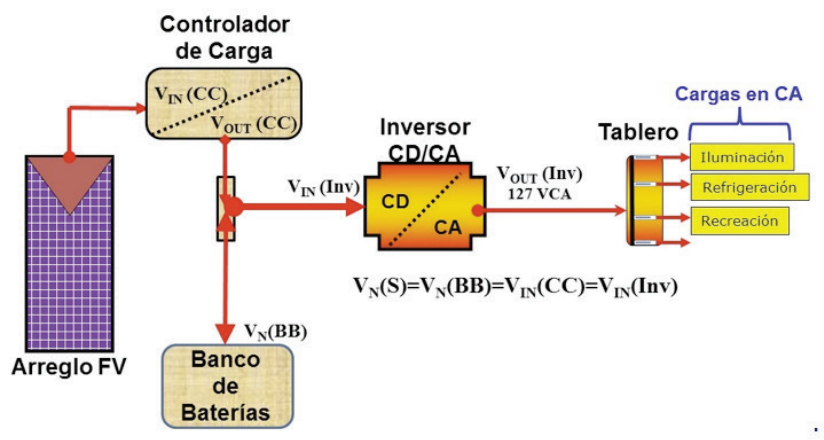

Figura V.6: Arquitectura típica de un SFV-A con almacenamiento electroquímico e inversor.

\section{2: Selección del mes de diseño o mes crítico}

El mes crítico se establece como aquel mes para el cual la potencia efectiva fotovoltaica que se requiere es máxima. Dicha potencia se obtiene al dividir la energía promedio diario mensual entre el recurso solar promedio diario mensual; es decir,

Potencia Efectiva $=\mathrm{E}_{\mathrm{CL}} / \mathrm{R}_{\mathrm{S}}$

Así, la columna \#4 de la Tabla V.1 muestra los valores del cociente anterior, y en color rojo con fondo amarillo se iden- 
tifica el mes para el cual dicho valor es máximo. En consecuencia se tiene que para el proceso de dimensionamiento se deben considerar los datos mostrados en la Tabla V.2.

Tabla V.2: Valores energéticos a considerar para el dimensionamiento en el mes crítico

\begin{tabular}{|c|c|c|}
\hline \multicolumn{2}{|c|}{ DATOS PARA EL DIMENSIONAMIENTO } \\
\hline $\begin{array}{c}\text { Mes de } \\
\text { Diseño }\end{array}$ & $\begin{array}{c}\text { Recurso Solar } \\
(\mathrm{kWh} / \mathrm{m} 2)\end{array}$ & $\begin{array}{c}\text { Energía a Proporcionar } \\
(\mathrm{kWh})\end{array}$ \\
\hline Julio & 6.27 & 14.6 \\
\hline
\end{tabular}

\section{3: Selección de Tecnologías}

a) Módulos FV.- Se usaran MFV de silicio policristalino de la marca Solaretec, de 36 celdas en serie, ya que dicha empresa oferta sus productos con potencias pico que van desde los 90, 95, y $100 \mathrm{~W} ; 140,145,150$, y $155 \mathrm{~W}$, y de 72 celdas en serie con potencias desde 190, 195, 200 y $205 \mathrm{~W}$, y 300, 305, 310, 315, $320 \mathrm{~W}$. La empresa fabrica dichos MFV con celdas cuadradas de $125 \mathrm{~mm}$ y $156 \mathrm{~mm}$ de lado para construir sus productos y los integra con 2 y 4 diodos de paso, un diodo por cada 18 celdas conectadas en serie, respectivamente, para prevenir la formación de puntos calientes. La Temperatura NOCT de sus MFV es de $45^{\circ} \mathrm{C}$ y el coeficiente de temperatura de dichos dispositivos, en la Potencia, es de $-0.5 \% /{ }^{\circ} \mathrm{C}$; y es el que se aplica para determinar el porcentaje de las Pérdidas en la Potencia Pico, $\mathrm{P} P_{P}$ por efecto de la temperatura.

Usando las Ecs IV-6 a la IV-8 se tiene que, para el mes de julio, el Rendimiento Promedio de los MFV elegidos, considerando la mayor irradiancia que es para una $\mathrm{G}=1,000 \mathrm{~W} / \mathrm{m}^{2}$ es de:

$\mathrm{R}_{\mathrm{T}}=81 \%$

b) Inversor.-Según su integración en un SFV, los inversores pueden ser de dos tipos: Uso para sistemas autónomos 
(SFV-A); y uso para sistemas interconectados a la red (SFV-I).

En el caso de SFV-A, que es el que compete al problema, el inversor está alimentado por una fuente de tensión constante en $\mathrm{CD}$, generalmente en múltiplos de 12 VCD y tiene la función de proporcionar la potencia eléctrica que requiere una o varias cargas, en corriente alterna, a la tensión y frecuencia de operación de los aparatos eléctricos, generalmente es 127/220 VAC@60Hz. Estos inversores se especifican por su Potencia Nominal y el Voltaje de alimentación en CD; y se eligen de acuerdo a los siguientes criterios:

Potencia Nominal, $P_{N}(\operatorname{Inv})$ : Se recomienda elegirla al 80\% de la Potencia Total, $\mathrm{P}_{\mathrm{T}}$, de las "cargas" conectadas al circuito eléctrico local del usuario.

Tipo de Onda: Cuadrada (baja eficiencia, especial para "cargas" que no requieren de una onda senoidal como por ejemplo motores de baja potencia, cargas resistivas, focos de filamento), cuasi senoidal (con eficiencias en el rango 85-90\%, aplicable para todas las "cargas" excepto aquellas que incluyen temporizadores), o senoidal (eficiencias en el rango del 90 al 95\%, aplicable para cualquier carga). Tensión de alimentación en $\mathrm{CD}, \mathrm{V}_{\mathrm{IN}}$ (Inv): La tensión de corriente directa que debe transformar el inversor se le llama la tensión de alimentación, $\mathrm{V}_{\mathrm{IN}}$ (Inv). Como oferta comercial hay inversores con tensión de alimentación de 12, 24, 36, 48, 60, y hasta $120 \mathrm{VCD}$.

Tensión de salida, $\mathrm{V}_{\text {ouT }}$ (Inv): Generalmente son monofásicos a 127 VCA, pero también los hay trifásicos 220V/127 VCA.

Para efecto del dimensionamiento, el más importante es la Potencia Nominal y la Tensión de alimentación. Determinada la Potencia Nominal del Inversor, entre más grande se elija la Tensión de alimentación, mayor será el rendimiento eléctrico en los conductores que alimentan a éste. 
Por ejemplo, si se ha determinado que el inversor debe ser de 4,000 W de potencia nominal, y las "cargas" demandan una Potencia de operación de 3,600 W a 120 VCA, entonces el inversor proporcionará dicha potencia a 120 V CA, $60 \mathrm{~Hz}$ con una corriente de 30 A. Esta potencia (tensión y corriente) la debe de extraer del Banco de Baterías, el cual, debe tener un Voltaje Nominal, $V_{N}(B B)$ igual al Voltaje de Alimentación del Inversor, $\mathrm{V}_{\text {IN }}(\mathrm{Inv})$.

Así, si el $\mathrm{V}_{\text {IN }}$ (Inv)=12 VCD, el Banco de Baterías debe estar a 12 VCD y sin considerar las pérdidas en el inversor para dar 3,600 W a $120 \mathrm{V@60} \mathrm{Hz,} \mathrm{éste} \mathrm{extrae} \mathrm{del} \mathrm{Banco}$ de Baterías 300 Amper a 12 VCD, la cual es una corriente demasiada grande y para evitar pérdidas grandes en el proceso de conducción, los conductores deben ser gruesos y cortos. Por el contrario, si el $\mathrm{V}_{\mathrm{IN}}(\mathrm{Inv})=48 \mathrm{VCD}$, el inversor extraerá una corriente de 75 Amper a $48 \mathrm{VCD}$, que es un valor que, al ser conducido en cables, ocasionará menos pérdidas de potencia.

c) Controlador de Carga (CC).- Dependiendo de su electrónica de control, los CC se clasifican en control con tensión fija y control con tensión variable y se especifican por su Voltaje de Entrada, $\mathrm{V}_{\mathrm{IN}}(\mathrm{CC})$ y su Voltaje de Control a la salida, $\mathrm{V}_{\text {OUT }}(\mathrm{CC})$.

Los CC de tensión fija son aquellos que en su circuito de entrada fotovoltaica solo acepta aquel que provengan de un AFV integrado con MFV de 36 celdas en serie o múltiplos de ellos, cada MFV se le ha asignado una tensión nominal de $12 \mathrm{~V}$; y controlan la inyección de corriente en Bancos de Baterías de 12 V nominales o múltiplos de ésta; es decir:

Si el $\mathrm{V}_{\mathrm{N}}(\mathrm{BB})$ es de $48 \mathrm{VCD}$, entonces $\mathrm{V}_{\text {OUT }}(\mathrm{CC})=48 \mathrm{VCD}$, y el $\mathrm{V}_{\mathrm{IN}}(\mathrm{CC})=48 \mathrm{VCD}(4 \mathrm{MFV}$ de 36 celdas conectados en serie o dos MFV de 72 celdas conectados en serie). Por el contrario, 
Si $\mathrm{V}_{\mathrm{N}}(\mathrm{BB})=12 \mathrm{VCD}$, entonces $\mathrm{V}_{\text {OUT }}(\mathrm{CC})=12 \mathrm{VCD}$, y el $\mathrm{V}_{\text {IN }}(\mathrm{CC})=12 \mathrm{VCD}$ (1 MFV de 36 celdas).

Los CC de tensión variable son aquellos que en su circuito de entrada fotovoltaica tienen un seguidor de máxima potencia (MPPT) y acepta circuitos con tensiones en $\mathrm{CD}$ que provengan de un $\mathrm{AFV}$ que genera un $\mathrm{V}_{\mathrm{CA}}(\mathrm{AFV})$ hasta un valor máximo de $150 \mathrm{VCD}$ cuando los MFV que lo integran están fríos; es decir, acepta un rango amplio de tensión de entrada, de aquí el nombre de tensión variable; y controlan la inyección de corriente en Banco de Baterías de $12 \mathrm{~V}$ nominales o múltiplos de ésta; es decir:

Si el $V_{\mathrm{N}}(\mathrm{BB})$ es de $48 \mathrm{VCD}(36,24$ o 12), entonces el Voltaje de Control debe ser $\mathrm{V}_{\text {ouT }}(\mathrm{CC})=48 \operatorname{VCD}(36,24$, $12)$, y el voltaje de entrada al controlador, $\mathrm{V}_{\mathrm{IN}}(\mathrm{CC})$, cualquier valor comprendido desde el que corresponda al $V_{M P}$ de un MFV de 36 celdas en serie o más, hasta un valor máximo que corresponda al de una conexión serie de MFV (cadena FV) cuyo voltaje a circuito abierto no exceda 150 $\mathrm{V}$ cuando los MFV están fríos.

Habiendo seleccionado el controlador con cualquiera de las dos opciones, el siguiente criterio de selección es la corriente máxima que puede administrar el dispositivo, dato que siempre es proporcionado por su fabricante.

\section{4: Dimensionamiento FV}

Considerando la Ec V.2, que establece que la Potencia Pico del Arreglo FV que satisface el Balance de Energía está dada por:

$$
P_{p}(\mathrm{AFV})=\frac{\mathrm{E}_{\mathbb{C}}}{\mathrm{H}_{\mathbb{R}} \mathcal{R}_{\mathrm{T}}}
$$

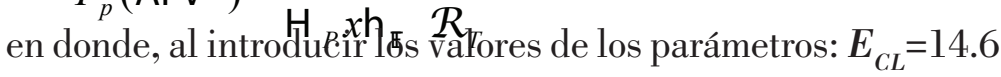
kWh; Recurso Solar $\boldsymbol{H}_{P}=6.27 \mathrm{kWh} / \mathrm{m}^{2}(6.27 \mathrm{hsp})$ para el mes crítico (julio), Rendimiento Térmico de los MFV elegidos, $\mathbf{R}_{\mathrm{T}}=\mathbf{8 1 \%}$; y la eficiencia eléctrica total $\eta_{\mathrm{ET}}$ dada por $\eta_{\mathrm{ET}}=\eta_{\mathrm{W}}$ $\eta_{\mathrm{cc}} \eta_{\text {Inv }} \eta_{\mathrm{B}}=(0.97) \mathrm{x}(0.97) \mathrm{x}(0.95) \mathrm{x}(0.85)=0.76$, se obtiene $P_{P}(\mathrm{AFV})=3.784 \mathrm{~kW}$ 


\section{5: Voltaje Nominal del Sistema.-Selección del Inver- sor, y Tensiones de acoplamiento}

Para establecer la configuración del AFV, es decir, cuantos MFV se deben conectar en serie para crear la cadena fotovoltaica (CFV) y cuantas CFV se deben conectar en paralelo para proporcionar la $P_{P}$ requerida, se necesita elegir el Voltaje Nominal del Sistema, $\mathrm{V}_{\mathrm{N}}(\mathrm{S})$.

De la Figura V.6 se tiene que es el inversor el que define el $V_{N}(S)$. Como la Potencia Total, $P_{T}$, de las cargas del usuario suman un total de 5,200 W, entonces para SFV-A, según el criterio 3-b antes mencionado, la Potencia Nominal del Inversor, $P_{N}(\operatorname{Inv})$, debe ser del orden del $80 \%$ de $\mathrm{P}_{\mathrm{T}^{\circ}}$ De esta manera se debe buscar un inversor $\mathrm{CD} / \mathrm{CA}$ con una $P_{N}(\operatorname{Inv}): \cong 4,160 \mathrm{~W}$ La oferta comercial de inversores incluye a dos productos de la marca Xantrex-Schneider, con una potencia nominal de 4,000 W, que se aproxima al valor buscado. La Figura V.7 muestra una copia de la hoja de especificaciones de dichos productos. Sus características más relevantes son las siguientes:

- Estos productos, cuyos modelos son SW4024 y SW4048 son Inversores/Cargadores, es decir, tienen dos funciones: una la de convertir la CD en CA (Inversor), y la otra, si hay una fuente adicional de CA (un motogenerador, un generador eólico e inclusive la red eléctrica convencional), el equipo tiene la función de convertir la CA en CD y ser un cargador de baterías.

- Ambos son de onda senoidal pura, su tensión de salida es $\mathrm{V}_{\text {OUT }}(\mathrm{Inv})=120 \mathrm{VCA}$ y tienen la misma potencia nominal, $P_{N}(\operatorname{Inv})=4,000 \mathrm{~W}$.

- El SW4024 se alimenta con una tensión de entrada de 24 VCD, es decir, $\mathrm{V}_{\text {IN }}(\mathrm{Inv})=24 \mathrm{VCD}$ y tiene una eficiencia del 94\%; mientras que el SW4048 se alimenta con una tensión de entrada de $48 \mathrm{VCD}$, es decir, $\mathrm{V}_{\mathrm{IN}}(\mathrm{Inv})=48 \mathrm{VCD}$ y tienen una eficiencia del $95 \%$. 


\begin{tabular}{|c|c|c|c|}
\hline \multirow{6}{*}{$\begin{array}{l}\text { Tensión de entrada } \\
\text { para operar como } \\
\text { Cargador: } \\
120 \mathrm{VCA}\end{array}$} & \multicolumn{3}{|l|}{ Electrical Specifications } \\
\hline & Models & SW4024 & SW4048 \\
\hline & AC input voltage & $120 \mathrm{Vac}$ & $120 \mathrm{Vac}$ \\
\hline & AC input voltage range & $80-149 \mathrm{Vac}$ & $80-149 \mathrm{Vac}$ \\
\hline & $A C$ input current & 60 Aac pass through & 60 Aac pass through \\
\hline & & 30Aaccharging & 30 Aaccharging \\
\hline \multirow[b]{2}{*}{ Parámetros de Salida: } & Continuous power $\left(\Theta 25^{\circ} \mathrm{C}\right)$ & $4000 \mathrm{VA}$ & $4000 \mathrm{VA}$ \\
\hline & Efficiency (peak) & $94 \%$ & $95 \%$ \\
\hline \multirow{5}{*}{$\begin{array}{c}P_{M}(\operatorname{Inv})=4,000 \mathrm{~W} \\
\eta_{\text {lnv }}=0.94 \text { a } 0.96 \% \\
V_{\text {OuTT }}(\text { Inv })=120 \mathrm{~V} \\
\text { Frecuencia }=60 \mathrm{~Hz}\end{array}$} & Output voltage (RMS) & $120 \mathrm{Vac}$ & $120 \mathrm{Vac}$ \\
\hline & Output voltage regulation & $\pm 3 \%$ & $\pm 3 \%$ \\
\hline & Frequency & $60 \mathrm{~Hz}$ & $60 \mathrm{~Hz}$ \\
\hline & Continuous output $\left(\Theta 25^{\circ} \mathrm{C}\right)$ & $33 \mathrm{Aac}$ & $33 \mathrm{AaC}$ \\
\hline & 100 mSec surge capability & $78 \mathrm{AaC}$ & $78 \mathrm{AaC}$ \\
\hline \multirow{12}{*}{$\begin{array}{l}\text { Tensión de entrada } \\
\text { Corriente Directa para } \\
\text { operar como Inversor: } \\
2 \text { valores: } V_{\mathrm{nN}}(\text { Inv })=24 \mathrm{~V} \\
\text { y } \mathrm{V}_{\mathrm{nV}}(\text { Inv })=48 \mathrm{~V}\end{array}$} & Automatic transfer relay & $60 \mathrm{~A}$ & $60 \mathrm{~A}$ \\
\hline & DC input voltage (nominal) & $24 \mathrm{Vdc}$ & $48 \mathrm{Vdc}$ \\
\hline & DC input voltage range & $22.33 \mathrm{Vdc}$ & $44-66 \mathrm{Vdc}$ \\
\hline & DC current at rated nower & $200 \mathrm{Adc}$ & $10.0 \mathrm{Adc}$ \\
\hline & Idle consumption (typ at full voltage) & $<16 W$ & $<16 W$ \\
\hline & Search mode consumption & $<1 W$ & $<1 W$ \\
\hline & Low battery protection (enabled) & \multicolumn{2}{|c|}{ Adjustable low-battery cut out and cut in (all models) } \\
\hline & Max. continuous charge rate & $110 \mathrm{Adc}$ & $60 \mathrm{Adc}$ \\
\hline & Total harmonic distortion & $<5 \%$ & $<5 \%$ \\
\hline & Waveform & \multicolumn{2}{|c|}{ Sine wave, 34 to 52 steps per cycle } \\
\hline & Load sensing (inverter mode) & \multicolumn{2}{|c|}{ Adjustable, 0 to over $200 \mathrm{~W}$ ( $48 \mathrm{~W}$ default) } \\
\hline & Power factor (allowed) & -1.0 to 1.0 & -1.0 to 1.0 \\
\hline
\end{tabular}

Figura V.7: Especificaciones técnicas más relevantes para inversores Xantrex de la serie SW, modelos SW4024 y SW4048

Para mantener un buen rendimiento eléctrico en el uso y manejo de la energía, se elige el modelo SW4048 cuyo voltaje de alimentación es $48 \mathrm{~V}$ CD.

Debido a la elección, el voltaje nominal del Banco de Baterías, $\mathrm{V}_{\mathrm{N}}(\mathrm{BB})$, debe ser $48 \mathrm{VCD}$; y se elegirá un controlador de tensión fija con un voltaje de control, $\mathrm{V}_{\text {OUT }}(\mathrm{CC})$, a 48 VCD y un Voltaje de entrada, $\mathrm{V}_{\mathrm{IN}}(\mathrm{CC})$, de $48 \mathrm{VCD}$; es decir:

$\mathrm{V}_{\mathrm{N}}(\mathrm{BB})=48 \mathrm{VCD}$,

$\mathrm{V}_{\text {OUT }}(\mathrm{CC})=48 \mathrm{VCD}, \mathrm{y}$

$\mathrm{V}_{\mathrm{IN}}(\mathrm{CC})=48 \mathrm{VCD}(4 \mathrm{MFV}$ de 36 celdas conectados en serie o dos MFV de 72 celdas conectados en serie).

En consecuencia, el Voltaje Nominal del Sistema, $V_{N}(S)$, es $48 \mathrm{VCD}$

\section{6: Configuración del AFV}

Ya que se ha elegido MFV de la marca Solartec, cuya oferta comercial incluyen módulos ensamblados con 36 celdas en 
serie, potencias pico desde: 90, 95, y $100 \mathrm{~W}$; 140, 145, 150, y $155 \mathrm{~W}$, y de módulos ensamblados con 72 celdas en serie con potencias desde 190, 195, 200 y 205 W, y 300, 305, 310, 315, $320 \mathrm{~W}$, entonces se debe realizar un proceso iterativo basado en el valor para el voltaje nominal del sistema, la potencia pico calculada para el AFV y la Potencia Pico del MFV elegido.

Al elegir el modulo a usar, cuya potencia pico bajo condiciones STC es $P_{P}(\mathrm{MFV})$. entonces el número total de módulos, $\mathrm{N}_{\mathrm{T}}$, está dado por la Ec. V.5:

$$
\mathrm{N}_{\mathrm{T}} \text { (módulos) }=\frac{P_{P}(A F V)}{P_{P}(M F V)}
$$

Por otra parte, ya que se tiene que $V_{N}(S)=48 \mathrm{VCD}$, entonces de la Ec. V.6 se sigue que:

a) Si el MFV elegido es de 36 celdas en serie con una Potencia Pico $P_{P}(\mathrm{MFV})$, entonces el Número de éstos a conectarse en Serie, $\mathrm{N}_{\mathrm{S}}$, es:

$$
\mathrm{N}_{\mathrm{S}}(\text { B S })=\frac{\mathrm{V}_{N}(\mathrm{~S})}{\left.\mathrm{V}_{\sqrt{N}} \mathrm{MFV}\right)}=48 / 12=4
$$

b) Si el MFV elegido es de 72 celdas en serie con una Potencia Pico $P_{P}(\mathrm{MFV})$, entonces el Número éstos a conectarse en Serie, $\mathrm{N}_{\mathrm{S}}$, es:

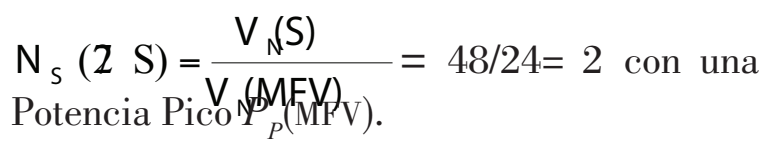

y el número de paneles o cadenas conectados en paralelo $\mathrm{M}_{\mathrm{P}}$ será:

$$
\mathrm{M}_{P}(\text { cadenas })=\frac{\mathrm{N}_{\mathrm{T}}}{\mathrm{N}_{\mathrm{S}}},
$$

redondeando esta fracción al número entero superior. 
Considerando lo antes dicho, se divide la Potencia Pico calculada para el AFV entre la Potencia pico del MFV elegido, y el cociente (resultado) se divide entre el número de módulos en serie, redondeando el resultado al entero inmediato superior. De esta manera, las soluciones que más se aproximan a la potencia pico requerida son las siguientes:

- Dentro de la gama comercial de Solartec con MFV de 36 celdas, el que proporciona la mejor aproximación a la potencia pico requerida es el de una Potencia Pico $P_{P}(\mathrm{M}-$ $\mathrm{FV})=95 \mathrm{~W}$.

Así, el número total de módulos, $\mathrm{N}_{\mathrm{T}}$, de $95 \mathrm{~W}$ es 40 pzas, configurados eléctricamente como $4 \mathrm{~S}$ (cadena fotovoltaica formada por cuatro módulos conectados en serie para dar el voltaje nominal de $48 \mathrm{VCD}$ ) y 10 cadenas FV conectados en paralelo para proporcionar la potencia requerida. $\mathrm{N}_{\mathrm{T}}(95 \mathrm{~W} @ 36$ celdas $)=40$ pzas

\section{Configuración: 4Sx10P}

$P_{P}(\mathrm{AFV})=40 \times 95 \mathrm{~W}=3,800 \mathrm{~W}$

Potencia pico requerida, $P_{P R}(A F V)=3,784 \mathrm{~W}$;

Potencia Pico a instalar, $P_{P I}(A F V)=3,800 \mathrm{~W}$; exceso de $16 \mathrm{~W}$

\section{Tensión Nominal de $V_{N}(S)=48 \mathrm{VCD}$}

Los parámetros eléctricos del MFV, CFV y AFV se muestran en la Tabla V-3.

Tabla V.3: Parámetros eléctricos del MFV, Cadena FV y Arreglo FV

Características eléctricas bas adas en un MFV de silicio monocristalino de $\mathbf{3 6}$ celdas de la marca Solartec, Modelo S36MC-95

\begin{tabular}{|c|c|c|c|}
\hline Parámetro & Módulos & CADENA (4S) & $\begin{array}{c}\text { ARREGLO } \\
(4 \mathrm{Sx} 10 \mathrm{P})\end{array}$ \\
\hline Potencia $P_{P} \quad$ (W) & 95 & 380 & 3,800 \\
\hline Volta $V_{C A} \quad(V)$ & 22.6 & 90.4 & 90.4 \\
\hline Corriente $I_{C C} \quad$ (A) & 5.46 & 5.46 & 54.6 \\
\hline Voltaje $V_{M P} \quad$ (V) & 18.72 & 74.89 & 74.89 \\
\hline Corriente $I_{M P} \quad$ (A) & 5.08 & 5.08 & 50.8 \\
\hline Voltaje Nominal, $\mathbf{v}_{\mathrm{N}}$ (V) & 12 & 48 & 48 \\
\hline $\mathrm{T}_{\text {NOCT }} \quad\left({ }^{\circ} \mathrm{C}\right)$ & \multicolumn{3}{|c|}{45} \\
\hline Coef Tem en $P_{P} \quad \%^{\circ} \mathrm{C}$ & \multicolumn{3}{|c|}{-0.46} \\
\hline Coef. Temp en $V_{C A} \quad \%^{\circ} \mathrm{C}$ & \multicolumn{3}{|c|}{-0.356} \\
\hline
\end{tabular}


- Dentro de la gama comercial de la empresa Solartec con MFV de 72 celdas, el que proporciona la mejor aproximación a la potencia pico requerida es el $P_{P}(\mathrm{MFV})=190 \mathrm{~W}$.

Así, el número total de módulos, $\mathrm{N}_{\mathrm{T}}$, de $190 \mathrm{~W}$ es 20 pzas, configurados eléctricamente como $2 \mathrm{~S}$ (cadena fotovoltaica formada por dos módulos conectados en serie para dar el voltaje nominal de $48 \mathrm{VCD}$ ) y 10 cadenas FV conectados en paralelo para proporcionar la potencia requerida.

$\mathrm{N}_{\mathrm{T}}(190 \mathrm{~W} @ 72$ celdas $)=20$ pzas

Configuración: $2 S_{x} 10 P ; \quad P P(A F V)=20 \times 190 \mathrm{~W}=3,800 \mathrm{~W}$

Potencia pico requerida, $\operatorname{PPR}(A F V)=3,784 \mathrm{~W}$;

Potencia Pico a instalar, $P P I(A F V)=3,800 \mathrm{~W}$; exceso de $16 \mathrm{~W}$

Tensión Nominal de $\mathrm{VN}(\mathrm{S})=48 \mathrm{VCD}$

\section{7: Balance energético}

En ambos casos anteriores, la Potencia Pico dimensionada para el mes crítico es de $3.8 \mathrm{~kW}$. Considerando que el proyecto fue dimensionado con un rendimiento térmico de 0.81 y una eficiencia eléctrica total de 0.76 (ver paso 4), entonces la Energía Generada Estimada, $\mathrm{E}_{\mathrm{G}}$, promedio diario mensual, estará dada por:

$$
\boldsymbol{E}_{G}=P_{P}(\boldsymbol{A F V}) * \boldsymbol{H}_{P} * \eta_{\mathrm{ET}} * R_{T}
$$

$\mathrm{Al}$ introducir en esta expresión los valores para el recuso solar promedio diario mensual y compararlos con la energía consumida, mediante un gráfico de barras, se tiene el comportamiento mostrado en la Figura V.8. En él se observa que para el mes de julio, se satisface el balance energético, y tal y como se esperaba, en los demás meses se tiene un exceso de energía, que en el caso del mes de marzo, es de 2.60 kWh promedio diario. 


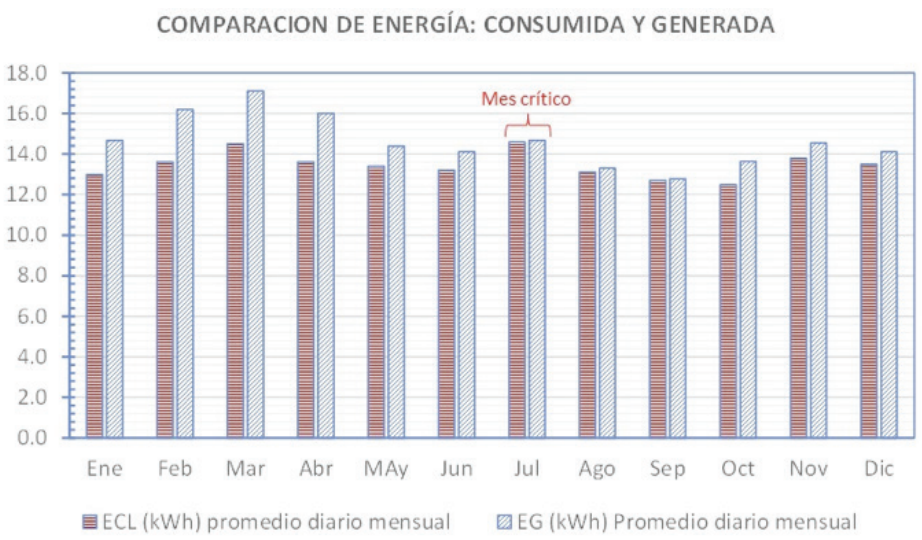

Figura V.8: Perfil mensual del valor promedio diario de energía requerida $E_{C L}$ con respecto a la energía generada estimada $E_{G}$ por el AFV de $3.8 \mathrm{~kW}$ pico.

\section{8: Banco de Baterías}

La energía que consumen las cargas eléctricas, promedio diario en el mes de diseño tiene un valor de:

$$
E_{C L}=14.6 \mathrm{kWh}=304 \text { Ah@48 VCD }
$$

Hay una gama muy amplia de fabricantes de baterías para aplicaciones FV, la más común es la de Pb-ácido. Dentro de éstas empresas, la compañía MK-Deka oferta baterías base Gel de 12 V CD con 225 AH de capacidad, placa gruesa, de ciclado profundo (fu=0.8 y Fi=1.35). En la Figura V.9 muestra las características más relevantes de dicho producto.

Considerando estos datos y con una autonomía de 3 días, a partir de la Ec. V.11 se tiene que:

$$
C_{B}=\frac{E_{C} A_{U}}{\left.V_{N} S\right) \quad f_{U} F}=844.9 \text { AH@48 VCD }
$$

Si $V_{\text {BAT }}$ es el voltaje de la batería seleccionada con una Capacidad de Almacenamiento $\mathrm{C}_{\mathrm{BAT}}$, entonces:

a) Número de Baterías conectadas en Serie:

b) $\mathrm{N}_{\mathrm{S}}=\mathrm{V}_{\mathrm{N}}(\mathrm{S}) / \mathrm{V}_{\mathrm{BAT}}=48 / 12=4$ Baterías en Serie

c) Número de arreglos (de baterías en serie) conectados en paralelo: 
d) $\mathrm{M}_{\mathrm{P}}=\mathrm{C}_{\mathrm{BB}} / \mathrm{C}_{\mathrm{BAT}}=844.9 / 225=3.76 \approx 4$

e) Arreglo de Baterías: $4 \mathrm{Sx} 4 \mathrm{P}$

f) Capacidad Total del Banco de Baterías: $\mathbf{C}_{\mathbf{B B}}=\mathbf{9 0 0}$ Ah@48 $\mathbf{V}$

g) Número Total de Baterías: $\mathrm{N}_{\mathrm{TB}}=\mathrm{N}_{\mathrm{S}} \mathrm{x} \mathrm{M}_{\mathrm{P}}=16$ Pzas.

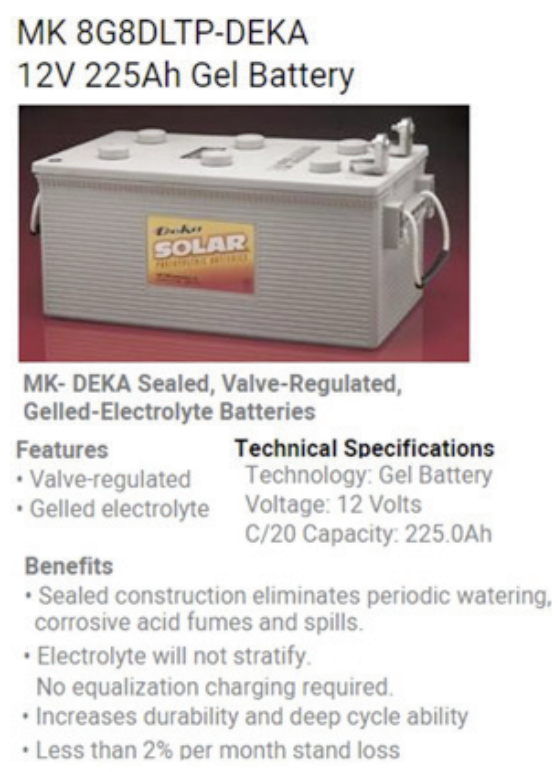

Figura V.9: Características de la Batería MK Deka 12VCD@225 Ah a C/20

Figura V.10: Perfil mensual del valor promedio diario de energía requerida $\mathrm{E}_{\mathrm{CL}}$ con respecto a la energía generada estimada $\mathrm{E}_{\mathrm{G}}$ por el $\mathrm{AFV}$ de $12.48 \mathrm{~kW}$ pico.

\section{9: Superficie Activa a ocupar}

El MFV elegido, modelo S60PC-260, con una potencia pico de $260 \mathrm{~W}$, tiene las siguientes dimensiones: largo de 11.65 $\mathrm{m}$; ancho de $0.992 \mathrm{~m}$; espesor de $0.035 \mathrm{~m}$, y pesa $18.5 \mathrm{~kg}$. Su eficiencia bajo condiciones STC es de $16.01 \%$.

Dado que se requiere instalar 40 pzas con una potencia pico de $3,800 \mathrm{~W}$, la Superficie Activa, $S_{A}$, se puede derivar de la Ec. V.10, por lo que:

$S A=P P(A F V) /(h G P)=3,800 \mathrm{~W} /(0.144 \times 1000 \mathrm{~W} / \mathrm{m} 2)=26.39 \mathrm{~m} 2$ 
Por lo tanto, la Superficie Activa es de $S A=26.39 \mathrm{~m} 2$.

\section{0: Orientación y ángulo óptimo.}

El análisis realizado es para un SFV sin seguimiento solar, así que la cara de los MFV que integran al AFV deben estar orientada hacia el Sur verdadero, es decir, el ángulo acimutal debe ser $0^{\circ}$. Dado que el mes critico corresponde al verano y en los demás meses se tiene un exceso de energía, la inclinación óptima debe corresponder a $18^{\circ}$, ya que el recurso solar se seleccionó para ese ángulo.

Conclusión: Para proporcionar la energía eléctrica promedio diaria mensual, que requiere el usuario, en el mes de diseño, se necesita una Potencia Pico para el AFV de 3,800 W, la que es $16 \mathrm{~W}$ más grande que la dimensionada.

Se eligió un inversor/cargador de la marca Xantrex, Modelo 4048 con una potencia nominal de 4,000 W, con una tensión de salida 120 VCA@60 Hz, requiriendo un voltaje de entrada de 48.0 VCD, el cual define el voltaje nominal del sistema.

Se ha dimensionado un Banco de Baterías con una Capacidad de Almacenamiento de $900 \mathrm{AH}$ a 48.0 VCD.

Para proporcionar la Potencia a Instalar, $3,800 \mathrm{~W}$, hay dos alternativas:

Una usando MFV de 36 celdas con una potencia pico de 95 W, requiriéndose 40 Pzas configuradas en un arreglo 4Sx10P.

La otra, usando MFV de 72 celdas con una potencia pico de $190 \mathrm{~W}$, requiriéndose 20 Pzas configuradas en un arreglo 2Sx10P

En ambos casos, los MFV que integran al AFV (4Sx10P, o 2Sx10P) deben montarse en una estructura metálica que les permita orientarse al Sur verdadero con una ángulo de inclinación de $18^{\circ}$.

V.3.c.- Sistemas interconectados en CA.

La siguiente Tabla muestra el perfil de consumo eléctrico mensual de una tienda de abarrotes en el medio urbano cuyas 
cargas eléctricas son refrigeradores para refrescos, iluminación y computación, teniendo una carga eléctrica total de 20.0 kW y una acometida trifásica 220/127 VCA@60 Hz. El usuario desea saber cuánta potencia pico debe tener un SFV, bajo la modalidad de interconexión a la red eléctrica convencional, para que le genere toda la energía que consume.

El proyecto eléctrico está ubicado en la Ciudad de Jojutla, Morelos, y los datos energéticos se muestran en la tabla adjunta. El Recurso Solar fue obtenido del sitio www.eosweb.larc. nasa.gov/sse para la localidad con coordenadas: $18^{\circ} 36^{\prime} 53$ " Latitud Norte y 99¹0'49”' Longitud Oeste.

Se requiere además, determinar el periodo para el cual se desarrollará el proceso de dimensionamiento y especificar cuál es el ángulo óptimo a la que deben estar los módulos para la captación de energía, y la Superficie Activa que ocupará el arreglo fotovoltaico.

Tabla V.4: Valores energéticos para el dimensionamiento fotovoltaico. El Recurso Solar corresponde a un captador inclinado a un ángulo de $18^{\circ}$.

\begin{tabular}{|c|c|c|c|c|c|}
\hline \multirow[b]{2}{*}{ Mes } & $\mathbf{E}_{\mathrm{Cl}}$ & $\mathbf{E}_{\mathrm{CL}}$ & $\begin{array}{c}\text { Recurso } \\
\text { Solar }\end{array}$ & Potencia & Temperatura \\
\hline & $\begin{array}{c}\text { (kWh) al } \\
\text { mes }\end{array}$ & $\begin{array}{c}\text { (kWh) } \\
\text { promedio } \\
\text { diario } \\
\text { mensual }\end{array}$ & $\begin{array}{c}\left(\mathrm{kWh} / \mathrm{m}^{2}\right) \\
\text { Prome dio } \\
\text { diario } \\
\text { mensual }\end{array}$ & $\begin{array}{c}\text { (W) } \\
\text { Efectiva } \\
\text { promedio } \\
\text { diaria }\end{array}$ & $\begin{array}{c}{ }^{\circ} \mathrm{C} \\
\text { Temperatura } \\
\text { media máxima }\end{array}$ \\
\hline Ene & 1620 & 52.26 & 5.80 & 9.010 & 27 \\
\hline Feb & 1580 & 56.43 & 5.90 & 9.564 & 30 \\
\hline Mar & 1630 & 52.58 & 6.10 & 8.620 & 30 \\
\hline Abr & 1625 & 54.17 & 6.20 & 8.737 & 32 \\
\hline MAy & 1720 & 55.48 & 6.30 & 8.807 & 34 \\
\hline Jun & 1780 & 59.33 & 6.20 & 9.570 & 35 \\
\hline Jul & 1750 & 56.45 & 6.00 & 9.409 & 32 \\
\hline Ago & 1720 & 55.48 & 5.90 & 9.404 & 30 \\
\hline Sep & 1690 & 56.33 & 5.46 & 10.317 & 29 \\
\hline Oct & 1885 & 60.81 & 5.83 & 10.430 & 28 \\
\hline Nov & 1795 & 59.83 & 6.22 & 9.620 & 27 \\
\hline Dic & 1800 & 58.06 & 6.03 & 9.629 & 26 \\
\hline Anual & 20595 & 677.22 & 71.94 & 9.414 & 30 \\
\hline $\begin{array}{c}\text { Promedio } \\
\text { Diario } \\
\text { Anual }\end{array}$ & 56.42 & 56.42 & 6.00 & 9.411 & 30 \\
\hline
\end{tabular}

\section{SOLUCIÓN:}

La solución será realizada a través de los siguientes pasos: 


\section{1: Arquitectura del Sistema}

Ya que el usuario se desea conectar a la red eléctrica convencional de CFE, el proyecto FV corresponde a un Sistema Fotovoltaico Interconectado (SFV-I). Ya que la potencia máxima instalada en la tienda, la que es la suma de la potencia individual de cada "carga" eléctrica es de $20.0 \mathrm{~kW}$, y tomando en consideración el "Manual de Interconexión de Centrales de Generación con Capacidad Menor a 0.5 MW", publicado en el Diario Oficial de la Federación el 15 de diciembre de 2016, el SFV-I no puede tener una potencia mayor a dicho valor y queda clasificado en la clase de baja escala.

Como los refrigeradores de enfriamiento son cargas eléctricas que operan con tres fases a $220 \mathrm{VCA}$, se requiere de un inversor CD/CA trifásico 220VCA, $60 \mathrm{~Hz}$ para transformar la electricidad de CD a CA con una tensión nominal entre fases de220 V @60 Hz.

La Figura V.10 proporciona la arquitectura para el SFV-I que generará la energía requerida en el periodo de diseño.

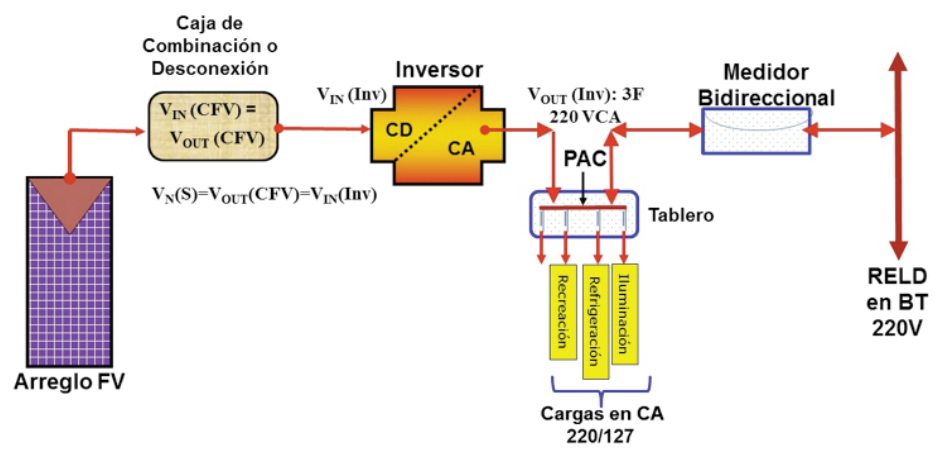

Figura V.11: Arquitectura típica de un SFV-A con almacenamiento electroquímico e inversor.

\section{2: Selección del periodo de diseño o mes crítico}

El periodo de diseño en los SFV-I se establece en términos del Contrato de Interconexión a la red que tendrá el usuario. 
Dado que en este caso el sistema energético es para autoconsumo, no venderá energía eléctrica, el contrato será de medición neta a través de un medidor bidireccional que contabilizara la energía que extrae el usuario de la RELD y aquellos excedentes que pudiera introducir a ésta. Ya que el contrato de medición neta establece periodos de balance energéticos anuales, se sugiere que el Dimensionamiento Fotovoltaico se realice con los valores energéticos que correspondan al promedio diario anual. Así, la Tabla V.5 muestra los valores a usar para el dimensionamiento.

Tabla V.5: Valores energéticos a considerar para el dimensionamiento usando los datos de los promedios diarios anuales.

\begin{tabular}{|c|c|c|}
\hline \multicolumn{3}{|c|}{ DATOS PARA EL DIMENSIONAMIENTO } \\
\hline $\begin{array}{c}\text { Periodo de } \\
\text { Diseño }\end{array}$ & $\begin{array}{c}\text { Recurso Solar } \\
(\mathrm{kWh} / \mathrm{m} 2)\end{array}$ & $\begin{array}{c}\text { Energía a Proporcionar } \\
(\mathrm{kWh})\end{array}$ \\
\hline Anual & 6.00 & 56.42 \\
\hline
\end{tabular}

\section{3: Selección de Tecnologías}

a) Módulos FV.- Se usaran MFV de silicio policristalino de la marca Solaretec, de 60 celdas en serie, ya que dicha empresa oferta sus productos con potencias pico que van desde los 240 hasta 270 , en pasos de 5.0 W; pero, el procedimiento es el mismo para cualquier tipo de MFV. La empresa fabrica dichos MFV con celdas cuadradas de $156 \mathrm{~mm}$ de lado para construir sus productos y los integra con 3 diodos de paso, un diodo por cada serie de 20 celdas, para prevenir la formación de puntos calientes. La Temperatura NOCT de sus MFV es de $45^{\circ} \mathrm{C}$ y el coeficiente de temperatura de dichos dispositivos, en la Potencia, es de $-0.5 \% /{ }^{\circ} \mathrm{C}$; y es el que se aplica para determinar el porcentaje de las Pérdidas en la Potencia Pico, $\mathrm{PP}_{P}$ por efecto de la 
temperatura. La Figura XXX muesta un extracto delas especificaciones técnicas de éstos productos.

\begin{tabular}{|c|c|c|c|c|c|c|c|c|c|c|}
\hline \multicolumn{11}{|c|}{$5-1 \Rightarrow r+\underline{ }$} \\
\hline Modelo & \multicolumn{2}{|c|}{$560 P C-240$} & \multicolumn{2}{|c|}{$560 P C-245$} & \multicolumn{2}{|c|}{ S60PC-250 } & \multicolumn{2}{|c|}{ S60PC-255 } & \multicolumn{2}{|c|}{$560 P C-260$} \\
\hline Condiciones de Mediciobn & ste & ност & ste & мост & STC & Noст & ste & Noct & stc & NoCt \\
\hline Voltaje de circulito abierto (Voc) & $35.70 \mathrm{~V}$ & $35.64 \mathrm{~V}$ & $36.10 \mathrm{~V}$ & $36.04 \mathrm{~V}$ & $36.30 \mathrm{~V}$ & $36.24 \mathrm{~V}$ & $36.40 \mathrm{~V}$ & $36.34 \mathrm{~V}$ & $36.70 \mathrm{~V}$ & $36.64 \mathrm{~V}$ \\
\hline Voltaje en et punto de mixima potencia (Vmpp) & $30.00 \mathrm{~V}$ & $29.24 \mathrm{~V}$ & $30.40 \mathrm{~V}$ & $30.34 \mathrm{~V}$ & $30.60 \mathrm{~V}$ & $30.54 \mathrm{~V}$ & $30.70 \mathrm{~V}$ & $30.64 \mathrm{~V}$ & $30.90 \mathrm{~V}$ & $30.84 \mathrm{~V}$ \\
\hline Cerriente de cortocirevite thacl & $8.57 \mathrm{~A}$ & $6.87 \mathrm{~A}$ & $8.63 \mathrm{~A}$ & $6.92 \mathrm{~A}$ & 8.7.A & $6.98 \mathrm{~A}$ & $2.80 \mathrm{~A}$ & $7.05 \mathrm{~A}$ & $8.89 \mathrm{~A}$ & $7.13 \mathrm{~A}$ \\
\hline Corriente en el punto de míxima potencia (IImpo) & $8.00 \mathrm{~A}$ & $6.41 \mathrm{~A}$ & $8.05 \mathrm{~A}$ & $6.45 \mathrm{~A}$ & 8.17 A & $6.55 \mathrm{~A}$ & $8.30 \mathrm{~A}$ & $6.65 \mathrm{~A}$ & $8.42 \mathrm{~A}$ & $6.75 \mathrm{~A}$ \\
\hline Potencia máxima (Pmax) & $240 \mathrm{~W}$ & 1916 & $245 \mathrm{w}$ & $195 \mathrm{~W}$ & $250 \mathrm{~W}$ & $200 \mathrm{~W}$ & $255 \mathrm{w}$ & $203 \mathrm{~W}$ & $260 \mathrm{~W}$ & $208 \mathrm{~W}$ \\
\hline Eficiencia det mobulo & \multicolumn{2}{|c|}{$14.78 \%$} & \multicolumn{2}{|c|}{$15.08 \%$} & \multicolumn{2}{|c|}{$15.39 \%$} & \multicolumn{2}{|c|}{$15.70 \%$} & \multicolumn{2}{|c|}{$16.01 \%$} \\
\hline \multicolumn{11}{|c|}{ Coeficientes de Temperatura } \\
\hline de $|s c| a \mid$ & $1{ }^{\circ} \mathrm{C}$ & \multicolumn{2}{|c|}{ de Voc $(\beta)$} & \multicolumn{3}{|c|}{$-0.31 \% /{ }^{\circ} \mathrm{C}$} & \multicolumn{2}{|c|}{ de $P \max (y)$} & \multicolumn{2}{|c|}{$-0.50 \% /{ }^{\circ} \mathrm{C}$} \\
\hline \multicolumn{11}{|c|}{ Panel Solar con Celdas de $156 \mathrm{~mm}$ de Siticio Monocristalino } \\
\hline Modelo & \multicolumn{2}{|c|}{ S6OMC-250 } & \multicolumn{2}{|c|}{ S60MC-255 } & \multicolumn{2}{|c|}{ S60MC-260 } & \multicolumn{2}{|c|}{ S6OMC-265 } & \multicolumn{2}{|c|}{ S6OMC-270 } \\
\hline Condiciones de Medición & sTc & Noct & sTc & мост & stc & мост & stc & мост & sTc & Nост \\
\hline Voltaje de circuito atierto fVoct & $37.30 \mathrm{~V}$ & $37.23 \mathrm{~V}$ & $37.40 \mathrm{~V}$ & $37.33 \mathrm{~V}$ & $38.00 \mathrm{~V}$ & $37.93 \mathrm{~V}$ & $38.30 \mathrm{~V}$ & $38.23 \mathrm{~V}$ & $37.80 \mathrm{~V}$ & $37.73 \mathrm{~V}$ \\
\hline Vottaje en et punto de máxima potencia (Vmpol) & $30.50 \mathrm{~V}$ & $30.40 \mathrm{~V}$ & $30.60 \mathrm{~V}$ & $30.50 \mathrm{~V}$ & $31.10 \mathrm{~V}$ & $31.00 \mathrm{~V}$ & $31.30 \mathrm{~V}$ & $31.20 \mathrm{~V}$ & $31.70 \mathrm{~V}$ & $31.60 \mathrm{~V}$ \\
\hline Corriente se cortecirculato flisc) & $8.74 \mathrm{~A}$ & $7.03 \mathrm{~A}$ & 2.85A & $7.11 \mathrm{~A}$ & $8.89 \mathrm{~A}$ & $7.15 \mathrm{~A}$ & $9.02 \mathrm{~A}$ & $7.25 \mathrm{~A}$ & $9.07 \mathrm{~A}$ & $7.29 \mathrm{~A}$ \\
\hline Corriente en el punto de mixims potencis (Impp) & $8.21 \mathrm{~A}$ & $6.92 \mathrm{~A}$ & $8.32 \mathrm{~A}$ & $7.02 \mathrm{~A}$ & $8.35 \mathrm{~A}$ & $7.04 \mathrm{~A}$ & $8.48 \mathrm{~A}$ & $7.15 \mathrm{~A}$ & $8.51 \mathrm{~A}$ & $7.18 \mathrm{~A}$ \\
\hline Poteocis mixima (Pmax) & $250 \mathrm{~W}$ & $210 \mathrm{w}$ & $255 \mathrm{~W}$ & $213 \mathrm{w}$ & $260 \mathrm{~W}$ & $218 \mathrm{w}$ & $265 \mathrm{~W}$ & $223 \mathrm{w}$ & $270 \mathrm{~W}$ & $226 \mathrm{w}$ \\
\hline Eficiencia det modulato & \multicolumn{2}{|c|}{ 15. $39 \%$} & \multicolumn{2}{|c|}{ 15.70\% } & \multicolumn{2}{|c|}{$16.01 \%$} & \multicolumn{2}{|c|}{$16.32 \%$} & \multicolumn{2}{|c|}{$16.62 \%$} \\
\hline \multicolumn{11}{|c|}{ Coeficientes de Temperatura } \\
\hline de $|s c| a \mid$ & $\% /{ }^{\circ} \mathrm{C}$ & & Voc $|\beta|$ & & $0.369 \% /{ }^{\circ} \mathrm{C}$ & & de $P$ max & & -0.516 & $6 /{ }^{\circ} \mathrm{C}$ \\
\hline
\end{tabular}

Figura V.12: Especificaciones técnicas de MFV de silicio mono y policristalino de la maca Solartec.

Usando las Ecs IV-6 a la IV-8 se tiene que, para la temperatura media máxima anual $\left(30^{\circ} \mathrm{C}\right)$, el Rendimiento Promedio de los MFV elegidos, considerando la mayor irradiancia, $\mathrm{G}=1,000 \mathrm{~W} / \mathrm{m}^{2}$ es de:

$\mathbf{R}_{\mathrm{T}}=\mathbf{8 2 \%}$

b) Inversor.- Para el caso de SFV-I el inversor está alimentado por una fuente de tensión variable en $\mathrm{CD}$, que es la tensión de salida del AFV que corresponde al Voltaje en el Punto de la Máxima Potencia de éste y se debe acoplar a una red eléctrica en corriente alterna. Ya que la energía eléctrica que distribuye el Sistema Eléctrico Nacional (SEN) en las redes eléctricas locales de distribución (RELD) se proporciona a una tensión de $220 \mathrm{VCA}$, trifásica a $60 \mathrm{~Hz}$, el inversor para 
interconexión a la RELD tiene la función de sincronizarse con la Tensión y frecuencia de la RELD e inyectar corriente eléctrica, es decir, ya estando sincronizado, éste actúa como un generador de corriente eléctrica en alterna.

Estos inversores se especifican por sus características eléctricas para acoplarse a la RELD; su Potencia Nominal, $P_{N}(\operatorname{Inv})$; y el rango de voltajes en CD, llamada la "ventana de acoplamiento" para determinar, con el MFV elegido, cuantos MFV hay que conectar en serie, para crear la Cadena Fotovoltaica (CFV) y definir el valor de la Tensión de Acoplamiento, $\mathrm{V}_{\mathrm{ACO}}$ (Inv), en $\mathrm{CD}$. La manera en que se elige el inversor es la siguiente:

$\varnothing$ Potencia Nominal, $P_{N}(\operatorname{Inv})$ : Se recomienda establecerla prácticamente igual a la Potencia Pico del AFV; es decir:

$$
P_{N}(\operatorname{Inv}) » P_{P}(A F V),
$$

Con este criterio, se debe buscar en la oferta comercial de inversores, el que mejor se adapte a dicha selección, pero siempre considerando la recomendación del fabricante respecto del rango de potencia FV para el acoplamiento.

$\varnothing$ Tensión de Acoplamiento de alimentación en CD, $\mathrm{V}_{\text {IN }}$ (Inv): La tensión de CD que debe transformar el inversor se le llama la tensión de acoplamiento de alimentación, $\mathrm{V}_{\text {IN }}$ (Inv). Estos se fabrican integrando en su electrónica uno o más seguidores de máxima potencia (MPPT) que han sido diseñados para operar en un rango amplio de voltajes llamado "la ventana" de acoplamiento CFV/Inversor, la que está determinada por un Vmin y un Vmax. Por lo anterior se sugiere que la tensión de acoplamiento se elija alrededor del punto medio de dicho rango; es decir, 


$$
\mathrm{V}_{\text {IN }}(\mathrm{Inv}) »(\mathrm{~V} \max +\mathrm{Vmin}) / 2 .
$$

Así, el $\mathrm{V}_{\text {IN }}($ Inv) tiene un valor óptimo que queda determinado por un valor que debe estar dentro de la ventana de acoplamiento, siendo el recomendado aquel que se aproxime al dado por la expresión anterior; y como consecuencia, $\mathrm{V}_{\mathrm{N}}(\mathrm{S})$ queda determinado por el $\mathrm{V}_{\mathrm{IN}}(\mathrm{INV})$ (ver Figura $\mathrm{V}-10)$.

$\varnothing$ Tensión de salida, $\mathrm{V}_{\text {out }}$ (Inv): Dependiendo de su potencia nominal hay productos que son bifásicos 208/240 VCA (menos de 3.0 kW) y la gran mayoría son trifásicos 208/240 VCA@60 Hz.

Para efecto del dimensionamiento, el más importante es la Potencia Nominal y la Tensión de acoplamiento que alimentará al inversor.

\section{4: Dimensionamiento FV}

Considerando la Ec V.2, que establece que la Potencia Pico del Arreglo FV que satisface el Balance de Energía está dada por:

$$
\begin{aligned}
& P_{p}(\mathrm{AFV})=\frac{\mathrm{E}_{\mathbb{C}}}{\mathrm{H}_{P} x \mathrm{~h}_{\mathbb{E}} \mathcal{R}_{T}} \\
& =56.42 /(6.0 \times 0.82 \times 0.9216)=12.444 \mathrm{~kW}
\end{aligned}
$$

en donde, al introducir los valores de los parámetros: $E_{C L}=56.42 \mathrm{kWh}$; Recurso Solar $\boldsymbol{H}_{P}=6.0 \mathrm{kWh} / \mathrm{m}^{2}(6.0 \mathrm{hsp})$ para el periodo de diseño, Rendimiento Térmico de los MFV elegidos, $\mathbf{R}_{\mathbf{T}}=\mathbf{8 2 \%}$; y la eficiencia eléctrica total $\eta_{\mathrm{ET}}$ dada por $\eta_{\mathrm{ET}}=\eta_{\mathrm{W}} \eta_{\mathrm{Inv}}=(0.97) \mathrm{x}(0.95)=0.9215$, se obtiene

$P_{P}(\mathrm{AFV})=12.444 \mathrm{~kW}$ 


\section{5: Voltaje Nominal del Sistema.-Selección del Inver- sor, y Tensión de acoplamiento}

Para establecer la configuración del AFV, es decir, cuantos MFV se deben conectar en serie para crear la cadena fotovoltaica (CFV) y cuantas CFV se deben conectar en paralelo para proporcionar la $P_{P}(\boldsymbol{A F V})$ requerida, se necesita elegir el Voltaje Nominal del Sistema, $V_{N}(S)$, que ya se ha establecido que su valor queda determinado a partir de la Tensión de Acoplamiento CFV/Inversor (ver Figura V.10).

Como la Potencia Pico del AFV es de 12.444 kW, la Potencia Nominal del Inversor, $P_{N}($ Inv $)$, debe ser del orden de ese valor. De esta manera se debe buscar un inversor CD/CA con una $P_{N}(\operatorname{Inv}): \cong 12.0 \mathrm{~kW}$, o bien, una combinación de inversores cuya suma de potencias sea de ese valor: dos de $6.0 \mathrm{~kW}, 3$ de $4.0 \mathrm{~kW}$, etc., teniendo presente que se deben de sincronizar a 220VCA@60 Hz.

La oferta comercial de inversores incluye, entre otros fabricantes a los de la maca Fronius que ofertan dos productos, uno modelo IG Plus 11.4-3 Delta con una Potencia nominal de $11.4 \mathrm{~kW}$, y otro, modelo IG Plus 12.0-3 Wye con una Potencia nominal de $12.0 \mathrm{~kW}$, ambos trifásicos, el primero 208/240 VCA, y el segundo 480/277 VCA, 60 Hz. La Figura V.11 muestra un extracto de la hoja de especificaciones en donde se tienen las características eléctricas más relevantes de ambos inversores. 


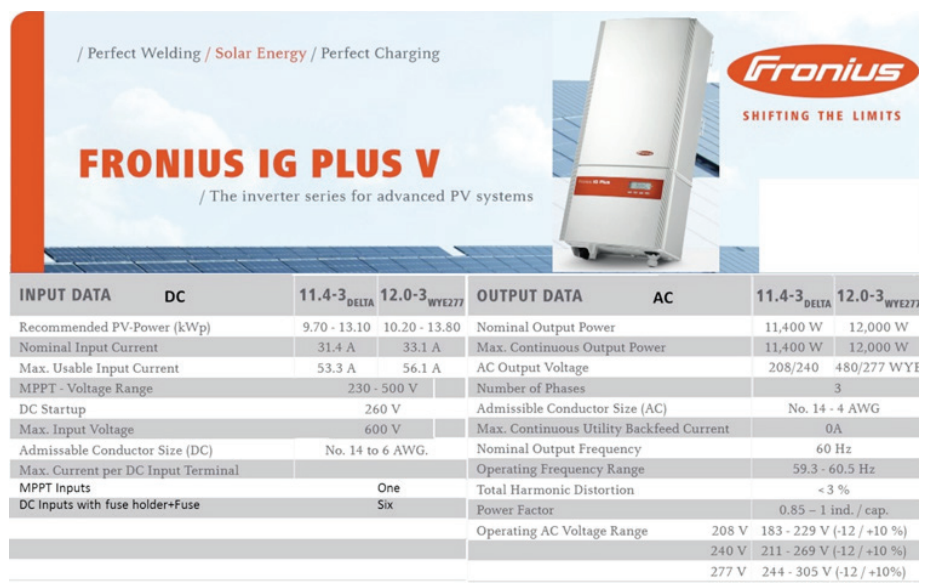

Figura V.13: Hoja de especificaciones del inversor Fronius IG Plus V modelos 11.4-3 Delta y 12.0-3 Wye.

De dicha hoja se tiene que la ventana de acoplamiento es desde: 230 a 500 VCD.

La máxima tensión admisible a la entada es de: 600 VCD que significa un $V_{C A}(A F V) \leq 600$ VCD estando los módulos trabajando a la temperatura más baja del sitio de instalación.

Considerando lo anterior, el $\mathrm{V}_{\mathrm{ACO}}$ (Inv) recomendado debe ser: $\mathrm{V}_{\text {IN }}(\mathrm{Inv}) »(\mathrm{~V} \max +\mathrm{Vmin}) / 2=(500+230) / 2=365$; es decir, $\mathrm{V}_{\text {IN }}($ Inv)»365 VCD.

\section{6: Selección del MFV y la Configuración del AFV}

Ya que se ha elegido MFV de la marca Solartec, cuya oferta comercial incluyen módulos ensamblados con 60 celdas en serie, potencias pico desde: 240 a $270 \mathrm{~W}$, entonces se debe realizar un proceso iterativo basado en el valor para el voltaje nominal del sistema, la potencia pico calculada para el AFV y la Potencia Pico del MFV elegido.

Al elegir el modulo a usar, cuya potencia pico bajo condiciones STC es $P_{P}(\mathrm{MFV})$, entonces el número total de módulos, $N_{T}$, está dado por la Ec. V.5:

$$
\mathrm{N}_{\mathrm{T}} \text { (módulos) }=\frac{P_{P}(A F V)}{P_{P}(M F V)}
$$


El Número de MFV conectados en Serie, $N_{S}$, para formar la CFV será

$$
\mathrm{N}_{S} \text { (módulos) }=\frac{\mathrm{V}_{\text {IN }}(\text { Inv })}{V_{M Y}(M F V)}
$$

y el número de paneles o cadenas conectados en paralelo $\mathrm{M}_{\mathrm{P}}$ será:

$$
M_{\mathrm{p}} \text { (cadenas) }=\frac{\mathrm{N}_{\mathrm{T}}}{\mathrm{N}_{\mathrm{S}}},
$$

redondeando las fracciones al número entero superior tal que, al multiplicarse el número de MFV en serie con el número de CFV en paralelo por la potencia del MFV, ésta debe ser igual o lo más cercana al valor dimensionado de la Potencia Pico del AFV..

De las especificaciones técnicas de los MFV propuestos que se proporcionan en la Figura V.11, se obtiene que, para una potencia pico requ47.86erida de $12,444 \mathrm{~W}$ y un voltaje de acoplamiento de $365 \mathrm{~V}$, la mejor combinación es:

$$
\begin{gathered}
\mathrm{N}_{\mathrm{T}} \text { (módulos) }=\frac{P_{P}(A F V)}{P_{P}(M F V)}=12,444 / 260=47.86 \\
\text { aproximado a } 48 \mathrm{MFV}
\end{gathered}
$$$$
\begin{gathered}
\mathrm{N}_{\mathrm{s}} \text { (módulos) }=\frac{\mathrm{V}_{\mathrm{IN}}(\mathrm{Inv})}{V_{\text {aproximado }}(\mathrm{MFV}) \mathrm{MFV}}=365 / 30.9=11.81
\end{gathered}
$$

$$
\mathrm{M}_{\mathrm{p}} \text { (cadenas) } \quad=\frac{\mathrm{N}_{\mathrm{T}}}{\mathrm{N}_{\mathrm{S}}}=48 / 12=4
$$

De esta manera, el Arreglo Fotovoltaico (AFV) estará configurado con una Cadena Fotovoltaica (CFV) de 12 MFV en Serie y $4 \mathrm{CFV}$ conectadas en paralelo para dar un total de 48 MFV de 260 W cada uno; y en consecuencia, la Potencia Pico a Instalar, tiene una magnitud de 12,480 W; es decir:

$$
\mathrm{P}_{\mathrm{P}}(\text { Instalar })=12,480 \mathrm{~W}
$$


la cual es 36 Watt mayor que la requerida. El lector debe corroborar esta aseveración. La Tabla V.6 muestra las características eléctricas del Arreglo Fotovoltaico.

Tabla V.6: Parámetros eléctricos del MFV, Cadena FV y Arreglo FV

\begin{tabular}{|c|c|c|c|}
\hline \multicolumn{4}{|c|}{$\begin{array}{l}\text { Características eléctricas basadas en un MFV de silicio } \\
\text { policristalino de } 60 \text { celdas, marca Solartec, Modelo S60PC-260 }\end{array}$} \\
\hline PARAMETROS & MóDULOS & $\begin{array}{c}\text { CADENA } \\
(12 \mathrm{~S})\end{array}$ & $\begin{array}{c}\text { ARREGLO } \\
(12 \mathrm{Sx} 4 \mathrm{P})\end{array}$ \\
\hline Potencia $P_{P} \quad$ (W) & 260 & 3,120 & 12,480 \\
\hline Volta $V_{C A}$ & 36.7 & 440.4 & 440.4 \\
\hline Corriente $I_{C C}$ & 8.89 & 8.89 & 35.56 \\
\hline Voltaje $V_{M P}$ & 30.9 & 370.8 & 370.8 \\
\hline Corriente $I_{M P}$ & 8.42 & 8.42 & 33.68 \\
\hline \multicolumn{4}{|l|}{ Voltaje Nominal, $\mathbf{V}_{\mathrm{N}}$ (V) } \\
\hline $\begin{array}{ll}T_{\text {NOCT }} & \left({ }^{\circ} \mathrm{C}\right) \\
\end{array}$ & \multicolumn{3}{|c|}{45} \\
\hline Coef Tem en $P_{P} \quad \%^{\circ} \mathrm{C}$ & \multicolumn{3}{|c|}{-0.5} \\
\hline Coef. Temp en $V_{C A} \quad \%^{\circ} C$ & \multicolumn{3}{|c|}{-0.31} \\
\hline
\end{tabular}

\section{7: Balance energético}

En ambos casos anteriores, la Potencia Pico dimensionada para el mes crítico es de $3.8 \mathrm{~kW}$. Considerando que el proyecto fue dimensionado con un rendimiento térmico de 0.81 y una eficiencia eléctrica total de 0.76 (ver paso 4), entonces la Energía Generada Estimada, $\mathrm{E}_{\mathrm{G}}$, promedio diario mensual, estará dada por:

$$
\boldsymbol{E}_{G}=P_{P}(\boldsymbol{A F V}) * \boldsymbol{H}_{P} * \eta_{\mathrm{ET}} * R_{T}
$$

Al introducir en esta expresión los valores para el recuso solar promedio diario mensual y compararlos con la energía consumida, mediante un gráfico de barras, se tiene el comportamiento mostrado en la Figura V.14. En él se observa que para los meses de enero, marzo a mayo, julio y agosto, la Energía Generada, $\boldsymbol{E}_{G}$, es mayor que la Energía Consumida por las "cagas", $E_{C L}$, por lo que se tendrá un exceso de energía que es 
inyectado a la red y su magnitud es contabilizada en el medidor bidireccional a favor del usuario; sin embargo, para los restantes meses, se tendrá una deficiencia de energía, la que es tomada de la red, contabilizada en el medidor bidireccional en el medidor y facturada al usuario.

Al final del año, el balance de energía es: $677.21 \mathrm{~kW}$ para la consumida, y de 678.41 W para la generada, es decir, la diferencia ente lo generado y lo consumido es de $1.2 \mathrm{kWh}$ a favor del usuario.

COMPARACION DE ENERGÍA: CONSUMIDA Y GENERADA

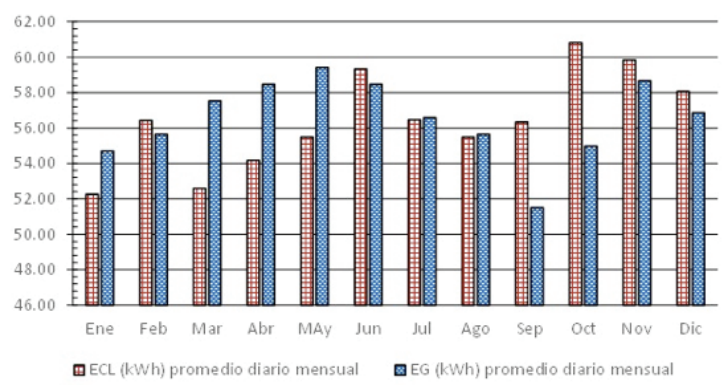

Figura V.14: Perfil mensual del valor promedio diario de energía requerida $E_{C L}$ con respecto a la energía generada estimada $E_{G}$ por el AFV de $12.48 \mathrm{~kW}$ pico.

\section{8: Superficie Activa a ocupar}

El MFV elegido, modelo S60PC260, con una potencia pico de $260 \mathrm{~W}$, tiene las siguientes dimensiones: largo de $1.64 \mathrm{~m}$; ancho de $0.992 \mathrm{~m}$; espesor de $0.035 \mathrm{~m}$, y pesa $18.5 \mathrm{~kg}$. Su eficiencia bajo condiciones STC es de $16.01 \%$.

Dado que se requiere instalar 48 pzas con una potencia pico de $12,480 \mathrm{~W}$, la Superficie Activa, $S_{A}$, se puede derivar de la Ec. V.10, por lo que:

$S_{A}=P_{P}(\mathrm{AFV}) /\left(\eta \quad G_{P}\right)=12,480 \mathrm{~W} /(0.1601 \times 1000 \mathrm{~W} /$ $\left.m^{2}\right)=77.95 \mathrm{~m}^{2}$

Por lo tanto, la Superficie Activa es de $S_{A}=77.95 \mathrm{~m}^{2}$. 


\section{9: Orientación y ángulo óptimo.}

El análisis realizado es para un SFV sin seguimiento solar, así que la cara de los MFV que integran al AFV deben estar orientada hacia el Sur verdadero, es decir, el ángulo acimutal debe ser $0^{\circ}$. Dado que el mes critico corresponde al verano y en los demás meses se tiene un exceso de energía, la inclinación óptima debe corresponder a $18^{\circ}$, ya que el recurso solar se seleccionó para ese ángulo.

\section{0: Conclusión}

Para proporcionar la energía eléctrica promedio diaria anual que requiere el usuario, en el periodo anual, se necesita un Arreglo Fotovoltaico con una Potencia Pico de 12,480 W, la que es $36 \mathrm{~W}$ más grande que la dimensionada.

- El MFV elegido es de la marca Solartec, modelo S60PC260, con una potencia pico de $260 \mathrm{~W}$, con las siguientes características físicas: sus dimensiones son: largo de $1.64 \mathrm{~m}$; ancho de $0.992 \mathrm{~m}$; espesor de $0.035 \mathrm{~m}$, y pesa $18.5 \mathrm{~kg}$. Su eficiencia bajo condiciones STC es de $16.01 \%$.

- Se eligió un inversor/cargador de la marca Fronius, Modelo IG Plus 11.4-3 Delta 208/240 VCA@60Hz.

- La configuración eléctrica para el Arreglo Fotovoltaico es: 12 MFV conectados en serie para formar la Cadena Fotovoltaica; y 4 Cadenas FV conectadas en paralelo (12Sx4P).

- Los MFV que integran al AFV deben montarse en una estructura que permita orientarlos con un azimut de $0^{\circ}$ y un ángulo de inclinación de $18^{\circ}$ respecto de la horizontal. 


\section{6}

\section{REQUERIMIENTOS PARA EL DISEÑO ELÉCTRICO}

\subsection{El marco regulatorio}

El diseño eléctrico de una instalación fotovoltaica está regido por normas nacionales, internacionales y especificaciones técnicas de los proveedores del servicio eléctrico o marcos normativos gubernamentales. Dentro de éstos, la NOM 001 SEDE 2012-Instalaciones Eléctricas (utilización), publicada en el DOF el 29 de noviembre de 2012, entrando en vigor a partir del 29 de mayo de 2013, es la Norma Oficial Mexicana que rige y regula las instalaciones eléctricas para fines comerciales e industriales; y en su Art. 690 Sistemas Solares Fotovoltaicos, se especifica los requerimientos mínimos de seguridad que debe tener una instalación fotovoltaica para que sea confiable, durable y segura tanto para el usuario como para el suministrador de potencia eléctrica (CFE).

En consecuencia, los Sistemas Fotovoltaicos se deben diseñar considerando el cumplimiento de la Normas Oficiales Mexicanas:

1. NOM 001 SEDE 2012.- Instalaciones Eléctricas (Utilización);

2. NOM-008-SCFI-2002, Sistema general de unidades de medida. 
Además, para los SFV-I se deben satisfacer los requerimientos técnicos exigidos por parte de la Comisión Reguladora de Energía (CRE) que son aplicables para todos los sistemas con una potencia tanto en Baja como en Media Escala y que se contemplan en:

1. “El Manual de Interconexión de Centrales de Generación con Capacidad Menor a 0.5 MW", publicado en el Diario Oficial de la Federación el 15 de diciembre de 2016, Observación y cumplimiento de las Normas internacionales siguientes:

1. IEC 60364-7-712 - "Electrical installations of buildings Part 7-712: Requirements for special installations or locations - Solar photovoltaic (PV) power supply systems".

2. IEC 62548 Design requirements for photovoltaic (PV) arrays

3. EC 62738 Design guidelines and recommendations for photovoltaic power plants.

Observación y cumplimiento de los requerimientos contemplados en:

1. Especificaciones técnicas de la Comisión Federal de Electricidad y del Centro Nacional de Control de Energía (CENACE).

\subsection{Aspectos relacionados con el diseño de SFV}

Por lo anterior, en el diseño de cualquier sistema fotovoltaico se deben tener presente los siguientes aspectos:

\section{2.a.- Seguridad}

Toda la instalación en su conjunto, tanto civil, mecánica y eléctrica, de los SFV-IR debe ser segura y confiable tanto para el usuario como para los operadores del SEN, por lo que debe cumplir con las especificaciones de seguridad que, sobre la instalación, se indican en el presente documento. 


\section{2.b. Certificación de Componentes}

Todas y cada una de las partes y componentes deben cumplir con las Normas Oficiales Mexicanas, Normas Mexicanas o en su defecto, Normas Internacionales aplicables en su caso, con respecto a su fabricación, desempeño y seguridad, por lo que deben estar certificados por un Organismo Nacional de Certificación de acuerdo a la normatividad correspondiente.

\section{2.c. Pruebas de Desempeño}

El Módulo Fotovoltaico (MFV) debe producir la potencia eléctrica para el cual fue diseñado, cuyo valor es obtenido bajo Condiciones de Medición Estándar (STC: Standard Test Conditions) y especificado por el fabricante en su placa de identificación. El desempeño eléctrico, calidad, seguridad y durabilidad del MFV debe estar evaluado con base en pruebas de laboratorio basadas en la Normatividad vigente y certificado por la Asociación de Normalización y Certificación (ANCE) que es un Organismo Nacional de Certificación de producto, en términos de la Ley Federal sobre Metrología y Normalización y su reglamento; o bien, por un Organismo Internacional de Certificación perteneciente al Sistema de Conformidad de Pruebas y Certificados de Equipo Eléctrico (IECEE), que forme parte de la Comisión Electrotécnica Internacional (IEC: International Electrotechnical Commission), del que se deriva el Acuerdo Multilateral de Reconocimiento Mutuo de Organismos de Certificación (CB-Scheme: Certification Body).

\subsection{Definiciones}

Para una correcta interpretación, las definiciones de los términos usados en este documento son las consideradas en el Art. 690-2 de la Norma NOM 001-SEDE-2012, las expuestas en las Reglas Generales para la Interconexión al Sistema Eléctrico Nacional y en la especificación CFE G0100-04 (Ver Anexo 
$\mathrm{XX)}$, una de las cuales se presenta a continuación así como la figura alusiva a ella (ver Figura 6.1)

Fuente de Energía Fotovoltaica (FEFV): Integración de un generador fotovoltaico con sistemas de protección, acondicionadores y almacenamiento de energía, según sea requerido, los cuales proporcionan energía eléctrica en corriente continua a la tensión y potencia eléctrica requerida.

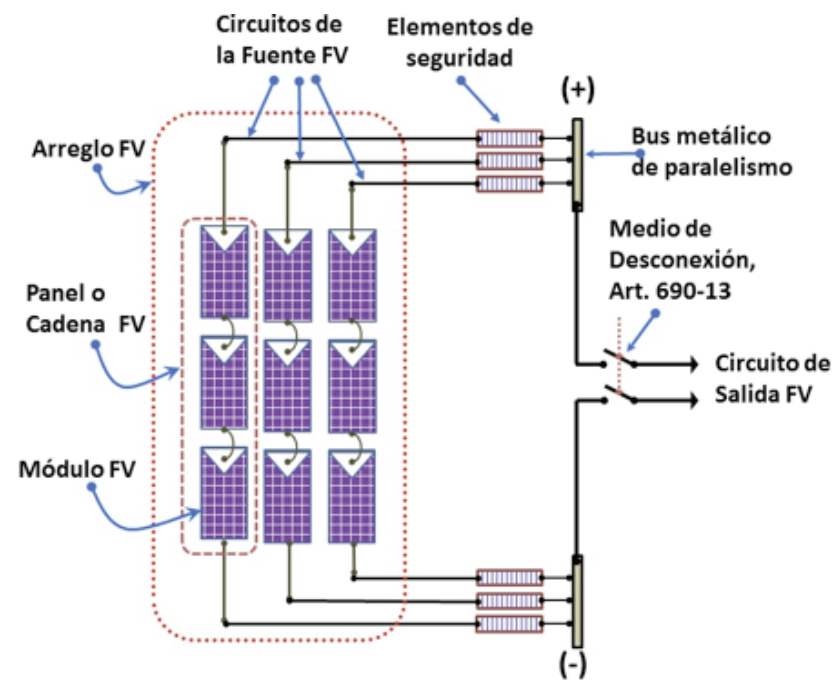

Figura 6.1: Diagrama simplificado de una Fuente de Energía Fotovoltaica,

FEFV. No se muestra el circuito de puesta a tierra del sistema.

\subsection{Componentes}

Un Sistema fotovoltaico conectado a una Red Eléctrica de Distribución (RED) del SEN está constituido por un conjunto de componentes encargados de realizar las funciones de captar la radiación solar, generar energía eléctrica en forma de corriente continua (CC) y acondicionar dicha energía a las características que la hagan utilizable por los consumidores conectados a la red de distribución de corriente alterna (CA). 
Este tipo de instalaciones fotovoltaicas trabajan en paralelo con la RED del SEN.

El siguiente diagrama a bloques (ver Figura 6.2) muestra las componentes principales de un Sistema Fotovoltaico Interconectado al SEN (SFV-I).

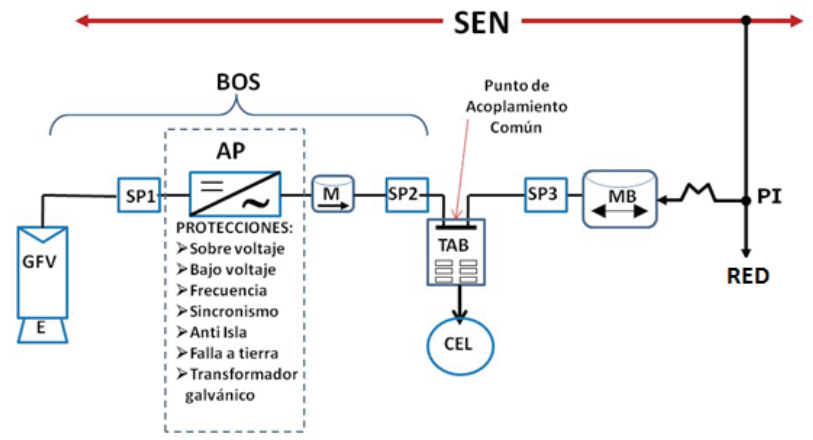

Figura 6.2: Diagrama de bloques de un Sistema Fotovoltaico Interconectado al SEN.

La nomenclatura en dicho diagrama es la siguiente:

\begin{tabular}{|l|l|}
\hline $\begin{array}{l}\text { GFV: Módulo, Arreglo o } \\
\text { Generador fotovoltaico, } \\
\text { GFV. }\end{array}$ & E: Estructura de soporte para el GFV. \\
\hline $\begin{array}{l}\text { SP: Sistema de protección } \\
\text { para seguridad. }\end{array}$ & $\begin{array}{l}\text { AP: Acondicionador de potencia o } \\
\text { inversor. }\end{array}$ \\
$\begin{array}{l}\text { TAB: Tablero de distribu- } \\
\text { ción o interfaz entre el GFV }\end{array}$ & $\begin{array}{l}\text { M: Medidor de energía eléctrica (watto- } \\
\text { y el SEN (Red de Distribu- } \\
\text { ción Eléctrica). }\end{array}$ \\
\hline $\begin{array}{l}\text { CEL: Cargas Eléctricas } \\
\text { Locales. }\end{array}$ & MB: Medidor bidireccional de energía. \\
\hline $\begin{array}{l}\text { SEN: Sistema Eléctri- } \\
\text { co Nacional (RED: Red de } \\
\text { Distribución Eléctrica). }\end{array}$ & BOS: Siglas que denotan Balance del \\
\hline
\end{tabular}

A continuación se describen los requerimientos de cada uno de los componentes: 


\section{4.a. El Módulo Fotovoltaico}

Los módulos fotovoltaicos, independientemente de la tecnología fotovoltaica del que estén ensamblados, es el generador de potencia eléctrica básico que debe cumplir con lo siguiente:

a) Estar construidos de acuerdo a la Norma NMX-J-618/1ANCE-2010 (IEC 61730-1) - Evaluación de la seguridad en módulos fotovoltaicos (FV)-Parte 1: Requisitos generales para construcción, homologación de la Norma Internacional IEC 61730-1; o bien, UL 1703, "Standard for Flat-Plate Photovoltaic Modules and Panels".

b) Deben estar certificados con respecto a su desempeño eléctrico, seguridad y durabilidad; es decir, deben tener el certificado de conformidad de producto emitido por un Organismo Nacional de Certificación acreditado en términos de la Ley Federal de Metrología y Normalización (LFMN) y su reglamento. En caso de no existir infraestructura en el país, los módulos deben estar certificados por un organismo NCB (National Certification Body), miembro de IECEE, CB Scheme, así como el informe de pruebas emitido por un laboratorio (CBTL Certification Body Testing Laboratory) que sea acreditado bajo ISO/IEC 17025. La verificación del certificado será por medio de la página web www.iecee.org

c) Tener placa de identificación original que indique o muestre: características eléctricas, fabricante, marca, modelo, clase y número de serie, y logotipo de la Entidad Certificadora.

NOTA: Para una mayor descripción de los requerimientos exigidos a un MFV referirse a la referencia: "Especificaciones Técnicas para Sistemas Fotovoltaicos Conectados a la Red Eléctrica Asociados a Proyectos Productivos Agropecuarios" (Ver Anexo XXX). 


\section{4.b. Conductores Eléctricos}

El cableado debe realizarse y cumplir con lo requerido de acuerdo a lo especificado en la Norma NOM 001-SEDE 2012, especialmente el Art. 690, Art. 250 y Art. 705; en las Normas Internacionales IEC 60364-4-41, IEC 60364-7-712; y la IEC 62548: 2013, "Photovoltaic PV Arrays- Design requirements; destacándose lo siguiente:

\section{a) Tipo de Conductor}

- Todo el conductor eléctrico (cable) que se use en la instalación fotovoltaica debe ser de cobre, formado por alambres de cobre temple suave, trenzados Clase B, con 7 alambres trenzados por conductor para cables calibre AWG \#18 al \#2, con 19 alambres trenzados por conductor para cables calibre AWG \#1 al \#4/0, y con 37 alambres trenzados por conductor para cables calibre \#250 kcmil al \#1000 kcmil.

- El cable conductor debe tener aislante certificado para $600 \mathrm{~V}$ o superior y contar con certificación NOM-063-SCFI vigente.

- Todo cable conductor expuesto a la intemperie, además de satisfacer la Norma NOM-063-SCFI, debe estar certificado para ser expuesto a la radiación solar (resistentes a la luz solar) como lo son: USE-2 (underground service entrance), UF (Underground Feeder- Sunlight Resistant), SE (Service Entrance), TWD-UV, grado solar o equivalente.

- El cable conductor para los circuitos de la fuente fotovoltaica como de salida fotovoltaica en corriente directa preferentemente debe tener doble aislamiento para garantizar un aislamiento Clase II, (Vulcanel EP antillama Tipo RHH ò RHW-2); y con recubrimiento aislante a $90^{\circ} \mathrm{C}$.

- Cable sugerido para dichos circuitos fotovoltaicos: RHW-2 (Rubber insulation, Heat resistant, Wet)

- Para cables de sección transversal de $13 \mathrm{~mm}^{2}$ o mayor (desde cable calibre $\cdot 6$ hacia secciones transversales más gruesas $4,2,1 / 0$, etc), se puede usar cable de aluminio 
grado eléctrico de la serie AA 8000 según el Art 310.14 de la NOM 001 SEDE 2012, siempre que los conectores para la interconexión de los circuitos eléctricos sean del tipo CO/ALR; o bien, que tengan un recubierto metálico que permita la compatibilidad con conectores tradicionales de cobre tipo tornillo. Deben ser del tipo USE-2, RHH. RHHW-2 con aislamiento XLPE para intemperie.

- No se acepta cable uso rudo en los circuitos del sistema fotovoltaico.

Excepción: Solo se acepta cable del tipo uso rudo, para el caso de estructuras con seguimiento solar, en el circuito de salida de la fuente fotovoltaica hasta la caja de control si es que está certificado para intemperie y con protección UV (cable tipo grado solar).

\section{b) Ampacidad del Conductor}

- En los circuitos de la fuente y de salida fotovoltaica la ampacidad o capacidad de conducción de los conductores debe seleccionarse con un valor de 1.56 veces la corriente de corto circuito, $I_{C C}$, del módulo, panel o arreglo fotovoltaico (NOM-001 SEDE 2012, Art.690-8), efectuando las correcciones a dicho valor por efecto de temperatura o agrupamiento, tal y como se requiere en las siguientes secciones.

- En el circuito de salida del inversor (salida en CA), la capacidad de conducción de los conductores debe seleccionarse con un valor de 1.25 veces la corriente a la potencia nominal del inversor, efectuando las correcciones a dicho valor por efecto de temperatura o agrupamiento, tal y como se requiere en las siguientes secciones.

- Todo cable conductor que no sea para intemperie y que no sea resistente a la luz solar debe estar contenido en una canalización cerrada que puede ser: tubo conduit metálico pesado (RMC, pared gruesa), tubo conduit metálico flexible (FMC), tubo conduit metálico semipesado (IMC, pared 
gruesa), tubo conduit metálico hermético a los líquidos (LFMC *ver Art. 350 de la NOM-001 SEDE 2012), tubo conduit no metálico hermético a los líquidos (LFNC-B * ver Art. 356 de la NOM-001 SEDE 2012), cuya selección sea adecuada al tipo de instalación.

- Para temperaturas ambiente que excedan de $30^{\circ} \mathrm{C}$, la capacidad de conducción de corriente debe corregirse, reduciendo su valor, con los factores dados por la Tabla No. 310-15(b)(2)(a) de la NOM-001-SEDE 2012, que para referencia rápida se presenta en la siguiente tabla.

\begin{tabular}{|c|c|c|c|}
\hline \multirow{2}{*}{$\begin{array}{c}\text { Temperatura } \\
\text { ambiente } \\
\left({ }^{\circ} \mathbf{C}\right)\end{array}$} & \multicolumn{3}{|c|}{$\begin{array}{r}\text { Factores de corrección basados en una temperatura ambiente de } 30^{\circ} \mathrm{C} \\
\text { No más de tres conductores monopolares aislados }\end{array}$} \\
\cline { 2 - 4 } & \multicolumn{3}{|c|}{ Rango de temperatura del conductor } \\
\cline { 2 - 4 } & $\mathbf{6 0} \mathrm{C}$ & $\mathbf{7 5}^{\circ} \mathrm{C}$ & $\mathbf{9 0}{ }^{\circ} \mathrm{C}$ \\
\hline $21-25$ & 1.08 & 1.05 & 1.04 \\
\hline $26-30$ & 1,0 & 1,0 & 1,0 \\
\hline $31-35$ & 0,91 & 0,94 & 0,96 \\
\hline $36-40$ & 0,82 & 0,88 & 0,91 \\
\hline $41-45$ & 0,71 & 0,82 & 0,87 \\
\hline $46-50$ & 0,58 & 0,75 & 0,82 \\
\hline $51-55$ & 0,41 & 0,67 & 0,76 \\
\hline
\end{tabular}

- Para canalizaciones circulares expuestas a la luz solar colocados en o por encima de azoteas, la temperatura "ambiente" de los cables conductores dentro de la canalización debe incrementarse por los valores proporcionados por la Tabla 310-15(b)(3)(c) de la NOM-001-SEDE 2012, que para referencia rápida se presenta en la siguiente tabla:

\begin{tabular}{|c|c|}
\hline $\begin{array}{c}\text { Distancia por encima del techo hasta la base } \\
\text { del tubo conduit. } \\
(\mathrm{mm})\end{array}$ & $\begin{array}{c}\text { Sumar a la temperatura ambiente. } \\
\left({ }^{\circ} \mathrm{C}\right)\end{array}$ \\
\hline De 0 hasta 13 & 33 \\
\hline Más de 13 hasta 90 & 22 \\
\hline Más de 90 hasta 300 & 17 \\
\hline Más de 300 hasta 900 & 14 \\
\hline
\end{tabular}


- Para más de tres cables conductores portadores de corriente en una canalización, la capacidad de conducción de corriente debe corregirse, reduciendo su valor, con los factores dados por la Tabla No. 310-15(b)(3)(a) de la NOM-001-SEDE 2012, que para referencia rápida se presenta en la siguiente tabla:

\begin{tabular}{|c|c|}
\hline $\begin{array}{c}\text { Número de } \\
\text { conductores }\end{array}$ & $\begin{array}{c}\text { Porcentaje de los valores en las Tablas 310-15(b)(16) a 310- } \\
\text { 15(b)(19), ajustadas para temperatura ambiente, si es necesario }\end{array}$ \\
\hline $4-6$ & 80 \\
\hline $7-9$ & 70 \\
\hline $10-20$ & 50 \\
\hline $21-30$ & 45 \\
\hline $31-40$ & 40 \\
\hline 41 y más & 35 \\
\hline
\end{tabular}

- Caídas de Tensión.- Se recomienda que la máxima caída de tensión desde el punto de generación hasta el punto de acoplamiento no sea mayor al 3\% del VMP del AFV bajo condiciones STC. En consecuencia se sugiere que: El calibre de los conductores del circuito de la fuente fotovoltaica a la caja de combinación debe ser seleccionado para evitar una caída de tensión no mayor al 1\%. El calibre de los conductores del circuito de salida fotovoltaico hacia el inversor debe ser seleccionado para evitar una caída de tensión no mayor al 1\%. El calibre de los conductores del circuito de salida del inversor hacia el tablero de distribución debe ser seleccionado con una caída de tensión no mayor al $1 \%$.

- Si dos o más módulos o cadenas de módulos se conectarán en paralelo, la diferencia en la tensión eléctrica VMP entre dichos módulos o cadenas, en dicho punto, no debe diferir más del $0.5 \%$ de su valor.

\section{4.c. El Inversor o Acondicionador de Potencia}

El Inversor o acondicionador de potencia debe cumplir con lo siguiente: 
a) Satisfacer los requerimientos exigidos en el "Manual de Interconexión de Centrales de Generación con Capacidad Menor a 0.5 MW", publicado en el Diario Oficial de la Federación el 15 de diciembre de 2016, y que son aplicables para todos los SFV-I con una potencia tanto en Baja como en Media Escala.

b) Satisfacer los requerimientos técnicos de la Norma internacional IEC 62109 Part 1 y Part 2, o alternativamente, de la Norma UL 1741 basada en la Norma IEEE 1547 los que deben comprobarse mediante el certificado de conformidad emitido por un Organismo Nacional de Certificación acreditado en términos de la Ley LFMN (Ley Federal de Metrología y Normalización). En caso de no existir infraestructura de certificación en el país, el inversor debe estar certificado por un organismo NCB (National Certification Body), miembro de IECEE, CB Scheme, así como el informe de pruebas emitido por un laboratorio (CBTL Certification Body Testing Laboratory) que sea acreditado bajo ISO/IEC 17025. La verificación del certificado será por medio de la página web www.iecee.org-

c) Contar con el certificado correspondiente que garantice el cumplimiento de los requerimientos eléctricos para la función anti-isla de acuerdo a la Norma IEC 62116:2008 Ed 1, o la Norma UL 1741 que permite su conexión a la red, emitido por un organismo nacional o internacional del NCB (National Certification Body), miembro de IECEE, CB Scheme, así como el informe de pruebas emitido por un laboratorio (CBTL Certification Body Testing Laboratory) que sea acreditado bajo ISO/IEC 17025. La verificación del certificado será por medio de la página web www. iecee.org.

d) Tener una placa de identificación que incluya información de la marca, modelo, especificaciones, fabricante o importador responsable. 
e) El inversor no debe ser una fuente de inyección de corriente directa hacia la red de corriente alterna del SEN, por lo cual, debe tener a su salida un medio de aislamiento galvánico que puede ser; un transformador u otro aditamento de estado sólido. El valor máximo permisible es de $0.5 \%$ de la corriente de salida nominal del inversor (Art. 5.2 de la Norma IEEE Std 929-2000).

f) Si el inversor NO incluye el transformador de salida, el "Proveedor" debe incluir en la instalación, antes del Punto de Acoplamiento Común (PAC), un medio de aislamiento galvánico con una potencia igual a 1.25 veces la potencia nominal del inversor.

NOTA: Si la Red Eléctrica Local del usuario incluye un transformador de Media Tensión (MT) a Baja Tensión (BT) y el Punto de Acoplamiento del SFV-I está en el Tablero de Distribución en BT, se puede aceptar un inversor sin transformador.

NOTA: La potencia nominal del inversor no debe ser menor a la potencia de operación del arreglo FV (potencia generada en el punto de la máxima potencia cuando los módulos están calientes). Dicho de otra manera: La Potencia Pico del AFV debe estar en el intervalo de potencia de acoplamiento recomendado por el fabricante.

NOTA: Para una mayor descripción de los requerimientos exigidos a un MFV referirse a la referencia: "Especificaciones Técnicas para Sistemas Fotovoltaicos Conectados a la Red Eléctrica Asociados a Proyectos Productivos Agropecuarios".

\section{4.d. Topología Eléctrica del SFV-I}

Dependiendo del tipo de inversor, con transformador o sin transformador, o bien, dependiendo de las especificaciones del fabricante del inversor, el SFV-I puede tener dos topologías: 
- SFV Intencionalmente Puesto a Tierra (PIT).- Es aquel sistema en el que uno de los dos conductores del circuito de salida del GFV, el positivo o el negativo, se ha puesto intencionalmente a tierra (PIT) mediante un Conductor de Puesta a Tierra (CPT). Un diagrama ilustrativo se muestra en la Figura 6.3

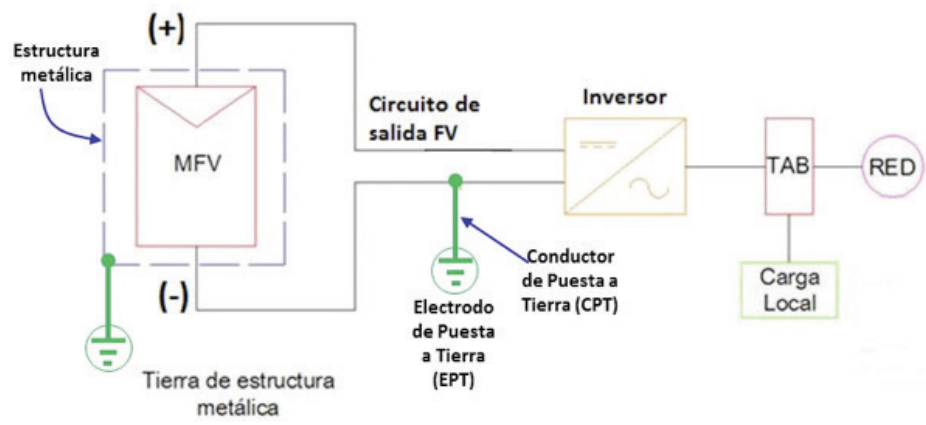

Figura 6.3: Sistema Fotovoltaico aterrizado. Se muestra el caso en el que el conductor negativo del CS-FV se ha puesto intencionalmente a tierra

- SFV en Flotación.- Es aquel sistema en el que ninguno de los conductores del circuito de salida fotovoltaico se ha puesto a tierra intencionalmente. Un diagrama ilustrativo se muestra en la Figura 6.4.

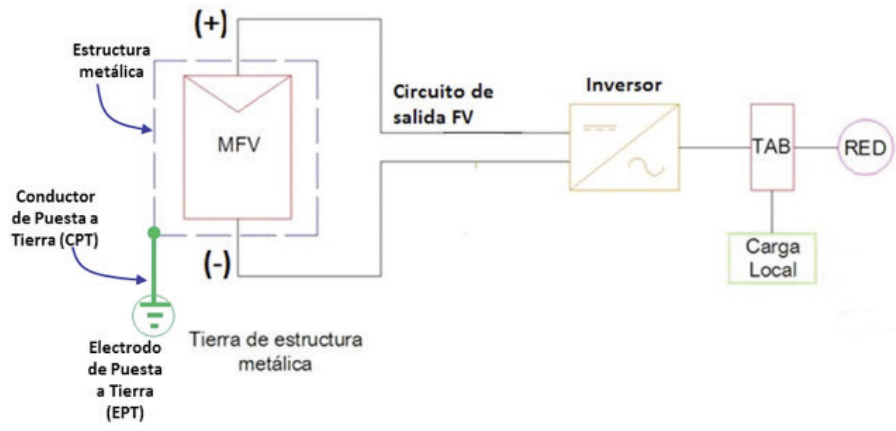

Figura 6.4: Sistema Fotovoltaico en Flotación. Ninguno de los conductores del CS-FV se ha aterrizado intencionalmente. Se muestra unicamente la Puesta a tierra de la estructura metálica en la que se soporta al AFV. 


\section{4.e. Dispositivos de Seguridad}

La NOM 001 SEDE 2012 requiere, que en la instalación eléctrica, se incluyan dispositivos de seguridad que garanticen la operación segura del sistema bajo cualquier eventualidad no prevista, por ejemplo: descargas atmosféricas, cortos circuitos, desprendimiento de cables, etc. Por lo que es necesario la integración de éstos tomando como referencia la recomendación normativa.

\section{4.e1. Medios de Desconexión}

De acuerdo a la NOM 001-SEDE 2012 (Artículos 690-13, 690-15), se requiere de un Medio de Desconexión (Dsc) para abrir los circuitos eléctricos NO aterrizados (conductores que lleven corriente eléctrica) en todas las fuentes de energía o equipos que consuman energía. En consecuencia, todos los SFV-IR deben tener medios de desconexión en los circuitos de salida del GFV o entrada del inversor, y salida del inversor, como un Sistema de Protección para seguridad del usuario y mantenimiento del sistema; es decir, tanto el circuito (s) de salida fotovoltaica como el del inversor deben satisfacer dicho requerimiento. La Figura 6.5 proporciona un diagrama esquemático de un SFV-I en donde se muestran las posiciones sugeridas en donde deben localizarse los Medios de Desconexión (Dsc).

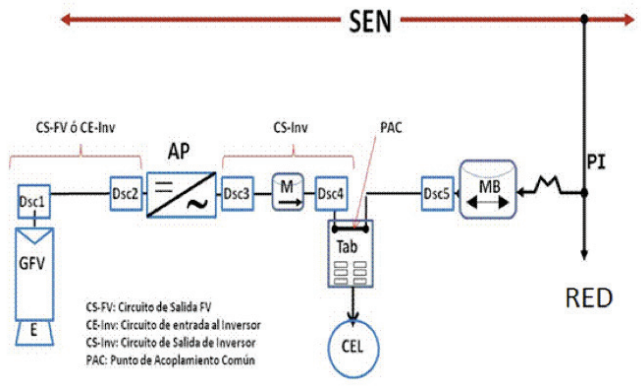

Figura 6.5: Diagrama esquemático de un SFV-I en donde se muestran los sitios sugeridos para los Dsc. 
Los requerimientos son los siguientes:

a) Los Dsc pueden ser interruptores de cuchilla, interruptores termomagnéticos, o interruptores de palanca y deben seleccionarse de acuerdo al tipo de corriente a manejar (corriente alterna o corriente continua).

b) Los Dsc deben instalarse en lugares fácilmente accesibles, en interiores o exteriores, y estar contenidos en una envolvente o caja, con hermeticidad de acuerdo al sitio de instalación. La Caja debe tener grado de protección de acuerdo a su ubicación: interior IP54 (NEMA tipo 2) o exterior IP65 (NEMA tipo 4 o 4X en ambientes salinos) o superior. Alternativamente, pueden instalarse en o dentro del inversor siempre y cuando se pueda garantizar la desconexión eléctrica para realizar trabajos de servicio y mantenimiento.

c) Los Dsc para el Circuito de Salida fotovoltaico (CS-FV: zona de corriente continua) deben ser del tipo de Interrupción con carga; pudiendo ser bipolares para interrumpir efectivamente tanto el conductor positivo como el conductor negativo o monopolares, uno para cada conductor. En el CS-FV se recomienda que el Dsc sea multipolar (más de dos polos) para evitar el arqueo.

d) La Capacidad de Conducción de los Medios de Desconexión debe seleccionarse de acuerdo a la Norma NOM 001 SEDE 2012; es decir: para el CS-FV, el Dsc debe tener una ampacidad de 1.56 veces ICC del MFV o CFV (o GFV); y para el circuito de salida del inversor (CS-Inv), con un valor de 1.25 veces la corriente a la potencia nominal del inversor; en ambos casos corregida por los factores correspondientes.

e) Contar con certificación NOM-003-SCFI-vigente.

f) El circuito de salida fotovoltaico (CS-FV) debe tener un Medio de Desconexión (Dscl) instalado tan cerca como sea posible al GFV. 
g) Cuando el Inversor NO se encuentre "a la vista" del Medio de Desconexión del GFV (Dscl) y el inversor NO incluya un Medio de Desconexión en su circuito de entrada (CE-Inv), se requiere a la entrada del inversor un Medio de Desconexión (Dsc2).

h) Cuando el Inversor NO tenga un Medio de Desconexión en su Circuito de Salida (CS-Inv), se requiere a la salida del inversor un medio de desconexión (Dsc3) tan cerca como sea posible de éste.

i) La conexión del circuito de salida del inversor (CS-Inv) en el Punto de Acoplamiento Común (PAC), que se sugiere sea en el Tablero de Distribución General (TAB), debe hacerse a través de un Medio de Desconexión (Dsc4).

j) El Medio de Desconexión Dsc5 lo exige CFE como el interruptor de servicio de la acometida, que debe estar instalado de manera accesible al personal del Suministrador de energía eléctrica (CFE).

k) El Medio de Desconexión a usar debe tener marcado claramente las dos posiciones: abierto y cerrado.

l) Si ninguno de los conductores de electricidad del sistema FV del circuito de salida, positivo y negativo, estará aterrizado, ambos conductores deben tener un Dsc. La figura 6.6 muestra el caso de un AFV configurado con $3 \mathrm{MFV}$ conectados en serie para formar la CFV, y 3 CFV conectadas en paralelo en un Bus Metálico (Bm). El desconector Dscl aisla cada uno de los cicuitos de la fuente fotovoltaica (MFV o CFV). El desconector Dsc2 aisla todo el AFV (en este caso la configuración3Sx3P) 


\section{Arreglo o Generador FV}

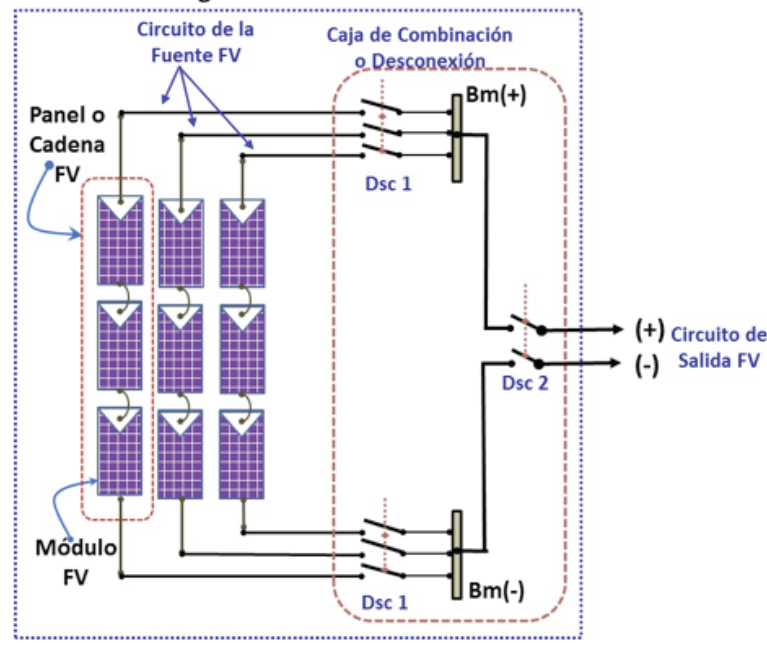

Figura 6.6: Localización del Medio de desconexión en un AFV en Flotación.

m) Por el contrario, si en el circuito de salida fotovoltaica (circuito de entrada al inversor), el conductor negativo está aterrizado, el conductor positivo debe tener el medio de desconexión y la puesta a tierra del conductor negativo debe hacerse entre el medio de desconexión y el inversor o dentro del inversor (ver diagrama en la Figura 6.7).

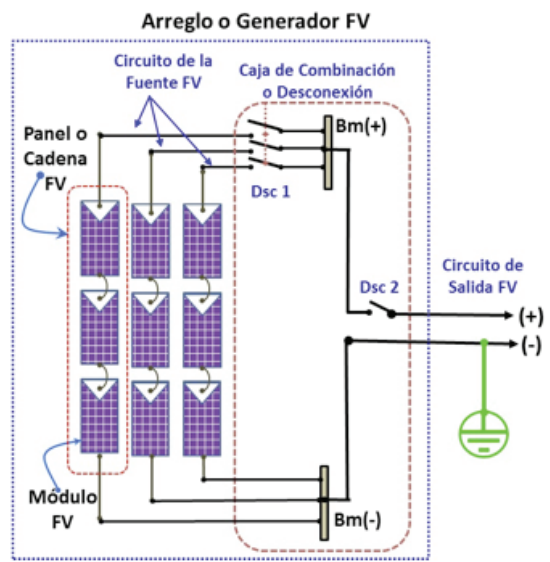

Figura 6.7: Localización del Medio de desconexión en un Sistema FV intencionalmente puesto a tierra 
n) En el caso de microinversores que tienen integrados conectores para la terminal positiva y terminal negativa en el circuito de entrada, por ejemplo del tipo MC4 o equivalente, se acepta al conector/enchufe como medio de desconexión para el circuito de salida fotovoltaica (NOM 001-SEDE 2012, Art. 690-33).

o) Se aceptan los conectores para aplicaciones fotovoltaicas (por ejemplo MC4 o similar uso intemperie) como medios de desconexión para el circuito de salida fotovoltaica, siempre y cuando tengan la ampacidad correspondiente, y hayan sido aprobados para ese uso (NOM 001-SEDE 2012, Art. 690-32).

Para instalaciones fotovoltaicas realizadas sobre lozas o techos de inmuebles (casas, comercios, o naves industriales, etc.) y el inversor se encuentre ubicado en el interior del inmueble, se debe contar con un sistema de desconexión de emergencia que conste de un contactor o interruptor y un botón de paro cuya función es desconectar el generador fotovoltaico del resto del sistema en caso de una emergencia (incendio o temblor). Su ampacidad debe ser igual a la de los conductores del circuito de salida

El interruptor o contactor debe interrumpir o abrir los conductores del circuito de salida del arreglo FV, mientras que el botón de paro, debe estar instalado tan cerca como sea posible del Tablero de distribución o de la acometida del suministrador de potencia eléctrica (CFE).

Se debe instalar dentro de la Caja de Desconexión o Combinación, o Concentradora.

Excepción: No se requiere dicho sistema de desconexión de emergencia cuando la tensión eléctrica a circuito abierto del módulo, panel o arreglo fotovoltaico sea menor de $40 \mathrm{~V}$, cuando se usen micro inversores que se instalan debajo de los módulos, o cuando la distancia de los conductores del circuito de salida de la Fuente de energía Fotovoltaica a la entrada del inversor sea menor de $2.0 \mathrm{~m}$ 
NOTA: A la envolvente o caja que contenga a los Dsc requeridos se le llama Caja de Desconexión (o Combinación si esta contiene además el Bus Metálico para realizar la conexión en paralelo de MFV o CFV.

\section{4.e2. Dispositivos de Protección contra Fallas a Tierra (PFT)}

a) Todo GFV puesto a tierra debe contar con un Sistema de Detección de Fallas a Tierra (SDFT) de acuerdo al Art. 690-5 de la Norma NOM 001-SEDE 2012; en caso contrario, para un GFV NO puesto a tierra, este debe cumplir con lo que indica el Art. 690-35.

b) Para el caso de un GFV puesto a tierra, el SDFT debe tener un sensor de corriente, un sistema de detección con indicador del tipo de falla y un contactor o interruptor automático. El sensor de corriente y el contactor o interruptor deben instalarse entre la salida del arreglo FV y el punto de conexión a tierra, antes del inversor (Figura 6.8).

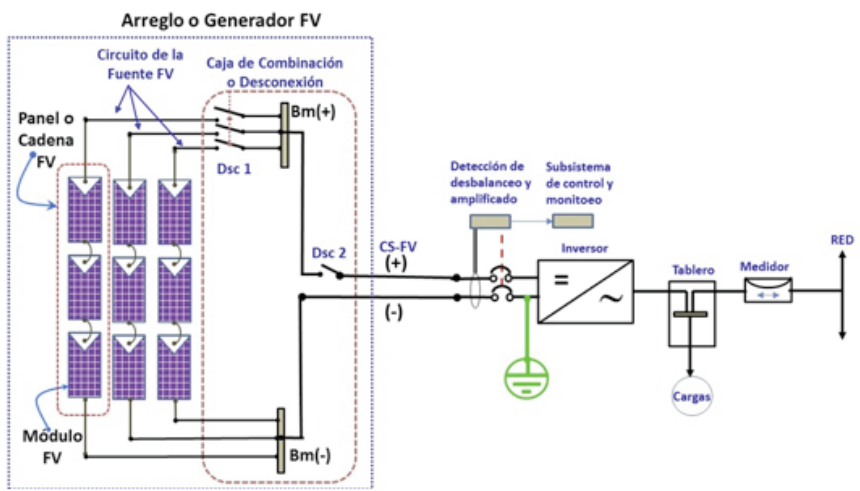

Figura 6.8: Dispositivo para detectar fallas a tierra en un SFV aterrizado.

c) Para un GFV flotante se puede instalar un dispositivo "monitor de aislamiento" permanente que verifique la resistencia a tierra de ambos polos con una frecuencia predeterminada o instalar un dispositivo de corriente residual a la salida del subsistema de acondicionamiento 
de potencia según se especifica en CFE G0100-04 (Figura 6.9).

Excepción: Se puede omitir el dispositivo de detección de falla a tierras si todos los componentes del GFV, especialmente los cables de los circuitos en $\mathrm{CD}$, cuentan con doble aislamiento (clase II) y si se ha realizado un buen cableado de acuerdo a lo especificado en la NOM-001-SEDE-2012 y por CFE.

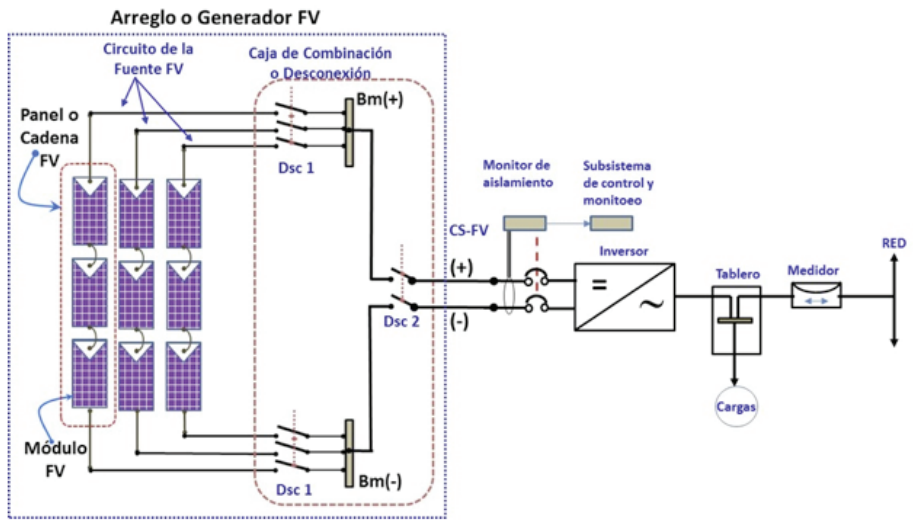

Figura 6.9: Dispositivo para detectar fallas a tierra en un SFV flotante.

Excepción: En el caso de microinversores instalados debajo de los módulos fotovoltaicos o que la distancia del circuito de salida fotovoltaica al inversor sea menor de $2.0 \mathrm{~m}$, no se requiere del SDFT.

\section{4.e3.-Conexión de MFV o CFV en paralelo}

d) La conexión en paralelo de dos o más MFV o CFV debe hacerse en un Block Metálico (Bm) o Bus de Paralelismo que provea los medios mecánicos necesarios para realizar la conexión eléctrica de ellos (ver Figura VI-.6 o 6.7).

e) El Bm debe estar montado en un receptáculo aislante (aislamiento mínimo de $600 \mathrm{~V}$ ) y debe proveer el asilamiento necesario para que las partes metálicas que lleven 
corriente eléctrica (partes “vivas”) no estén al alcance del usuario.

f) Se debe tener un Bm para cada uno de los conductores del circuito de la fuente fotovoltaica (circuito de salida de un MFV o circuito de salida de una CFV), y uno adicional para la Puesta a Tierra del SFV.

g) El Bm tanto para la terminal positiva como para la terminal negativa, así como el de Puesta a Tierra, deben estar contenidos en una caja o envolvente con hermeticidad de acuerdo al sitio de instalación. La Caja debe tener grado de protección de acuerdo a su ubicación: interior IP54 (NEMA tipo 2) o exterior IP65 (NEMA tipo 4 o 4X en ambientes salinos) o superior.

NOTA: Esta caja se llama Caja de Combinación y también debe contenerd al medio de desconexión del circuito de salida FV.

\section{4.e4. Dispositivos contra Corrientes de Retorno (PCR)}

a) En AFV que incluyan más de dos módulos o panel o rama o cadena FV que se conecten en paralelo, se debe instalar un dispositivo Protector contra Corrientes de Retorno (PCR) en cada panel o cadena o rama antes del punto de conexión en paralelo, para prevenir la posibilidad de una corriente de retorno hacia uno de ellos cuando éste se sombrea o presenta fallas a tierra.

b) El PCR puede ser un fusible o un interruptor termomagnético bidireccional, o una combinación de ambos. Se puede usar un diodo de silicio que bloque las corrientes de retorno, por lo que se le conoce como Diodo de Bloqueo. aunque realmente no son dispositivos de sobrecorriente.

c) El PCR debe conectarse en el circuito de salida de cada módulo o panel fotovoltaico que se vaya a conectar en paralelo; y debe instalarse dentro de la Caja de combinación, Concentración o Desconexión que contenga a los elementos de protección (ver Figura 6.10). 
d) En SFV con un conductor de corriente aterrizado, el conductor no aterrizado debe tener la protección contra corrientes de retorno.

e) En SFV flotantes, ambos conductores de corriente deben tener la protección contra corrientes de retorno.

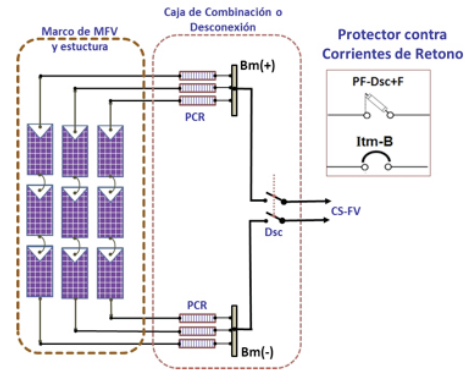

Figura 6.10: Posición del dispositivo contra corrientes de retorno. Nomenclatura: Dsc Desconector; Bm Bus metálico para conexiones en paralelo; BT Bus principal de puesta a tierra; PCR Protector contra corrientes de retorno

f) Si se utiliza un Fusible como PCR, en un circuito energizado en ambas direcciones, se debe instalar un medio de desconexión para desconectar al fusible en ambas direcciones (NOM 001-SEDE 2012, Art. 690-16) independientemente de los fusibles que haya en otros circuitos. Se sugiere que se monte al Fusible en un Porta Fusible Desconector (PF-Dsc) más un Desconector (Dsc) (Ver Figura 6.11)

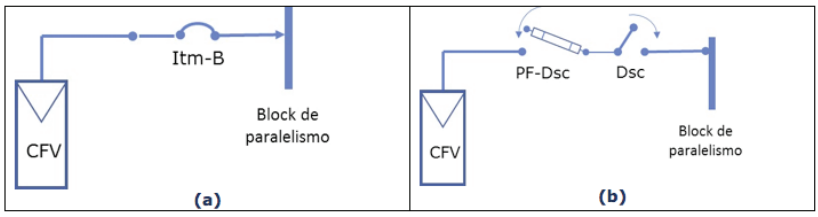

Figura 6.11: Posición de los PCR's. En (a) usando un Interruptor Termomagnético Bidireccional (Itm-B); En (b) usando una combinación Fusible montado en un Porta Fusible Desconector (PF-Dsc) con un Desconector 
g) La capacidad de conducción del dispositivo contra corrientes de retorno debe seleccionarse tal que su corriente nominal sea igual al valor estipulado por el fabricante del módulo fotovoltaico, en la etiqueta de identificación, como fuse rating; y en caso de que no lo indique, o bien que se tengan varios subarreglos conectados en paralelo, mayor que 1.5 pero menor que 2.4 veces la corriente de corto circuito bajo STC del módulo, o cadena o panel o arreglo FV que está protegiendo, a una tensión de 1.25 veces la tensión eléctrica a circuito abierto del mismo.

h) Los diodos de bloqueo no son elementos de protección contra corrientes de retorno. Si se usan diodos de bloqueo, estos deben seleccionarse tal que su corriente nominal sea 1.4 veces la corriente de corto circuito del módulo, cadena, o panel o arreglo FV, con una tensión de 2 (dos) veces el voltaje a circuito abierto del módulo, cadena, panel o arreglo FV a la temperatura ambiente mínima esperada.

Nota: No se recomienda el uso de Diodos de Bloqueo como un PCR dado que, si el diodo no funciona debido a cualquier evento, éste se transforma en un conductor de resistencia cero y no es posible identificar, por simple inspección visual su desempeño.

\section{4.e5. Dispositivos de Protección contra Descargas Atmosféricas (PDA)}

Los dispositivos que sirven para prevenir que una descarga atmosférica dañe a los equipos electrónicos se les llaman comúnmente "supresores de pico". Pueden ser elementos de estado sólido como los varistores, o bien, tubos de descarga, los cuales, se ponen en conducción cuando se les somete a un pico voltaje con una magnitud superior a la de su diseño. Los PDA se deben colocar tal y como se especifica y muestra a continuación (ver Figura 6.12):

a) El circuito de salida fotovoltaica (CS-FV) así como el circuito de salida del inversor (CS-Inv) deben tener 
instalado un Dispositivo de Protección contra Descargas Atmosféricas (PDA).

b) Si ninguno de los conductores de electricidad del CS-FV está aterrizado, ambos conductores, el positivo y el negativo, deben tener un dispositivo de protección contra descargas atmosféricas. Si uno de los conductores de electricidad esta puesto a tierra, el otro conductor debe tener un dispositivo de protección contra descargas atmosféricas.

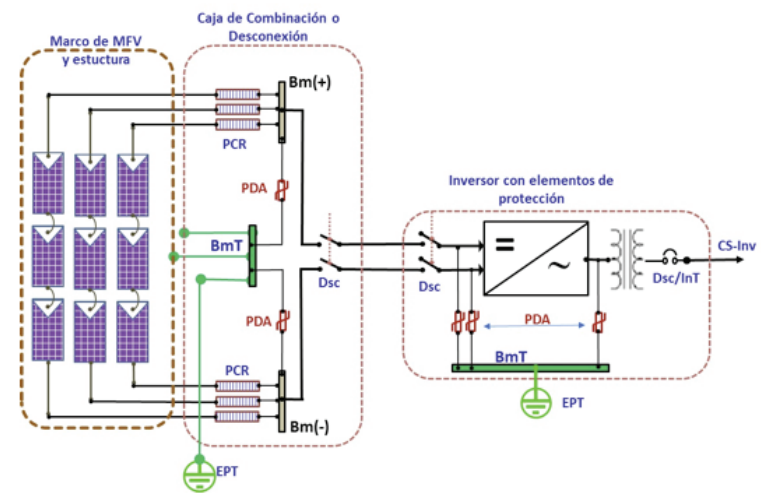

Figura 6.12: Diagrama eléctrico de un sistema solar fotovoltaico en flotación. Se muestra la posición de los sistemas de protección contra descargas atmosféricas (PDA: varistores o tubos de descarga).

c) La protección contra descargas atmosféricas debe estar ubicada físicamente en la caja que contiene al medio de desconexión del circuito de salida fotovoltaica, es decir, en la Caja de Desconexión, de Combinación o Concentradora, la cual debe tener un Bus Metálico que sirva como terminal de puesta a tierra (BMT).

d) El dispositivo de protección contra descargas atmosféricas debe instalarse antes del medio de desconexión principal del circuito de salida fotovoltaico, y en el caso de tener circuitos en paralelo, que se empalman en un Bus Metálico o block de potencia, el PDA debe conectarse en dicho elemento. 
e) Si el inversor trae integrado un PDA en la entrada del circuito en CC (circuito de la fuente FV), no se requiere instalar un PDA en dicha posición. Sin embargo, si la Caja de Combinación o de Paralelismo o Concentradora y el Inversor NO están a la vista, se sugiere instalar, antes del inversor y en la entrada del circuito en CC, un PDA. Dicho PDA debe estar contenido en una envolvente o Caja con hermeticidad de acuerdo al sitio de instalación.

f) El dispositivo contra descargas atmosféricas debe seleccionarse de tal forma que actúe a una tensión eléctrica mayor que 1.25 la tensión eléctrica a circuito abierto de la fuente fotovoltaica (AFV) bajo condiciones de temperatura ambiente local mínima anual, con una capacidad mínima de $5.0 \mathrm{k} A$.

g) Se sugiere que el dispositivo contra descargas atmosféricas debe tener un indicador o marca que indique su estado de operación.

Excepción: No se requiere de dicho dispositivo en el caso de microinversores que ya lo tengan integrado en el circuito de entrada fotovoltaica; pero se requiere en el circuito de salida del inversor.

\section{4.f. Sistema de Tierra}

Un Sistema de Tierra o como se le llama comúnmente Sistema de Tierra Física, STF, es un conjunto de elementos formado por conductores eléctricos llamados Conductores de Puesta a Tierra, CPT, conectores mecánicos de opresión (tornillos, tuercas y arandelas), y uno o varios Electrodos de Puesta a Tierra, EPT.

\section{4.f1. El Electrodo de Puesta a Tierra (EPT)}

Según se establece en el Art. 250-52 de la NOM 001-SEDE 2012, el EPT, debe cumplir con lo siguiente: 
a) En ningún caso se permite que el valor de resistencia a tierra del sistema de electrodos de puesta a tierra sea superior a 25.0 Ohms.

b) El EPT puede ser uno o alguna combinación de los que se indican a continuación:

- Una varilla de acero cobrizada del tipo Copper Weld de 5/8" de diámetro y $3 \mathrm{~m}$ de longitud enterrada de manera vertical por lo menos $2.4 \mathrm{~m}$; si no se puede enterrar por ser el terreno material rocoso, se debe clavar a un ángulo oblicuo que no forme más de $45^{\circ}$ con la vertical; o bien, enterrarla en una zanja que tenga como mínimo $80.0 \mathrm{~cm}$ de profundidad; según se establece en el Art. 250-52-g de la NOM 001-SEDE 2012.

- Estructura metálica de un edificio si éste está puesto a tierra eficazmente.

- Electrodo empotrado en concreto como se especifica en el Art. 250-52-a)3) de la NOM 001-SEDE-2012.

- Cualquier elemento metálico enterrado, varilla, tubería, placa, o combinación de ellas, que no sea de aluminio, cuya resistencia a tierra no sea mayor a 25.0 Ohms según se especifica en el Art. 250-52 de la NOM 001-SEDE 2012.

Si en una edificación o estructura existe más de un electrodo de puesta a tierra, todos los EPT se deben unir o conectar sólidamente entre sí para formar el Sistema de Electrodos de Puesta a Tierra (Art. 250-50 de la NOM 001-SEDE 2012).

Todos los EPT tienen que estar al mismo potencial.

\section{4.f2. Conductores de puesta a tierra (CPT)}

a) Los materiales de los CPT's pueden ser de cobre o de cualquier material conductor de la electricidad, de preferencia metales, que sean resistentes a la corrosión (aluminio, por ejemplo). 
b) El CPT puede ser: alambre o cable; aislado, forrado o desnudo; pero, en cualquier caso debe ser de un solo tramo continuo, sin empalmes ni uniones.

c) Si el CPT está forrado o recubierto con un material aislante, éste debe ser color verde, o verde con franjas amarillas.

d) En circuitos de corriente directa, el calibre del CPT no debe ser inferior al calibre del conductor que tiene la mayor capacidad de conducción (cable más grueso) según se establece en el Art. 250-166 de la NOM 001 SEDE 2012. En ningún caso menor a $8.37 \mathrm{~mm}^{2}$ de sección transversal (calibre 8AWG) para conductores de cobre; o 13.3 mm2 (calibre 6 AWG) para conductores de aluminio.

e) Para el caso de canalizaciones y envolventes metálicas de equipos o cualquier estructura metálica expuesta a la intemperie, o cualquier parte metálica que NO sea portadora de corriente eléctrica, éstas deben ponerse a tierra con un CPT. El CPT puede ser de cobre o aluminio, y su tamaño no debe ser inferior a lo especificado en la Tabla 250-122 de la NOM 001 SEDE 2012, de la cual se ha extraído la siguiente Tabla:

\begin{tabular}{|c|c|}
\hline $\begin{array}{c}\text { Capacidad o ajuste del dispositivo automático de } \\
\text { protección contra sobre corriente en el circuito antes de } \\
\text { los equipos, canalizaciones, etc. Sin exceder de: }\end{array}$ & $\begin{array}{c}\text { Calibre Nominal } \\
\mathrm{mm}^{2} \text { (AWG) }\end{array}$ \\
\hline $15 \mathrm{~A}$ & $2.08(14)$ \\
\hline $20 \mathrm{~A}$ & $3.31(12)$ \\
\hline $60 \mathrm{~A}$ & $5.26(10)$ \\
\hline $100 \mathrm{~A}$ & $8.37(8)$ \\
\hline $200 \mathrm{~A}$ & $13.3(6)$ \\
\hline
\end{tabular}

NOTA: Para utilizar esta tabla es necesario calcular las corrientes de los circuitos de acuerdo a 7.3 incisos (g) y (h).

a) Para circuitos en corriente alterna, el calibre nominal del conductor del electrodo de puesta a tierra de una instalación puesta o no puesta a tierra, no debe ser inferior a lo especificado en la Tabla 250-66 de la NOM 001-SEDE 2012, de la cual se ha extraído la siguiente Tabla. 


\begin{tabular}{|c|c|}
\hline $\begin{array}{c}\text { Calibre nominal del mayor conductor de } \\
\text { entrada a la acometida o circuito equivalente } \\
\text { de conductores en paralelo mm2 (AWG). } \\
\text { Conductor de cobre. }\end{array}$ & $\begin{array}{c}\text { Calibre Nominal del conductor al } \\
\text { electrodo de puesta a tierra } \mathrm{mm}^{2} \\
\text { (AWG) }\end{array}$ \\
\hline $33.6(2$ o menor)) & $8.37(8)$ \\
\hline 42.4 o $53.5(1$ ó $1 / 0)$ & $13.3(6)$ \\
\hline 67.4 o $85.0(2 / 0$ ó $3 / 0)$ & $21.2(4)$ \\
\hline Más de 85 a $177(3 / 0$ a 350 kcmil) & $33.6(2)$ \\
\hline Más de 177 a $304.0(350$ a 600$)$ & $6.5(1 / 0)$ \\
\hline
\end{tabular}

b) La conexión eléctrica entre el CPT y el elemento que se desea colocar a tierra debe hacerse mediante un dispositivo mecánico llamado "zapata de puesta a tierra”, el cual debe atornillarse creando un contacto íntimo entre ambos, y esta unión debe protegerse con un líquido antioxidante que retrase la corrosión galvánica. La Figura 6.13 muestra una fotografía de una "zapata de puesta a tierra" así como el líquido antioxidante (zapata ILSCO GBL4 DBT y el antioxidante Burndy Penetrox A 13).

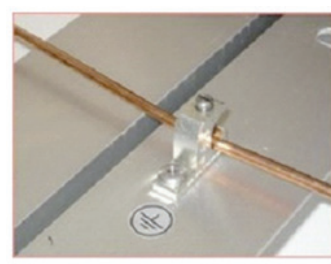

(a)

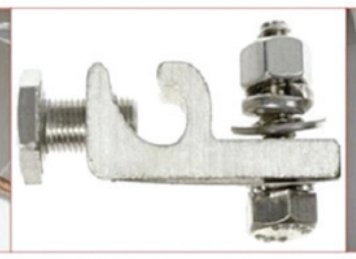

(b)

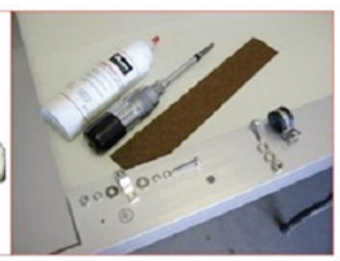

(c)

Figura 6.13: En (a) y (b) se muestra una fotografía de una Zapata para fijar el conductor de puesta a tierra al marco de un módulo; y en (c) se muestra una fotografía del líquido anticorrosivo. (información tomada de John Wiles, "Photovoltaic Power Systems And the 2005 National Electrical Code: Suggested Practices ; Southwest Technology Development Institute, New Mexico State University, Versión electronic

c) La conexión entre el CPT y el EPT debe estar soldada con soldadura de alta temperatura para garantizar una conexión íntima de larga duración. 


\section{4.f3. Sistema de Tierras en SFV}

Todas las partes metálicas del sistema fotovoltaico como son el marco de cada MFV, la estructura, las envolventes de los equipos (controlador y/o inversor), cajas de conexión o de paso, deben colocarse a tierra mediante un CPT sin importar la tensión eléctrica.

a) El marco metálico de cada uno de los módulos del arreglo fotovoltaico debe conectarse a tierra con un conductor continuo, es decir, sin empalmes.

b) El CPT para los marcos de módulos debe ser conectado en cada uno de ellos con una zapata terminal tipo compresión de cobre estañado ó aluminio estañado. Dicha zapata debe sujetarse al marco metálico con un tornillo de acero inoxidable tipo pija o tornillo con tuerca mecánico con arandela de presión y de "estrella", todo el conjunto en acero inoxidable.

c) La unión mecánica entre el marco del módulo y la zapata terminal, así como la conexión del CPT y la zapata terminal deben protegerse con un líquido retardador de corrosión galvánica.

d) El CPT del marco de módulos debe llegar y conectarse en la barra o bus de tierra local o general, según sea el caso.

e) Las partes metálicas que compongan a la estructura de soporte deben tener un CPT, y debe atornillarse a ésta usando una zapata terminal idéntica a la que se use en los marcos de los módulos, usando la misma técnica y protección anticorrosiva recomendada.

f) Los CPT's para el marco de los módulos y de la estructura deben llegar a la caja de desconexión en donde se encuentre la barra o bus de tierra local o general, según sea el caso.

g) La conexión del CPT en la barra o bus de tierra local o general debe hacerse mediante el tornillo de opresión del bus o usando una zapata terminal, 


\section{4.g. Estructuras, Anclaje y Cimentación}

Las estructuras son las encargadas de proporcionar un soporte Físico y Mecánico a los MFV para que se pueda garantizar seguridad, comodidad y operación. Además, permiten la orientación correcta del AFV que maximiza la generación de energía en el periodo de diseño. Es importante considerar que el diseño arquitectónico de la estructura no es único y generalmente se adapta al sitio de instalación; pero independientemente de ello, ésta puede constar de "anclas", "piernas", "trabes" y "durmientes", y en muchos casos, un mismo diseño incluye todos los elementos anteriores. La Figura 6.14 muestra un corte transversal representativo de una estructura típica.

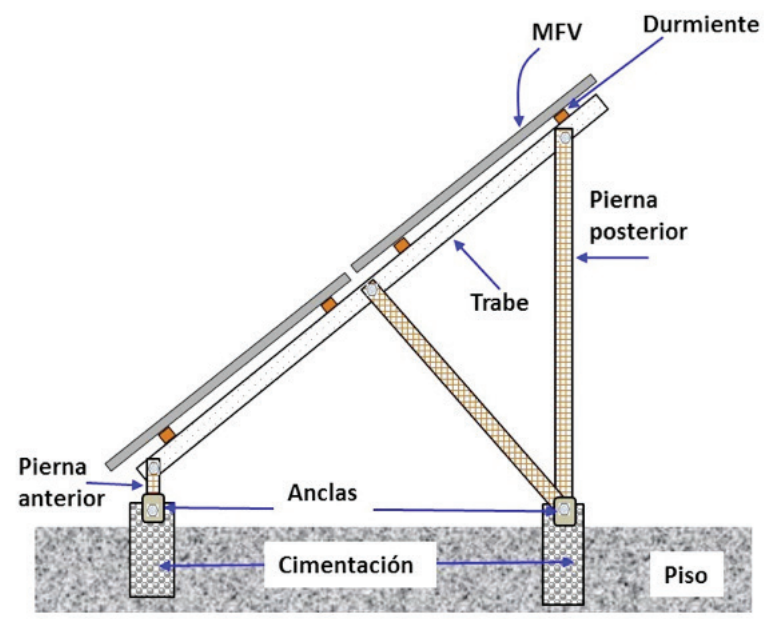

Figura 6.14: Corte tansversal de una estructura para montar MFV.

Es responsabilidad del proveedor/instalador que la estructura y la cimentación para el AFV sean diseñadas y construidas con materiales apropiados para evitar que, bajo condiciones de trabajo, presenten corrosión, deformaciones mecánicas, hundimientos, fallas de cimentación y problemas relacionados con la aerodinámica del arreglo; 
Los materiales de la estructura deben garantizar larga duración por lo que se seleccionarán de acuerdo al clima del sitio de instalación y serán resistentes al medio ambiente y a la corrosión. El anclaje debe resistir las fuerzas que actuarán sobre la estructura y el arreglo $\mathrm{FV}$ a consecuencia de la presión del viento que se ejercerá sobre ella; así que la estructura y su anclaje deben diseñase para que soporte cargas de viento de acuerdo a las características climatológicas del sitio de instalación, y lo más recomendables es hacerlo de acuerdo a los datos de velocidades de viento, según la localidad, proporcionados en el Manual de Diseño de obras civiles: Diseno por Viento 2008 CFE-IIE. La Figura 6.15 muestra una representación de las fuerzas que apaecen en una estructura inclinada debido a la acción del viento.
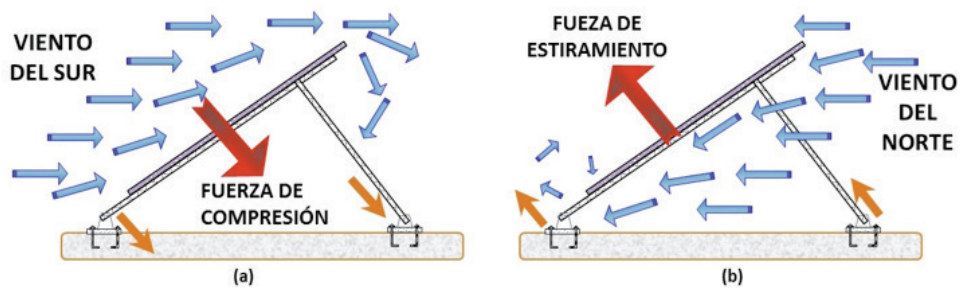

Figura 6.15: Fuezas en una estructura inclinada debido a la acción del viento.

Se requiere que la estructura y cimentación tengan una vida útil de 20 años como mínimo y debe cumplir con lo siguiente:

\section{4.g.1. Generalidades}

a) Ser de metal: aluminio anodizado o acero inoxidable, o bien, acero al carbón galvanizado en caliente o acero al carbón con un recubrimiento anticorrosivo y pintura acrílica anticorrosiva cumpliendo con la Especificación CFE D8500-02 "Recubrimientos anticorrosivos", para recubrimiento anticorrosivos de estructuras metálicas. 
b) En regiones de ambiente salino, la estructura debe de ser de aluminio anodizado o acero inoxidable.

c) Los "durmientes", elementos donde descansan y se atornillan los MFV deben ser de aluminio para evitar pares galvánicos anticorrosivos entre ellos.

d) Todos los herrajes (tornillos, tuercas, y las rondanas planas, de presión o de estrella, deben ser de acero inoxidable.

e) Pueden ser fijas o con seguimiento solar (uno o dos ejes).

f) Para estructuras fijas, sin seguimiento, la inclinación del AFV debe ser igual a la Latitud del lugar $\pm 5^{\circ}$ que es considerado el ángulo de diseño que maximiza la energía producida al año. En caso contrario, el proveedor debe justificar el ángulo seleccionado y entregar una memoria de cálculo del perfil mensual de generación de la energía durante un año.

g) Debe estar orientada tal que la "cara" o superficie activa de los módulos este hacia el sur verdadero $\pm 5^{\circ}$. Si por condiciones del sitio de instalación no se puede cumplir lo anterior, el proveedor debe entregar una memoria de cálculo del perfil mensual de generación de la energía durante un año.

h) Puede contar con un sistema de ajuste $\pm 15^{\circ}$ de acuerdo a la latitud del lugar.

\section{4.g.2. Ubicación}

a) La estructura se puede instalar sobre el terreno (suelo o piso) o sobre el techo o loza de una edificación. Para instalaciones sobre terreno se puede tener dos tipos de soportes: un solo punto de apoyo llamado tipo pedestal o poste; o varios puntos de apoyo. En ambos casos, los puntos de apoyo deben estar cimentados al piso o terreno, o techo.

b) El soporte tipo pedestal puede estar enterrado y/o cimentado en el terreno, o bien tener una base metálica para atornillarlo a una contra base con anclas roscadas embe- 
bidas en un "dado" o base de concreto armado cimentado en el terreno. En ambos casos, el diseño estructural debe ser tal que la estructura no sufra flexiones cuando es sometida a cargas de viento locales. El "proveedor" debe proporcionar la memoria de cálculo correspondiente acorde al Manual de Diseño de Obras civiles: Diseño por Viento 2008 CFE-IIE. El pedestal puede ser de concreto armado o metálico y estar diseñado para soportar la carga estática de la estructura y del AFV. La altura más baja del AFV no debe ser inferior a $0.60 \mathrm{~m}$ en su parte inferior referenciado al nivel del suelo.

c) El soporte con varios puntos de apoyo es aquel en la que la estructura esta sobre un terreno horizontal por lo menos con 4 "piernas", las que pueden incluir bases para sujetarse al piso según el diseño civil de la cimentación de concreto correspondiente. La sujeción puede hacerse con "anclas" roscadas embebidas en concreto, taquetes metálicos de expansión con tornillos insertados en el concreto, $\mathrm{u}$ otro mecanismo que garantice la firmeza de sujeción de la base de la "pierna al piso o terreno". La altura de la parte más baja del AFV, no debe ser inferior a $0.60 \mathrm{~m}$ referenciado al nivel del terreno. La separación entre las "piernas" debe ser tal que los "largueros o durmientes" que soportarán a los módulos no deben presentar flexiones superiores a $3 \mathrm{~mm}$ en ninguna dirección derivado de la carga estática producida por el peso de los módulos.

d) Cuando el AFV se instale en una azotea de concreto armado con el techo horizontal, el "anclaje al techo" debe satisfacer lo especificado en el inciso (b). En todos los casos, el proveedor debe solicitar al usuario de la tecnología un estudio de resistencia mecánica que garantice que el techo o la estructura de la edificación no cederá a la carga estática producida por el peso de los módulos y la carga dinámica producida por la presión del viento sobre la geometría del AFV. 
e) Para techos inclinados orientados al sur verdadero, con un ángulo igual a la Latitud del lugar $\pm 5^{\circ}$, el "anclaje al techo" puede ser tal que las "piernas" de soporte hagan que la superficie del AFV sea paralela a la superficie del techo y deben proveer una altura mínima de $0.20 \mathrm{~m}$ respecto del nivel del mismo. para permitir la ventilación de los módulos. Si el ángulo de inclinación del techo no es igual a la Latitud del lugar $\pm 5^{\circ}$, las "piernas" de la estructura deben proveer la inclinación de diseño para el AFV, considerando que la altura de la parte más baja del AFV, no debe ser inferior a $0.20 \mathrm{~m}$.

f) Para techos inclinados no orientados al sur verdadero, el "anclaje al techo" debe diseñarse de tal manera que la estructura quede orientada al sur verdadero e inclinada al ángulo de diseño, manteniendo el requerimiento que la altura de la parte más baja del AFV, no debe ser inferior a $0.20 \mathrm{~m}$. En caso contrario, el proveedor debe justificar el ángulo seleccionado y entregar una memoria de cálculo del perfil mensual de generación de la energía durante un año.

g) En todos los casos en que el techo de una edificación no sea de concreto armado, el "Proveedor" debe seleccionar el mejor sistema mecánico que permita sujetar firmemente las piernas del soporte a la estructura de la edificación correspondiente. 


\section{7}

\section{EJEMPLO DE DISEÑO: PLANTA FOTOVOLTAICA DE 27.0 KW}

El ejemplo que se presenta aquí corresponde al dimensionamiento de una Planta Solar Fotovoltaica de $27.0 \mathrm{~kW}$ pico instalada en el el Centro Morelense de Innovación Agropecuaria, CEMIAgro, dependiente de la Secretaría de Innovación, Ciencia y Tecnología del Estado de Morelos (SICyTEM), y forma parte de los Proyectos Demostrativos instalados y puestos en operación a través del proyecto No. 190603 financiado por el Consejo Nacional de Ciencia y Tecnología (CONACYT) a través del Fondo Institucional de Fomento Regional para el Desarrollo Científico, Tecnológico y de Innovación (FORDECYT), siendo el Instituto de Energías Renovables de la Universidad Nacional Autónoma de México (IER-UNAM) el responsable técnico de dichos proyectos.

El CEMIAgro) está ubicado en Carretera Av. Temixco 160, Ciudad de la Confección, Palo Escrito, CP 62760 Emiliano Zapata, Morelos y sus coordenadas geográficas son: $18.8^{\circ} \mathrm{de}$ Latitud Norte, 99.2 $2^{\circ}$ Longitud Oeste, 1,213 msnm. El sitio asignado para dicha instalación fue la azotea de una de las edificaciones de dicha organización.

Dado que el sitio asignado para instalar la PSFV fue la azotea correspondiente a las oficinas de gobierno (Ver Figu- 
ra 7.1), el dimensionamiento se basó en la superficie disponible considerando pasillos de mantenimiento, determinándose una capacidad máxima para la planta de $27.0 \mathrm{~kW}$ pico usando tecnología FV de silicio policristalino con una eficiencia aproximada del $15 \%$.

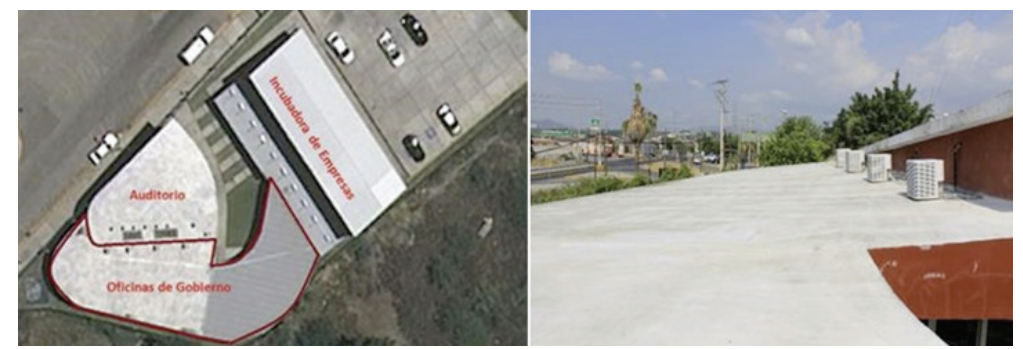

Figura 7.1: A la izquierda se tiene una vista aérea del CeMIAgro; y a la deecha, la zona destinada para la instalación mecánica de los AFV's. Ubicación del Sistema Fotovoltaico del CeMIAgro

Se seleccionaron MFV de la empresa Solartec modelo S60PC-250 con una potencia $P_{P}(\mathrm{AFV})=250 \mathrm{~W}$, requiriendo de 108 pzas para completar la potencia dimensionada.

La PSFV-27 fue dividida en tres (3) SFV-I, cada uno formado con un AFV de una Potencia Pico de $9.0 \mathrm{~kW}$, es decir, $P_{P}(\mathrm{AFV})=9.0 \mathrm{~kW}$, integrado por $36 \mathrm{MFV}$ con una configuración eléctrica 12Sx3P: una CFV de 12 pzas conectadas en serie y $3 \mathrm{CFV}$ conectadas en paralelo.

El circuito de salida fotovoltaica de cada AFV (CS-FV) se conectó a un inversor CD/CA de la marca Fronius modelo IG Plus V 10.0-3, 208/240 V@60 Hz trifásico, el cual cuenta con un desconector en su circuito de entrada CD.

Como la Red Eléctrica Local del edificio cuenta con un Tablero General para una potencia de 125.0 kVA, 220/127 VCA trifásico, se decidió usarlo como el Tablero de Paralelismo en donde lleguen los tres circuitos de salida de los inversores. Así, el Circuito de Salida de cada inversor (CS-Inv) se conectó al Tablero General de Distribución Eléctrica del edificio a través de un Desconector (Dsc3). Los Desconecto- 
res Dsc4 son los interruptores de seguridad de los circuitos eléctricos para las "Cargas" Eléctricas Locales (CEL) en Baja Tensión (BT); mientras que el Desconector Dsc5, es el interruptor general de seguridad, ambos ya existentes en la edificación.

El usuario cuenta con un contrato de servicio público con Tarifa en Media Tensión (MT), tiene un transformador de 100 kVA Delta MT/Estrella BT (13.2 kV a 220/127 VCA) y tiene instalado un medidor en la zona de BT que permite medir sus consumos eléctricos; el cual, ha sido sustituido por un Medidor Bidireccional, MB, con la capacidad de medir tanto la energía que se extrae de la RED derivado de una demanda de energía, como la posible energía generada que pudiera inyectarse a la RED cuando ésta no se consuma en la edificación. Un diagrama esquemático se muestra en la Figura 7.2.

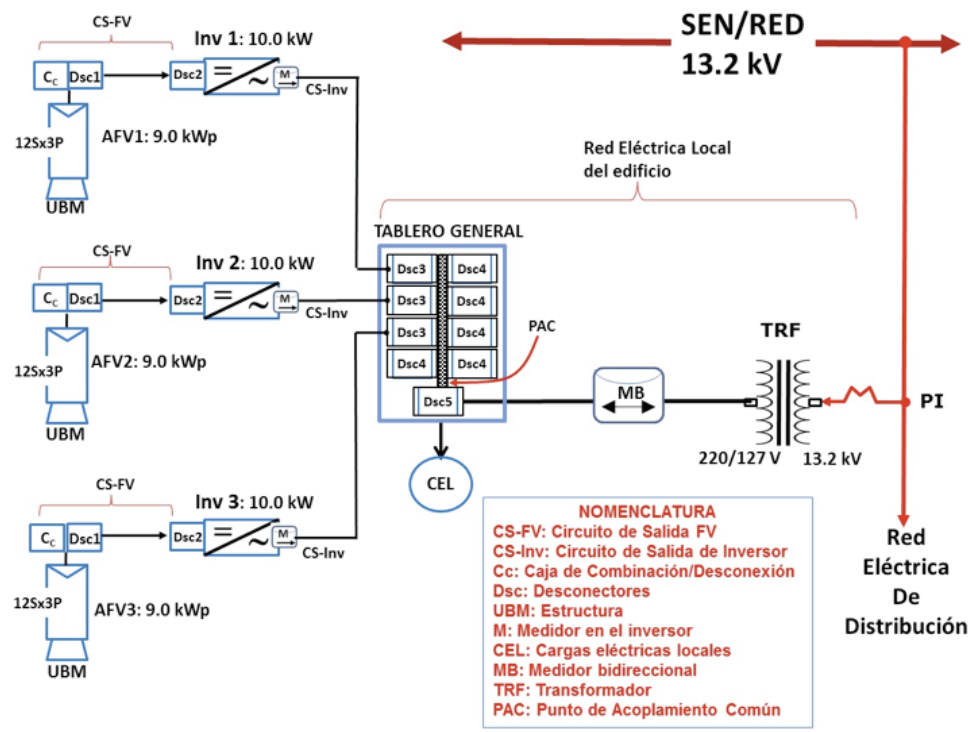

Figura 7.2: Diagrama esquemático de la PSFV-27 con los desconectores de seguridad

Dado que cada uno de los SFV-I tiene un AFV 12Sx3P, las 3 CFV's deben tener un medio de desconexión (Dsc), éstas se 
deben conectarse en paralelo en un Bus Metálico de Potencia $\left(\mathrm{B}_{\mathrm{M}}\right)$, y cada circuito debe tener un dispositivo protector contra corrientes de retorno (PCR). Además, el circuito de salida del $\mathrm{B}_{\mathrm{M}}$ debe contar con un medio de desconexión (Dscl) y contar con un medio de protección contra descargas atmosféricas (PDA). Este circuito llega al inversor en su Desconector integrado Dsc2. Todos estos dispositivos de seguridad deben estar dentro de una caja con una hermeticidad IP65 o mejor.

Se decidió diseñar una estructura metálica para los 36 MFV de cada SFV-I, a la que se le ha llamado Unidad Básica Mecánica (UBM), que permite su fijación mecánica en un arreglo de 4 renglones con 9 columnas. La concepción del "sembrado" de los 108 MFV repartidos en 3 UBM se muestra en la Figura 7.3.

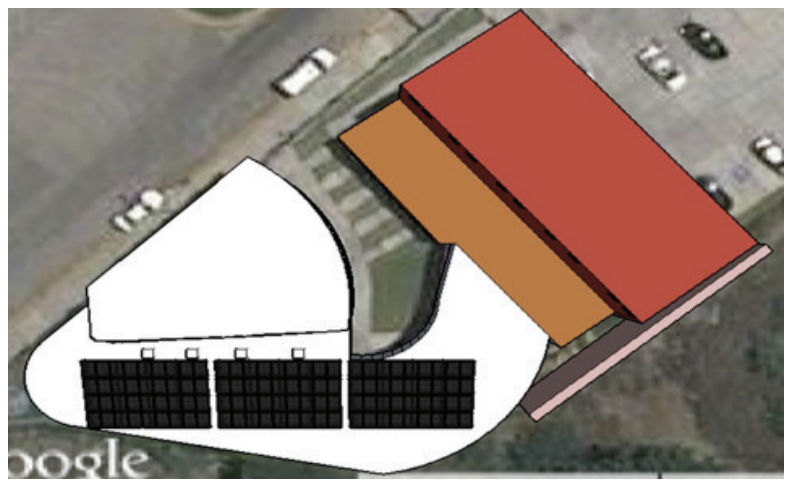

Figura 7.3: Render del "sembrado" de los 108 MFV repatidos en 3 UBM.

Para cada SFV-I y con los datos de placa de los MFV instalados, se han calculado los parámetros eléctricos tanto de la Cadena Fotovoltaica (12 MFV conectados en serie) así como del AFV (3 cadenas conectadas en paralelo) con el objeto de realizar el cálculo de ampacidades de los dispositivos de seguridad y la selección del calibre de los conductores eléctricos. La Tabla 7.1 muestra los valores de los parámetros eléctricos calculados. 
Tabla 7.1: Parámetros eléctricos de placa de los MFV, CFV y AFV

\begin{tabular}{cccc}
\hline Parámetro & Módulo FV & $\begin{array}{c}\text { Cadena FV } \\
12 \mathrm{~S}\end{array}$ & $\begin{array}{c}\text { Arreglo FV } \\
12 \mathrm{~S} \times 3 \mathrm{P}\end{array}$ \\
\hline PP (W) & 250 & 3,000 & 9,000 \\
VCA (V) & 37.85 & 454.2 & 454.20 \\
ICC (A) & 8.65 & 8.65 & 25.95 \\
VMP (V) & 30.12 & 361.44 & 361.44 \\
IMP (A) & 8.30 & 8.3 & 24.90 \\
Área $\left(\mathrm{m}^{2}\right)$ & 1.635 & 19.62 & 58.86 \\
Peso $(\mathrm{kg})$ & 20.5 & 246 & 738 \\
\hline
\end{tabular}

Ya que el inversor acepta la puesta a tierra en su terminal negativa, la configuración eléctrica del SFV-I es intencionalmente puesto a tierra. En consecuencia, para cada SFV-I se tiene que solamente se colocarán los dispositivos de seguridad en la terminal positiva o conductor positivo del circuito eléctrico correspondiente. El diagrama bifilar/unifilar se muestra en la Figura 7.4.

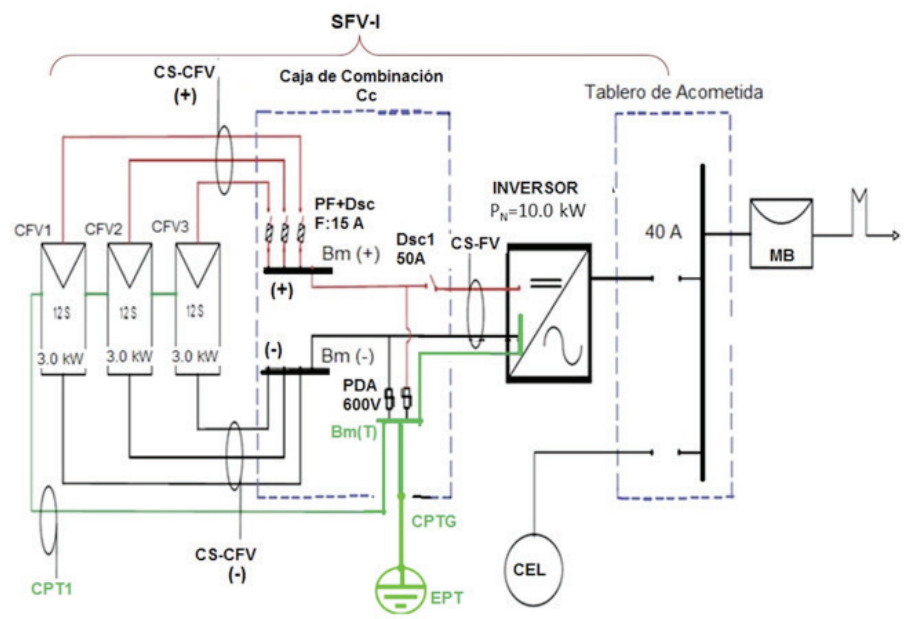

Figura 7.4: Diagrama bifilar/unifilar de cada uno de los SFV-I 


\subsection{Cálculo de Ampacidades}

En todos los circuitos de salida, tanto de la fuente FV (cadena) como del AFV (CS-FV), la ampacidad de los dispositivos de seguridad se debe calcular como 1.56 veces el valor de la corriente de corto circuito $\left(I_{C C}\right)$ y seleccionar el valor estándar inmediatamente superior al valor calculado y que no sea mayor de 2.4 veces $I_{C C^{\circ}}$

Todos los dispositivos que se mencionan en seguida deben estar cetificados para su uso en circuitos en Corriente Directa.

\section{1.a. Dispositivos de seguridad en el Circuito de Salida de cada CFV}

Ya que se requiere tanto de un medio de desconexión (Dsc) como de un PCR, se decidió usar un Portafusible Desconector como un Dsc y un Fusible (F) como PCR, el que aparecen indicado en la Figura 7.4 como PF+Dsc.

Ampacidad para el fusible: $\mathrm{I}_{\text {amp }}(\mathrm{F})=1.56 I_{C C}(\mathrm{CFV})=$ 1.56x8.65=13.5 A; valor estándar 15 A; por lo cual, I $(F)=15$ A.

Tensión de aislamiento mínima requerida para el PF-Dsc: $600 \mathrm{~V}$.

\section{1.b. Conductores eléctricos para el Circuito de Salida de cada CFV}

Se requiere prolongar el CS-CFV hacia la Caja de Combinación con un cable conductor; en consecuencia, éste debe ser del mismo tipo que traen los MFV, es decir, tanto en el calibre como en las características del aislamiento (cable tipo solar). El empalme entre los conductores debe hacerse usando conectores MC4.

El cable conductor que se instaló fue un cable de cobre tipo solar, con una sección transversal de $4.0 \mathrm{~mm}^{2}$, que es idéntico al que traen los MFV en su circuito de salida. 
NOTA: Debe corroborarse que cada una de las CFV lleguen al $\mathrm{B}_{\mathrm{M}}$ de paralelismo con no más del $0.5 \%$ de diferencia de su $V_{M P}(\mathrm{CFV})$.

\section{1.c. Bus Metálico $B_{M}$ para el paralelismo de cadenas}

Llegan $3 \mathrm{CFV}$ (tres circuitos) con una $I_{C C}(\mathrm{CFV})=8.65 \mathrm{~A}$, en consecuencia, recibe una corriente de corto circuito de 25.95 A, en consecuencia:

$\mathrm{I}_{\text {amp }}\left(\mathrm{B}_{\mathrm{M}}\right)=1.56 \times 25.95=40.5 \mathrm{~A}$; entonces el Bus debe tener por lo menos una $\mathrm{I}_{\text {amp }}\left(\mathrm{B}_{\mathrm{M}}\right) \geq 40.5 \mathrm{~A}$

Tensión de aislamiento mínima requerida para el receptáculo que lo contiene: $600 \mathrm{~V}$

\section{1.d. Desconector Dsc1 en el Circuito de salida del AFV (CS-} $\mathrm{FV})$

Este circuito sale de Bus Metálico, por lo cual el Desconector debe tener una ampacidad mínima de $\mathrm{I}_{\text {amp }}$ (Dsc1)=1.56x25.9=40.4 A. El valor estándar próximo es de $50 \mathrm{~A}$, por lo cual:

$\mathrm{I}_{\text {amp }}(\mathrm{Dscl})=50.0 \mathrm{~A}$

Tensión de aislamiento mínima requerida para el receptáculo que lo contiene: $600 \mathrm{~V}$

Se eligió un desconector de palanca de dos polos para evitar el arqueo.

\section{1.e. Conductores eléctricos para el Circuito de salida del AFV}

Se requiere prolongar el CS-FV hacia el inversor con un cable conductor. Se seleccionó cable RHW-2 enductándolo en un tubo metálico de pared rígida de 3/4" de diámetro. Ya que el ducto solo llevará dos conductores, la ampacidad del cable no será corregida por efectos de agrupamiento; sin embargo, al estar colocado sobe la loza a $10.0 \mathrm{~cm}$ de ella, hay que corregir la ampacidad por efecto de la temperatura. Considerando las Tablas de la Sección 6.4.b, para una temperatura ambiente de 
$30^{\circ} \mathrm{C}$, el factor de corrección es de 0.67 ; por lo cual, la ampacidad del conductor debe ser:

$\mathrm{I}_{\text {amp }}(\mathrm{CS}-\mathrm{FV})=1.56 \times 25.9 / 0.67=60.3 \mathrm{~A}$; ya que el cable calibre \#6 AWG tiene una ampacidad 65 A, se eligió a dicho conductor para el CS-FV.

NOTA: Se debe corroborar que la caída de tensión desde el punto de generación hasta la entrada del inversor no sea mayor al $3 \%$ del $V_{M P}$ del AFV.

\section{1.f. Dispositivo de Seguridad Contra Descargas Atmosféricas, PDA.}

Se requiere de un PDA para bajar los picos de tensión ocasionados por descargas atmosféricas. Los PDA para aplicaciones FV son varistores que vienen integrados en un dispositivo que tienen dos polos de entrada (una para el conductor positivo y otra para el conductor negativo) y uno de salida, que se usa para colocar el Conductor de Puesta a Tierra (CPT) que lleva los potenciales inducidos a tierra a través del Electrodo de Puesta a Tierra (EPT).

Los dispositivos PDA se eligen de tal manera que su Voltaje de Operación, $V(\mathrm{PDA})$, sea mayor a 1.25 veces el voltaje a circuito abierto del $\mathrm{FV}, V_{C A}(\mathrm{AFV})$; y como éste tiene un valor de $454.2 \mathrm{~V}$, entonces:

$V(\mathrm{PDA}) \geq 1.25 \times 454.2=567.75 \mathrm{~V}$; el valor estándar es de 600 V.

Las capacidades de corriente para dichos elementos son estándares y sus especificaciones sone: voltaje continuo de $600 V D C$, descarga nominal de $15 \boldsymbol{k A}$, voltaje de protección a $3.0 k V$, y una corriente máxima de retorno de $80 A$.

Ya que el PDA se debe conectar a tierra, se sugiere colocar dentro de la Caja de Combinación un Bus Metálico para la Puesta a Tierra, Bm(T), que reciba tanto el CPT del PDA como los CPT's de las partes metálicas expuestas: marco de los MFV's y estructura. 


\section{1.g. Conductores eléctricos para la Puesta a Tierra del AFV}

Todos los elementos metálicos expuestos del AFV deben ser puestos a tierra, eso abarca: el marco de los MFV, los "durmientes", las "piernas" y trabes.

Marco de los MFV.- Ya que se tienen 36 MFV montados en una estructura (3 CFV) y cada uno de ellos se atornilló a los durmientes (Dt) usando entre sus superficies una rondana tipo estrella de acero inoxidable que, al momento de apretar el tornillo ésta se incrusta dentro de sus superficies, solo se colocó un conductor continuo de puesta a tierra que une a todos los durmientes, el cual, se prolongó hasta el $\mathrm{Bm}(\mathrm{T})$ instalado en la Caja de Combinación. En el caso de que un C.S-CFV se ponga accidentalmente puesto a tierra (corto eléctrico), la corriente máxima que debe soportar dicho conductor es 1.56 la corriente de corto circuito de la cadena; por lo cual:

$\operatorname{Iamp}(\mathrm{CPT})=1.56 I_{C C}(\mathrm{CFV})=1.56 \times 8.56=13.5 \mathrm{~A}$.

Se decidió colocar un cable de cobre, desnudo, calibre \#10 AWG que tiene una ampacidad de 35 A@75. Este conductor fue colocado en zapatas que se atornillaron en cada uno de los durmientes.

Piernas y Trabes.- Considerando lo antes dicho en términos de un posible corto eléctrico, también se colocó un conductor continuo de cobre, desnudo, calibre \#10 AWG, para la puesta a tierra de esos elementos, el cual, se prolongó hasta el Bm(T) en la Caja de Combinación.

Conductor de Puesta a Tierra General, CPTG.- Del Bm(T)sale el CPTG y como en ese sitio se juntan en paralelo las 3 CFV's, teniendo en el $\mathrm{BM}(+)$ una corriente de corto circuito de 25.95 A, entonces la ampacidad para dicho coductor debe ser 1.56 ese valor; por lo cual:

$\operatorname{Iamp}(\mathrm{CPTG})=40.48 \mathrm{~A}$

Se decidió instalar un cable de cobre, desnudo, calibre \#6 AWG con una ampacidad de 65 A ya que este es el cable de mayor calibre en el CS-FV. 


\section{1.h. Electrodo de Puesta a Tierra del AFV, EPT}

Como EPT se usó una varilla de acero, cobrizada, de 7/8" de diámetro por $3.0 \mathrm{mts}$ de larga, enterrada completamente en un agujero, el cual, se rellenó con una mezcla de tierra y bentonita para favorecer la conducción iónica. El EPTG se soldó al EPT usando soldadura de alta temperatura. La impedancia a tierra es de

\subsubsection{Medio de desconexión en el Tablero General}

Cada uno de los circuitos de salida del inversor (CS-Inv) llega al Tablero General a través de un Medio de Desconexión (Dsc3) que permita aislar a cada uno de ellos y que proteja dicho circuitos contra sobrecorrientes. En consecuencia, este desconector debe ser un Interruptor Termomagnético Bidireccional ya que la corriente va a fluir en las dos direcciones: de la RED y hacia la RED.

Ya que la potencia nominal del inversor es de $10.0 \mathrm{~kW}$, con un voltaje entre fases de acoplamiento de $220 \mathrm{~V}$, entonces la corriente nominal de salida está dada por:

$$
\mathrm{I}_{N}(\operatorname{Inv})=\frac{P_{N}(\operatorname{Inv})}{\sqrt{3} V_{F} \operatorname{cosf}}=26.4 \mathrm{~A}
$$

Así que el Dsc3 debe tener una ampacidad de 1.25 ese valor; es decir Iamp(DSC3)=32.8 A; y el valor estándar es de 40 A. La capacidad de interrupción está en función de la máxima corriente que se recibe en el Tablero General en el desconector/protector Dsc5, y para éste caso, el DSC3 debe tener las mismas características de dicho interruptor.

\subsection{La estructura: unidad básica mecánica}

Ya que cada AFV consta de 36 MFV, se decidió diseñar para cada uno de ellos una estructura metálica para acomodarlos mecánicamente en una distribución de 9 columnas por 
4 renglones, estando los MFV en posición vertical. A dicha estructura se le ha llamado Unidad Básica Mecánica, UBM.

El diseño de la estructura para instalar mecánicamente los 36 MFV's de un AFV se muestra en la Figura 7.5 y así mismo, la manera en que éstos quedaron distribuidos. La estructura consta de postes y trabes de acero al carbón galvanizados en caliente para evitar la corrosión y rieles de aluminio anodizado que servirán como "durmientes" para los módulos. Los detalles del diseño se observan en dicha figura.
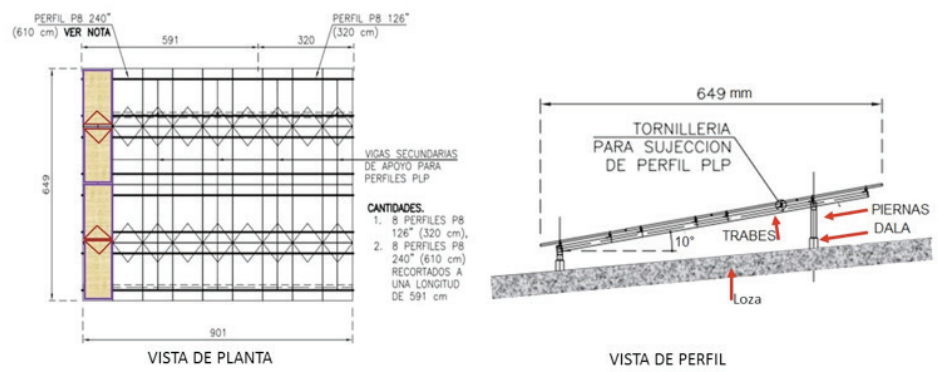

Figura 7.5: Detalles de la estructura de soporte de cada arreglo fotovoltaico del sistema

La inclinación que se le dio a la estructura fue de $10^{\circ}$ debido a requerimientos del propietario, con la intención de que el sistema no estuviera expuesto a cargas mecánicas originadas por el viento ni fuera muy visible desde el exterior del edificio. Una fotografía de dicha estructura se muestra en la Figura 7.6. En ella se puede distinguir a los durmientes, la Trabe y la Pierna. 


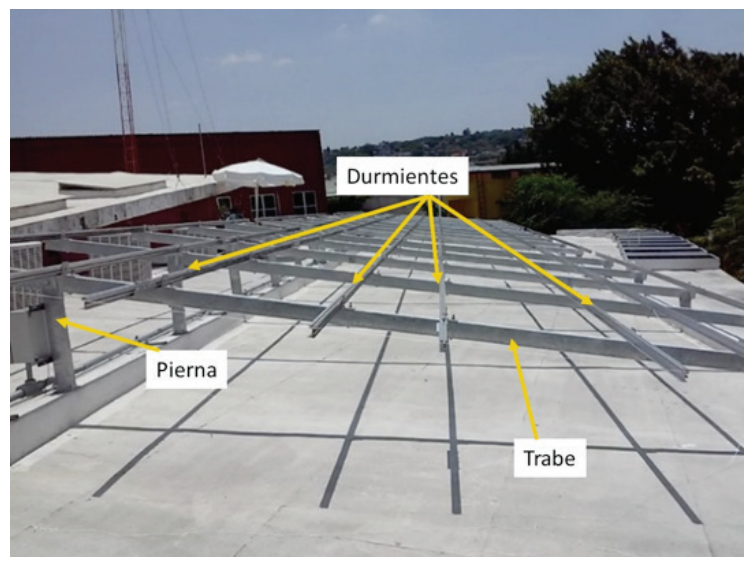

Figura 7.6: Montaje de la estructura de los módulos fotovoltaicos

\subsection{Conexión eléctrica entre módulos y cadenas}

La conexión eléctrica de los módulos es la misma para cada uno de los tres AFV's. Dado que los MFV se instalaron mecánicamente en la estructura en una distribución de 9 columnas con 4 renglones, para favorecer la conexión eléctrica tipo serie entre 12 de ellos, estos fueron colocados sobre la estructura tal y como se muestra en la Figura 7.7. Los módulos se encuentran etiquetados identificando módulo, cadena y al AFV al que pertenecen.

Ya que el circuito de salida de cada MFV, terminal positiva y terminal negativa, se proveen con dos cables conductores, tipo "solar" (cable para intemperie con protección contra rayos UV) de $4 \mathrm{~mm}^{2}$ de sección transversal que traen integrados en sus extremos conectores "rápidos" del tipo MC4, la conexión eléctrica entre módulo y módulo para realizar la conexión serie de 12 de ellos se realizó utilizando sus propios cables/conectores.

Ya que si se toma como circuito de salida de cada CFV la terminal (+) del $1^{\text {er }}$ MFV y terminal (-) del $12^{\text {avo }}$ MFV que la forman, se estará construyendo una bobina eléctrica de radio 
amplio lo que es NO recomendable ya que funcionaría como una antena receptora, entonces para evitar la formación de ésta, en cada CFV se conectó un cable conductor de retorno (cable tipo "solar" de $6.0 \mathrm{~mm}^{2}$ de sección transversal) para prolongar el circuito de salida de la CFV hacia el módulo inicial de ella (líneas color rojo en la Figura 7.7).

Ahora bien, para extender el circuito de salida de cada CFV desde el sitio en donde quedaron tanto la terminal (+) del $1^{\text {er }}$ MFV y la prolongación de la terminal (-) del $12^{\text {avo }}$ MFV hacia la Caja de Combinación $\mathrm{C}_{\mathrm{C}}$, se conectaron a dicho circuito, dos cables conductores (cable tipo "solar" de $6.0 \mathrm{~mm}^{2} \mathrm{de}$ sección transversal) y se prolongaron hacia dicha caja (líneas color azul en la Figura 5), lugar en donde los tres circuitos de las CFV que forman al AFV se conectan en paralelo. Los arreglos fotovoltaicos que integran a la PSFV-27 ya instalados se observan en la Figura7.8.

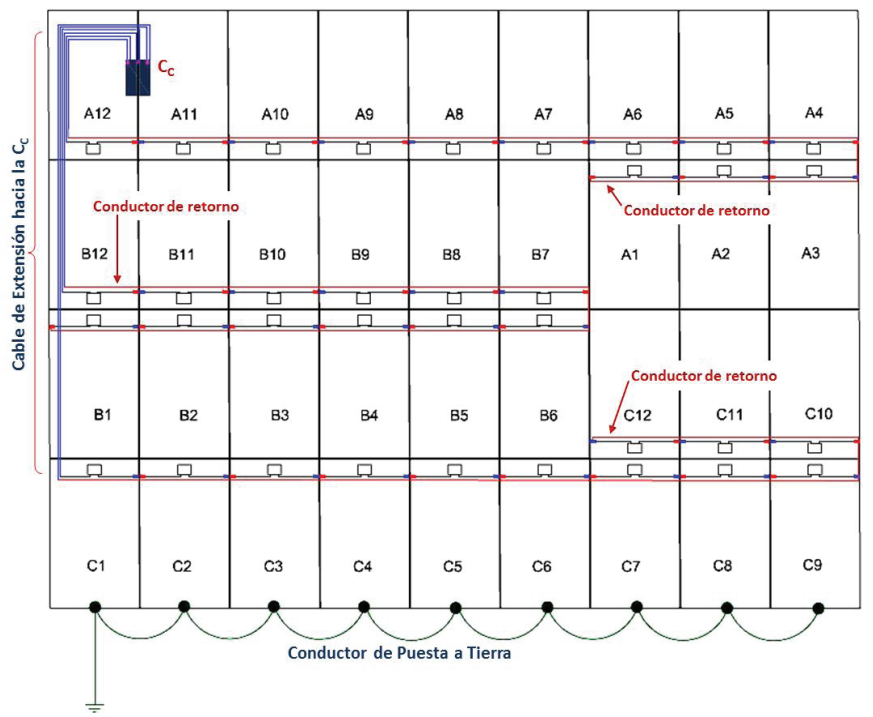

Figura 7.7: Diagrama esquemático de la conexión eléctrica de los 36 MFV s. Estos se de conexión serie de 12 MFV para formar la CFVde un AFV de la PSFV-27. 


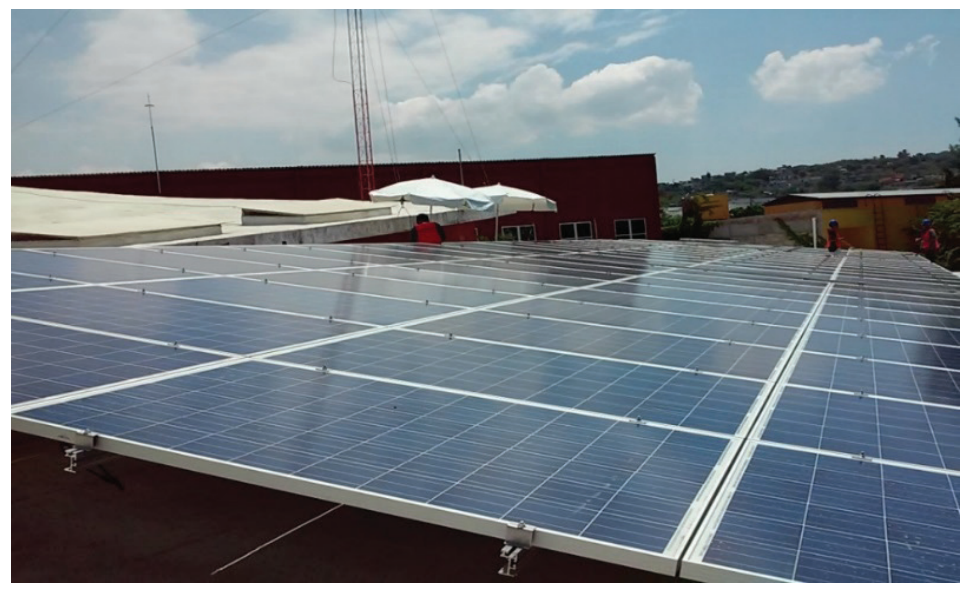

Figura 7.8: Sistema fotovoltaico interconectado a la red en las instalaciones del CeMIAgro.

\subsection{Caja de combinación, $\mathbf{c}_{\mathbf{c}}$.}

Se utilizó una caja de combinación por cada arreglo fotovoltaico, de la marca Legrand con grado de protección IP65 para uso a la intemperie. La caja se encuentra mecánicamente fija a la estructura que alberga a cada AFV y está colocada debajo de los módulos fotovoltaicos.

Ya que a cada $\mathbf{C}_{\mathbf{C}}$ llegan 3 circuitos de salida de las CFV's asociadas al AFV, en cada circuito se instaló un Protector contra Corrientes de Retorno $(\mathbf{P C R})$, el Bus Metálico $\left(\mathbf{B}_{\mathbf{M}}\right)$ para proveer la conexión en paralelo de los tres circuitos tanto para la terminal (+), terminal (-) así como para la puesta a tierra de la estructura, un Protector contra las Descargas Atmosféricas (PDA) y un Medio de Desconexión o interruptor/desconector $\left(\mathbf{D}_{\mathbf{S C}}\right)$ para el circuito de salida del AFV. Los dispositivos de seguridad antes mencionados solamente se instalaron en el conductor (+) ya que la configuración eléctrica del SFV es intencionalmente aterrizado y esto se realizó en la terminal negativa. 
PCR.- Dado que la corriente de ampacidad para cada circuito de salida de las CFV's es de 13.5 A considerando los factores recomendados por la NOM001 SEDE 2012, se eligió como PCR a un fusible (F) de 15 A montado en un Porta-Fusible Desconector $\left(\mathbf{P}-\mathbf{F} / \mathbf{D}_{\text {sC }}\right)$ de la marca Bussmann modelo PV-15A10F.

$\mathbf{B}_{\mathbf{M}^{-}}{ }^{-}$Como Bus metálico para realizar el paralelismo de circuitos se usó un Block de Potencia o Block de distribución, A dicho block llegan 3 circuitos con una ampacidad de 13.5 A cada uno, totalizando en el block una ampacidad de 40.5 A. En consecuencia, la ampacidad del block debe ser superior a éste valor. Se eligió un block de distribución de la marca Bussmann modelo PDBFS330 con una tensión máxima de 600 VCD y una ampacidad de 380A.

PDA.- Como protector contra descargas atmosféricas se eligió a un varistor de la marca Bussmann modelo BPM300YPV con un voltaje nominal de 500 VCD y una capacidad para corrientede $11.5 \mathrm{kA}$.

$\mathbf{D}_{\text {sc }^{-}}$- Como medio de desconexión o desconector para el circuito de salida de la Caja de Combinación se usó un Interruptor manual de dos polos de la marca Moeller modelo PLS6-C50/2, máxima tensión 600 VCD con una ampacidad de 50 A ya que la ampacidad para el circuito de salida es de $42.45 \mathrm{~A}$.

Adicionalmente a todos los componentes antes mencionados, se cuenta con un bus metálico para recibir los conductores eléctricos negativos, así como los conductores de la puesta a tierra.

El sistema de puesta a tierra contempla conductores de puesta a tierra para los marcos de cada uno de los módulos del sistema fotovoltaico, para las estructuras de soporte de los módulos, para las cajas de combinación, de tal manera que forman un solo sistema con el conductor de tierra de los inversores y con el conductor de tierra del circuito eléctrico de las cargas del edificio. 
Para una rápida identificación de los conductores que transportan la electricidad desde el punto de generación de cada CFV hasta el inversor se respetó el Código de Colores recomendado por la NOM 001SEDE 2012; es decir, los conductores de la terminal positiva tienen recubrimiento aislante color negro, los conductores de la terminal negativa tienen recubrimiento aislante color blanco; los conductores para la puesta a tierra NO tienen recubrimiento aislante, es decir, están "desnudos". La Figura 7.9 muestra una fotografía de los dispositivos antes mencionados instalados dentro de la Caja de Combinación.

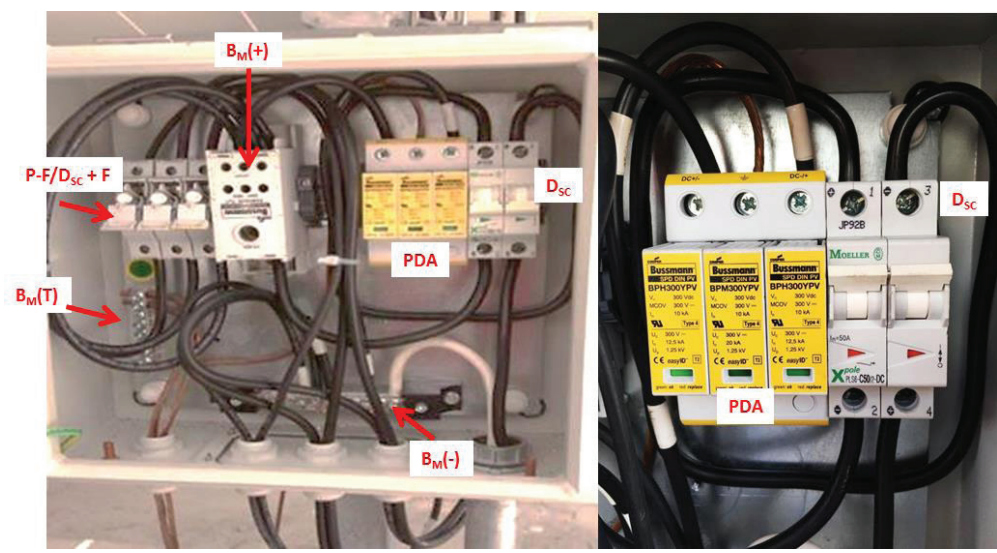

Figura 7.9: Caja de combinación de los arreglos fotovoltaicos del sistema

\section{5.- Inversores $\mathrm{cd} / \mathrm{ca}$ o acondicionadores de potencia}

La PSFV-27 tiene tres acondicionadores de potencia o inversores CD/CA para la interconexión con la red. Para cada AFV (tres en total) se tiene un inversor trifásico de $10 \mathrm{~kW}$ de potencia nominal de la marca Fronius modelo IG Plus V 10.0-3 Delta, con una eficiencia de conversión CD/CA máxima de 96.2\%. Los inversores se encuentran empotrados sobre la 
pared Oeste del edificio, tal y como se observa en la Figura 7.10, casi a la intemperie ya que cuentan con protección IP65.

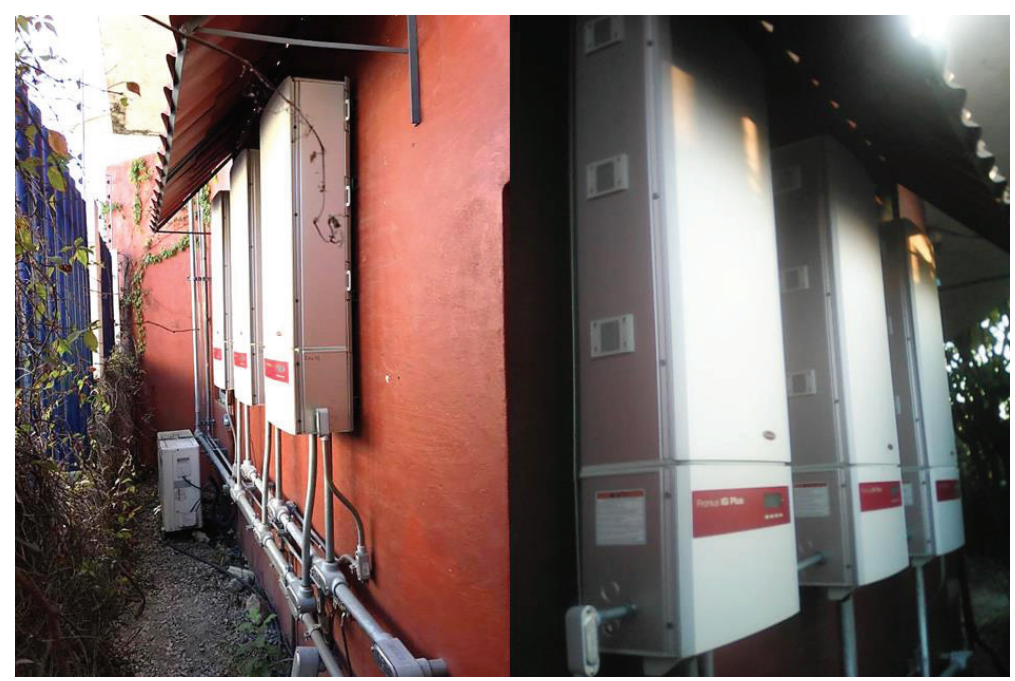

Figura 7.10: Inversores IG Plus V 10.0-3 Delta de la PSFV-27

Los inversores instalados tienen integrado un transformador, razón por la cual la tipología eléctrica de cada AFV es puesto a tierra; es decir, se ha aterrizado intencionalmente el conductor negativo a tierra.

Los inversores cuentan con un sistema de monitoreo interno y mediante una pantalla proporcionan información en tiempo real y acumulado de la potencia pico, voltaje y corriente, directa y alterna, frecuencia, emisiones de $\mathrm{CO}_{2}$ evitados y datos económicos de la instalación.

Además del sistema de monitoreo incluido en el inversor, se adquirió, adicionalmente, un sistema de monitoreo y adquisición de datos en tiempo real de las variables eléctricas por cada inversor de la marca Fronius. Este sistema mide y registra los datos en intervalos de 5 min. Las variables que se midieron para cada AFV de manera independiente, en corriente directa, son: potencia, voltaje, corriente y energía generada. A la salida del inversor, en corriente alterna se midieron: poten- 
cia inyectada a la red, energía inyectada a la red, voltaje y corriente.

Además, se agregó un sistema de sensores de variables ambientales integrados en una caja de sensores, también de la marca Fronius, que miden la radiación en el plano de los módulos a través de una celda de referencia con una precisión de $\pm 5 \%$, la temperatura ambiente con un sensor modelo PT1000 con precisión de $\pm 0.8^{\circ} \mathrm{C}$, la temperatura del módulo situado por debajo de éste midiendo con una precisión de \pm $0.8^{\circ} \mathrm{C}$ y la velocidad del viento a través de un anemómetro de copa con precisiones del $\pm 5 \%$. La posición de los sensores la podemos ver en la Figura 9.
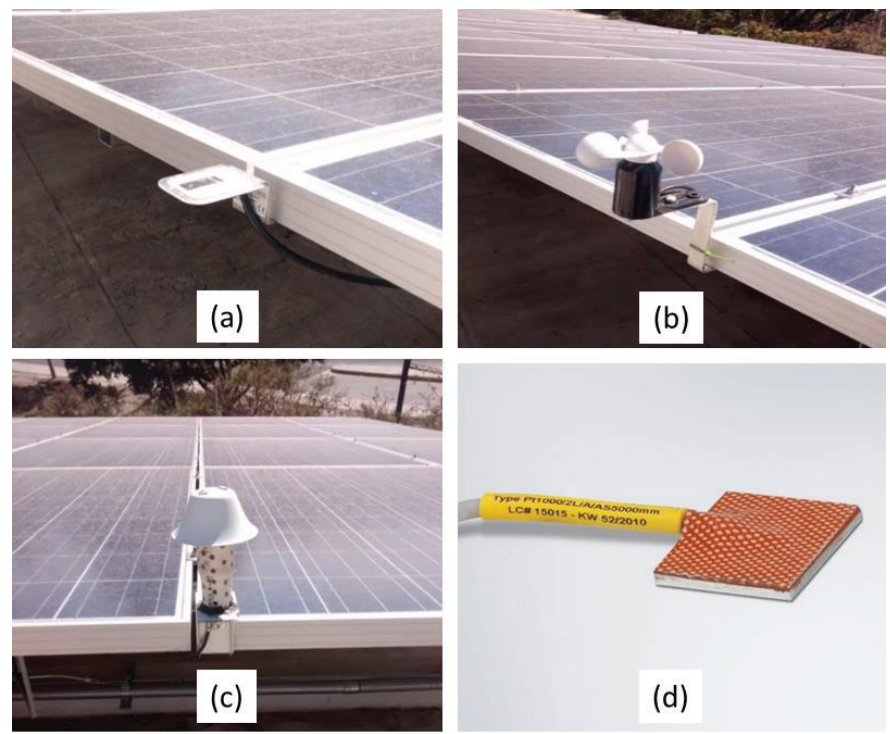

Figura 9: Sensores de parámetros ambientales del sistema de monitoreo. a) Celda de referencia. b) Anemómetro de copa. c) Sensor de temperatura ambiente. d) Sensor de temperatura del módulo.

El monitoreo del sistema se realizó a través de 2 plataformas. La primera es la Fronius Solar.web, la cual permite visualizar en línea de manera remota variables como producción, potencia actual, rendimiento, variables ambientales del 
sistema fotovoltaico, además de crear informes energéticos, así como de errores del mismo; y la segunda plataforma utilizada es la Fronius Solar.access, el cual permitió registrar, archivar y analizar datos del sistema a través de una computadora. Los datos se pueden exportar en archivos .cvs en intervalos de tiempo diarios o cada 5 minutos.

\subsection{Análisis energético}

Con el objeto de establecer un marco de comparación para la energía que está produciendo la PFV-27, se procedió a realizar una estimación simulada usando el programa PVSyst. El pronóstico de generación de dicha planta a partir del cálculo realizado en el programa es de 40,771 kWh/año, lo que equivale a $111.78 \mathrm{kWh}$ promedio diario. La producción específica, es decir, por cada $\mathrm{kW}$ instalado, así como las pérdidas en la generación y en el resto del sistema se pueden observar en la Figura 7.11.

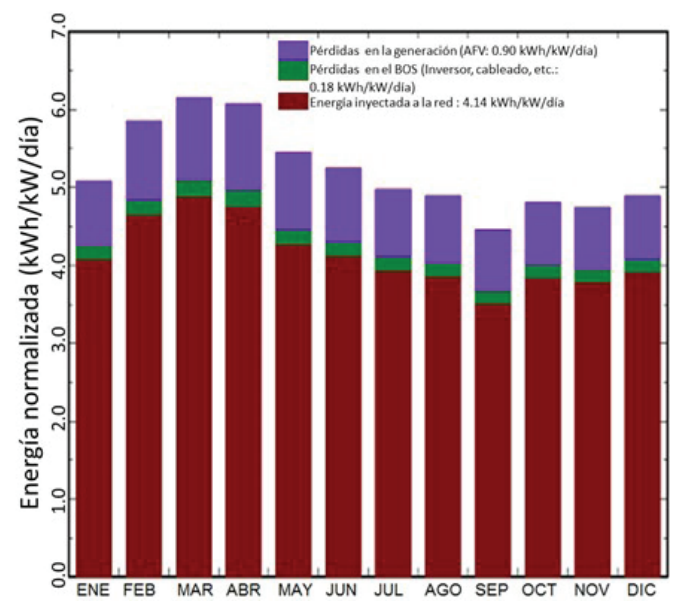

Figura 7.11: Estimación de la producción de energía mediante el programa PVSyst 
Este resultado podría suponer un valor ideal de generación de la PSFV-27, sin embargo, fue realizado con datos del recurso solar sintetizados con la metodología del programa a partir de una base de datos que no se encuentra ubicada en la misma zona geográfica que la planta, por lo que el resultado puede variar si se emplean los datos reales del recurso solar, medidos por los propios sensores.

En la Figura 7.12 se presenta el comportamiento mensual del rendimiento, que permite observar que bajo condiciones idóneas, el sistema tendrá un rendimiento constante durante su operación, con un valor promedio anual de 79.4\%, a pesar de las condiciones climatológicas que se presentan, como son la variación de temperatura y del recurso solar mes con mes, principalmente.

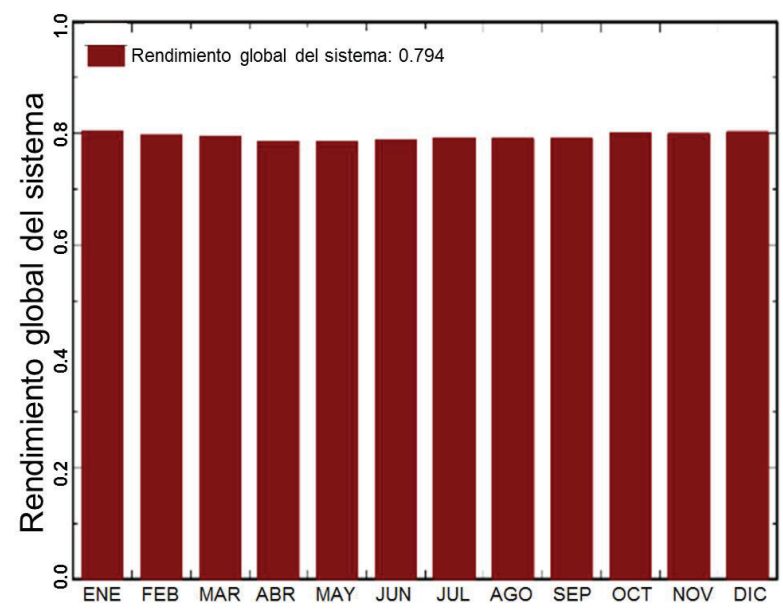

Figura 7.12: Rendimiento global del sistema simulado

En la Tabla 7.2 se muestran el balance y los resultados principales de la simulación. A través de dichos datos, se puede calcular la ganancia en la irradiación global en el plano receptor (GlobInc) a $10^{\circ}$ de inclinación con respecto al de la irradiación global horizontal (GlobHor) que es del orden 
del $3.2 \%$ anual, equivalente a $59 \mathrm{kWh} / \mathrm{m}^{2}$ anuales o 59 horas sol al año.

\begin{tabular}{|c|c|c|c|c|c|c|c|c|}
\hline Mes & $\begin{array}{l}\text { GlobHor } \\
\mathrm{kWh} / \mathrm{m}^{2}\end{array}$ & $\begin{array}{l}\text { T Amb } \\
{ }^{\circ} \mathrm{C}\end{array}$ & $\begin{array}{l}\text { Globlnc } \\
\mathrm{kWh} / \mathrm{m}^{2}\end{array}$ & $\begin{array}{l}\text { GlobEff } \\
\mathrm{kWh} / \mathrm{m}^{2}\end{array}$ & $\underset{\text { kWh }}{\text { EArray }}$ & $\underset{\mathrm{kWh}}{\text { E_Grid }}$ & $\begin{array}{c}\text { Eff_Array } \\
\%\end{array}$ & $\underset{\%}{\text { Eff_Syst }}$ \\
\hline Enero & 141.0 & 13.9 & 157.3 & 151.9 & 3561.0 & 3416.0 & 13.17 & 12.64 \\
\hline Febrero & 151.0 & 15.0 & 163.7 & 158.4 & 3664.0 & 3517.0 & 13.12 & 12.59 \\
\hline Marzo & 184.0 & 17.2 & 190.8 & 185.0 & 4264.0 & 4092.0 & 13.00 & 12.46 \\
\hline Abril & 182.0 & 18.9 & 182.1 & 176.3 & 4026.0 & 3861.0 & 13.06 & 12.52 \\
\hline Mayo & 173.0 & 19.4 & 168.8 & 162.9 & 3739.0 & 3582.0 & 13.09 & 12.54 \\
\hline Junio & 163.0 & 19.4 & 157.2 & 151.7 & 3489.0 & 3342.0 & 13.17 & 12.61 \\
\hline Julio & 159.0 & 18.3 & 154.3 & 148.9 & 3445.0 & 3298.0 & 13.14 & 12.58 \\
\hline Agosto & 153.0 & 18.3 & 151.6 & 146.4 & 3379.0 & 3236.0 & 13.13 & 12.58 \\
\hline Septiembre & 132.0 & 17.8 & 133.6 & 129.1 & 2979.0 & 2853.0 & 14.07 & 12.74 \\
\hline Octubre & 141.0 & 17.2 & 148.8 & 143.9 & 3558.0 & 3220.0 & 13.27 & 12.72 \\
\hline Noviembre & 130.0 & 15.6 & 142.3 & 137.4 & 3203.0 & 3071.0 & 13.35 & 12.81 \\
\hline Diciembre & 134.0 & 14.4 & 151.4 & 145.9 & 3423.0 & 3283.0 & 13.17 & 12.63 \\
\hline Año & $1,843.0$ & 17.1 & $1,902.0$ & $1,837.9$ & 42,531 & 40,770 & 13.17 & 12.64 \\
\hline
\end{tabular}

Tabla 7.2: Balances y resultados principales de la simulación de la producción

Leyendas:

\begin{tabular}{|c|l|l|l|}
\hline GlobHor & Irradiación global horizontal & E_Array & Energía total generada \\
\hline T Amb & Temperatura ambiente & E_Grid & Energía total inyectada a la red \\
\hline Globlnc & $\begin{array}{l}\text { Irradiación global en plano } \\
\text { receptor }\end{array}$ & Eff_Array & Eficiencia del arreglo fotovoltaico \\
\hline GlobEff & $\begin{array}{l}\text { Irradiación efectiva corregido para } \\
\text { AM }\end{array}$ & Eff_Syst & $\begin{array}{l}\text { Eficiencia del sistema fotovoltaico } \\
\text { completo }\end{array}$ \\
\hline
\end{tabular}

Con los datos de la tabla, se estimó que la irradiación efectiva sobre el plano receptor (GlobEff), es decir, la irradiación corregida por efectos del ángulo de incidencia por falta de seguimiento solar para el AFV disminuye en un 3.4 $\%$ con respecto de la irradiación global en el plano del receptor (GlobInc), lo que equivale a $64.1 \mathrm{kWh} / \mathrm{m}^{2}$ o 64.1 horas sol anuales.

En la Figura 7.13 se presenta el diagrama anual de pérdidas energéticas, desde la irradiación global horizontal, hasta la energía inyectada a la red. Las mayores pérdidas en el sistema son debidas a temperatura, representando una disminución del $7.7 \%$ de la energía nominal de la PSFV-27, lo que equivale a $3.87 \mathrm{MWh}$ anuales. 
Posterior a la generación fotovoltaica, las pérdidas más representativas se dan durante la conversión de corriente directa en corriente alterna, debido a la eficiencia del inversor, siendo este valor del $4.1 \%$ de la energía generada en el punto de máxima potencia, equivalentes a 1.74 MWh anuales.

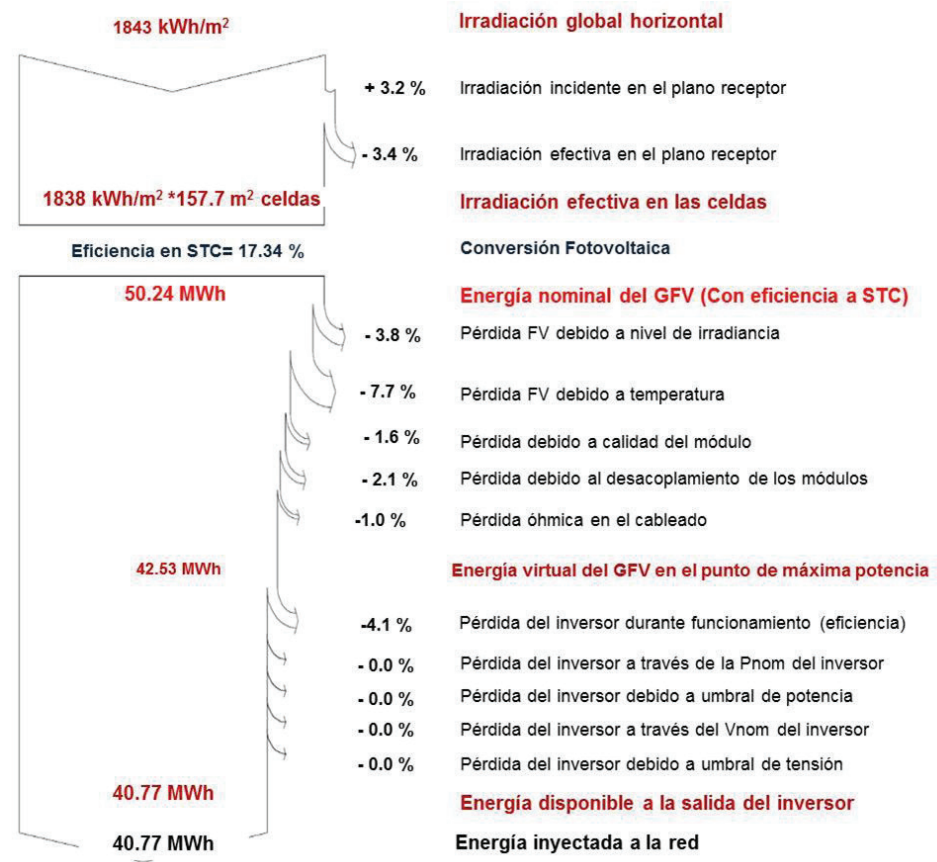

Figura 7.13: Diagrama anual de pérdidas en la simulación

\subsection{Conclusiones}

Se instaló y se ha monitoreado una Planta Solar Fotovoltaica de $27.0 \mathrm{~kW}$ pico (PSFV-27), referido éste valor a la potencia pico fotovoltaica instalada.

La Planta Solar Fotovoltaica (PSFV) está instalada sobre la azotea de uno de los edificios del Centro Morelense de Innovación Agropecuaria (CEMIAGRO), organismo que depende de la Secretaría de Innovación, Ciencia y Tecnología del 
Estado de Morelos (SECyTEM), edificación localizada con las siguientes coordenadas: $18.8^{\circ}$ de Latitud Norte; $99.2^{\circ}$ Longitud Oeste; 1,213 msnm; y ubicada en Carretera Av. Temixco 160, Ciudad de la Confección, Palo Escrito, CP 62760 Emiliano Zapata, Morelos

La PSFV-27 está diseñada para su interconexión a la Red Eléctrica Local (REL) del edificio en cuestión, en Baja Tensión, a un valor establecido de 220 VAC nominales, tres fases, con una frecuencia de $60 \mathrm{~Hz}$; y su Potencia Nominal es de $27.0 \mathrm{~kW}$.

Dicha planta está conformada por tres Sistemas Fotovoltaicos, cada uno integrado por un Arreglo Fotovoltaico con una Potencia Pico $\left(\mathrm{P}_{\mathrm{P}}\right)$ de $9.0 \mathrm{~kW}$ compuesto por $36 \mathrm{MFV}$ de silicio policristalino, con una potencia pico de $250 \mathrm{~W}$, conectados en una configuración de $12 \mathrm{MFV}$ en serie para formar la cadena fotovoltaica, y 3 cadenas conectadas en paralelo; un inversor CC/CA con una Potencia Nominal de 10.0 kW; un sistema de seguridad para evitar las corrientes de retorno, las descargas atmosféricas y fallas a tierra; y un sistema de tierra.

Los Arreglos Fotovoltaicos que conforman la PSFV han sido instalados y fijados mecánicamente, sobre la azotea inclinada de uno de los edificios ocupando una superficie activa de $178.2 \mathrm{~m}^{2}$. La superficie de los módulos fotovoltaicos esta inclinada $10^{\circ}$ respecto de la horizontal y su cara frontal está orientada hacia el sur geográfico.

\section{Estimación Energética}

Tomando en cuenta la climatología del lugar, la magnitud de la irradiación promedio diario anual estimada en bases de datos con un valor de $5.65 \mathrm{kWh} / \mathrm{m} 2$, la eficiencia del inversor (95.9\%), la eficiencia en el cableado eléctrico (97\%), la estimación simple de la energía promedio diario anual que podría generar la PSFV de $27.0 \mathrm{~kW}$ pico es de $\mathrm{Eg}=111.78$ kWh; mientras que la estimación para la Energía Anual consi- 
derando los supuestos anteriores es de 40.8 MWh. El Rendimiento Global estimado es de 0.69.

\section{Medición Energética}

El sistema se monitoreó durante 11 meses (11 de enero-14 de diciembre) con la finalidad de analizar el rendimiento energético del mismo.

Las normas internacionales indican que deben calcularse cuatro factores para analizar el rendimiento energético de un SFV-IR. La productividad de referencia, la productividad del arreglo, la productividad final y el rendimiento global del sistema. Adicional a esto, se calculó la eficiencia del sistema y se calcularon los porcentajes en que diversos factores disminuyeron el rendimiento del SFV.

El recurso solar promedio diario anual fue de 5.74 horas sol, siendo este un valor más alto el valor estimado con las bases de datos disponibles.

La energía inyectada a la red promedio diario anual fue de $107.96 \mathrm{kWh}$ y la energía inyectada a la red total fue de $39,452.03 \mathrm{kWh}$; valores que son ligeramente menores que los estimados derivado de todas las pérdidas asociadas al sistema.

La energía inyectada a la red por cada $\mathrm{kW}$ instalado, la productividad final, fue de $3.99 \mathrm{kWh} / \mathrm{kW} /$ día, es decir, casi el doble que algunos países europeos que ya implementan a los SFV en mayor escala.

Las pérdidas en el sistema (inversor, cableado, etc.) alcanzaron los $0.15 \mathrm{kWh} / \mathrm{kW} /$ día y las pérdidas en la generación (AFV) fueron de $1.58 \mathrm{kWh} / \mathrm{kW} /$ día en promedio diario anual.

El rendimiento global del sistema se calculó utilizando dos líneas bases.

a) La primera fue la productividad final, que considera únicamente el recurso solar. El Rendimiento bajo este criterio fue de 0.79. El primer criterio es el método empleado para calcular el rendimiento con base a las normas, y solamen- 
te así es posible la comparación de la evaluación de este trabajo con otros realizados anteriormente

b) La segunda línea base utilizada fue, además de la productividad final, la temperatura, ya que los MFV no pueden generar más que lo delimitado por el recurso solar y la temperatura. El Rendimiento bajo este criterio fue de 0.88. Para ambos criterios, la PSFV-27 se encuentra operando a un valor típico de rendimiento global para sistemas fotovoltaicos conectados a red.

La eficiencia del sistema bajo condiciones reales de operación fue de $10.7 \%$.

Durante el periodo de evaluación, se han dejado de emitir 17.2 toneladas de $\mathrm{CO} 2$, lo que equivale a 114, $567 \mathrm{~km}$ recorridos en coche o a 441 nuevos árboles plantados.

Si se considera el consumo histórico anual del edificio registrado el 13 de julio de 2015, con una magnitud de 78,560 kWh desde agosto de 2014 a julio de 2015, la PSFV estará aportando a la edificación el $54 \%$ de su consumo actual.

La PSFV de $27.0 \mathrm{~kW}$ pico ha contribuido a la reducción del dióxido de carbono $\left(\mathrm{CO}_{2}\right)$ que se emite por la operación de las Plantas de Generación de Electricidad que consumen combustibles fósiles. Considerando que por cada $\mathrm{kWh}$ producido en el sistema Eléctrico Nacional se produce $0.4946 \mathrm{~kg}$ de $\mathrm{CO}_{2}$, la PSFV de $27.0 \mathrm{~kW}$ pico contribuye con la reducción de gases de efecto de invernadero con una tasa de 20.18 toneladas equivalentes de $\mathrm{CO}_{2}$ por año, y durante el ciclo de vida útil de la tecnología (20 años), se tendrá una mitigación de $403.6 \mathrm{tCO}_{2} \mathrm{e}$. 



\section{EPÍLOGO}

La tecnología actual de celdas solares disponibles comercialmente y que domina el mercado mundial está basada en el material silicio. La celda solar de silicio cristalino formada por la unión íntima del tipo P-N genera un voltaje a circuito abierto del orden de $0.74 \mathrm{~V}$, y una densidad de corriente a corto circuito del orden de $42.25 \mathrm{~mA} / \mathrm{cm}^{2}$ (mejor celda solar 2016: Martina A. Green et al; Prog. Photovolt: Res Appl.2017, 25:313). La potencia máxima que se genera bajo condiciones STC es del orden de $26.3 \mathrm{~mW} / \mathrm{cm}^{2}$.

Para incrementar la potencia de generación las celdas se interconectan en asociaciones tipo serie, y la estructura así formada se llama módulo fotovoltaico (MFV).

Un MFVstá construido por la asociación de celdas idénticas conectadas en serie, encapsuladas al vacío, entre un par de polímeros soportados por un vidrio templado, el que posteriormente es colocado en una estructura rígida metálica, usualmente de aluminio anodizado, que garantiza la rigidez, maniobralidad, impermeabilidad, y larga duración del módulo.

Las sombras ocasionales o permanentes que se proyectan sobre celdas o incluso suciedad pegada en la superficie de un módulo o módulos, son causantes de desacoplamientos y desbalances eléctricos que ocasionan la formación de 
los puntos calientes. Por ésta razón, se debe exigir que todos los módulos que formen una asociación en serie, deben tener diodos de paso. Si la potencia requerida por la carga implica la formación de paneles en paralelo, es necesario la inclusión de un dispositivo de protección contra corrientes de retorno, los cuales los debe de proveer el instalador o vendedor. Estos dispositivos deben tener la capacidad de conducir la máxima corriente a corto circuito, y soportar un voltaje en polarización inversa igual al voltaje a circuito abierto del arreglo.

Se tienen disponibles en el mercado una gama amplia de MFV, desde aquellos para aplicaciones en relojes, calculadoras, juguetes, etc; hasta MFV para aplicaciones en Plantas de Generación de Energía (en el caso del silicio cristalino, MFV formados desde 36 hasta 120 celdas en serie).

Se determinó que la manera de incrementar la potencia para un arreglo es por medio de la conexión de módulos en serie y en paralelo. La conexión en serie incrementa el voltaje de salida, mientras que la conexión en paralelo incrementa la corriente. En ambos casos el proyectista, vendedor e instalador debe de asegurarse que todos los módulos participando en la asociación deben ser idénticos, es decir, tener las mismas características eléctricas.

La energía generada por un arreglo fotovoltaico depende del Recurso Solar, condiciones ambientales así como de factores geométricos involucrados con la orientación e inclinación. Usando la información vertida respecto del recurso Solar y Geometría Solar, se ha establecido que para arreglos montados en estructuras fijas, la máxima generación de electricidad producida anualmente corresponde a un arreglo orientado hacia el Sur con un ángulo de inclinación igual al valor de la latitud del lugar. Una disminución de $15^{\circ}$ en dicho ángulo maximiza la generación en el verano; mientras que un aumento de $15^{\circ}$, maximiza la producción en el invierno.

El tamaño del arreglo FV se calcula a partir de primeros principios que se formulan en un balance energético. Este 
criterio estable que la energía a producir debe ser igual a la energía a consumir. Con ésta idea, se generan una serie de relaciones algebraicas entre las variables del proyecto. La aplicación de éstas no requiere mayor conocimiento más que el manejo aritmético de nivel medio superior. La metodología debe seguirse paso por paso para llegar a la solución buscada.

Recuerde que se trata de hacer "un traje a la medida" del proyecto, así que no se debe de sobredimensionar el tamaño del arreglo FV.

Con respecto a los SFV que se han instalado a través de los diferentes proyectos sociales del gobierno, se tiene que para que sean una solución viable y sustentable en aplicaciones de poblaciones remotas, el uso de la TFV debe estar acompañada de una estructura institucional adecuada y manejable.

Las lecciones más importantes que se han aprendido de las experiencias exitosas con el uso de la TFV son las siguientes:

a. El apoyo técnico al usuario y su capacitación es crucial.

b. Es necesaria una planeación a largo plazo para todos los proyectos con base en el uso de la Tecnología Fotovoltaica.

c. Las responsabilidades y propiedad de los sistemas deben establecerse tempranamente.

d. Para la supervivencia a largo plazo del sistema, el mantenimiento es crítico.

e. Las organizaciones ejecutoras de proyectos deben luchar para trabajar con la industria para realizar instalaciones, fortaleciendo así a la industria local a la vez que se desarrolla una infraestructura para el mantenimiento de los sistemas.

f. Deben incluirse acciones para dar mantenimiento preventivo durante la planeación del proyecto desde el inicio mismo. Las actividades de mantenimiento con frecuencia pueden pagarse con los ingresos generados de los usuarios locales. Sin embargo, la falta de atención a los aspectos institucionales con frecuencia lleva 
a un inadecuado mantenimiento del sistema y causa una eventual degradación del mismo hasta que llega a fallar por completo.

g. Para evitar descomposturas, los SFV deben ser de un tamaño realista y deben contar con controles institucionales adecuados desde su concepción. Los planificadores deben anticipar el crecimiento en la demanda de energía y asegurase que ésta no rebase las expectativas de la generación. Recuerde que se realiza un "traje" energético a la medida

La tecnología FV para generar potencia eléctrica se ha convertido en la mejor alternativa para producir electricidad debido a todas las bondades que presenta. El éxito de su uso puede enfatizarse debido a lo siguiente: no hay partes móviles, infiriendo bajo mantenimiento y cero contaminación sónica; no hay consumo de combustibles, infiriendo nula contaminación ambiental y disminución de gastos a futuro por ese concepto; fácil manejo, infiriendo alta probabilidad de adopción y aceptación; larga duración indicado por una garantía de fabricación de 20 años o más; es modular por lo que los sistemas presentan el más alto rendimiento comparado con cualquier otro sistema de generación de energía.

Si la demanda de la tecnología FV sigue incrementándose en los países del primer mundo debido al fortalecimiento de programas gubernamentales que fomentan su uso, como es el caso de Japón, España, USA y Alemania, donde el costo de la electricidad generada por sistemas FV's es ya competitivo con la red convencional, en la próxima década es posible que la electricidad fotovoltaica sea competitiva con la electricidad convencional en muchas partes del mundo derivado de un incremento en la demanda de tecnología.

Por otra parte, la curva de experiencia Costo vs Venta de Tecnología, analizada por varios especialistas indican que, si el mercado de la tecnología FV crece a una tasa del 35\% anual, como se ha experimentado en los últimos 5 años, se 
puede proyectar que en el 2020 se estén comercializando módulos fotovoltaicos a un costo de usd $\$ 0.35$ por Watt pico, dando un precio nivelado para la energía eléctrica de $\$ 0.03$ usd por $\mathrm{kWh}$.

La demanda a corto plazo de la tecnología FV en nuestro país, derivada de su popularidad a nivel mundial como consecuencia de su simplicidad, seguridad, larga duración y bajo mantenimiento, así como de la conciencia ambientalista, se verá incrementada exigiendo de los proveedores del servicio público, servicios de interconexión a la red. Esto da la pauta para que las compañías suministradoras de la electricidad elaboren planes de capacitación para preparar a su personal técnico y directivo para enfrentar los requerimientos de servicios en un futuro cercano.

\section{Referencias}

1. v. V. Risser and H. Post, Manual de Prácticas Recomendadas para proyectos de Sistemas Fotovoltaicos Independientes, Sandia National Laboratories, 1988.

2. E. Lorenzo, Solar Electricity: Engineering of Photovoltaic Systems. PROGENSA, 1994.

3. M. T., Solar Electricity. Wiley, 1994.

4. D. Y. Goswani, Principles of Solar Engineering; Taylor and Francis, second ed., 2000.

5. W. A. B. J. A. Duffie, Solar Engineering of Thermal Processes; Wiley, second ed., 1991.

6. F. Kreith and J. F. Kreider, Principles of Solar Engineering; McGraw Hill, 1985.

7. J. F. Kreider, C. J. Hoogendoorn, and F.Kreith, SOLAR DESIGN: Components, Systems, Economics; Hemisphere Publishing Corporation, 1987.

8. A M. Sayigh, Solar Energy Engineering; Academic Press, 1977. 
9. E. Lorenzo, R. Zilles, and E. Camaño-Martín, Photovoltaic Rural Electrification: A Fieldwork Picture Book; Universidad Politécnica de Madrid.

10. Colectivo Greenpeace, GUÍA SOLAR: Como disponer de energía solar fotovoltaica conectada a la red eléctrica; Greenpeace.

11. Colectivo, Manual del Usuario De Instalaciones Fotovoltaicas. Universidad Politécnica de Madrid.

12. Colectivo, Sistemas de Energía Fotovoltaica y el Código Eléctrico Nacional de Los Estados Unidos: Prácticas Recomendadas; Universidad Politécnica de Madrid.

13. E. Alcor, Instalaciones Solares Fotovoltaicas; Universidad Politécnica de Madrid., 2002.

14. M. Castro, L. Dávila, and A. Colmenar, Sistemas Fotovoltaicos Conectados A Red: Estándares y Condiciones Técnicas. Censolar, 2000.

15. M. Castro, Sistemas de Bombeo Eólicos y Fotovoltaicos. Censolar, 2003.

16. M. Castro, J. Carpio, R. Guirado, A. Colmenar, and L. Dávila, Energía Solar Fotovoltaica. Censolar, 2004.

17. E. Lorenzo, E. Camaño-Martín, and R. Zilles, Cuaderno de Campo de Electrificación Rural Fotovoltaica. Censolar, 2001.

18. Colectivo, Sistemas De Energía Fotovoltaica Manual del Instalador. Censolar, 2005.

19. Colectivo, Energía Solar Fotovoltaica Normas UNE. Censolar.

20. E. Lorenzo, Ingeniería Fotovoltaica. Universidad Politécnica de Madrid., 2008.

21. E. Lorenzo, Radiación Solar y Dispositivos Fotovoltaicos. Universidad Politécnica de Madrid., 2006.

22. E. Lorenzo, Sobre El Papel de la Energia Solar en La Historia. Censolar, 2006.

23. F. A. Dürschner and K.-H. Remmers, Fotovoltaica Para Profesionales: Diseño, instalación y comercialización 
de plantas solares fotovoltaicas; Solar Praxanis Censolar, 2006.

24. E. Lorenzo, G. Araujo, A. Cuevas, M. Egido, J. Miñano, and R. Zilles, Solar Electricity. Engineering of Photovoltaic Systems. Universidad Politécnica de Madrid., 2000.

25. F. Lasnier and T. G. Ang, Photovoltaic Engineering Handbook. CRC Press, 1990.

26. A Luque and S. Hegedus, Handbook of Photovoltaic Science and Engineering. Wiley, 2003.

27. T.Markvart, Solar Electricity. University of Southampton , UK, second ed., 2000.

28. R. A. Messenger and J. Ventre, Photovoltaic Systems Engineering. CRC Press, second ed., 2004.

29. D. Gesellschaft, Planning and Installing Photovoltaic Systems: A guide for Installers, architects and engineers. Earthscan, 2005.

30. A. Sánchez-Juárez; Tecnología Fotovoltaica Aplicada al Bombeo de Agua; Fideicomiso de Riesgo compartido FITRCO-SAGARPA 2006. 



\section{GLOSARIO DE TERMINOS}

Acondicionador de energía $=$ Dispositivo electrónico que permite el acoplamiento eléctrico entre los módulos fotovoltaicos y las cargas eléctricas. Puede ser un controlador de carga para un acumulador, un seguidor de máxima potencia de un arreglo FV, ó un inversor.

Acumulador de carga eléctrica $=$ Es un dispositivo que almacena electricidad en una celda electroquímica. Los mas conocidos son los acumuladores de plomo-ácido para automóviles. Comúnmente se les llaman baterías.

Angulo de inclinación = Angulo sobre el horizonte al que estan inclinados los paneles solares fotovoltaicos, para captar los rayos del sol.

Arreglo Fotovoltaico $(\mathbf{A F V})=$ Un sistema interconectado de paneles fotovoltaicos que funciona como una sola unidad productora de electricidad. Los paneles esta armados como una estructura discreta, con un soporte común.

Batería $=$ Un dispositivo que almacena energía eléctrica (ver acumulador)

CA $=$ Corriente alterna

Captador solar $=$ Es cualquier objeto que recibe los rayos del Sol.

Carga $=$ Cualquier dispositivo o artefacto que esta usando potencia.

$\mathbf{C D}=$ Corriente directa

Celda Solar = Unidad mínima de conversión del efecto fotovoltaico 
CF (caballo de fuerza) $=$ Unidad de potencia que equivale a 745.7 watt (valor aproximado $746 \mathrm{~W}$ ).

Componentes periféricos en sistemas FV = Todos los elementos del sistema fotovoltaico, excepto los paneles y el equipo consumidor de energía, incluyendo estructuras, piezas de montaje, reguladores, baterías y cableado.

Controlador de carga eléctrica $=$ Es un dispositivo electrónico que regula el estado de carga de un acumulador acoplado a un sistema FV. Evita que se sobre carga y que se descargue.

Corriente eléctrica $=$ Flujo de portadores de carga en un conductor. Son electrones que se mueven por un metal debido a una fuerza electromotriz externa o diferencia de potencial que los esta impulsando. La corriente eléctrica se mueve de las zonas de mayor a las de menor potencial eléctrico. La unidad de medición es el amperio, simbolizado por A.

Corriente de corto circuito, $\boldsymbol{I}_{\mathrm{CC}}=$ Es la máxima corriente que produce una celda solar, módulo ó arreglo FV bajo condiciones de irradiancia máxima $\left(1 \mathrm{~kW} / \mathrm{m}^{2}\right)$.

Corriente para máxima potencia, $\boldsymbol{I}_{\mathrm{M}}=\mathrm{Es}$ la corriente que genera una celda, módulo o arreglo $\mathrm{FV}$, que produce la máxima potencia de ellos, para cualquier valor de la irradiancia.

Efecto fotovoltaico $=$ Generación de potencia eléctrica en un dispositivo debido a la absorción de luz.

Eficiencia = Es la razón entre la potencia entregada por un dispositivo respecto de la potencia suministrada, ó también, la razón aritmética entre la energía producida por la maquina, a la energía que se suministra para su funcionamiento.

Eficiencia de conversión FV = Es la razón entre la potencia máxima que genera una celda, módulo ó arreglo y la potencia de la radiación luminosa. Se expresa en porcentaje. 
Estructura $=$ Soporte metálico en donde se montan los módulos para darles inclinación, orientación, rigidez y confiabilidad al generador FV.

Fotocorriente $=$ La corriente generada en una celda solar debido a la absorción de luz.

Fotovoltaje $=$ La generación de un voltaje en las terminales de una celda solar debido a la absorción de luz.

FV = Fotovoltaico ó fotovoltaica

Hora-Sol u Hora-pico $=$ La insolación que seria recibida por el conjunto solar durante una hora a una irradiación de $1,000 \mathrm{~W} / \mathrm{m}^{2}\left(1 \mathrm{~kW} / \mathrm{m}^{2}=100 \mathrm{~mW} / \mathrm{cm}^{2}\right)$.

Irradiación = Es la irradiancia acumulada en la unidad de tiempo. Varia de acuerdo a la latitud, estación del año, hora del día, así como las condiciones locales del clima. En el sistema internacional las unidades son $\mathrm{J} / \mathrm{m}^{2}$. Si el tiempo se mide en horas, y la irradiancia en $\mathrm{W} / \mathrm{m}^{2}$, la insolación se mide en W-h/m². $1,000 \mathrm{~W}-\mathrm{h} / \mathrm{m}^{2}=3.6 \mathrm{MJ} / \mathrm{m}^{2}$.

Inversor $=$ Un mecanismo que convierte la corriente eléctrica directa en una corriente alterna (de CD a CA).

Irradiancia $=$ Es la potencia de la radiación luminosa o de la luz solar recibida en una superficie de área unitaria. Esta se mide en $\mathrm{W} / \mathrm{m}^{2}$.

Irradiancia difusa $=$ Es la que recibe el captador como si viniera de la bóveda celeste. Esta compuesta por rayos solares dispersados por nubes, partículas suspendidas en la atmósfera, y por rayos reflejados de superficies cercanas al captador. En un día nublado su valor puede ser hasta del $10 \%$ de la irradiancia global y es la mayor componente de ésta.

Irradiancia directa $=$ es aquella que incide normalmente sobre la superficie de un captador sin sufrir desviación alguna. Bajo condiciones de atmósfera limpia, estando el Sol en el cenit del captador y a nivel del mar, su valor es cercano a $1,000 \mathrm{~W} / \mathrm{m}^{2}$. 
Irradiancia pico $=$ Es el valor asignado como máximo para la irradiancia. Por convención éste valor es de 1,000 W/ $\mathrm{m}^{2}=1 \mathrm{~kW} / \mathrm{m}^{2}$.

Irradiancia Global $=$ Es la suma de la irradiancia directa con la difusa.

Kilowatt $=1,000 \mathrm{~W}$

Licitación o concurso $=$ Solicitud formal publica de equipos y/o servicios.

Mes critico $=$ En sistemas de bombeo es el mes definido como aquel que presenta la razón de bombeo al día más alta; y corresponde al mes con menor insolación y máxima demanda de agua.

Panel Fotovoltaico $=$ Estructura formada por la conexión eléctrica de celdas solares montadas generalmente en una unidad modular o panel sellado, de un tamaño conveniente para el transporte, manejo y armado en conjuntos.

Potencia del conjunto $=\mathrm{La}$ producción en watt de un conjunto fotovoltaico.

Producto, rendimiento $=$ La energía, potencia o trabajo producido por un sistema.

Seguidor de máxima potencia $=$ Dispositivo electrónico convertidor CD-CD que acopla las impedancias del arreglo y de la carga para que ésta extraiga la máxima potencia producida por el módulo o arreglo FV.

Sistema Fotovoltaico $=$ Un conjunto de componentes que convierte la luz del Sol en electricidad mediante el proceso fotovoltaico, se administra, almacena, distribuye y se consume. Está formado por módulos fotovoltaicos, estructuras, acondicionadores de energía (controladores, seguidores de máxima potencia, inversores), acumuladores de energía y cargas eléctricas.

Sistema Llave en mano = Instalación de un sistema en el sitio listo para funcionar. 
Tecnología Fotovoltaica $=$ La técnica disponible que transforma la luz solar en energía eléctrica; capaz de generar un voltaje al ser expuesto a la radiación visible o de otro tipo.

Valor neto actual $($ VNA $)=$ Valor presente después de que se hayan hecho las deducciones del caso o se hayan tomado en cuenta las perdidas.

Voltaje a circuito abierto, $\boldsymbol{V}_{\mathrm{CA}}=$ Es el máximo voltaje que genera una celda solar, un módulo ó arreglo FV cuándo sobre él incide la luz solar.

Voltaje para máxima potencia, $\boldsymbol{V}_{\mathrm{MP}}=\mathrm{Es}$ el valor del voltaje en una celda solar, módulo o arreglo FV para el cual la potencia que define es la máxima para cualquier valor de la irradiancia.

Watt = Unidad de potencia eléctrica equivalente a un joule por segundo, según el sistema internacional de medición. 


\section{Aplicaciones fotovoltaicas de la energía solar}

en los sectores residencial, servicio e industrial

editado por el Instituto de Energías Renovables de la UNAM, se terminó de imprimir en 21 de abril de 2017, en los talleres de Comercializadora Naxfra S.A. de C.V., ubicados Cerrada Madroño Mz 104 Lote 12, Col. Consejo Agrarista Mexicano, Delg. Iztapalapa, CP. 09760, Ciudad de México.

La edición estuvo al cuidado de Juan Tonda. En la impresión de interiores se usó papel Couché de $115 \mathrm{~g}$ y en los forros cartulina Couché de $300 \mathrm{~g}$ en offset. En su composición se utilizaron tipos Bodoni Stds y The Sans de 8, 11, 14 y 15 puntos.

El tiraje consta de 1,000 ejemplares. 
"La disponibilidad de la energía solar en todo el mundo y su carácter de fuente de energía renovable hacen de ésta una energía universal, la que es responsable también de la aparición de otras fuentes de energía como lo son: la energía del viento, la hidroeléctrica y la maremotríz, sin considerar aquellas posibles fuentes derivadas de la descomposición de desechos biológicos (biomasa).", señalan los autores.

Aplicaciones fotovoltaicas de la energía solar en los sectores residencial, servicio e industria proporciona una guía de gran utilidad para conocer cómo se puede diseñar un sistema de páneles fotovoltaicos y de qué dimensiones debe ser de acuerdo con diferentes necesidades. 